Prepared in cooperation with the U.S. Army Corps of Engineers, Missouri River RecoveryIntegrated Science Program

\title{
Ecological Requirements for Pallid Sturgeon Reproduction and Recruitment in the Missouri River-Annual Report 2014
}
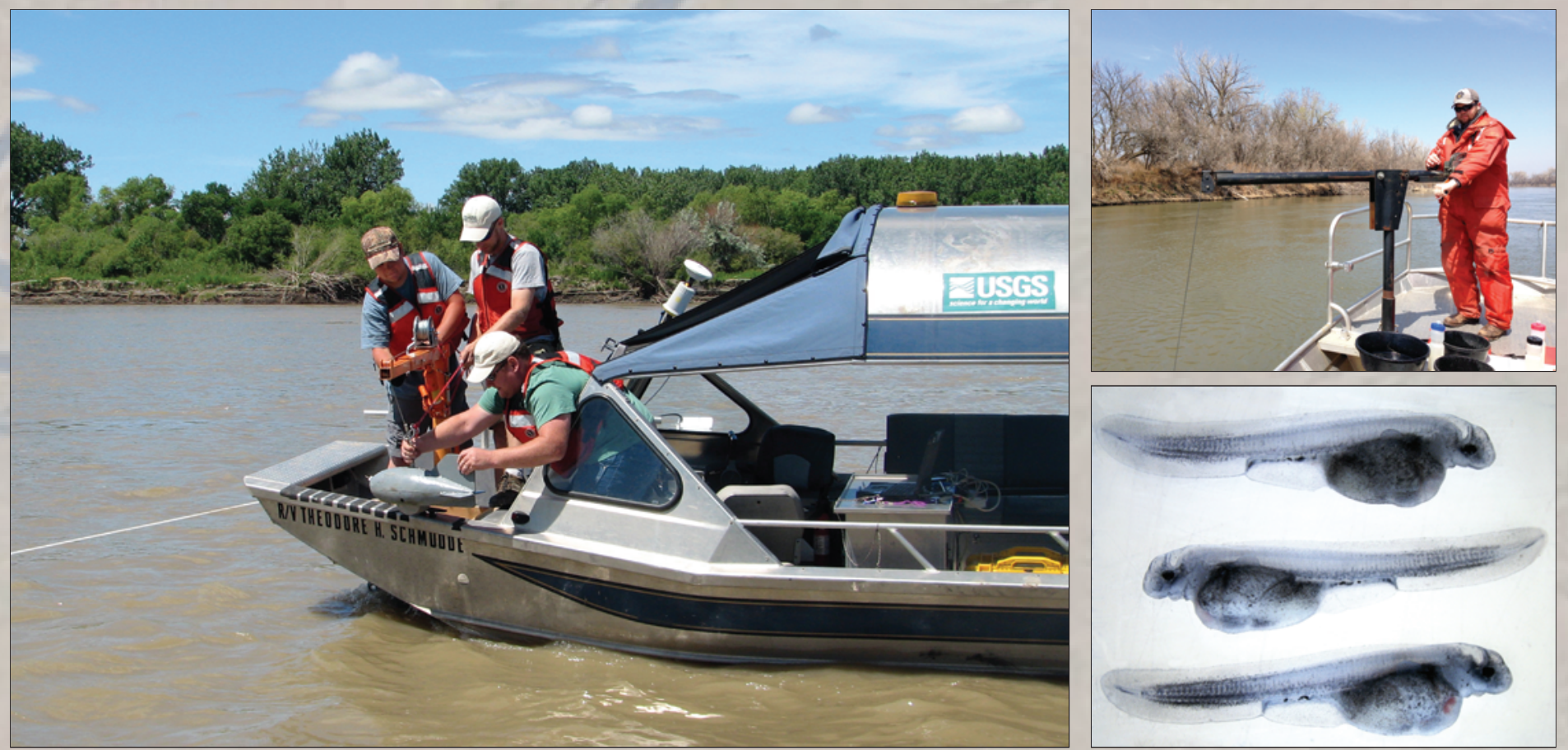

Open-File Report 2016-1013

U.S. Department of the Interior

U.S. Geological Survey 
Cover. LANDSAT image of the Yellowstone River near the Intake Diversion Dam in Montana on April 20, 2014 (background). Substrate sampling in the Yellowstone River (left, photograph by Beau Griffith, June 2014). Sampling for sturgeon free embryos and larvae in the Lower Missouri River in Nebraska (upper right, photograph by David Combs, April 2014). Microscopic image of pallid sturgeon free embryos at approximately 3 days post-hatch (lower right, photograph by Kimberly Chojnacki, July 2014). 


\section{Ecological Requirements for Pallid Sturgeon Reproduction and Recruitment in the Missouri River-Annual Report 2014}

By Aaron J. DeLonay, Kimberly A. Chojnacki, Robert B. Jacobson, Patrick J. Braaten, Kevin J. Buhl, Caroline M. Elliott, Susannah O. Erwin, Jake D. A.

Faulkner, James S. Candrl, David B. Fuller, Kenneth M. Backes, Tyler M. Haddix, Matthew L. Rugg, Christopher J. Wesolek, Brandon L. Eder, and Gerald E. Mestl

Prepared in cooperation with the U.S. Army Corps of Engineers, Missouri River Recovery ProgramIntegrated Science Program

Open-File Report 2016-1013 


\title{
U.S. Department of the Interior SALLY JEWELL, Secretary
}

\section{U.S. Geological Survey Suzette M. Kimball, Director}

\author{
U.S. Geological Survey, Reston, Virginia: 2016
}

For more information on the USGS - the Federal source for science about the Earth, its natural and living resources, natural hazards, and the environment-visit http://www.usgs.gov/ or call 1-888-ASK-USGS.

For an overview of USGS information products, including maps, imagery, and publications, visit http://www.usgs.gov/pubprod/.

Any use of trade, firm, or product names is for descriptive purposes only and does not imply endorsement by the U.S. Government.

Although this information product, for the most part, is in the public domain, it also may contain copyrighted materials as noted in the text. Permission to reproduce copyrighted items must be secured from the copyright owner.

Suggested citation:

DeLonay, A.J., Chojnacki, K.A., Jacobson, R.B., Braaten, P.J., Buhl, K.J., Elliott, C.M., Erwin, S.O., Faulkner, J.D.A., Candrl, J.S., Fuller, D.B., Backes, K.M., Haddix, T.M., Rugg, M.L., Wesolek, C.J., Eder, B.L., and Mestl, G.E., 2016, Ecological requirements for pallid sturgeon reproduction and recruitment in the Missouri River-Annual report 2014: U.S. Geological Survey Open-File Report 2016-1013, 131 p., http://dx.doi.org/10.3133/ofr20161013.

ISSN 2331-1258 (online) 


\section{Acknowledgments}

This report benefitted from technical reviews by Dane Shuman of the U.S. Fish and Wildlife Service and Michael Randall of the U.S. Geological Survey. Funding for this research was provided by the U.S. Army Corps of Engineers, Missouri River Recovery Program-Integrated Science Program and the U.S. Geological Survey. The authors gratefully acknowledge the collaboration of the U.S. Fish and Wildlife Service, Columbia Fish and Wildlife Conservation Office; U.S. Fish and Wildlife Service, Gavins Point and Neosho National Fish Hatcheries; Nebraska Game and Parks Commission; South Dakota Game, Fish, and Parks; and the Missouri Department of Conservation in the capture, handling, culture, and transport of pallid sturgeon for this study. 



\section{Contents}

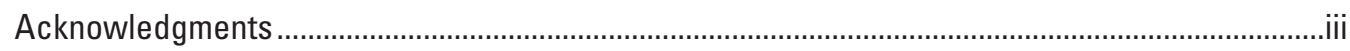

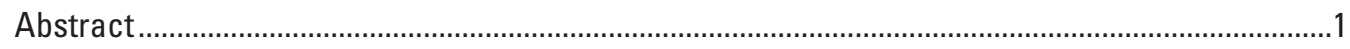

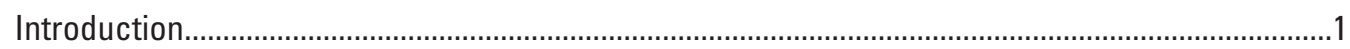

Comprehensive Sturgeon Research Project 2014 Scope of Work .................................................

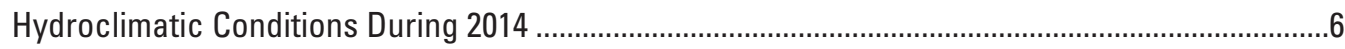

Assessments of Factors Affecting Pallid Sturgeon Spawning Success in the Missouri River

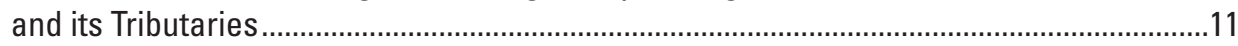

Field-Based Biotic Assessments of Factors Affecting Migration and SpawningLower Missouri River.....................................................................................................11

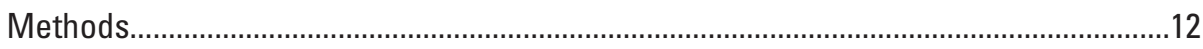

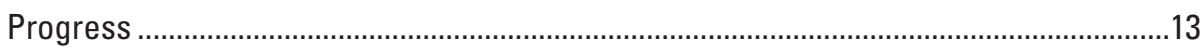

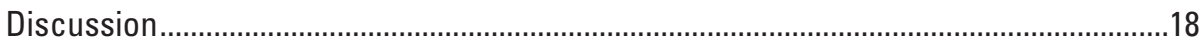

Field-Based Biotic Assessments of Factors Affecting Migration and Spawning-

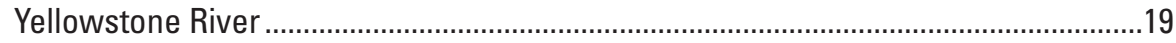

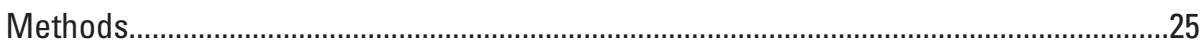

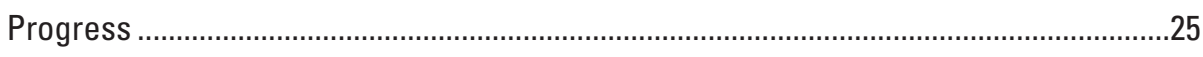

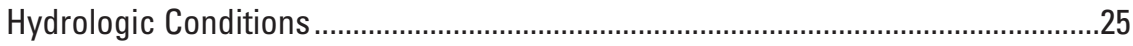

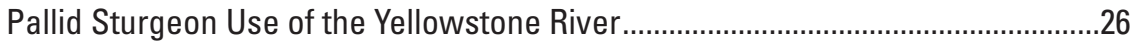

Migrations to and Around Intake Dam ................................................................2

Male Aggregations and Pallid Sturgeon Spawning Chronology ..............................29

Verification of Hatch and Drift Entry of Acipenseriformes Free Embryos

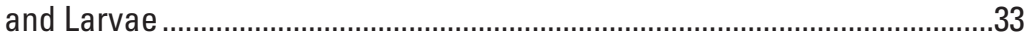

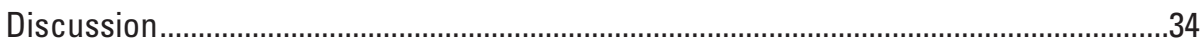

Field-Based Biotic Assessments of Factors Affecting Migration and Spawning-

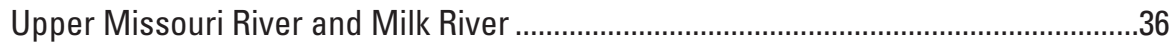

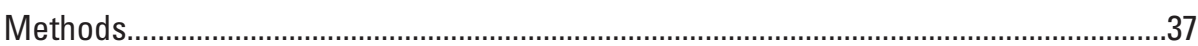

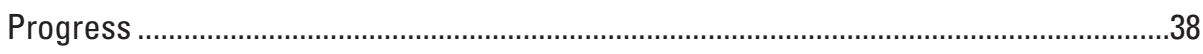

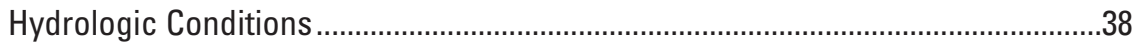

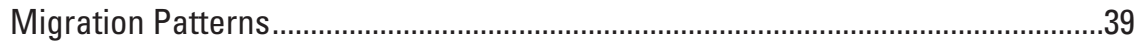

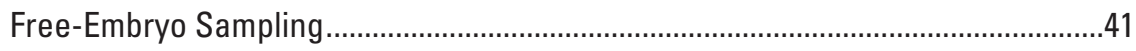

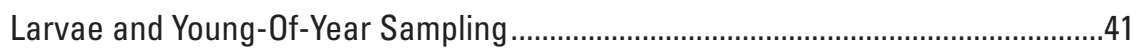

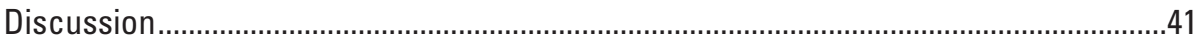

Field-Based Habitat Assessments of Habitats Supporting Spawning, Embryo

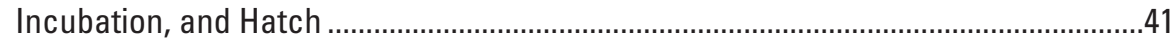

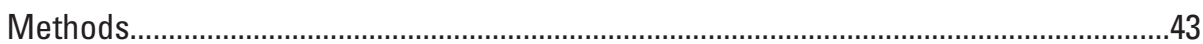

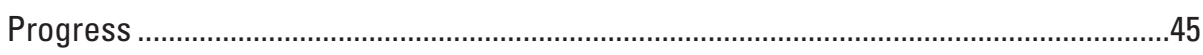

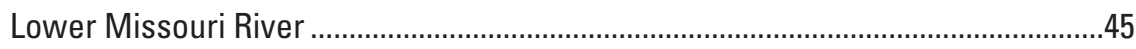

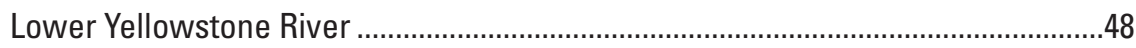

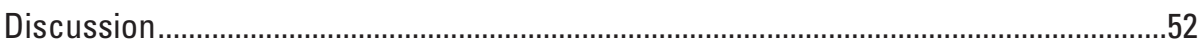

Laboratory Assessments of Abiotic and Biotic Aspects of Spawning and

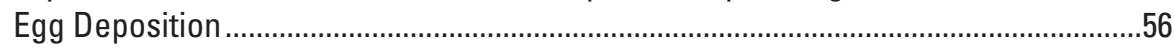

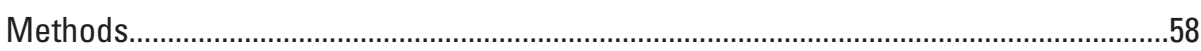

Improved Methods for Induction of Female and Male Pallid Sturgeon and Shovelnose Sturgeon ..................................................................................58 


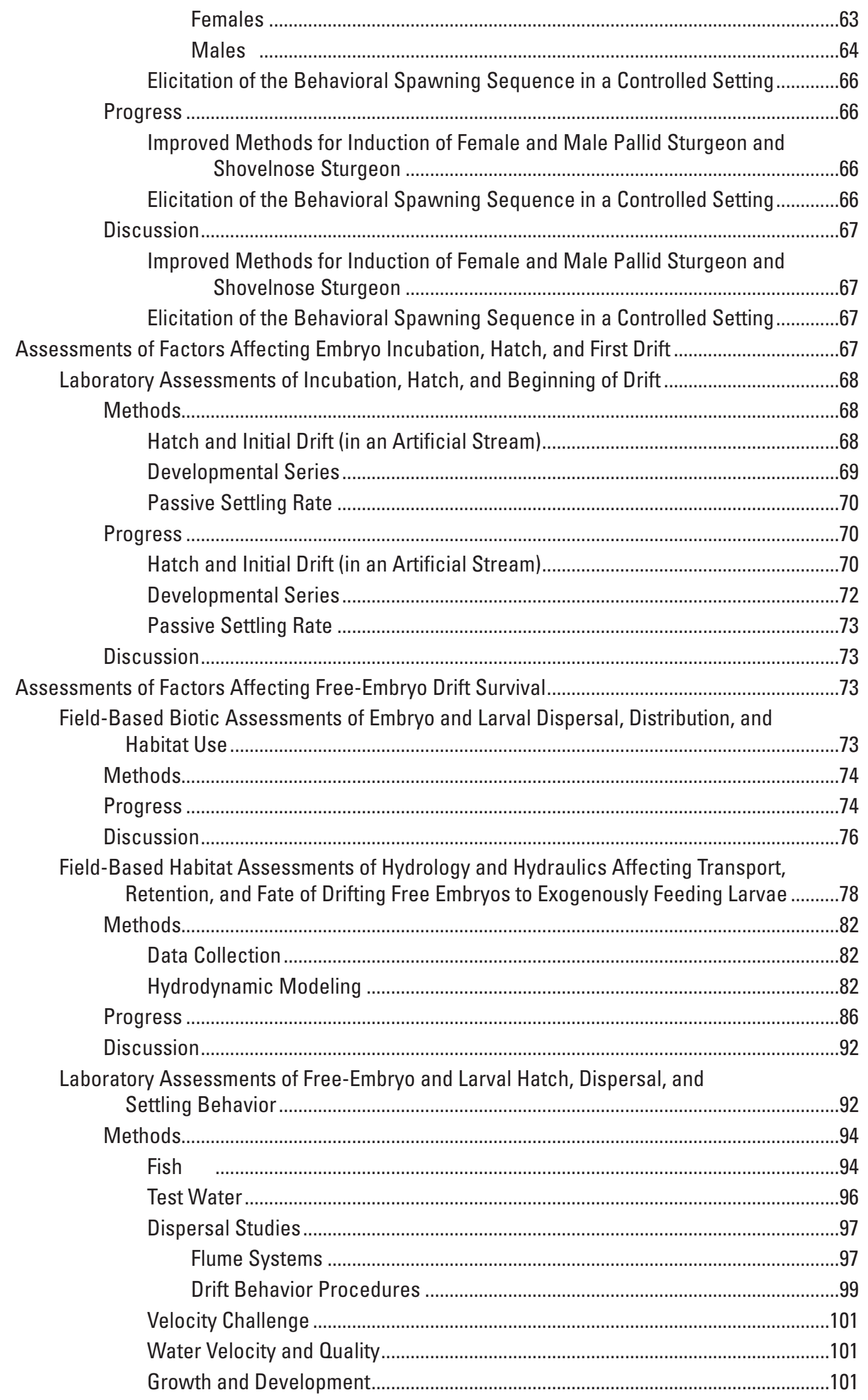




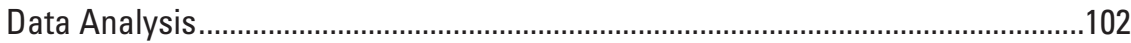

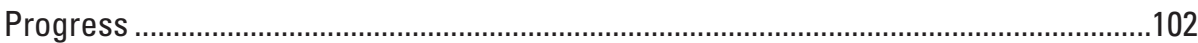

Culture and Test Conditions ...............................................................................102

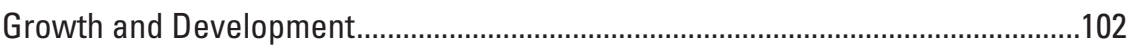

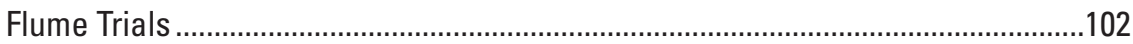

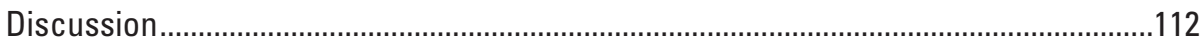

Missouri River Pallid Sturgeon Effects Analysis ..........................................................................112

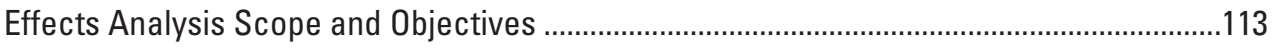

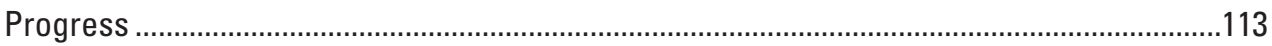

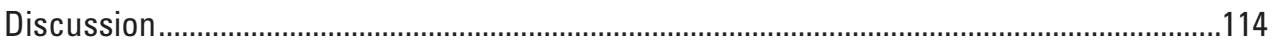

Effects Analysis Syntheses ......................................................................................114

Comprehensive Sturgeon Research Project and the Effects Analysis .........................115

Conservation Genetics of Pallid Sturgeon and the Effects of Population Augmentation on

Range-Wide Population Structure ………………………………………………...116

Pallid Sturgeon Propagation Data Recovery and Broodstock Reconstruction .....................116

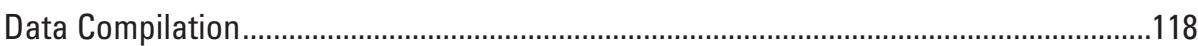

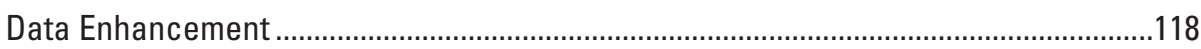

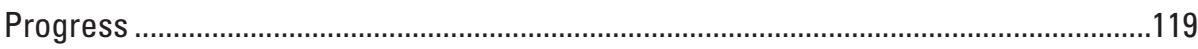

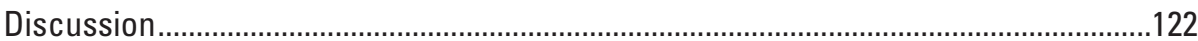

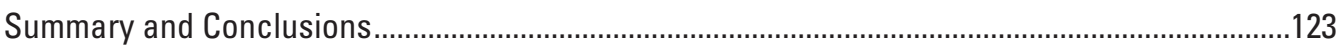

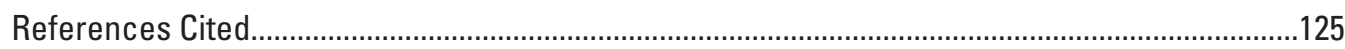

\section{Figures}

1. Map showing Missouri River Basin and primary tributary rivers, dams, and Comprehensive Sturgeon Research Project study sections..............................................3

2. Flowchart showing conceptual model of pallid sturgeon life stages .................................

3. Map showing variation in hydrologic alteration along the main stem Missouri River .....5

4. Box plots of annual runoff quantities for Yellowstone, Upper Missouri, and Lower Missouri River streamgaging stations comparing 1967-2013 to 2014 ..............................6

5. Hydrographs and thermographs for the Upper Missouri and Yellowstone Rivers,

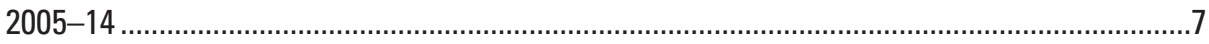

6. Hydrographs and thermographs for the Lower Missouri River, 2005-14 .......................9

7. Graph showing telemetry locations of female pallid sturgeon PLS10-029; depth and temperature recorded from data storage tag; Missouri River temperature and discharge from the nearest streamgage at Omaha, Nebraska; and Platte River temperature and discharge from the nearest streamgage at Louisville, Nebraska .......15

8. Graph showing telemetry locations of female pallid sturgeon PLS11-015; depth and temperature recorded from data storage tag; Missouri River temperature and discharge from the nearest streamgage at Nebraska City, Nebraska; and Platte River temperature and discharge from the nearest streamgage at Louisville, Nebraska

9. Graph showing telemetry locations of female pallid sturgeon PLS11-019, and Missouri River temperature and discharge from the nearest streamgage at Decatur, Nebraska. 
10. Graph showing telemetry locations of female pallid sturgeon PLS12-002, and Missouri River temperature and discharge from the nearest streamgage at Nebraska City, Nebraska.

11. Map showing locations of spawning sites used by telemetered pallid sturgeon in the Lower Missouri River, 2007-14

12. Map of the Yellowstone River near Intake Diversion Dam, including the high-flow side channel

13. Graph showing discharge and water temperature in the Yellowstone River and discharge in the Powder River during April-August 2014

14. Graph showing percentage of telemetered pallid sturgeon in the Yellowstone River and corresponding discharge, April-July 2014

15. Graph showing movements and locations by date of seven telemetered pallid sturgeon migrating to Intake Diversion Dam on the Yellowstone River and corresponding discharge in April-July 2014.

16. Diagram showing aggregations of telemetered male pallid sturgeon by river location and date in the Yellowstone River, May-June 2014.

17. Graphs showing migrations and mean daily locations of gravid female pallid sturgeon codes 30, 35, and 39 in the Yellowstone River during 2014; and corresponding discharge and temperature

18. Graph showing migrations and locations of pallid sturgeon female code 36; and male codes 49, 61, 68, and 76 in the Yellowstone and Powder Rivers during AprilOctober 2014; and corresponding discharge...

19. Map showing study sections of the Upper Missouri River, Milk River, and Lower Yellowstone River

20. Hydrograph of the Missouri River at Culbertson, Montana; Missouri River at Wolf Point, Montana; in the Milk River at Nashua, Montana; and in the Lower Yellowstone River at Sidney, Montana, during April-September 2014.

21. Graph showing water temperature for Missouri River sites—below Fort Peck Dam; Wolf Point, Montana; Culbertson, Montana; Missouri River below the confluence with the Yellowstone River; Milk River; Lower Yellowstone River; and Fort Peck Lake-during April-October 2014

22. Graph showing percentage of telemetered adult pallid sturgeon located in the Missouri River above the confluence with the Yellowstone River by date from 2005 to 2014 in April-October .

23. Graph showing percentage of telemetered adult pallid sturgeon located in the Missouri River above the confluence with the Yellowstone River and discharge at Culbertson, Montana, in April-October 2014.

24. Repeat mapping of pallid sturgeon PLS08-035 2013 spawning site near river mile 422.7 and Atchison, Kansas, and location of cross sections and longitudinal profiles

25. Graphs showing elevation of cross sections and longitudinal profiles for repeat mapping of pallid sturgeon PLS08-035 2013 spawning site near river mile 422.7 and Atchison, Kansas..

26. Repeat mapping of pallid sturgeon PLS09-007 spawning site near river mile 206 and Boonville, Missouri, on three days in 2014

27. Maps showing bedform differencing from repeat mapping of pallid sturgeon PLS09-007 spawning site near river mile 206 and Boonville, Missouri, on three days in 2014

28. Depth and velocity mapping from June $\mathbf{2 0 1 4}$ for the 4-kilometer reach including known pallid sturgeon spawning sites from 2012 to 2014 on the Lower Yellowstone River near Fairview, North Dakota. 
29. Velocity cross sections of the Lower Yellowstone River near Fairview, North Dakota, from 2013 and 2014 in a known pallid sturgeon spawning reach

30. Map showing 2012 U.S. Army Corps of Engineers transects, 2014 U.S. Geological Survey transects, and longitudinal profile survey lines in the Lower Yellowstone River near Fairview, North Dakota, in a known pallid sturgeon spawning reach ...........55

31. Cross sections from 2012 U.S. Army Corps of Engineers transects and 2014 U.S. Geological Survey transects surveyed in the Lower Yellowstone River near Fairview, North Dakota, in a known pallid sturgeon spawning reach.

32. Graphs showing longitudinal profiles of the 4-kilometer pallid sturgeon spawning reach on the Lower Yellowstone River near Fairview, North Dakota, from June 20-25, 2014

33. Graphs showing repeat longitudinal profiles of sand dunes near the suspected 2014 pallid sturgeon spawning site on the Lower Yellowstone River near river mile 5.4 and Fairview, North Dakota.....

34. Photographs showing locations and types of sediment sampling in the 2014 suspected pallid sturgeon spawning site near river mile 5.4 and Fairview, North Dakota, on the Lower Yellowstone River; and digital photographs of bed material taken with the underwater microscope.

35. Graph showing grain-size distributions from sieve results from 10 sites sampled using a BM-54 bed-material sampler.

36. Graph showing grain-size distributions from digital grain-size analysis results from 67 sites sampled using an underwater microscope

37. Sidescan sonar mapping in the 2014 suspected pallid sturgeon spawning site near river mile 5.4 and Fairview, North Dakota, on the Lower Yellowstone River

38. Graphs showing longitudinal profiles in and adjacent to known pallid sturgeon spawning sites on the Lower Missouri and Lower Yellowstone Rivers

39. Cross sections showing velocity distributions at known pallid sturgeon spawning sites on the Lower Missouri and Lower Yellowstone Rivers

40. Histograms showing the distributions of available and used depths and velocities at known pallid sturgeon spawning sites on the Lower Missouri and Lower Yellowstone Rivers

41. Diagram of experimental streams showing the orientation of substrate treatments ....68

42. Graph showing number of pallid sturgeon and shovelnose sturgeon embryos collected per hour postfertilization for each experiment within outdoor artificial streams in 2014

43. Maps showing free-embryo and larval sampling locations in the Lower Missouri River and the Platte River

44. Graph showing length of sturgeon (Scaphirhynchus spp.) free embryos and larvae collected at the Missouri River site during April-October 2014.

45. Graph showing length of sturgeon (Scaphirhynchus spp.) free embryos and larvae collected at the Platte River site during 2014

46. Graph showing length of paddlefish (Polyodon spathula) free embryos and larvae collected at the Missouri River site during 2014

47. Maps showing the Miami and Lisbon-Jameson reaches on the Lower Missouri River where two-dimensional hydrodynamic models were developed

48. Map showing bathymetric and topographic survey data used to construct the mesh for the Lisbon-Jameson hydrodynamic model.

49. Maps showing simulated depth-averaged velocities for a subset of discharges in the Miami modeling reach representing base flow, bankfull, and overbank conditions. 
50. Maps showing simulated depth-averaged velocities throughout the LisbonJameson modeling reach for a subset of discharges representing base flow, bankfull, and overbank conditions.

51. Box plot depicting the distribution of simulated velocities in the Lisbon-Jameson model, calculated for the two chutes and the main channel across a range of discharges

52. Graphs showing distribution of particle residence times calculated for the LisbonJameson and Miami modeling reaches.

53. Graphs showing percent survival of early life stage paddlefish in test flumes. 105

54. Bar graphs showing average number of fish passes during a 5-minute period and number of fish in the top and bottom one-half of the channel.

55. Graphs showing drift speed of paddlefish and water velocity in test flumes.....

56. Graph showing percent survival of early life stage pallid sturgeon in test flumes .......108

57. Bar graphs showing average number of fish passes during a 5-minute period and number of fish in the top and bottom one-half of the channel.

58. Graphs showing drift speed of pallid sturgeon and water velocity in test flumes ........110

59. Graph showing Kaplan-Meier survival curves for early life stage pallid sturgeon in the velocity challenge experiment

60. Bar graph showing the number of stocked pallid sturgeon, not including those stocked as free embryos for each management unit from 1992 to 2011

61. Bar graphs showing the number of stocked pallid sturgeon whose broodstock information was or is missing or incomplete in the U.S. Fish and Wildlife Service National Pallid Sturgeon Database for each management unit from 1992 to 2011

\section{Tables}

1. Probable spawning locations, periods, and tracking details of telemetered reproductive female pallid sturgeon, Missouri River and tributaries, 2007-14.

2. Dates and discharge when pallid sturgeon passed through the high-flow side channel around Intake Diversion Dam or were detected below Intake Diversion Dam by code and sex, Yellowstone River, Montana, 2014

3. Samples and numbers of Acipenseriformes eggs, embryos, free embryos, and larvae sampled in the Yellowstone and Powder Rivers by date in June-July 2014........34

4. Numbers of Acipenseriformes free embryos collected by date in the Upper Missouri River near Wolf Point, Montana, in June-August 2014

5. Fish collected with the benthic trawl in the Missouri River above and below the confluence with the Yellowstone River and total catch from July 23 to September 10, 2014.

6. Number of larval and young-of-year sturgeon collected in standard trawls, targeted trawls, minimum length, maximum length, and mean length by date in July-September 2014

7. Spawning habitat dates and details for pallid sturgeon, Lower Missouri and Yellowstone Rivers, 2008-14 ...

8. Lower Missouri River habitat surveys, 2009-14 ……………………………..................46

9. Lower Yellowstone River habitat surveys, June 2014................................................4

10. Longitudinal bed profiles on the Lower Yellowstone River, June 2014 ...........................48

11. Summary of female broodstock induced to ovulate using White Sturgeon Pituitary Extract during 2014 
12. Mean particle size and interstitial volume for materials used within substrate patches of the experimental stream.

13. Mean and standard error of measured water-quality properties for experiments within outdoor artificial streams in May and June 2014.

14. Number of fertilized pallid sturgeon eggs used and the number of embryos collected from ichthyoplankton nets for each treatment using eggs fertilized on May 6, 2014

15. Mean and standard error of fertilization and survival rates for control pallid sturgeon and shovelnose sturgeon embryos from each experiment spawned in 2014

16. Total number of pallid sturgeon and shovelnose sturgeon embryos recovered, percent recovered in ichthyoplankton nets, and percent recovered from the source for each experiment by treatment in 2014

17. Sampling period, number of sampling days, mean water volume sampled, number and density of sturgeon (Scaphirhynchus spp.) and paddlefish (Polyodon spathula) free embryos and larvae collected during 2014

18. Number, mean length, minimum length, and maximum length of free-embryo and larval sturgeon (Scaphirhynchus spp.) and paddlefish (Polyodon spathula) collected in the Missouri River at station 10.

19. Number, mean length, minimum length, and maximum length of free-embryo and larval sturgeon (Scaphirhynchus spp.) and paddlefish (Polyodon spathula) collected in the Missouri River at station 11

20. Number, mean length, minimum length, and maximum length of free-embryo and larval sturgeon (Scaphirhynchus spp.) and paddlefish (Polyodon spathula) collected in the Missouri River at station 12

21. Number, mean length, minimum length, and maximum length of free-embryo and larval sturgeon (Scaphirhynchus spp.) and paddlefish (Polyodon spathula) collected in the Missouri River at station 13

22. Number, mean length, minimum length, and maximum length of free-embryo and larval sturgeon (Scaphirhynchus spp.) and paddlefish (Polyodon spathula) collected in the Platte River at station 14

23. Number, mean length, minimum length, and maximum length of free-embryo and larval sturgeon (Scaphirhynchus spp.) and paddlefish (Polyodon spathula) collected in the Platte River at station 15.

24. Number, mean length, minimum length, and maximum length of free-embryo and larval sturgeon (Scaphirhynchus spp.) and paddlefish (Polyodon spathula) collected in the Platte River at station 16.

25. Mean density of sturgeon (Scaphirhynchus spp.) free embryos and larvae per sampling day

26. Mean density of paddlefish (Polyodon spathula) free embryos and larvae per sampling day

27. Summary data for Miami and Lisbon-Jameson reaches on the Lower Missouri River where two-dimensional hydrodynamic models were developed

28. Summary of field data collected in 2014 for development of the Lisbon-Jameson hydrodynamic model

29. Water-quality properties of reconstituted water used in culture and experiments with early life stage paddlefish and pallid sturgeon

30. Water quality in culture and test systems during drift behavior experiments with three lots of pallid sturgeon and one lot of paddlefish..... 
31. Age, daily cumulative temperature units, life stage, and growth metrics of one lot of paddlefish and three lots of pallid sturgeon in culture system...

32. Water velocity measured in test tanks during velocity challenge test with early life stage pallid sturgeon.

33. Description of age classes of hatchery-origin pallid sturgeon stocked by the Pallid Sturgeon Conservation Augmentation Program .

34. The number of broodstock added to the data within each year class and the number of progeny affected by corrections

35. Broodstock passive integrated transponder tags corrected using the string distance algorithm and verified by the Garrison Dam National Fish Hatchery

\section{Conversion Factors}

Inch/Pound to International System of Units

\begin{tabular}{lcl}
\hline & Multiply & \multicolumn{1}{c}{ To obtain } \\
\hline inch (in.) & Length & \\
inch (in.) & 2.54 & centimeter $(\mathrm{cm})$ \\
foot (ft) & 25.4 & millimeter $(\mathrm{mm})$ \\
mile (mi) & 0.3048 & meter $(\mathrm{m})$ \\
\hline & 1.609 & kilometer $(\mathrm{km})$ \\
\hline acre & Area & \\
acre & 4,047 & square meter $\left(\mathrm{m}^{2}\right)$ \\
acre & 0.4047 & hectare $(\mathrm{ha})$ \\
\hline & 0.004047 & square kilometer $\left(\mathrm{km}^{2}\right)$ \\
\hline gallon (gal) & Volume & \\
acre-foot (acre-ft) & 0.003785 & cubic meter $\left(\mathrm{m}^{3}\right)$ \\
\hline & 1,233 & cubic meter $\left(\mathrm{m}^{3}\right)$ \\
\hline cubic foot per second $\left(\mathrm{ft}^{3} / \mathrm{s}\right)$ & Flow rate & \\
\hline & 0.02832 & cubic meter per second $\left(\mathrm{m}^{3} / \mathrm{s}\right)$ \\
\hline pound, avoirdupois $(\mathrm{lb})$ & Mass & \\
\hline
\end{tabular}

International System of Units to Inch/Pound

\begin{tabular}{lll}
\hline \multicolumn{1}{c}{ Multiply } & By & \multicolumn{1}{c}{ To obtain } \\
\hline centimeter $(\mathrm{cm})$ & Length & \\
millimeter $(\mathrm{mm})$ & 0.3937 & inch (in.) \\
meter $(\mathrm{m})$ & 0.03937 & inch (in.) \\
kilometer $(\mathrm{km})$ & 3.281 & foot (ft) \\
meter $(\mathrm{m})$ & 0.6214 & mile (mi) \\
& 1.094 & yard (yd) \\
\hline square meter $\left(\mathrm{m}^{2}\right)$ & Area & \\
square meter $\left(\mathrm{m}^{2}\right)$ & 0.0002471 & acre \\
\hline
\end{tabular}




\begin{tabular}{|c|c|c|}
\hline Multiply & By & To obtain \\
\hline \multicolumn{3}{|c|}{ Volume } \\
\hline liter (L) & 33.82 & ounce, fluid (fl. oz) \\
\hline liter (L) & 2.113 & pint $(\mathrm{pt})$ \\
\hline liter $(\mathrm{L})$ & 1.057 & quart (qt) \\
\hline liter (L) & 0.2642 & gallon (gal) \\
\hline milliliter (mL) & 0.0338 & ounce, avoirdupois (oz) \\
\hline cubic meter $\left(\mathrm{m}^{3}\right)$ & 264.2 & gallon (gal) \\
\hline cubic meter $\left(\mathrm{m}^{3}\right)$ & 0.0002642 & million gallons (Mgal) \\
\hline liter $(\mathrm{L})$ & 61.02 & cubic inch $\left(\right.$ in $\left.^{3}\right)$ \\
\hline cubic meter $\left(\mathrm{m}^{3}\right)$ & 35.31 & cubic foot $\left(\mathrm{ft}^{3}\right)$ \\
\hline cubic meter $\left(\mathrm{m}^{3}\right)$ & 1.308 & cubic yard $\left(\mathrm{yd}^{3}\right)$ \\
\hline cubic meter $\left(\mathrm{m}^{3}\right)$ & 0.0008107 & acre-foot (acre-ft) \\
\hline \multicolumn{3}{|c|}{ Flow rate } \\
\hline cubic meter per second $\left(\mathrm{m}^{3} / \mathrm{s}\right)$ & 70.07 & acre-foot per day (acre-ft/d) \\
\hline meter per second $(\mathrm{m} / \mathrm{s})$ & 3.281 & foot per second (ft/s) \\
\hline meter per hour $(\mathrm{m} / \mathrm{h})$ & 3.281 & foot per hour (ft/h) \\
\hline cubic meter per second $\left(\mathrm{m}^{3} / \mathrm{s}\right)$ & 35.31 & cubic foot per second $\left(\mathrm{ft}^{3} / \mathrm{s}\right)$ \\
\hline cubic meter per second $\left(\mathrm{m}^{3} / \mathrm{s}\right)$ & 22.83 & million gallons per day (Mgal/d) \\
\hline \multicolumn{3}{|c|}{ Mass } \\
\hline $\operatorname{gram}(\mathrm{g})$ & 0.03527 & ounce, avoirdupois (oz) \\
\hline milligram (mg) & 0.00003527 & ounce, avoirdupois (oz) \\
\hline kilogram (kg) & 2.205 & pound avoirdupois (lb) \\
\hline
\end{tabular}

Temperature in degrees Celsius $\left({ }^{\circ} \mathrm{C}\right)$ may be converted to degrees Fahrenheit $\left({ }^{\circ} \mathrm{F}\right)$ as ${ }^{\circ} \mathrm{F}=\left(1.8 \times{ }^{\circ} \mathrm{C}\right)+32$.

\section{Supplemental Information}

To communicate effectively with stakeholders, managers, and other scientists working on the Missouri River, distances along the Missouri River are given in river miles (RM) upstream from the confluence with the Mississippi River at St. Louis, Missouri, as measured by the U.S. Army Corps of Engineers in 1960. Distances along the Yellowstone River are given in river miles (RM) upstream from the confluence with the Missouri River. Discharges are provided in the customary units of cubic feet per second $\left(\mathrm{ft}^{3} / \mathrm{s}\right)$. 


\section{Abbreviations}

\begin{tabular}{|c|c|}
\hline ADCP & acoustic Doppler current profiler \\
\hline BPSFH & Blind Pony State Fish Hatchery \\
\hline CEM & conceptual ecological model \\
\hline CERC & Columbia Environmental Research Center \\
\hline CSRP & Comprehensive Sturgeon Research Project \\
\hline CTU & cumulative temperature unit \\
\hline DI & deionized \\
\hline DO & dissolved oxygen \\
\hline $\mathrm{dph}$ & days post-hatch \\
\hline DST & data storage tag \\
\hline E2 & estradiol \\
\hline EA & Effects Analysis \\
\hline FRS & Field Research Station \\
\hline GNSS & Global Navigation Satellite System \\
\hline GPNFH & Gavins Point National Fish Hatchery \\
\hline GPS & global positioning system \\
\hline HFSC & high-flow side channel \\
\hline HOPS & hatchery-origin pallid sturgeon \\
\hline ISAP & Independent Science Advisory Panel \\
\hline LHRHa & luteinizing hormone releasing hormone analog \\
\hline MBES & multibeam echosounder \\
\hline MEID & mutually exclusive identifier \\
\hline MFWP & Montana Fish, Wildlife, and Parks \\
\hline MU & Management Unit \\
\hline NBF & neutral buffered formalin \\
\hline NPSDB & National Pallid Sturgeon Database \\
\hline $\mathrm{p}$ & probability \\
\hline $\mathrm{PI}$ & polarization index \\
\hline PIT & passive integrated transponder \\
\hline PSCAP & Pallid Sturgeon Conservation Augmentation Program \\
\hline RDBM & relational database management \\
\hline RPMA & recovery priority management area \\
\hline RTK & real-time kinematic \\
\hline
\end{tabular}




$\begin{array}{ll}\text { SAS } & \text { Statistical Analysis System (SAS Institute Inc., Cary, North Carolina) } \\ \text { SIU } & \text { Southern Illinois University Carbondale } \\ \text { sonar } & \text { sound and navigation ranging } \\ \text { TL } & \text { total length } \\ \text { USACE } & \text { U.S. Army Corps of Engineers } \\ \text { USFWS } & \text { U.S. Fish and Wildlife Service } \\ \text { USGS } & \text { U.S. Geological Survey } \\ \text { WSPE } & \text { white sturgeon pituitary extract }\end{array}$





\title{
Ecological Requirements for Pallid Sturgeon Reproduction and Recruitment in the Missouri River- Annual Report 2014
}

\author{
By Aaron J. DeLonay, ${ }^{1}$ Kimberly A. Chojnacki, ${ }^{1}$ Robert B. Jacobson, ${ }^{1}$ Patrick J. Braaten, ${ }^{1}$ Kevin J. Buhl, ${ }^{1}$ \\ Caroline M. Elliott, ${ }^{1}$ Susannah 0. Erwin, ${ }^{1}$ Jake D. A. Faulkner, ${ }^{1}$ James S. Candrl,, David B. Fuller, ${ }^{2}$ Kenneth M. \\ Backes, ${ }^{2}$ Tyler M. Haddix, ${ }^{2}$ Matthew L. Rugg, ${ }^{2}$ Christopher J. Wesolek, ${ }^{2}$ Brandon L. Eder, ${ }^{3}$ and Gerald E. Mestl ${ }^{3}$
}

\section{Abstract}

The Comprehensive Sturgeon Research Project is a multiyear, multiagency collaborative research framework developed to provide information to support pallid sturgeon recovery and Missouri River management decisions. The project strategy integrates field and laboratory studies of sturgeon reproductive ecology, early life history, habitat requirements, and physiology. The project scope of work is developed annually with collaborating research partners and in cooperation with the U.S. Army Corps of Engineers, Missouri River Recovery Program-Integrated Science Program. The project research consists of several interdependent and complementary tasks that involve multiple disciplines.

The project research tasks in the 2014 scope of work emphasized understanding of reproductive migrations and spawning of adult pallid sturgeon and hatch and drift of larvae. These tasks were addressed in three hydrologically and geomorphologically distinct parts of the Missouri River Basin: the Lower Missouri River downstream from Gavins Point Dam, the Upper Missouri River downstream from Fort Peck Dam and downstream reaches of the Milk River, and the Lower Yellowstone River. The project research is designed to inform management decisions related to channel re-engineering, flow modification, and pallid sturgeon population augmentation on the Missouri River and throughout the range of the species. Research and progress made through this project are reported to the U.S. Army Corps of Engineers annually. This annual report details the research effort and progress made by the Comprehensive Sturgeon Research Project during 2014.

\footnotetext{
${ }^{1}$ U.S. Geological Survey.

${ }^{2}$ Montana Fish, Wildlife and Parks.

${ }^{3}$ Nebraska Game and Parks Commission.
}

\section{Introduction}

This report prepared by the U.S. Geological Survey (USGS), in cooperation with the U.S. Army Corps of Engineers (USACE), Missouri River Recovery Program-Integrated Science Program, documents research tasks completed through the Comprehensive Sturgeon Research Project (CSRP) for calendar year 2014. The CSRP is a multiagency collaboration of the USGS with the Nebraska Game and Parks Commission (NGPC); U.S. Fish and Wildlife Service (USFWS); and Montana Fish, Wildlife, and Parks (MFWP). The goal of the CSRP is to improve the fundamental understanding of the reproductive ecology of the pallid sturgeon (Scaphirhynchus albus) to better inform river- and species-management decisions. Specific objectives include the following:

- Determine movement, habitat use, and reproductive behavior of pallid sturgeon;

- Understand reproductive physiology of pallid sturgeon and relations to environmental conditions;

- Determine origin, transport, and fate of drifting pallid sturgeon free embryos and evaluate bottlenecks for recruitment of early life stages;

- Quantify availability and dynamics of aquatic habitats needed by pallid sturgeon for all life stages; and

- Manage databases, integrate understanding of pallid sturgeon requirements and habitat dynamics, and publish information relevant to management decisions in the public domain.

Management actions to increase reproductive success and survival of pallid sturgeon in the Missouri River have been focused on renaturalizing the flow regime, re-engineering channel morphology, and population augmentation (U.S. Fish and Wildlife Service, 2003). Since 2005, scientists at the USGS Columbia Environmental Research Center (CERC) 
and partner agencies have engaged in interdisciplinary research to provide the fundamental information necessary to understand linkages between management actions and pallid sturgeon responses.

The CSRP direction has been guided by results of pallid sturgeon research workshops convened in 2004 (Quist and others, 2004) and 2007 (Bergman and others, 2008), hypotheses that emerged about the role of a naturalized flow regime in pallid sturgeon reproduction during a series of workshops in 2005 (Jacobson and Galat, 2008), feedback from an independent science review (Sustainable Ecosystems Institute, 2008), and an independent science panel review of spring pulses (Doyle and others, 2011). Objectives have emphasized science information gaps related to priority management issues, including understanding of the role of pulsed-flow releases from Gavins Point Dam and Fort Peck Dam (fig. 1), understanding of the functions of constructed shallow-water habitat in pallid sturgeon recruitment, evaluating quality of spawning habitat in the Yellowstone River, and understanding the role of free-embryo dispersal distance in recruitment failure in the Upper Missouri and Lower Yellowstone Rivers.

Our research priorities have been guided by a conceptual model of pallid sturgeon biology (Wildhaber and others, 2007a, 2011a) and an understanding of how pallid sturgeon use the Missouri River spatially for different life stages (fig. 2). Priorities also continue to be informed by the work of the Missouri River pallid sturgeon Effects Analysis (EA), which has been charged with providing a systematic evaluation of information about recruitment failure for Missouri River pallid sturgeon and how management actions can be used to remove and preclude jeopardy to the species (Jacobson and others, 2015a). The "Missouri River Pallid Sturgeon Effect Analysis" section of this report expands on the EA processes and the role of the EA in Missouri River decision making.

The CSRP approach integrates field-based experiments and controlled laboratory studies. The field study plan is designed to explore the roles of flow regime, channel configuration, and environmental cues in pallid sturgeon reproduction and recruitment. The CSRP uses an upstream-downstream experimental design to compare pallid sturgeon reproductive behavior among four study sections with varying hydrologic regimes in the Missouri River system (fig. 1). Variation in channel morphology among study sections, from near natural conditions in the Upper Missouri and Yellowstone River study sections to channelized and variably restored in the upper and lower study sections of the Lower Missouri River, allows for the evaluation of how channel form relates to spawning, dispersal, and rearing.

The Yellowstone River study section provides a nearly unaltered flow regime (fig. 3) and channel morphology that is natural and complex with the exception of a weir that limits (but does not completely prevent) fish passage (DeLonay and others, 2016b). The Upper Missouri River study section has a highly altered flow and temperature regime (fig. 3 ) because of its location downstream from Fort Peck Dam and natural and complex channel morphology. The Upper Missouri River study section also offers the opportunity to evaluate the Milk River, a tributary which may be selected by pallid sturgeon because it has higher temperatures and turbidity than the main stem Upper Missouri River.

The upper study section of the Lower Missouri River has a highly altered flow regime (fig. 3) and channel morphology that varies between the unchannelized Gavins segment and the narrow, channelized Big Sioux segment (DeLonay and others, 2016b). The upper study section of the Lower Missouri River also has the potential for experimental flow treatments that can be used for more controlled comparisons of reproductive behavior in years with pulsed-flow modifications (often referred to as "spring rises") to years without pulsed-flow modifications. The lower study section of the Lower Missouri River downstream from the confluence with the Kansas River (fig. 1) has a flow regime that has recovered some of the natural variability (fig. 3), thereby providing flow pulses in most years. The lower study section of the Lower Missouri River has also been channelized, but it has greater width and somewhat greater complexity compared to the Big Sioux segment (DeLonay and others, 2016b).

Field studies of pallid sturgeon migration, spawning, and dispersal are complemented with laboratory studies that seek to provide more precise understanding under controlled conditions. During 2014, laboratory studies focused on hatch and free-embryo dispersal behaviors.

\section{Comprehensive Sturgeon Research Project 2014 Scope of Work}

The 2014 scope of work was developed based on (1) five coordinated tasks organized by life-stage processes, (2) a task synthesizing population structure and viability, (3) a reporting task, and (4) a task including the USGS-CSRP role in the EA. Progress on an additional task, funded by multiple agency cooperators, is included in this report: examine the effect of artificial propagation on the genetic structure of pallid sturgeon. In the case of the life-stage processes tasks, subtasks are included for field-based habitat assessments, field-based biotic assessments, and laboratory assessments. Some subtasks are grouped among life stages to simplify project management (typically in field-based habitat assessment subtasks), and some subtasks were not pursued in 2014. The tasks and subtasks (indicated by the lowercase letters) under the 2014 scope of work include the following:

1. Assessments of factors affecting pallid sturgeon spawning success in the Missouri River and its tributaries.

a. Field-based biotic assessments of factors affecting pallid sturgeon migration and spawning in the Missouri River and its tributaries. 


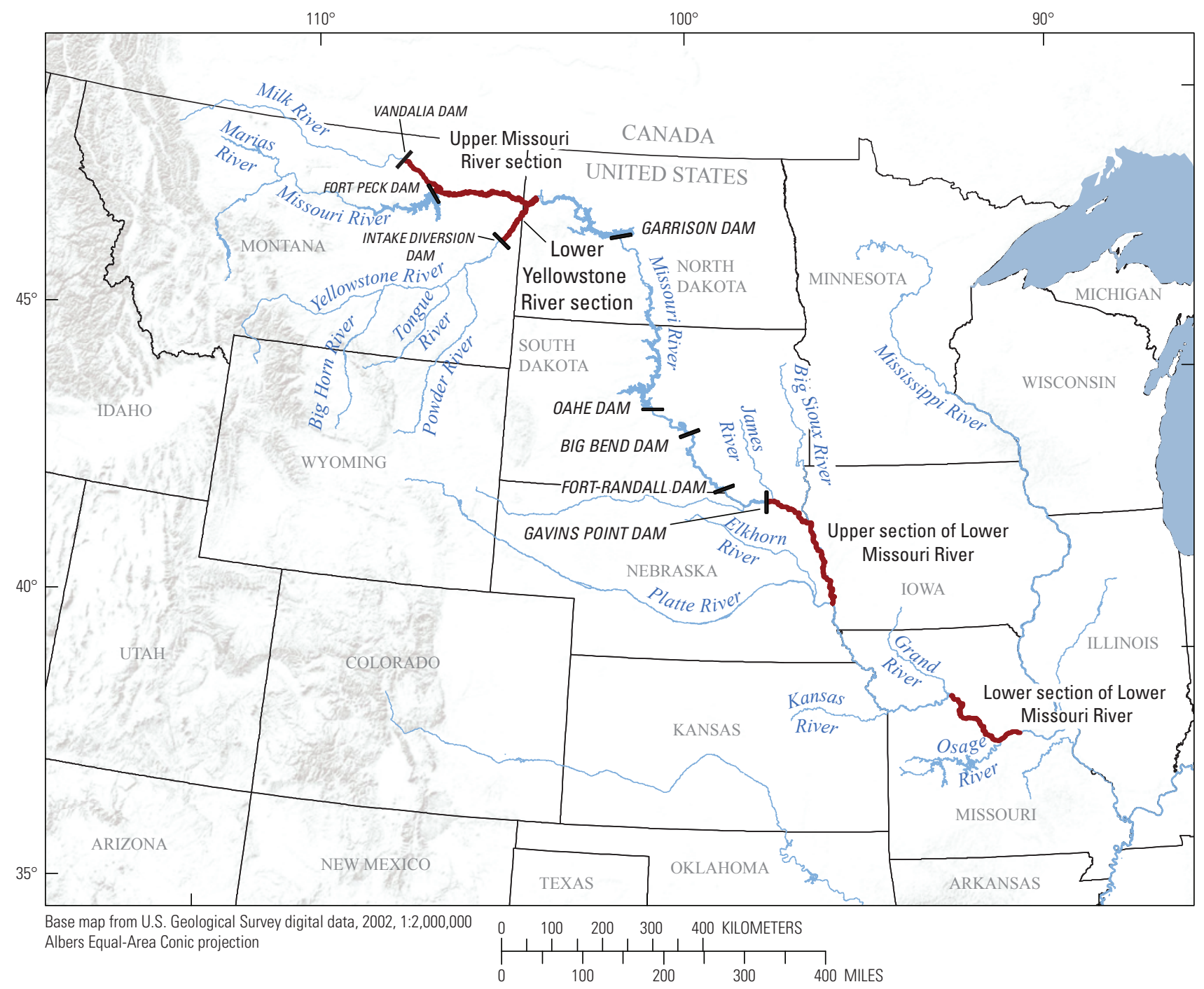

Figure 1. Missouri River Basin and primary tributary rivers, dams, and Comprehensive Sturgeon Research Project study sections.

b. Field-based habitat assessments of habitat dynamics for spawning, incubation, and hatch (integrated tasks 1 and 2 field-based habitat assessments).

c. Laboratory assessments that focus on understanding abiotic and biotic aspects of spawning and egg deposition.

2. Assessments of factors affecting pallid sturgeon survival during incubation, hatch, and beginning of free-embryo drift.

a. Field-based biotic assessments that focus on verification of embryo hatch and dispersal from known spawning locations (included in task 1 biotic assessments). b. Field-based habitat assessments of habitat dynamics for spawning, incubation, and hatch (integrated tasks 1 and 2 field-based habitat assessments).

c. Laboratory assessments of abiotic factors affecting egg deposition, adhesion, and hatch.

3. Assessments of factors affecting pallid sturgeon survival during free-embryo drift, including interactions with water transport.

a. Field-based biotic assessments that focus on timing, distribution, and composition of pallid sturgeon and paddlefish drift in the Missouri River. 


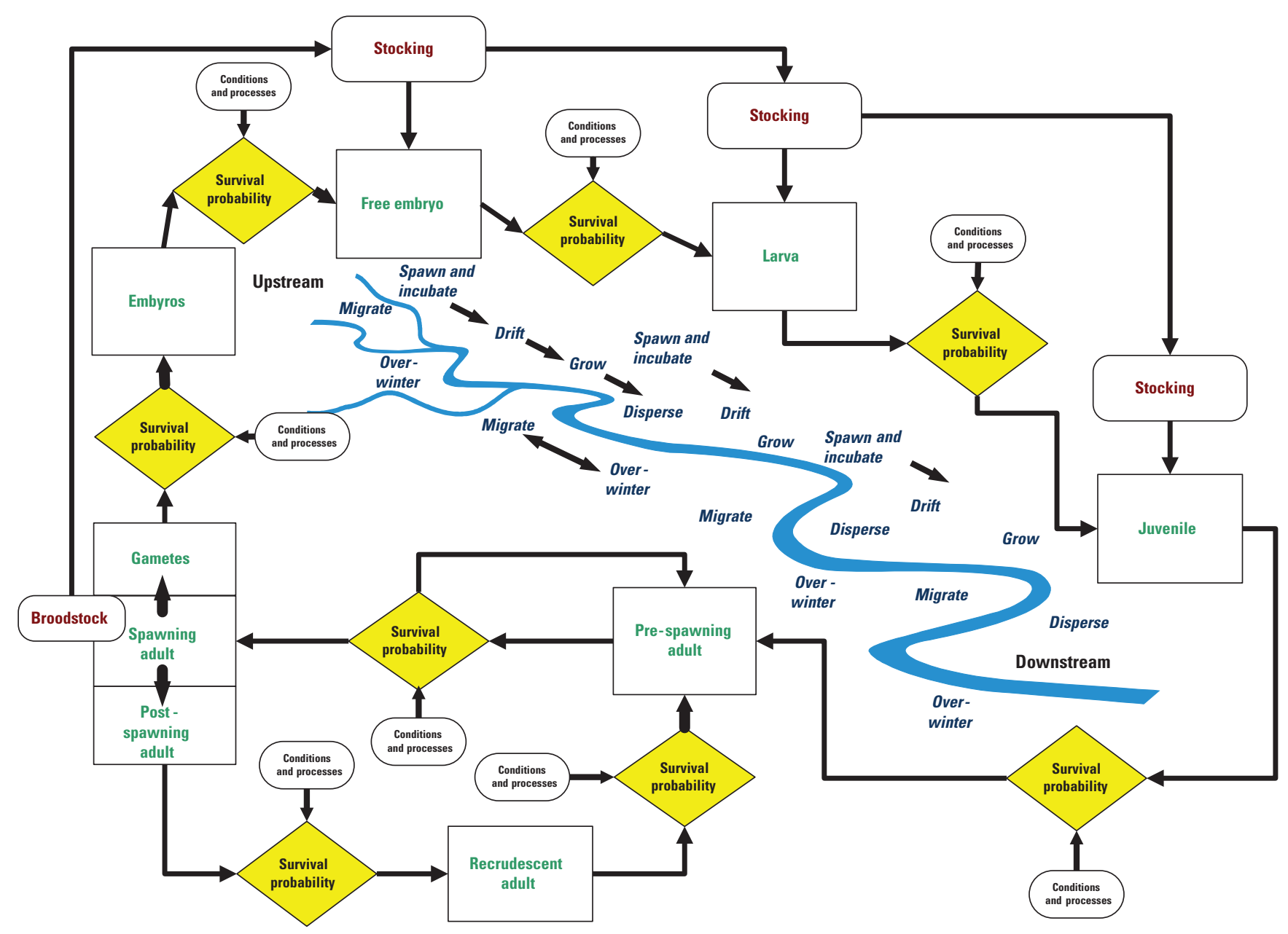

Figure 2. Conceptual model of pallid sturgeon life stages (modified from DeLonay and others, 2016b).

b. Field-based habitat assessments that focus on effects of hydrology and hydraulics on transport, retention, and fate of drifting free embryos to exogenously feeding larvae (integration of tasks 3,4 , and 5 field-based habitat assessments).

c. Laboratory assessments that focus on hatch, dispersal, and settling behavior of early life stage pallid sturgeon from free embryos through first feeding.

4. Assessments of factors affecting the survival of exogenously-feeding larval pallid sturgeon, including transport and retention.

a. Field-based biotic assessments were not planned or funded in 2014.

b. Field-based habitat assessments that focus on effects of hydrology and hydraulics on transport, retention, and fate of drifting free embryos to exogenously feeding larvae (integration of tasks 3,4 , and 5 field-based habitat assessments).

c. Laboratory assessments were not planned or funded in 2014.

5. Assessments of factors affecting pallid sturgeon survival during first feeding and transition to exogenously feeding larvae, including conditions in retention zones, food availability, and ontogenetic development.

a. Field-based biotic assessments were not completed in 2014.

b. Field-based habitat assessments that focus on effects of hydrology and hydraulics on transport, retention, and fate of drifting free embryos to exogenously feeding larvae (integration of tasks 3,4 , and 5 field-based habitat assessments).

c. Laboratory assessments were not completed in 2014. 

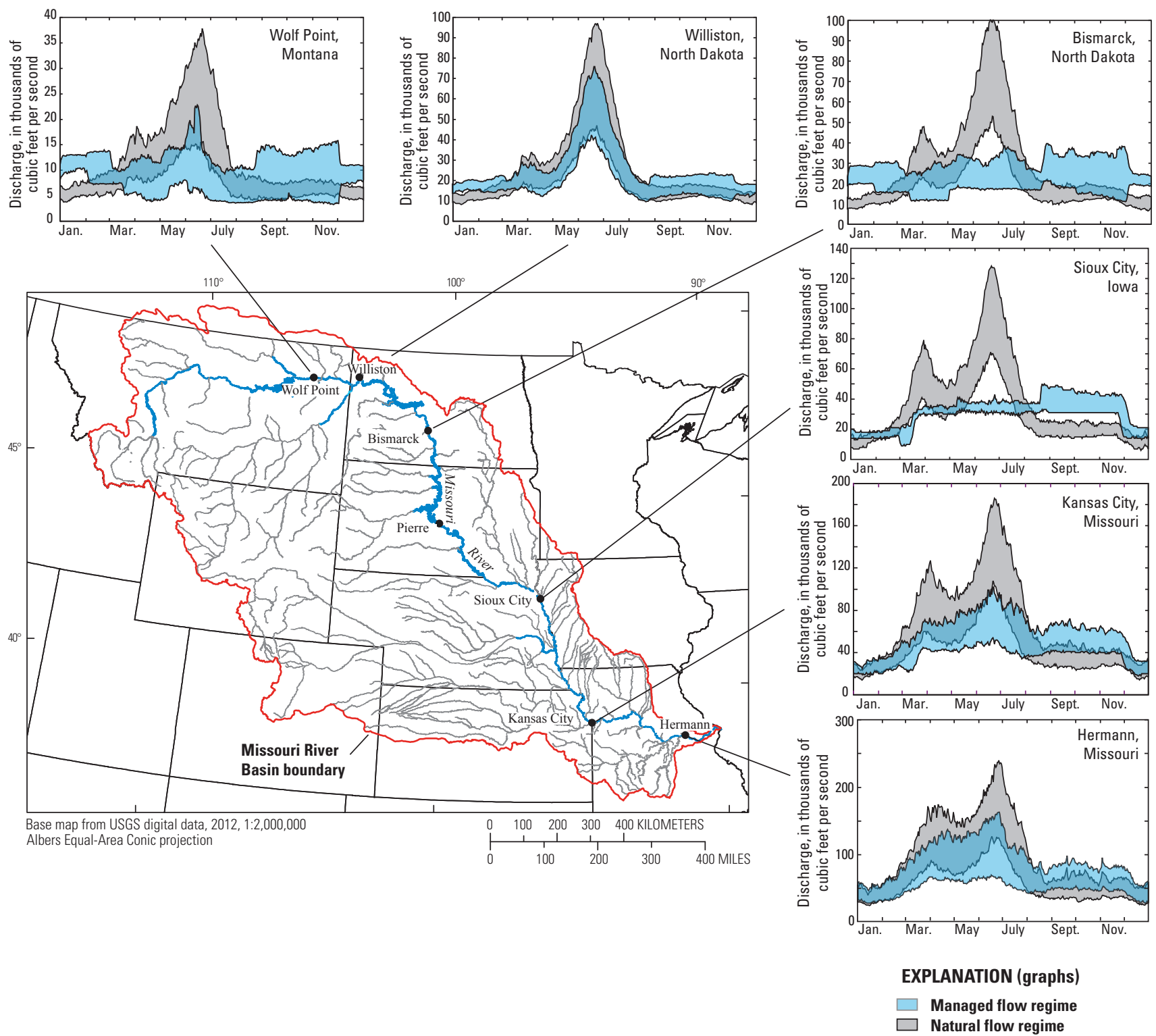

Figure 3. Variation in hydrologic alteration along the main stem Missouri River. Duration hydrographs show the interquartile range of discharges for each day of the year calculated from 1898 to 1997 (U.S. Army Corps of Engineers, 1998, unpub. data).

6. Use available Missouri River data and identify additional data needs to develop Upper and Lower Missouri River population structure and viability analyses. No new studies were begun in 2014. Results from previous years continue to be analyzed and published.

a. Analysis of relative abundance with environmental covariates.

b. Analysis of tag retention effects and spatial context in capture probability, survival, and population size.

c. Development of pallid sturgeon population and population viability models.
7. Evaluate migration pathways, flow response in conjunction with impediments, and reproduction of pallid sturgeon in the Yellowstone River and Missouri River below Fort Peck Dam (Milk River) and below Gavins Point Dam. This task was suspended in 2014 pending analysis of data collected in 2011-2013.

8. Produce monthly and annual progress reports; and facilitate dissemination of science results to managers, stakeholders, the science community, and the public.

9. Participate in Missouri River pallid sturgeon Effects Analysis. Actively engage with a team that has been assembled to provide effects models linking 
management actions to reproduction, growth, and survival of the pallid sturgeon, interior least tern, and piping plover. These activities are reported on extensively in a series of separate reports (Jacobson and others, 2015a, 2015b, 2016).

10. Assess conservation genetics of pallid sturgeon and the effects of population augmentation on range-wide population structure, and develop a relational database to support recovery of missing genotypes and enable the characterization of a pallid sturgeon population structure.

\section{Hydroclimatic Conditions During 2014}

Hydroclimatic conditions (for example, annual runoff) in the Missouri River Basin varied substantially by location (fig. 4). For 2014, estimated runoff in the Yellowstone River at Sidney, Montana, was in the upper 10 percentile, whereas runoff in the Upper Missouri River at Culbertson, Mont., was near the lower quartile (these are estimates because the values have not been corrected for flows under ice-covered conditions). Runoff in the Lower Missouri River at Sioux City, Iowa, was between the lower quartile and median, whereas at Nebraska City, Nebraska, runoff was almost exactly equal to median flow in the postdam record. In the Lower Missouri
River at Boonville, Missouri, runoff was between the lower quartile and median.

Hydroclimatic conditions in 2014 provided another set of treatments to the CSRP experimental framework for addressing how environmental conditions relate to reproductive ecology of pallid sturgeon (figs. 5 and 6). Snowmelt flows started on the Yellowstone River at Sidney, Mont., in mid-May and peaked at 68,100 cubic feet per second $\left(\mathrm{ft}^{3} / \mathrm{s}\right)$ on June 2, 2014; the return interval for the peak discharge is between 1.25 and 2 years (U.S. Geological Survey, 2014). Similar to most typical years on the Yellowstone River, discharge returned to base flow in late July to early August (fig. 5). Water temperature on the Yellowstone River was decreased relative to previous years (2005-2013), tracking closely with Upper Missouri River temperature until mid-July when it became 1-2 degrees Celsius $\left({ }^{\circ} \mathrm{C}\right)$ higher. The flattening to decreasing trend in water temperatures through most of June is common to both rivers; therefore, water temperature does not seem to be related to increased discharges. Temperatures increased and decreased several times during mid-August through November. Because these excursions are common to both rivers, they are likely associated with weather events rather than controlled by flow variation directly. Water temperature on the Yellowstone River reached $16{ }^{\circ} \mathrm{C}$ - considered to be a threshold temperature for pallid sturgeon spawning (DeLonay and others, 2016b) _on May 20, 2014.

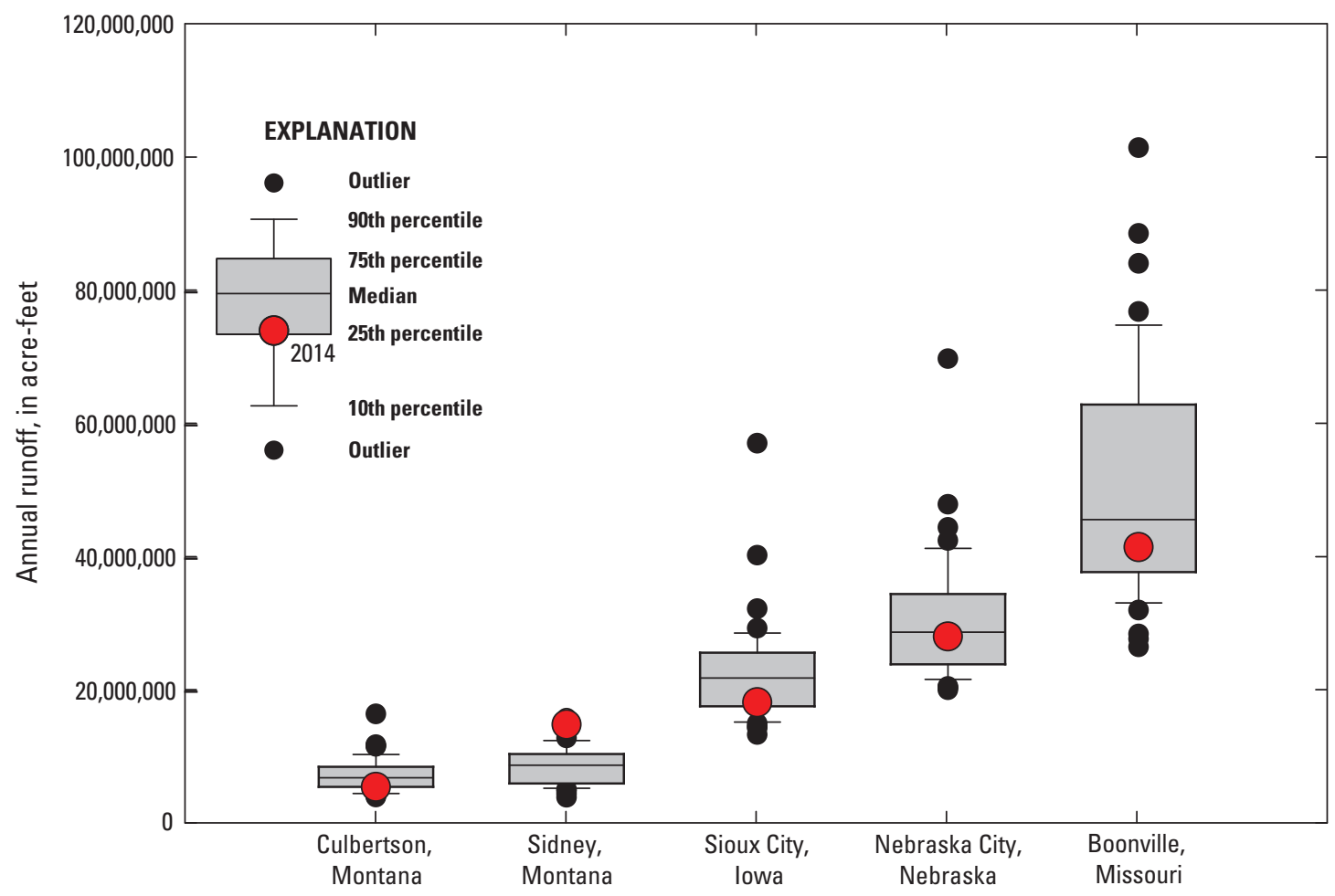

Figure 4. Box plots of annual runoff quantities for Yellowstone, Upper Missouri, and Lower Missouri River streamgaging stations comparing 1967-2013 to 2014. 


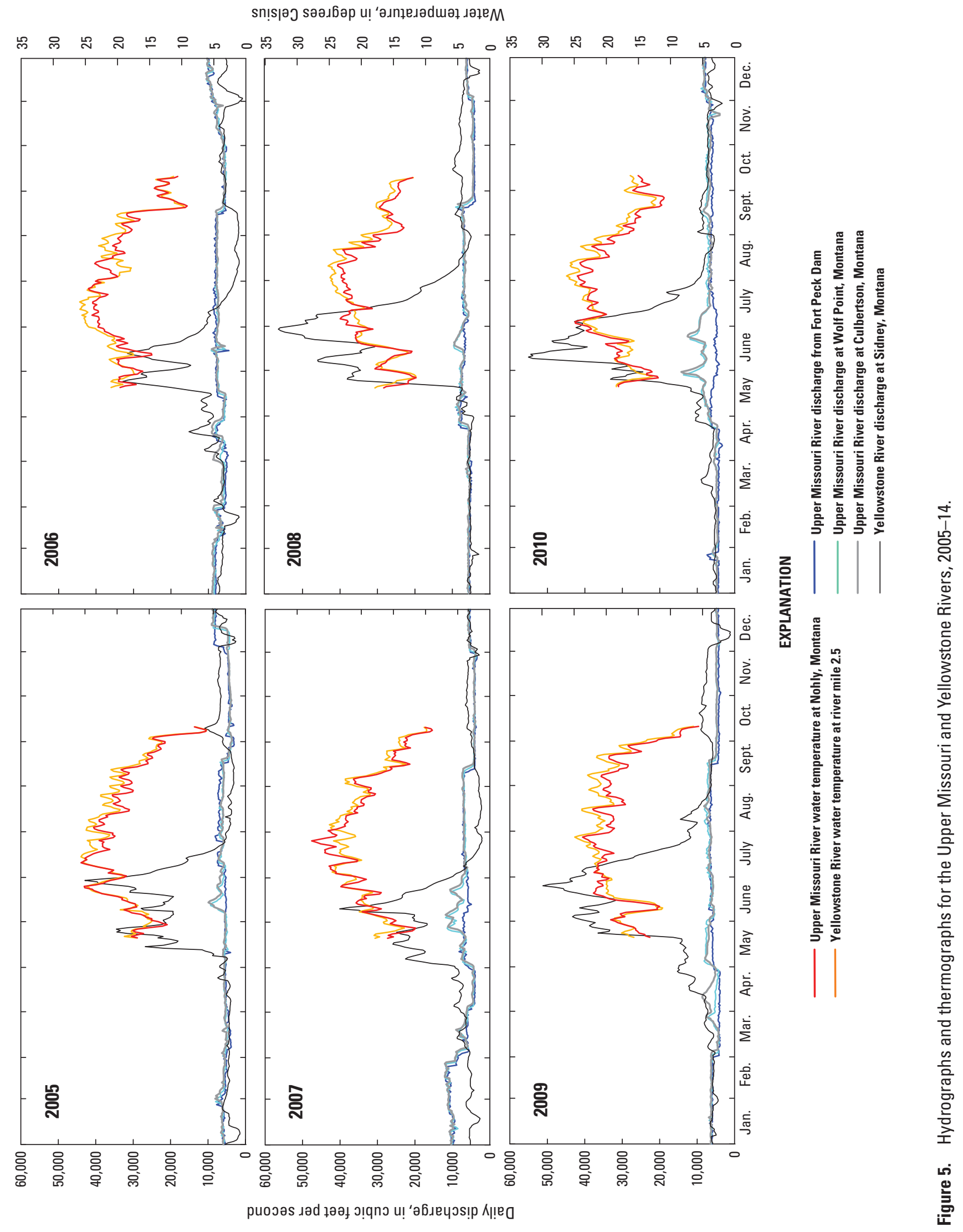




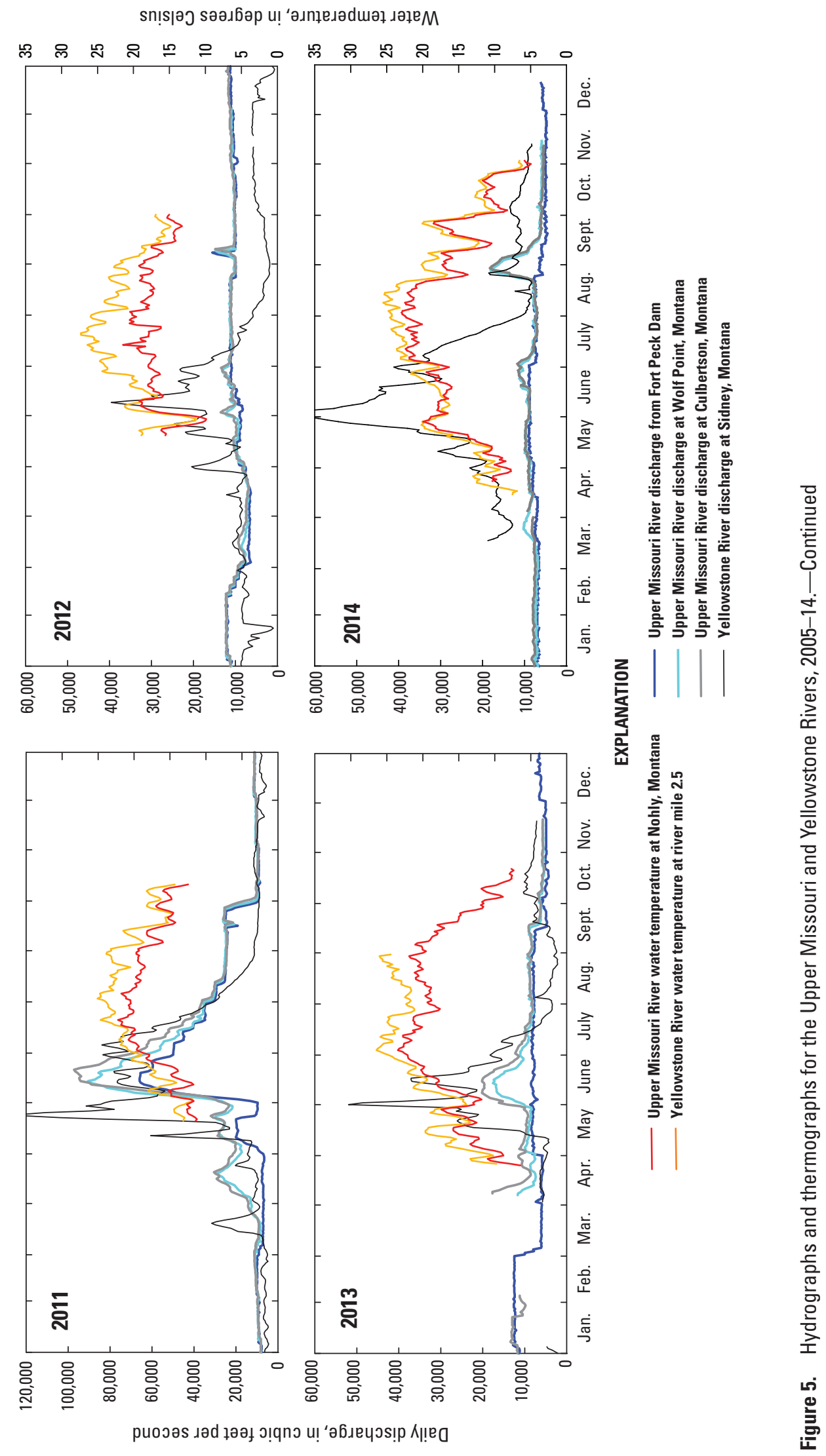




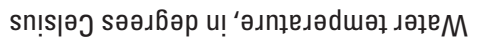

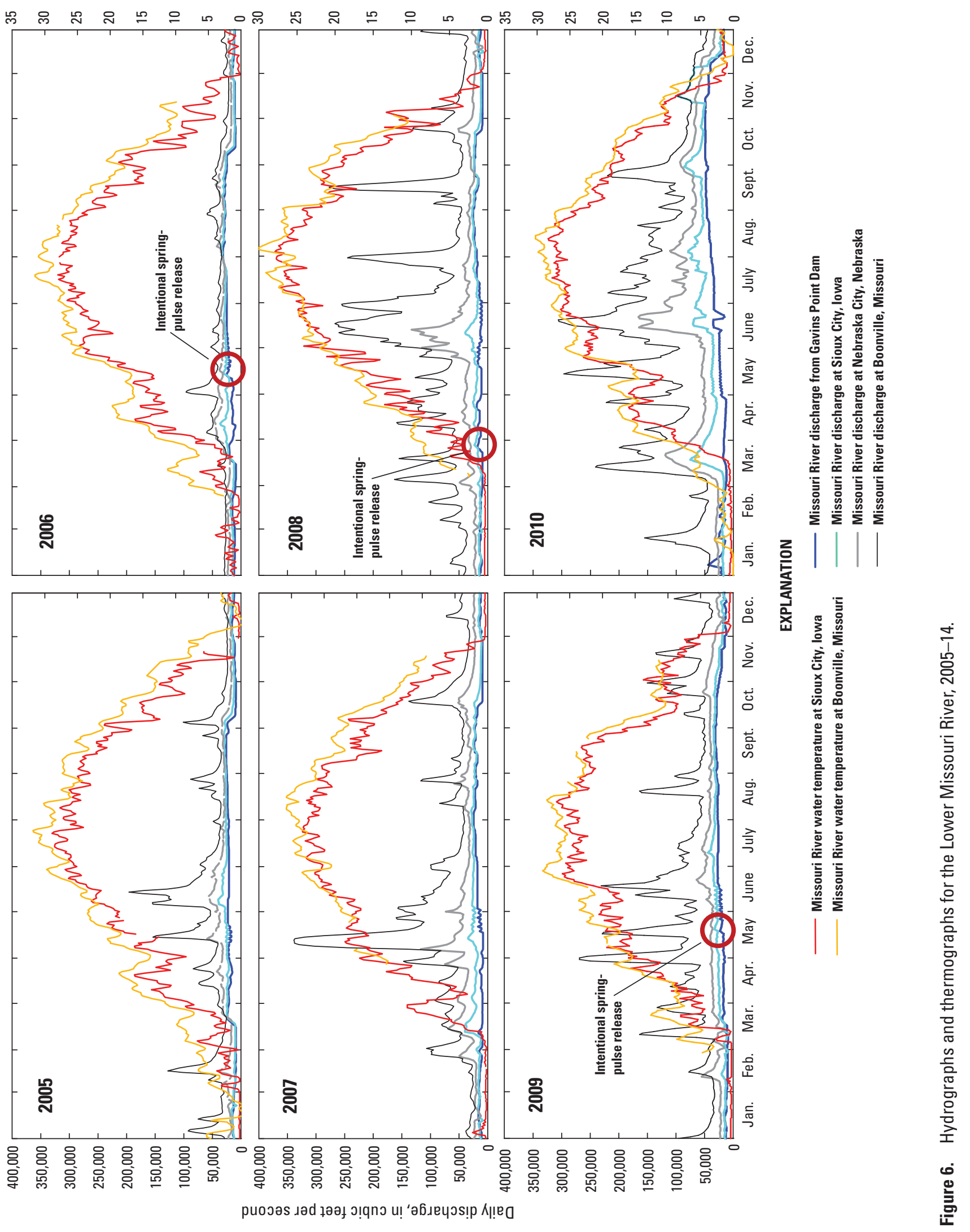




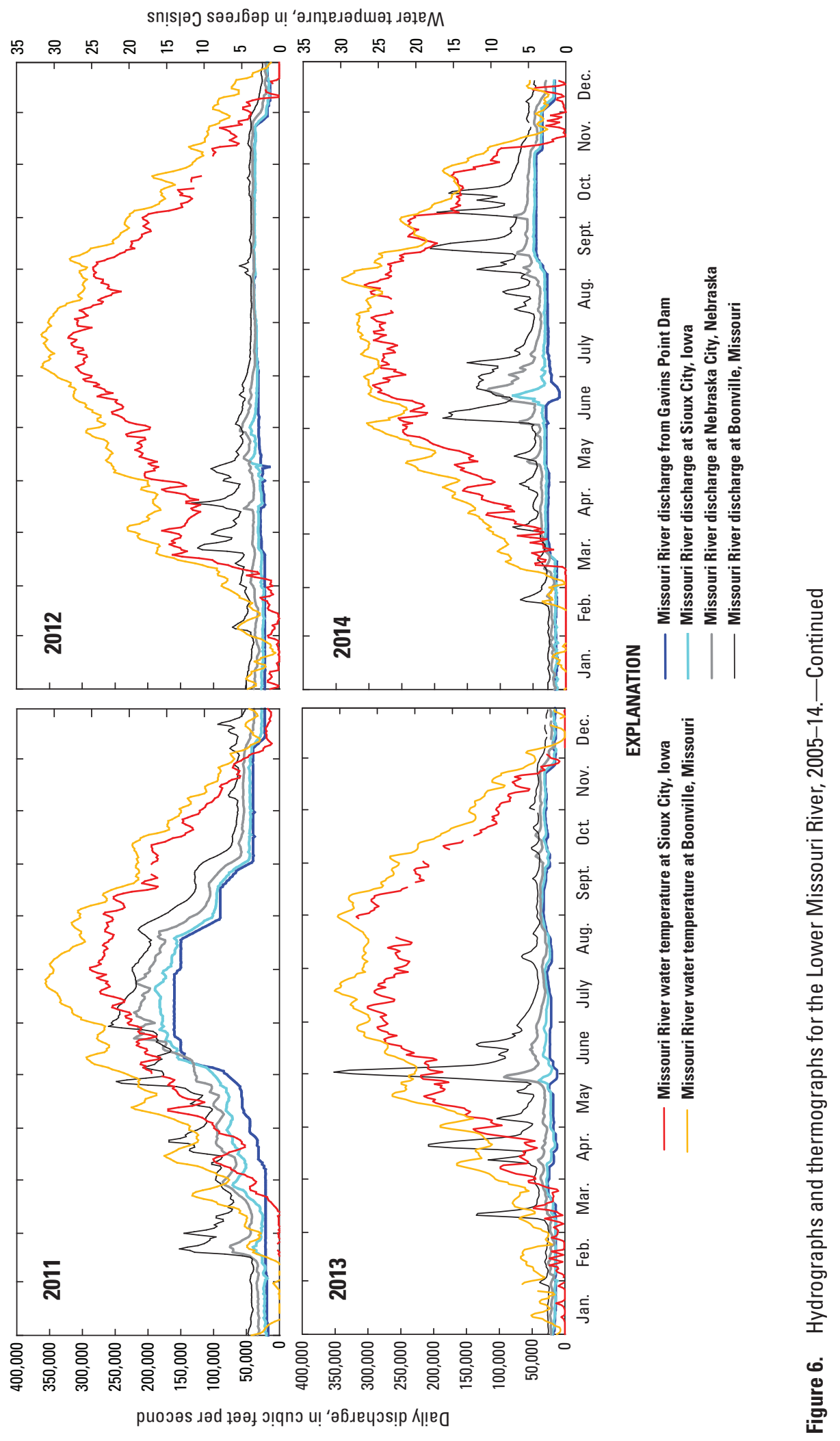


The Upper Missouri River experienced very little flow variation through late August as a result of steady, low releases of 7,000-9,000 $\mathrm{ft}^{3} / \mathrm{s}$ from Fort Peck Dam and small local rainfall events (fig. 5). A flow pulse atypically peaked at about $18,000 \mathrm{ft}^{3} / \mathrm{s}$ on August 22 through September 16 as a result of regional rainfall. Temperatures on the Upper Missouri River reached $16^{\circ} \mathrm{C}$ on May 23 .

There was no intentional spring pulse-flow release on the Lower Missouri River in 2014 (fig. 6). Flows at Sioux City, Iowa, were uniformly low because of steady navigation releases from Gavins Point Dam until June 8 when a regional rain event produced a flow pulse that peaked at just greater than $80,000 \mathrm{ft}^{3} / \mathrm{s}$. Discharges returned to navigation-supporting flows by July $15\left(28,000-33,000 \mathrm{ft}^{3} / \mathrm{s}\right)$. Releases from Gavins Point Dam were ramped to $45,500 \mathrm{ft}^{3} / \mathrm{s}$ between September 1 and September 7 and were maintained at 45,500 $\mathrm{ft}^{3} / \mathrm{s}$ through November 6 to evacuate storage in the reservoir system. Discharges at Nebraska City, Nebr., and Boonville, Mo., were more highly variable. Nebraska City, Nebr., experienced two flow pulses peaking at 58,000 and $70,000 \mathrm{ft}^{3} / \mathrm{s}$ during May and June, respectively, and had a more substantial flow pulse with peak discharge of about $120,000 \mathrm{ft}^{3} / \mathrm{s}$ on June 23 . Discharges at Boonville, Mo., had typical variation with as many as seven distinct flow pulses between late February and mid-August followed by an atypical series of six flow pulses from August through October. A flow pulse between June 3 and June 15 peaked at about $185,000 \mathrm{ft}^{3} / \mathrm{s}$, and a flow pulse between September 10 and September 21 peaked at $206,000 \mathrm{ft}^{3} / \mathrm{s}$.

Water temperatures fluctuated with typical seasonal variation; Boonville, Mo., temperatures were as much as $6{ }^{\circ} \mathrm{C}$ warmer than Sioux City, Iowa, temperatures in the spring (fig. 6). Differences in water temperatures between the upper and lower sections of the Lower Missouri River diminish September through December with Boonville, Mo., being no more than $2{ }^{\circ} \mathrm{C}$ warmer than Sioux City, Iowa. Temperature excursions were mostly synchronized between the upper and lower sections of the Lower Missouri River, indicating that weekly to monthly variability is controlled by weather rather than discharges. Water temperature at Boonville, Mo., reached $16^{\circ} \mathrm{C}$ on April 28,2014 , whereas $16^{\circ} \mathrm{C}$ was not achieved at Sioux City, Iowa, until May 21, 2014 (fig. 6). For the upper and lower sections of the Lower Missouri River, once water temperature reached $16{ }^{\circ} \mathrm{C}$, it did not fall below $16^{\circ} \mathrm{C}$ until October.

\section{Assessments of Factors Affecting Pallid Sturgeon Spawning Success in the Missouri River and its Tributaries}

Evidence from various monitoring efforts suggests that recruitment of pallid sturgeon to the adult population is rare or nonexistent throughout most of the Missouri River (U.S. Fish and Wildlife Service, 2000). Recent CSRP studies have documented spawning in the Lower Missouri River by wild and hatchery-origin pallid sturgeon (HOPS) (DeLonay and others, 2009) and in the Upper Missouri and Yellowstone Rivers by wild pallid sturgeon (DeLonay and others, 2015). Despite evidence of recent spawning, the factors or combination of factors that determine where and when pallid sturgeon spawn remain poorly understood.

This CSRP task provides data to inform numerous parameters necessary to construct population growth and viability models because it continuously examines habitat use, behavior, and reproductive status of pallid sturgeon during extended periods of time, throughout the reproductive cycle, and across the entire landscape. Data collected in this CSRP task provide information on growth, age at first reproduction, frequency of spawning, proportion of females reproducing, fecundity, and spawning success. Changes in these parameters can be used to assess the effect of various factors in limiting population growth and as metrics to monitor management actions. Data collected in this CSRP task also provide insight into pallid sturgeon behavior, spawning location distribution, reproductive isolation, and genetic structure on the landscape, which is information that may be necessary to support the designation of discrete population segments as described by the revised USFWS Pallid Sturgeon Recovery Plan (U.S. Fish and Wildlife Service, 2014). Because this CSRP task examines pallid sturgeon spawning requirements and success, it also provides the foundation for understanding causative factors resulting in increased rates of hybridization in altered habitats that threaten population viability and genetic diversity. Relating environmental changes or management actions to parameters of population growth, viability, and diversity is not possible unless the spatial bounds and temporal scale of the response of the fish are known. Studies of spawning habitat under this CSRP assessment have been combined with studies of habitat supporting embryo incubation and hatch.

\section{Field-Based Biotic Assessments of Factors Affecting Migration and Spawning-Lower Missouri River}

Efforts under the CSRP in previous years have resulted in the documentation of spawning by pallid sturgeon in the Lower Missouri River and in the Platte River, which is a tributary to the Lower Missouri River (DeLonay and others, $2009,2010,2012,2014)$. Increasing numbers of observations of spawning adults during the course of the study have provided important insight into where, when, and in what conditions pallid sturgeon spawn. The CSRP studies have also demonstrated that some individually tagged pallid sturgeon in the Lower Missouri River exhibit patterns of delayed maturation, reduced fecundity, restricted habitat use during migration, disrupted or maladaptive migration patterns, atresia or failure to spawn, hybridization, and selection of unnatural constructed substrates for spawning (DeLonay and others, 2016b). The CRSP studies in the Lower Missouri River have failed to 
document substantial aggregations of males near spawning females; the existence of discrete, persistently used, welldefined spawning areas; and viable free embryos downstream from documented spawning locations. Continued studies focus efforts on determining where on the landscape pallid sturgeon are spawning, if spawning is successful, and what conditions are conducive to survival and recruitment of young-of-year pallid sturgeon.

In previous years, the CSRP has used telemetry to locate individual pallid sturgeon over multiple years to collect information on movement, habitat use, behavior, and response to environmental cues or habitat manipulations in the Lower Missouri River. Telemetry allows scientists to recapture, reevaluate, and reimplant individual sturgeon to monitor changes in growth, condition, and reproductive status. Telemetry provides information that cannot be developed through traditional fishery sampling techniques, especially in large systems where all habitats cannot be sampled or sampled throughout all time periods. Telemetry has allowed us to define characteristic migration patterns of reproductive pallid sturgeon and spawning locations (DeLonay and others, 2007, 2009, 2012; Holan and others, 2009; Wildhaber and others, 2011b). The CSRP has used telemetry as part of a multidisciplinary approach in which telemetry is coordinated with physiological assessments of reproductive condition and hydroacoustic habitat assessments (DeLonay and others, 2007, 2009). The physiologic context provides an understanding of the reproductive state of a tagged fish and thereby provides interpretation of why the fish behaves as it does (Wildhaber and others, 2007b). Similarly, detailed habitat mapping around tagged fish locations places the behavior of individuals within a larger spatial context that allows researchers to characterize habitat availability and selection and thereby understand how channel morphology and flow regime can be managed to maximize reproduction and survival (Reuter and others, 2008, 2009; DeLonay and others, 2009; Jacobson and others, 2009; Bonnot and others, 2011). Identifying and characterizing spawning locations in the Lower Missouri River and connected tributaries provides information necessary to guide studies of egg survival, hatch, and free-embryo dispersal.

\section{Methods}

In previous years, the CSRP emphasized tagging male and female sturgeon in reproductive condition to focus on spawning cues, behaviors, and habitat (DeLonay and others, 2009). Generally, fish have been captured in the spring; assessed for reproductive condition; and implanted and intensively tracked, if reproductive, throughout the spring and summer. After a spawning migration or at the end of the spring spawning season (April-June), the fish are targeted for recapture to reassess their reproductive condition and determine if they spawned. In 2014, capture and telemetry implantation efforts for this CSRP task continued to focus primarily within two geographically and hydrologically distinct sections of the Lower Missouri River (fig. 1). The two study sections (upper and lower) have been used throughout the study to represent the longitudinal variability in the system for comparative purposes (DeLonay and others, 2009). The core area of the upper section of the Lower Missouri River is between the Platte River in Nebraska and the Big Sioux River on the border of Iowa and South Dakota (river miles [RM] 595-734). The core area of the lower section of the Lower Missouri River is between the Osage River and Grand River in Missouri (RM 130-250). Regardless of their capture location, pallid sturgeon implanted with acoustic-telemetry transmitters were tracked and targeted for recapture and reimplantation wherever they may have been located throughout the Lower Missouri River.

Early in the CSRP, implantation efforts emphasized the evaluation of the response of pallid sturgeon from the two study sections of the Lower Missouri River to environmental factors and cues that may affect migration and spawning (DeLonay and others, 2009). Through time, the focus on spawning cues by management agencies has diminished, and efforts have been redirected towards verification and validation of spawning and spawning success. Although we retain the original geographic experimental construct of the study, the change in focus away from the examination of environmental cues, coupled with logistical factors, has resulted in an unequal distribution of telemetered pallid sturgeon and tracking effort between the two study sections. A disproportionately greater pallid sturgeon sampling effort in the upper study section associated with spring broodstock collection, the tendency of telemetered pallid sturgeon to migrate out of the lower study section, and an increased emphasis on multiyear study of tagged pallid sturgeon with known reproductive histories has resulted in greater numbers of telemetered pallid sturgeon in the upper study section of the Lower Missouri River. Through time, our tracking data and the documentation of spawning events on the landscape have reflected this migration of focus and effort.

Methods used in the Lower Missouri River during 2014 followed closely those developed by the CSRP in previous years (DeLonay and others, 2009, 2010, 2012, 2014). During 2014, reproductively mature female and male pallid sturgeon weighing 2 kilograms $(\mathrm{kg})$ or more were implanted with an acoustic-telemetry transmitter and an archival data storage tag (DST). Acoustic-telemetry transmitters and DSTs were manufactured by Lotek Wireless, Inc. of Newmarket, Ontario, Canada. Acoustic-telemetry transmitters (model MM-M16-50) measure $16 \times 80$ millimeters $(\mathrm{mm})$, weigh 35 grams (g) in air, and operate at 76 kilohertz $(\mathrm{kHz})$ with a burst rate of 10 seconds, which yields an estimated life of 861 days. Acoustic-telemetry transmitters emit a MAP-encoded signal with a digital identification code unique to individual fish. Archival DSTs (model LAT1400) measure $11 \times 35 \mathrm{~mm}$ and weigh $4.5 \mathrm{~g}$ in air with a memory capacity of 128 kilobytes. The DSTs are programmed to record depth and temperature at 30-minute ( $\mathrm{min}$ ) intervals until the memory capacity is exhausted, which yields more than 2 years of data (DeLonay and others, 2009). Data from the DSTs can only be retrieved 
after recapturing the tagged fish and surgically removing the implanted DST.

Throughout the study, concerted efforts were made to recapture, reevaluate, and reimplant telemetered pallid sturgeon from previous years. Within the study population the primary objective was to have at least two but no more than five gravid females with acoustic-telemetry transmitters within each of the two study sections of the Lower Missouri River before the onset of spring migration and spawning. Actual numbers of newly tagged sturgeon added to the study in any specific year were determined in consultation with the USFWS and the Middle Basin Pallid Sturgeon Workgroup. Pallid sturgeon collected by other agencies for use as broodstock in the Pallid Sturgeon Conservation Augmentation Program (PSCAP) were also implanted opportunistically with acoustictelemetry transmitters before their return to the Missouri River near their capture site. The goal of the study has been to retain more than 80 adult pallid sturgeon with active acoustic-telemetry transmitters and known reproductive histories for multiyear analyses of migration patterns, spawning site selection and fidelity, and reproductive frequency and success.

Telemetry tracking crews from the USGS and Nebraska Game and Parks Commission located and tracked individual telemetered pallid sturgeon to record habitat use and seasonal movements in the Lower Missouri River. Measurements of water conditions (temperature, conductivity, dissolved oxygen [DO], and turbidity) and habitat characteristics (depth and substrate) were recorded at each telemetry contact location to qualitatively and quantitatively describe habitat used by pallid sturgeon. Telemetry tracking of pallid sturgeon in reproductive condition was prioritized to better allocate resources and increase the probability of documenting spawning events. Reproductive condition or readiness to spawn was assessed using a combination of ultrasound, oocyte biopsy, and direct surgical examination of the gonads (Wildhaber and others, 2007b; DeLonay and others, 2009; Papoulias and others, 2011). When present, late-stage oocytes (grey or black) were collected in the field through the abdominal incision during surgical implantation of acoustic-telemetry transmitters or using the needle biopsy technique developed by Candrl and others (2010) when transmitter implantation was not required. Oocytes collected from late-stage females (grey or black oocytes) were preserved in formalin and evaluated for readiness in the laboratory using the polarization index (PI) (Dettlaff and others, 1993). Pallid sturgeon not in reproductive condition were tracked extensively throughout the year (located one to three times per month). Pallid sturgeon in reproductive condition were tracked intensively (located at frequencies ranging from weekly to daily) as temperatures increased from April through June and fish began migrating upstream. Reproductive female pallid sturgeon were located daily during the spring as water temperatures reached $14-16{ }^{\circ} \mathrm{C}$ and spawning became imminent. Telemetry crews attempted to collect more frequent observations, ranging from daily to hourly, of fish locations and habitat use during upstream migration and spawning. As spawning neared, selected pallid sturgeon were located several times daily during intensive tracking to monitor direction and rate of movement. Intensive tracking of reproductive pallid sturgeon adults continued until behavior indicated that spawning was complete. Spawning success (ovulation and release of oocytes) of recaptured pallid sturgeon females was evaluated based on ultrasound and confirmed by direct surgical examination of the ovaries (Wildhaber and others, 2007b).

All sturgeon used in Lower Missouri River tracking studies were given a unique database identifier, implanted with an acoustic-telemetry transmitter with a unique digital identification code, and tagged with a passive integrated transponder (PIT) tag (DeLonay and others, 2009). The database identifier includes the species code (PLS for pallid sturgeon), the two-digit year the fish was first implanted with a transmitter (for example, "14," for a fish first implanted in 2014), and a three-digit sequential number representing the order that the fish was implanted within the year; for example, PLS14-001 was the first pallid sturgeon implanted in 2014. Pallid sturgeon retain their unique database identifiers regardless of how many times they are recaptured and reimplanted. Tissue samples were taken from pectoral or caudal fins and submitted for genetic analyses to verify the species identity of all telemetered pallid sturgeon and determine whether individual pallid sturgeon were of hatchery origin (progeny of artificial propagation) or probable wild origin. The species identification, implantation history, past reproductive status, and life expectancy of implanted transmitters for all pallid sturgeon at large were tracked using an internal project database. The inventory of telemetered pallid sturgeon in the database was assessed monthly, and individual pallid sturgeon were identified and prioritized for targeted recapture.

Recapture, reassessment, and reimplantation of telemetered pallid sturgeon began in March 2014 and continued through June. Recapture efforts were suspended in July when water temperatures approached $25-28^{\circ} \mathrm{C}$. Targeted recapture efforts resumed in early September when water temperatures declined and continued through November until water temperatures fell below $8^{\circ} \mathrm{C}$. Pallid sturgeon targeted by CSRP researchers were precisely located using acoustic-telemetry transmitters and recaptured using drifted trammel nets (40 meters [m] long, $2 \mathrm{~m}$ high, 8.9-centimeter [cm] bar-mesh inner panel, 40.6-cm bar-mesh outer panel) as described by DeLonay and others (2009).

\section{Progress}

During 2014, 25 previously telemetered pallid sturgeon were recaptured and either reimplanted with a new acoustictelemetry transmitter or evaluated for reproductive status and readiness. Recaptured pallid sturgeon included fish first captured and telemetered in 2006 (1), 2007 (2), 2008 (4), 2009 (3), 2010 (8), 2011 (5), 2012 (1), and 2013 (1). Four female pallid sturgeon (PLS06-011, PLS10-029, PLS11-019, and PLS12-002) and three male pallid sturgeon (PLS08-043, PLS09-006, and PLS09-010) were recaptured and identified 
by CSRP researchers as likely to spawn in spring 2014. All seven pallid sturgeon were located in the upper study section of the Lower Missouri River. No reproductive telemetered pallid sturgeon were identified in the lower study section of the Lower Missouri River. Of these seven telemetered pallid sturgeon known to be in reproductive condition, one female (PLS06-011) and two males (PLS09-006 and PLS09-010) were captured by other agencies before spawning and removed for use as broodstock in the PSCAP. Additionally, five nonreproductive telemetered pallid sturgeon, two females (PLS10-031 and PLS11-020) and three males (PLS08-031, PLS10-021, and PLS10-032), were caught during broodstock collection efforts and sent to hatcheries in the Lower Missouri River Basin. Telemetered pallid sturgeon removed and transported to hatcheries for use as broodstock were ultimately returned to the CSRP for evaluation, reimplantation, and release; however, their removal during the spawning period and use as broodstock prevented intensive tracking to determine spawning locations.

In anticipation of a need for greater numbers of adults for propagation broodstock and research purposes in 2015 and 2016, 18 previously untagged pallid sturgeon caught during broodstock collection efforts were released to the CSRP for acoustic-telemetry transmitter implantation in 2014. Those fish included nine untagged females (PLS14-001, PLS14-002, PLS14-003, PLS14-004, PLS14-005, PLS14-007, PLS14008, PLS14-009, and PLS14-017) and nine untagged males (PLS14-006, PLS14-010, PLS14-011, PLS14-012, PLS14013, PLS14-014, PLS14-015, PLS14-016, and PLS14-018). Seven of the females were released back to the Missouri River from late April to late May 2014 and were not in reproductive condition at the time of release. Two of the nine females (PLS14-007 and PLS14-008) were in reproductive condition and induced for artificial spawning at Blind Pony State Fish Hatchery (BPSFH); however, induction failed, and the fish did not ovulate. They were tagged and subsequently released back into the Missouri River in early May 2014. Evaluation of the oocytes collected during acoustic-telemetry transmitter implantation within days of failed induction suggested that the oocytes were still viable and that both females were still in reproductive condition. The females were released to the CSRP for research because previous hatchery experience had indicated that repeating the artificial induction procedure rarely results in ovulation. PLS14-007 and PLS14-008 were assigned a low priority for intensive tracking during spring 2014. It was surmised that failed induction attempts in the hatchery may have resulted in lasting physiological effects and, therefore, the females had a low likelihood of exhibiting normal behavior and natural spawning. PLS14-007 and PLS14-008 will be targeted for recapture in winter 2015 to determine if females that fail to respond to induction attempts in the hatchery still respond to natural cues and spawn when returned to the river.

The study population of telemetered pallid sturgeon in the Lower Missouri River in 2014 included an estimated 80 fish with active acoustic-telemetry transmitters. The Mississippi
River was not searched for telemetered pallid sturgeon in 2014. Lower Missouri River tributaries were not routinely searched for pallid sturgeon with active acoustic-telemetry transmitters, although the Platte River in Nebraska was searched during the spawning period. Through December 1, 2014, CSRP telemetry crews tracked a total of 6,254 RM in the Lower Missouri River and 98 RM in the Platte River. Telemetry crews recorded a total of 730 telemetry locations for 70 unique pallid sturgeon. The mean number of telemetry locations per pallid sturgeon was 10.4 and ranged from 1 to 105 . In 2014, telemetry crews located five unique pallid sturgeon in the Platte River on a total of eight occasions. Of the five pallid sturgeon recorded in the Platte River, two were females in reproductive condition, and three were males of unknown reproductive status. The two females and two of the males were inferred to be wild, and one male was of known hatchery origin. The mean distance upstream for the five pallid sturgeon in the Platte River was 7.1 RM and ranged from about 1 to 33 RM upstream (PLS11-015 on May 28).

The three available, known reproductive females (PLS10-029, PLS11-019, and PLS12-002) from the upper study section of the Lower Missouri River were tracked during spring 2014 to document spawning location and success. An additional female pallid sturgeon from the upper study section (PLS11-015) was not assessed before spawning season, but records of her reproductive history suggested that she was likely to be in reproductive condition in 2014. PLS11-015 had previously spawned in the Platte River. It was expected that she would return to the Platte River to spawn in 2014, but PLS11-015 moved into the Platte River before she could be recaptured and her reproductive status confirmed. Extensive tracking of PLS11-015 indicated that she did move into the Platte River in early spring. PLS11-015 was targeted for recapture when she emerged from the Platte River, and reproductive evaluation indicated that she had been in reproductive condition and spawned during spring 2014. Extensive tracking of PLS10-029 also documented her movement upstream into the Platte River to spawn. Intensive tracking in the Platte River was not possible because of shallow water. The Platte River was extensively tracked to document that PLS11-015 and PLS10-029 were indeed in the Platte River and verify that DST temperature records accurately reflected the location of the tagged fish (main stem Missouri River or Platte River). Two female pallid sturgeon were intensively tracked in the main stem Missouri River. One female (PLS11-019) failed to begin upstream migration and ultimately failed to spawn. The second female pallid sturgeon (PLS12-002) migrated upstream, was recaptured, and seemed to have spawned in the Missouri River.

Female pallid sturgeon PLS10-029 was first captured near RM 563.2 in the Missouri River and transported to the Neosho National Fish Hatchery on March 31, 2009. PLS10 029 spent more than 1 year in captivity before being used as broodstock for the PSCAP in spring 2010. PLS10-029 was then released to the CSRP on May 7, 2010, in post-spawn condition, implanted with an acoustic-telemetry transmitter 
and DST, and released near her first capture site. PLS10-029 was located from about RM 700 to 590 in the Missouri River during 2010 and 2011. Although not in reproductive condition in 2011, PLS10-029 was located in the Platte River near the mouth of the Elkhorn River on May 11, 2011, about 33 RM upstream from the confluence of the Platte and Missouri Rivers. By October 2011, PLS10-029 was near RM 590 in the Missouri River. The reproductive condition of PLS10-029 was not evaluated before spring 2012, nor was this female intensively tracked during that time, but was recaptured in post-spawn condition with few remaining oocytes on May 2, 2012. Temperature data downloaded from the implanted DST closely matched the temperature profile of the Platte River for much of March and April 2012. Comparison of temperature profiles indicates that PLS10-029 probably spawned in the Platte River during spring 2012 (DeLonay and others, 2016b). After May 2012, PLS10-029 spent most of her time between RM 595 and 601. PLS10-029 was targeted for recapture and evaluation on September 17, 2013, and field assessments indicated that she was ready to spawn during spring 2014. On April 26, 2014, PLS10-029 was located in the Platte River about 1 mile (mi) upstream from the confluence of the Platte and Missouri Rivers. PLS10-029 was again located in the Platte River on May 13, 2014, about 2 mi upstream from the confluence of the Platte and Missouri Rivers. PLS10-029 was first located downstream back in the Missouri River near RM 596.9 on June 17, 2014. On July 10, 2014, PLS10-029 was recaptured near RM 595.9 and was determined to have spawned completely. Temperature data recorded by the implanted DST closely matched the temperature profile of the Platte River from late April through early June 2014 (fig. 7), which indicates that she probably spawned in the Platte River during that time.

Female pallid sturgeon PLS11-015 was originally captured in reproductive condition near RM 586 and transported to the BPSFH on April 7, 2011. PLS11-015 was not used as broodstock for the PSCAP and was instead released to the CSRP on April 28, 2011, in reproductive condition and implanted with an acoustic-telemetry transmitter and DST. After her release into the Missouri River at RM 591.5, PLS11-015 was not located during the 2011 spawning period. PLS11-015 was subsequently recaptured near RM 554.2

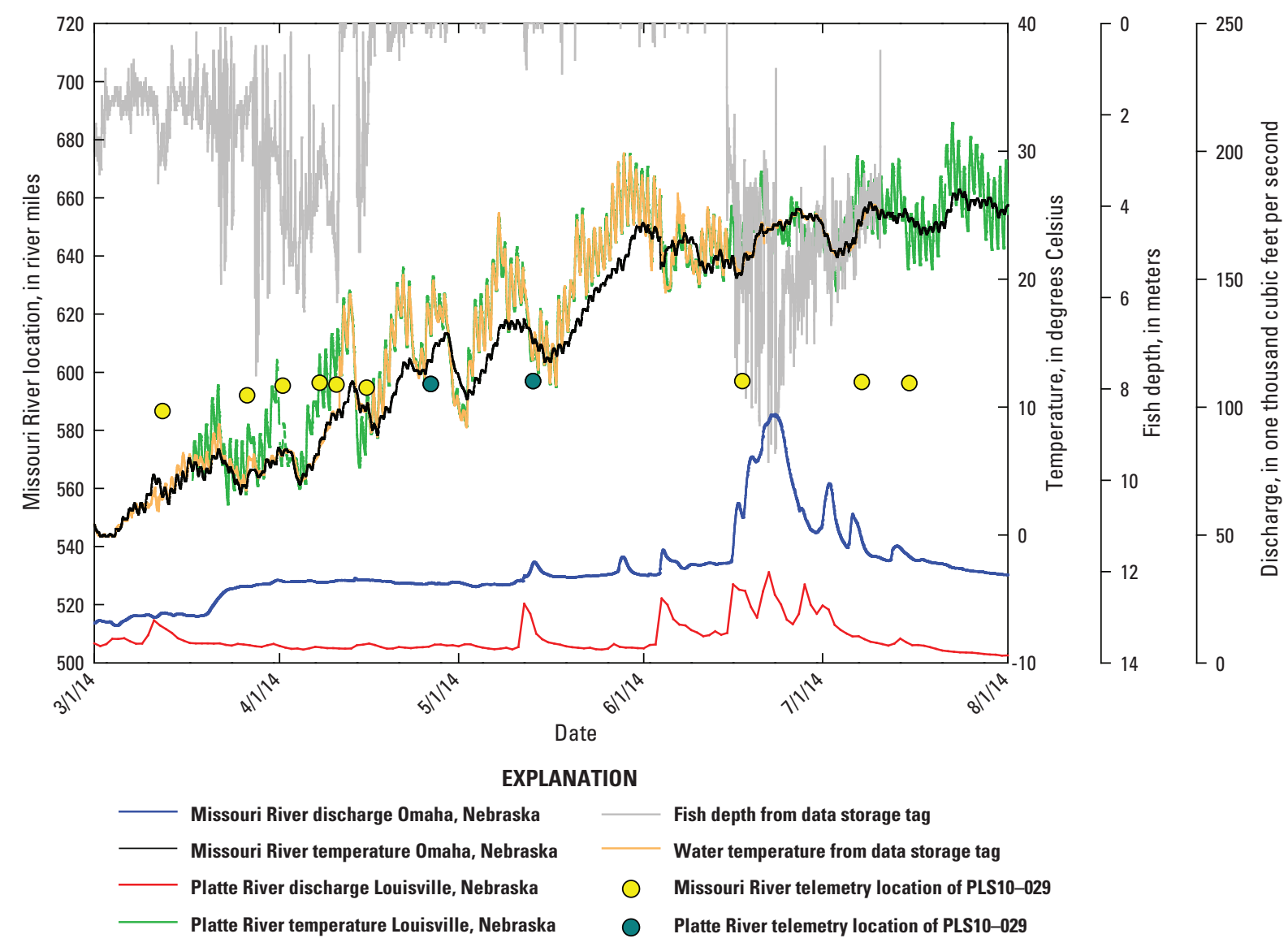

Figure 7. Telemetry locations of female pallid sturgeon PLS10-029; depth and temperature recorded from data storage tag; Missouri River temperature and discharge from the nearest streamgage at Omaha, Nebraska; and Platte River temperature and discharge from the nearest streamgage at Louisville, Nebraska. 
on November 1, 2011. Surgical examination of the ovaries of PLS11-015 at recapture found no remaining oocytes or evidence of atresia, and indicated a complete spawn during the preceding spring. The temperature data recorded by the implanted DST in PLS11-015 closely matched the temperature profile of the Platte River recorded at the Louisville, Nebr., streamgage for most of the month of May 2011. Data suggest that PLS11-015 spawned somewhere in the Platte River during May 2011 based on the reproductive readiness at implantation and the length of time inferred to be in the Platte River (DeLonay and others, 2014). From May 2013 to March 2014, PLS11-015 was located on eight occasions between RM 553.7 and 564. PLS11-015 was not reproductively assessed before the 2014 spawning season but was extensively tracked by CSRP researchers and located on four separate occasions from April 2, 2014, to May 12, 2014 , between RM 553.6 and 589.6. Attempts to recapture PLS11015 before spawning were unsuccessful. On May 13, 2014, PLS11-015 was located in the Platte River approximately 1.7 RM upstream from the confluence with the Missouri River. PLS11-015 was located on two more occasions in the Platte
River on May 15 and May 28, 2014, at 12 and 33 RM, respectively, upstream from the confluence with the Missouri River. Recapture of PLS11-015 on July 11, 2014, indicated that she had been in reproductive condition in 2014. Temperature data recorded by the implanted DST closely matched the temperature profile of the Platte River from mid-May through midJune 2014 (fig. 8), which indicates that she probably spawned in the Platte River during that time.

Female pallid sturgeon PLS11-019 was first captured near RM 717 in reproductive condition and transported to the Neosho National Fish Hatchery on March 30, 2010. PLS11-019 was retained for use as broodstock in the PSCAP for more than 1 year before being released to the CSRP on May 4, 2011, in nonreproductive condition. PLS11-019 was in reproductive condition in 2012 when her spawning migration pattern was recorded as an irregular series of upstream and downstream movements, which made spawning behavior and the precise location of spawning difficult to discern. PLS11-019 was recaptured on May 31, 2012, and determined to have spawned completely. PLS11-019 is inferred to have spawned between RM 700.1 and 713.7 between May 5 and

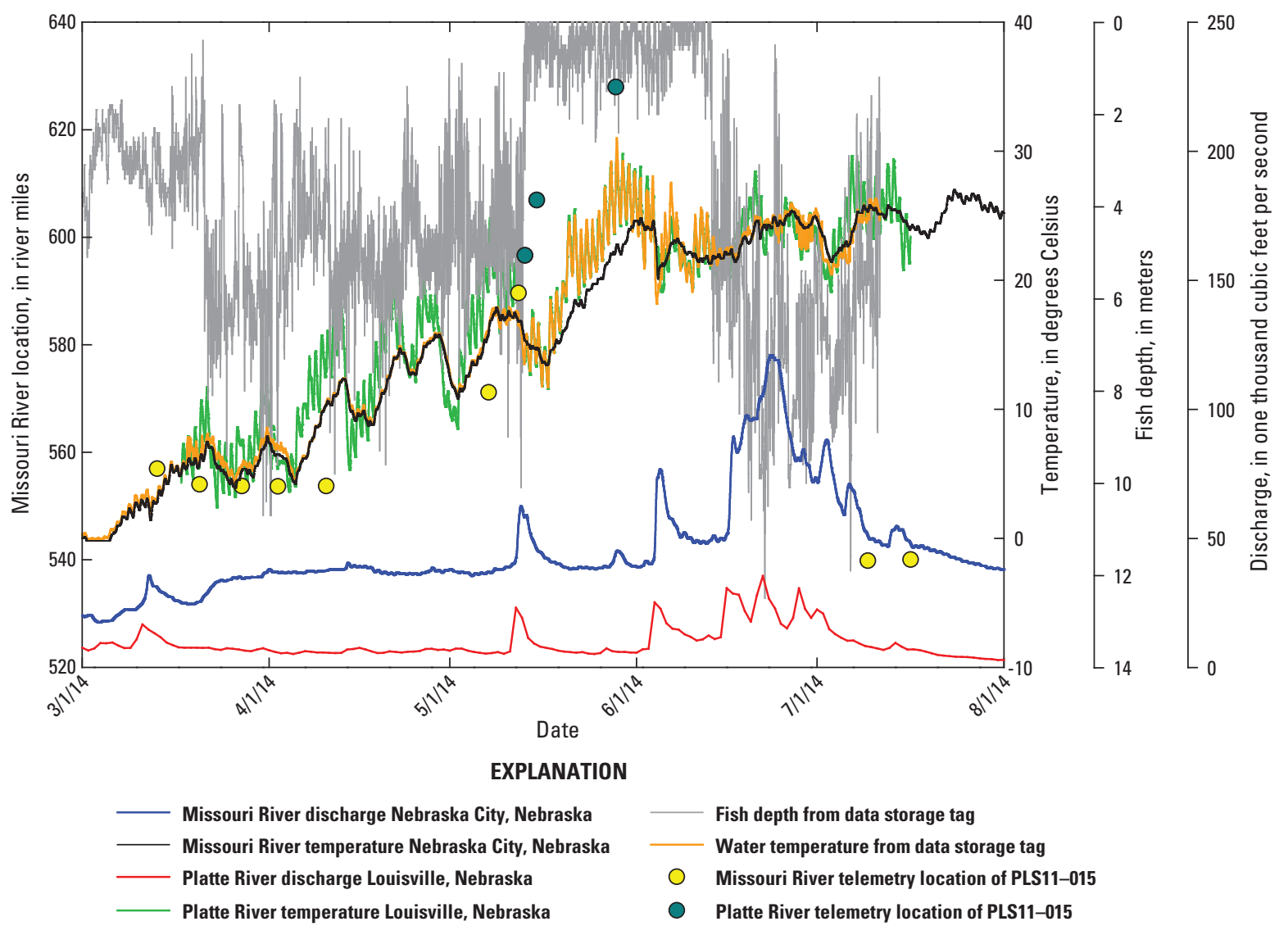

Figure 8. Telemetry locations of female pallid sturgeon PLS11-015; depth and temperature recorded from data storage tag; Missouri River temperature and discharge from the nearest streamgage at Nebraska City, Nebraska; and Platte River temperature and discharge from the nearest streamgage at Louisville, Nebraska. 
May 31, 2012 (DeLonay and others, 2016b). After the 2012 spawning event to September 2013, PLS11-019 was located on 18 occasions between RM 688.2 and 716.5. On September 18, 2013, PLS11-019 was targeted for recapture and reproductive evaluation, and field assessments of reproductive condition at the time indicated that she would likely spawn during spring 2014. PLS11-019 did not begin upstream migration, displaying minor upstream and downstream movements between RM 710.8 and 718.9 from April 9 to May 28, 2014. Between May 28 and May 30, 2014, PLS11-019 moved downstream approximately $5.8 \mathrm{mi}$, indicating that she may have spawned (fig. 9). PLS11-019 was targeted for recapture and reproductive evaluation on June 3, 2014, at RM 713.3. A reproductive assessment performed by CSRP researchers revealed that PLS11-019 had failed to spawn, and her oocytes had become atretic.

Female pallid sturgeon PLS12-002 was originally captured in nonreproductive condition on October 10, 2012, near RM 576.2. PLS12-002 was implanted with an acoustictelemetry transmitter and DST and released back into the Missouri River near her first capture site. The CSRP researchers deduced that PLS12-002 was a HOPS from the 1992 or
1997 year class based on the presence and location of a coded wire tag. On September 19, 2013, PLS12-002 was targeted for recapture near RM 496. Reproductive assessments at the time of recapture indicated that she would likely spawn during spring 2014. PLS12-002 moved upstream about $17 \mathrm{mi}$ by late October 2013. The CSRP researchers located PLS12-002 with increasing frequency from April through June 2014 (fig. 10). She was recaptured on July 16, 2014, near RM 595 and determined to have spawned completely. The spawning location of PLS12-002 was between RM 572.5 and 591.8 in the Missouri River between June 11 and July 7, 2014, based on telemetry data.

No telemetered pallid sturgeon were tracked to their precise spawning location in the Lower Missouri River in 2014. Because of the inability to identify new spawning sites, it was not possible to characterize or map new spawning habitat patches or sample for eggs or free embryos at known spawning sites. In the absence of precisely identified spawning sites, resources to validate and verify spawning were redirected to comparative studies on the Yellowstone River within the same task.

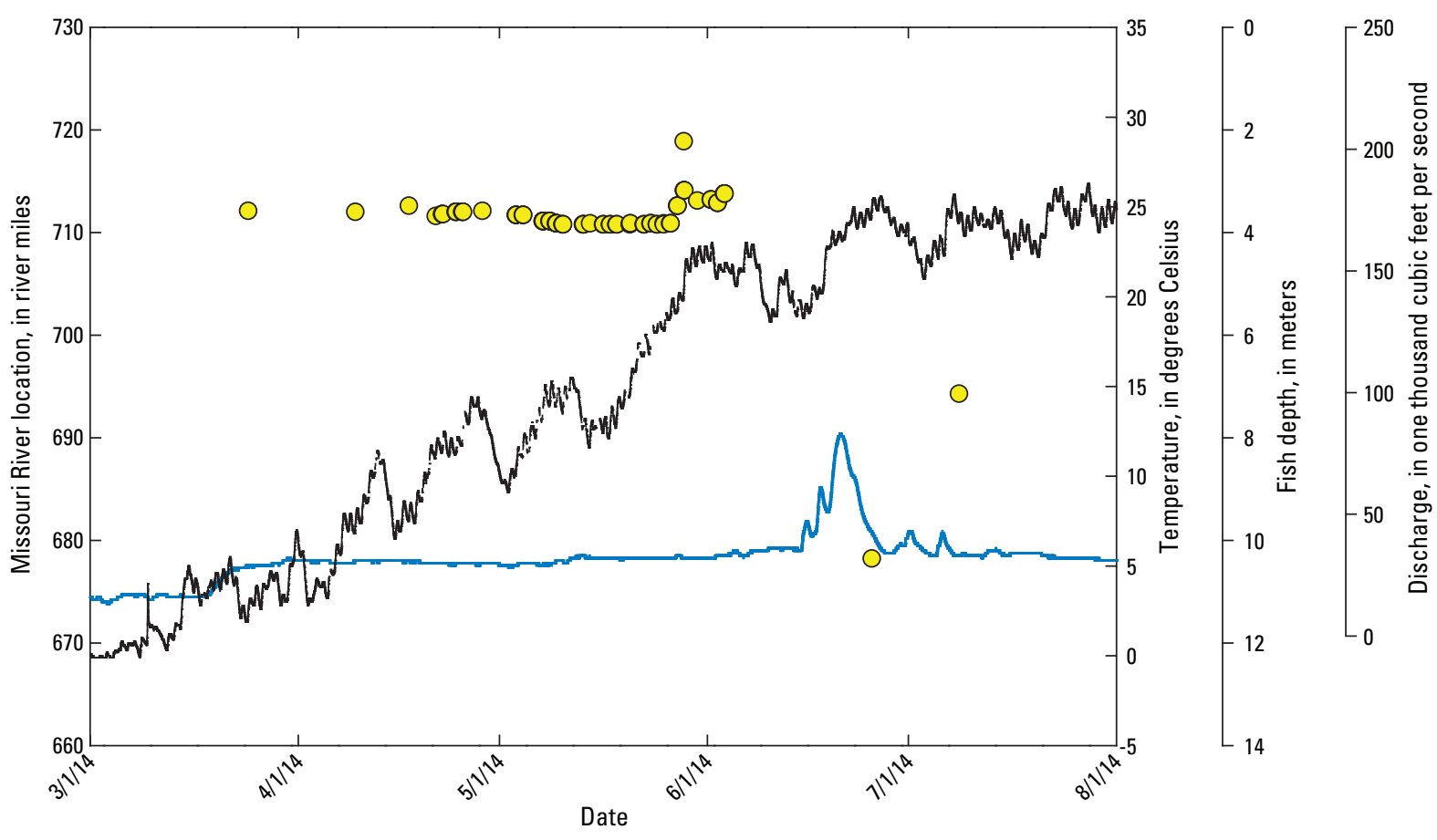

EXPLANATION

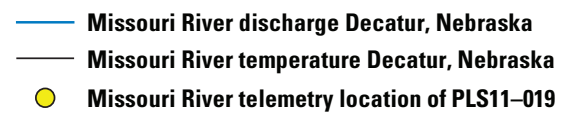

Figure 9. Telemetry locations of female pallid sturgeon PLS11-019, and Missouri River temperature and discharge from the nearest streamgage at Decatur, Nebraska. 


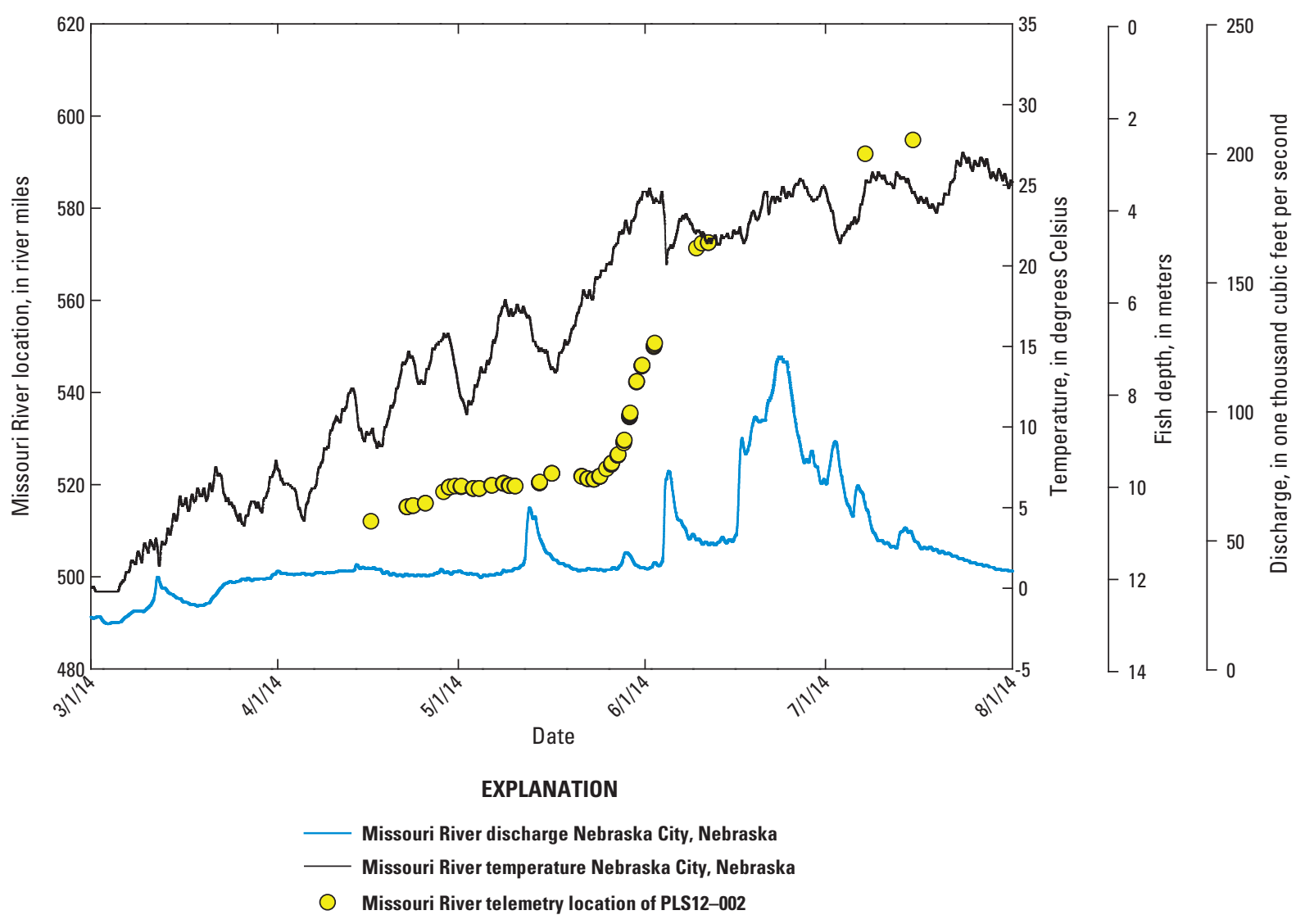

Figure 10. Telemetry locations of female pallid sturgeon PLS12-002, and Missouri River temperature and discharge from the nearest streamgage at Nebraska City, Nebraska.

\section{Discussion}

Intensive and extensive tracking of pallid sturgeon between 2007 and 2014 has resulted in the documentation of 32 spawning events by 27 individual females in the Lower Missouri River and its tributaries (table 1). The precision that spawning sites of individual females have been documented varies. Documentation of spawning events by some intensively tracked and recaptured females has defined spawning as happening over a few hundred meters of an outside bend of the river in a 12- to 36-hour (h) period (DeLonay and others, 2009) after a characteristic upstream migration. Estimates of the timing and location of spawning of other tagged females may be more broadly defined, especially if the migration pattern of intensively tracked females was complex and disrupted without a clear indication of spawning behavior or if females were tracked extensively with only a few observations between the first reproductive evaluation and the post-spawn recapture (DeLonay and others, 2012). At this time (2015) the spawning locations of eight known HOPS females have been documented (table 1). Five of these are known to be from the 1992 year class. The documented spawning locations of seven of eight HOPS females have been located downstream from RM 400 in the Missouri River. This may be a result of their original stocking locations. The spawning locations of five putative wild female pallid sturgeon (PLS07-001, PLS10-029, PLS11-016, PLS11-015, and PLS11-020) have been documented during two consecutive spawning cycles. Three of these females spawned on a 2-year cycle (PLS11-016 and PLS11-020 spawned in 2011 and 2013 and PLS10-029 spawned in 2012 and 2014). Two of the five females spawned on a 3-year cycle (PLS07-001 spawned in 2008 and 2011 and PLS11-015 spawned in 2011 and 2014). Of the five females for which repeated spawning has been documented, four of these females are inferred to have spawned in the Platte River and one in the Missouri River.

Observations of spawning in 2014 were consistent with trends observed in previous years (DeLonay and others, 2012). Although it is clear that pallid sturgeon are capable of spawning in most reaches of the main stem Missouri River under a wide variety of conditions, it remains unclear if this is the natural, adaptive condition (fig. 11). It is uncertain if spawning distributions have been altered by modified hydrology and channel engineering. The success of pallid sturgeon spawning at different locations along the Missouri River remains unknown. 
The timing of spawning by pallid sturgeon in the Lower Missouri River during 2014 was also consistent with observations made during previous years. Pallid sturgeon in the Lower Missouri River generally spawn during a shorter timeframe than the closely related shovelnose sturgeon (Scaphirhynchus platorynchus); generally, from the end of April through May (DeLonay and others, 2009, 2010, 2012, 2014) at temperatures of $16-25^{\circ} \mathrm{C}$, except during the exceptionally warm spring 2012 (DeLonay and others, 2016a) when spawning was recorded as early as March 31 . Shovelnose sturgeon, in contrast, tend to spawn from mid-April to July (DeLonay and others, 2009) and, in some years, are capable of spawning during the fall (DeLonay and others, 2016b). Pallid sturgeon seem to be more synchronous in their spawning behavior based on these data, whereas shovelnose sturgeon spawn during a much longer timeframe, in a broader range of habitat, and in a wider geographic extent.

Pallid sturgeon in the Lower Missouri River may exhibit either a single-step spawning migration beginning in the spring or a two-step spawning migration beginning in the fall before the subsequent spring spawning (2014; DeLonay and others, 2016b). During the spring, female pallid sturgeon in the Lower Missouri River exhibit two variations of migration patterns as spawning nears. Females either exhibit a characteristic, rapid upstream movement pattern and generally spawn near the most-upstream location, or apex, of the spawning migration; or exhibit a complex, seemingly disrupted upstream and downstream movement pattern (DeLonay and others, 2010). Female pallid sturgeon that exhibit the typical singleapex movement pattern generally spawn farther downstream from Gavins Point Dam and usually spawn successfully. Female pallid sturgeon that exhibit the complex or disrupted movement pattern are more likely to fail to spawn successfully. Pallid sturgeon with complex disrupted movement patterns nearer Gavins Point Dam typically spawn later from mid-May to mid-June. Reproductive female pallid sturgeon that do not migrate fail to spawn, and their oocytes eventually become atretic.

Data indicate that pallid sturgeon are spawning in the Platte River, and there are examples of individual pallid sturgeon of both sexes returning to the same section of the river to spawn. Spawning in the Platte River happened over several years with markedly different temperature and flow conditions. Although the precise locations of spawning in the Platte River remain unknown, repeated observations suggest that there is some level of fidelity to the Platte River for individual sturgeon and that spawning in the Platte River is likely not an opportunistic event triggered by unusual flow conditions. Pallid sturgeon that spawn in the Platte River enter the Platte River early and stay for an extended period until spawning is complete. The role and relative contribution to recruitment of spawning in the Platte River and other tributaries is unknown. All adults documented to use the Platte River for spawning have been probable wild sturgeon. Whether or not there are any unique genetic characteristics to populations that use the Platte River or other tributaries is also unknown.
Tracking adult pallid sturgeon during longer periods would allow researchers to assess the level of spawning-site fidelity in pallid sturgeon and the role that geographic specificity may play in preserving population genetic structure. Documenting and characterizing spawning locations in the Platte River may also support observations of spawning conditions in the Yellowstone River, where more natural channel geomorphology may provide a comparative template for the enhancement or construction of spawning habitat in the main stem Lower Missouri River.

\section{Field-Based Biotic Assessments of Factors Affecting Migration and Spawning- Yellowstone River}

During the last decade, research investigations in the Upper Missouri River Basin of North Dakota and Montana have substantially advanced knowledge of the reproductive ecology of wild pallid sturgeon. Before 2007, it was unknown if spawning happened in the wild stock of pallid sturgeon inhabiting the Yellowstone River and Missouri River downstream from Fort Peck Dam (U.S. Fish and Wildlife Service, 2007), although inferences from telemetry studies suggested the possibility of spawning in the Lower Yellowstone River (Bramblett and White, 2001). The first documentation of pallid sturgeon spawning in the Upper Missouri River Basin happened in 2007; Fuller and others (2008) verified that two female pallid sturgeon spawned in the Yellowstone River. Although the specific timing and location of spawning events were not determined, inferences from telemetry and female capture and recapture events suggested spawning happened during mid-June in the lower reaches of the Yellowstone River (Fuller and others, 2008). Additional verification of pallid sturgeon spawning in the Lower Yellowstone River was obtained in 2008 as it was determined that two females spawned (Fuller and Braaten, 2012); but, similar to the 2007 work, the specific timing and location of spawning events were not determined. Expanding on these earlier studies, collaboration between the USGS and MFWP began in 2011 to examine the reproductive ecology of pallid sturgeon in the Yellowstone River. Much of the emphasis of this work has focused on assessing pre-spawn migratory behavior, identifying specific dates and locations of spawning events, and quantifying habitat conditions at spawning locations; moreover, research activities since 2011 have also focused on documenting the instances of pallid sturgeon free embryos because collections of this early life stage would verify functionality of the spawning and reproductive processes, including successful fertilization of gametes and successful incubation and hatch of embryos under habitat conditions at the spawning sites. Research activities during 2011-13 documented that pallid sturgeon can exhibit pre-spawn migrations of several hundred miles, spawning events happen during mid- to late June at sites in the Lower Yellowstone River, spawning habitat sites are characterized as swift-flowing with interspersed sand-gravel substrates, and functionality of the 
Table 1. Probable spawning locations, periods, and tracking details of telemetered reproductive female pallid sturgeon, Missouri River and tributaries, 2007-14.

[FishID, fish identification code; >, greater than; NA, not available; Nebr., Nebraska; <, less than]

\begin{tabular}{|c|c|c|c|c|c|c|c|c|}
\hline \multirow{2}{*}{$\begin{array}{c}\text { Spawning site } \\
\text { confidence } \\
\text { score }^{1}\end{array}$} & \multirow[b]{2}{*}{ FishID } & \multirow[b]{2}{*}{ Origin } & \multicolumn{3}{|c|}{ Spawning period ${ }^{2}$} & \multicolumn{3}{|c|}{ Boundary of probable spawning extent (river mile) ${ }^{3}$} \\
\hline & & & $\begin{array}{c}\text { Spawning } \\
\text { year }\end{array}$ & $\begin{array}{l}\text { Spawning } \\
\text { begin date }\end{array}$ & $\begin{array}{l}\text { Spawning } \\
\text { end date }\end{array}$ & Upstream extent & $\begin{array}{c}\text { Downstream } \\
\text { extent }\end{array}$ & $\begin{array}{c}\text { Center of } \\
\text { spawning site }\end{array}$ \\
\hline 3 & PLS07-007 & $\begin{array}{c}\text { Probable } \\
\text { wild }\end{array}$ & 2007 & $4 / 29 / 2007$ & $5 / 8 / 2007$ & $>694.9$ & 681.1 & NA \\
\hline 1 & PLS08-008 & Hatchery & 2008 & $5 / 8 / 2008$ & $5 / 9 / 2008$ & 366.8 & 366.1 & 366.4 \\
\hline 1 & PLS08-009 & Hatchery & 2008 & $5 / 7 / 2008$ & $5 / 8 / 2008$ & 369.7 & 369.3 & 369.5 \\
\hline 3 & PLS08-014 & $\begin{array}{c}\text { Probable } \\
\text { wild }\end{array}$ & 2008 & $5 / 22 / 2008$ & $5 / 31 / 2008$ & 688.4 & 670.7 & NA \\
\hline 3 & PLS07-001 & $\begin{array}{c}\text { Probable } \\
\text { wild }\end{array}$ & 2008 & NA & $6 / 3 / 2008$ & 811.0 & 790.7 & NA \\
\hline 2 & PLS09-009 & $\begin{array}{c}\text { Probable } \\
\text { wild }\end{array}$ & 2009 & $5 / 7 / 2009$ & $5 / 11 / 2009$ & 659.8 & 650.3 & NA \\
\hline 1 & PLS10-006 & Hatchery & 2010 & $4 / 30 / 2010$ & $5 / 1 / 2010$ & 202.4 & 202.0 & 202.2 \\
\hline 1 & PLS10-013 & $\begin{array}{c}\text { Probable } \\
\text { wild }\end{array}$ & 2010 & $4 / 28 / 2010$ & $4 / 29 / 2010$ & 634.2 & 633.7 & 633.9 \\
\hline 5 & PLS10-023 & $\begin{array}{c}\text { Probable } \\
\text { wild }\end{array}$ & 2010 & $5 / 13 / 2010$ & $5 / 26 / 2010$ & 642.7 & 494.9 & NA \\
\hline 3 & PLS07-001 & $\begin{array}{c}\text { Probable } \\
\text { wild }\end{array}$ & 2011 & $5 / 8 / 2011$ & $5 / 23 / 2011$ & $799.6(3.3)$ & 787.1 & NA \\
\hline 4 & PLS11-015 & $\begin{array}{c}\text { Probable } \\
\text { wild }\end{array}$ & 2011 & $5 / 16 / 2011$ & $5 / 30 / 2011$ & Platte River, Nebr. & NA & NA \\
\hline 4 & PLS11-016 & $\begin{array}{c}\text { Probable } \\
\text { wild }\end{array}$ & 2011 & $5 / 16 / 2011$ & $6 / 1 / 2011$ & Platte River, Nebr. & NA & NA \\
\hline 4 & PLS11-017 & $\begin{array}{c}\text { Probable } \\
\text { wild }\end{array}$ & 2011 & $5 / 9 / 2011$ & $6 / 11 / 2011$ & Missouri River, Nebr. & NA & NA \\
\hline 4 & PLS11-020 & $\begin{array}{c}\text { Probable } \\
\text { wild }\end{array}$ & 2011 & $5 / 16 / 2011$ & $6 / 1 / 2011$ & Platte River, Nebr. & NA & NA \\
\hline 1 & PLS11-007 & $\begin{array}{c}\text { Probable } \\
\text { wild }\end{array}$ & 2012 & $3 / 31 / 2012$ & $3 / 31 / 2012$ & 322.2 & 322.2 & 322.2 \\
\hline 3 & PLS11-019 & $\begin{array}{c}\text { Probable } \\
\text { wild }\end{array}$ & 2012 & $5 / 5 / 2012$ & $5 / 31 / 2012$ & 713.7 & 700.1 & NA \\
\hline
\end{tabular}




\begin{tabular}{|c|c|c|c|}
\hline \multicolumn{3}{|c|}{ Tracking details ${ }^{4}$} & \multirow[b]{2}{*}{ Notes } \\
\hline $\begin{array}{l}\text { Pre-spawn } \\
\text { evaluation }\end{array}$ & Tracking & $\begin{array}{l}\text { Spawning } \\
\text { confirmed }\end{array}$ & \\
\hline Yes & Intensive & Yes & Intensive tracking interrupted by lethal tornado. Complete migration and spawning not documented. \\
\hline Yes & Intensive & Yes & Intensive tracking to spawning location. Complete migration and spawning behavior documented. \\
\hline Yes & Intensive & Yes & Intensive tracking to spawning location. Complete migration and spawning behavior documented. \\
\hline Yes & Intensive & Yes & $\begin{array}{l}\text { Intensively tracked female exhibited complex disrupted pattern. Complete migration pattern docu- } \\
\text { mented, but spawning behavior difficult to discern. }\end{array}$ \\
\hline No & Extensive & Yes & $\begin{array}{l}\text { Female not intensively tracked. Recovered in July after spawning season with spent ovaries indicat- } \\
\text { ing she had spawned that spring, most likely before downstream movement. Minimal observations } \\
\text { suggest that this fish most likely spawned in the unchannelized reach above river mile } 790 \text {. }\end{array}$ \\
\hline Yes & Intensive & No & $\begin{array}{l}\text { Female intensively tracked and aggregations with males documented, but female not recovered. } \\
\text { Spawning not verified. }\end{array}$ \\
\hline Yes & Intensive & Yes & Intensive tracking to spawning location. Complete migration and spawning behavior documented. \\
\hline Yes & Intensive & Yes & Intensive tracking to spawning location. Complete migration and spawning behavior documented. \\
\hline Yes & Intensive & Yes & $\begin{array}{l}\text { Translocated fish from propagation program. Intensively tracked as it moved upstream to spawn. It } \\
\text { reached its upstream apex and began moving downstream. It was recovered on May } 13 \text { after its } \\
\text { first downstream movement and it had not yet spawned. It was recovered again June } 9 \text { more than } \\
\text { nearly } 150 \text { miles downstream and it had spawned. }\end{array}$ \\
\hline Yes & Intensive & Yes & $\begin{array}{l}\text { Intensively tracked. Complete migration documented. Complex, disrupted migrations. May have } \\
\text { spawned in the James River. Most likely spawned in the Missouri River. Spawning behavior not } \\
\text { documented. }\end{array}$ \\
\hline Yes & NA & Yes & $\begin{array}{l}\text { The fish was not located during the spawning period. Spawning location is inferred from data storage } \\
\text { tag records of temperature matching the temperature profile of the Platte River, Nebr. }\end{array}$ \\
\hline Yes & NA & Yes & $\begin{array}{l}\text { The fish was not located during the spawning period. Spawning location is inferred from data storage } \\
\text { tag records of temperature matching the temperature profile of the Platte River, Nebr. }\end{array}$ \\
\hline Yes & NA & Yes & $\begin{array}{l}\text { The fish was not located during the spawning period. Spawning location is inferred from data stor- } \\
\text { age tag records of temperature matching the temperature profile of the main stem Missouri River, } \\
\text { Nebr. }\end{array}$ \\
\hline Yes & NA & Yes & $\begin{array}{l}\text { The fish was not located during the spawning period. Spawning location is inferred from data storage } \\
\text { tag records of temperature matching the temperature profile of the Platte River, Nebr. }\end{array}$ \\
\hline Yes & Intensive & Yes & Intensive tracking to spawning location. Complete migration and spawning behavior documented. \\
\hline Yes & Intensive & Yes & $\begin{array}{l}\text { Intensively tracked female exhibited complex disrupted pattern. Complete migration pattern and } \\
\text { spawning behavior not documented. Spawning confirmed but spawning behavior difficult to } \\
\text { discern. }\end{array}$ \\
\hline
\end{tabular}


Table 1. Probable spawning locations, periods, and tracking details of telemetered reproductive female pallid sturgeon, Missouri River and tributaries, 2007-14.-Continued

[FishID, fish identification code; >, greater than; NA, not available; Nebr., Nebraska; <, less than]

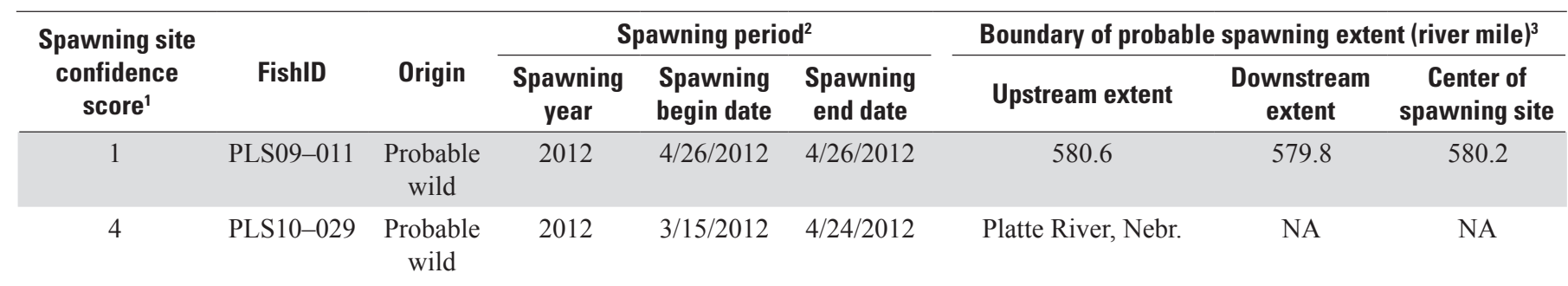

\begin{tabular}{ccccccccc}
4 & PLS11-016 & $\begin{array}{c}\text { Probable } \\
\text { wild }\end{array}$ & 2013 & $3 / 26 / 2013$ & $6 / 11 / 2013$ & Platte River, Nebr. & NA & NA \\
\hline 1 & PLS11-018 & $\begin{array}{c}\text { Probable } \\
\text { wild }\end{array}$ & 2013 & $5 / 16 / 2013$ & $5 / 20 / 2013$ & 592.2 & 591.9 & 592.0 \\
\hline
\end{tabular}

\begin{tabular}{|c|c|c|c|c|c|c|c|c|}
\hline 1 & PLS08-035 & $\begin{array}{c}\text { Probable } \\
\text { wild }\end{array}$ & 2013 & $5 / 10 / 2013$ & $5 / 11 / 2013$ & 423.4 & 422.7 & 423.0 \\
\hline 4 & PLS11-020 & $\begin{array}{c}\text { Probable } \\
\text { wild }\end{array}$ & 2013 & $4 / 9 / 2013$ & $6 / 12 / 2013$ & Platte River, Nebr. & NA & NA \\
\hline
\end{tabular}

\begin{tabular}{|c|c|c|c|c|c|c|c|c|}
\hline 1 & PLS13-001 & Hatchery & 2013 & $5 / 10 / 2013$ & $5 / 11 / 2013$ & 399.1 & 389.6 & 389.9 \\
\hline 1 & PLS13-003 & $\begin{array}{c}\text { Probable } \\
\text { wild }\end{array}$ & 2013 & $5 / 12 / 2013$ & $5 / 13 / 2013$ & 603.8 & 603.2 & 603.5 \\
\hline 4 & PLS12-002 & Hatchery & 2014 & $6 / 11 / 2014$ & 7/7/2014 & 591.8 & 572.5 & NA \\
\hline 4 & PLS10-029 & $\begin{array}{c}\text { Probable } \\
\text { wild }\end{array}$ & 2014 & $5 / 18 / 2014$ & $6 / 14 / 2014$ & Platte River, Nebr. & NA & NA \\
\hline
\end{tabular}

4 PLS11-015 $\begin{gathered}\text { Probable } \\ \text { wild }\end{gathered} \quad 2014 \quad 5 / 20 / 2014 \quad 6 / 13 / 2014 \quad$ Platte River, Nebr. $\quad$ NA $\quad$ NA

\footnotetext{
${ }^{1} 1=$ probable spawning site located within $<1$ river miles; $2=$ probable spawning site located within $1-10$ miles; $3=$ probable spawning site located within 10-25 miles; 4=probable spawning site located within 25-100 miles; 5=probable spawning site located within $>100$ miles.

${ }^{2}$ The act of spawning by a female sturgeon may take from 12 to 36 hours. The spawning begin and end dates indicate the time during which a female sturgeon may have spawned. The spawning period reported reflects the uncertainty surrounding the actual timing of the spawning event, not the actual time spent spawning.

${ }^{3}$ Female sturgeon spawn in a fairly limited area. As we understand it, spawning by pallid sturgeon may happen in a patch of spawning habitat ranging from 0.3 to 0.7 river miles in length. The upstream and downstream extents reported reflect the uncertainty surrounding where the patch of spawning habitat is located, not the extent in which the individual actually deposited eggs. Values in parentheses are river miles in a Missouri River tributary. In some instances the female sturgeon was tracked to the probable spawning site and spawning behavior was documented. In this case a river mile for the center of the spawning habitat patch
} is reported.

${ }^{4}$ The tracking details indicate if the female sturgeon was evaluated for reproductive condition in the months just prior to spawning, if the sturgeon was targeted for intensive tracking (daily) or extensively tracked as resources allowed, and if the female sturgeon was recaptured following spawning to confirm that eggs had been released successfully. 


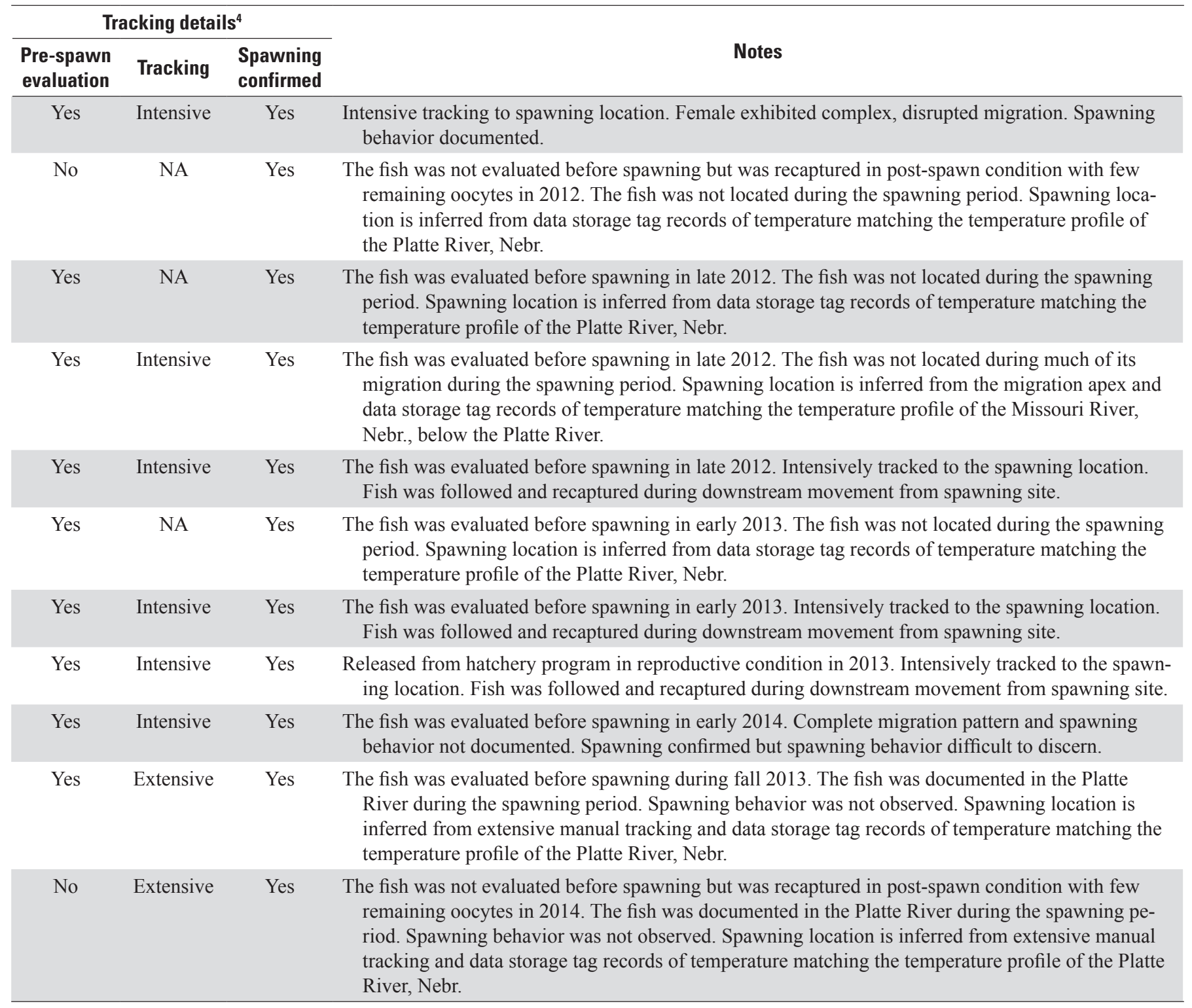




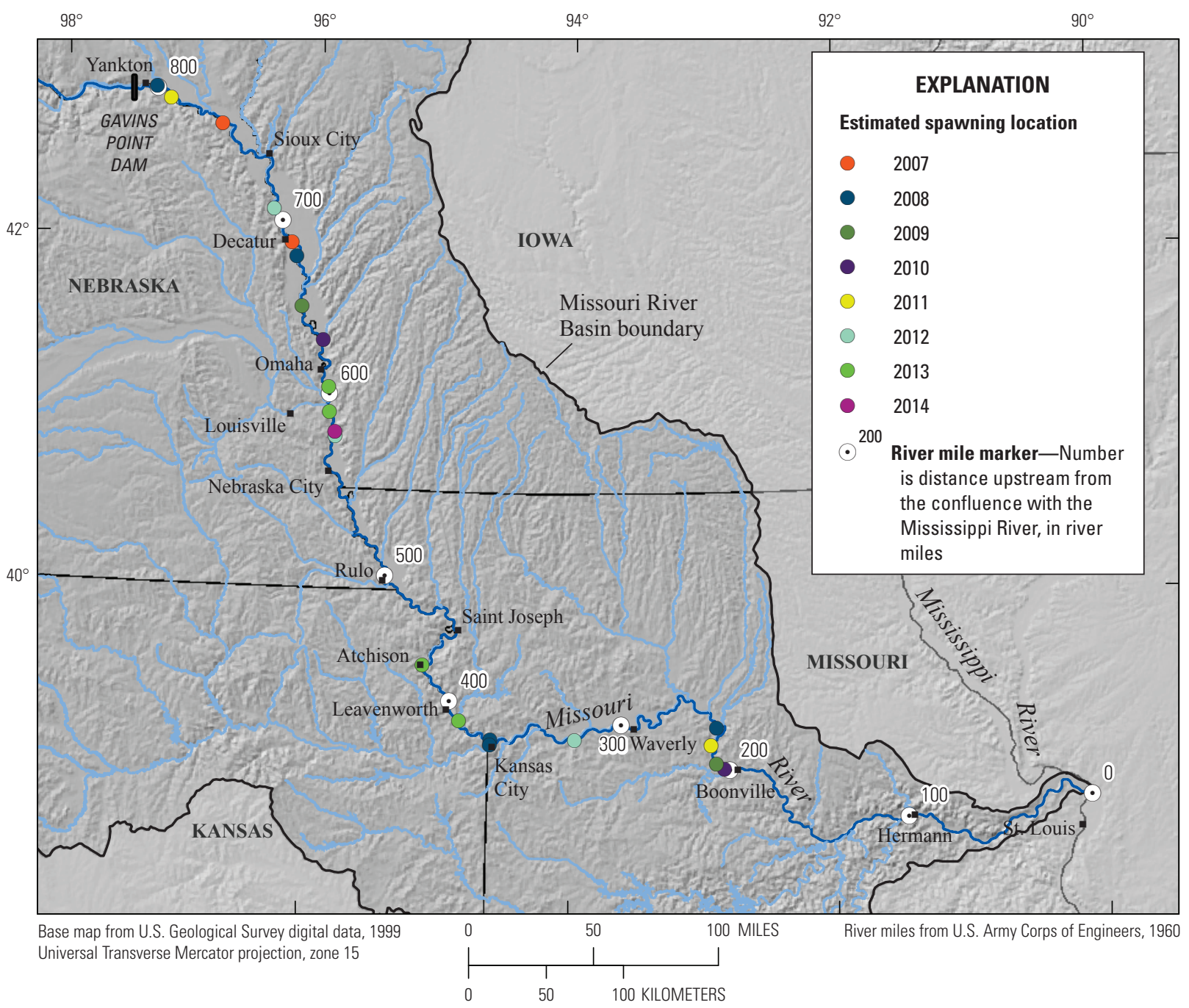

Figure 11. Locations of spawning sites used by telemetered pallid sturgeon in the Lower Missouri River, $2007-14$.

spawning process has been verified based on collections of pallid sturgeon free embryos downstream from known spawning sites (DeLonay and others, 2014, 2016b).

Recent research activities in the Yellowstone River have also provided information critical to habitat restoration efforts throughout the Missouri River Basin. First, the Intake Diversion Dam (hereinafter referred to as "Intake Dam") on the Yellowstone River has been identified as an impediment to pallid sturgeon passage (U.S. Bureau of Reclamation and U.S. Army Corps of Engineers, 2010). Restoration alternatives, including construction of a rock ramp or a by-pass channel around Intake Dam, have been proposed to facilitate upstream passage and provide access to potential spawning sites in upstream reaches of the Yellowstone River (U.S. Bureau of Reclamation and U.S. Army Corps of Engineers, 2010, 2014). Work during 2011-13 provided information relevant to fish passage alternatives. As temporal instances of pallid sturgeon migrations to Intake Dam were documented across a range of discharges, use of main-channel and side-channel habitats during upstream migrations were assessed and habitat conditions (depth, velocity) negotiated by pallid sturgeon during prespawn migrations were quantified (Braaten and others, 2014) to guide design specifications for the fish passage alternatives. Second, functionality of the spawning process (successful spawn, incubation, egg hatch, free-embryo drift) observed in the Yellowstone River serves as a comparative template to the reproductive ecology of pallid sturgeon in other parts of the Missouri River Basin; for example, habitat conditions (depth, velocity, substrate) quantified within functional spawning and incubation habitats of the Yellowstone River may be used to guide habitat improvements in other river reaches where functional spawning habitats may be lacking.

Collaborative work between the USGS and MFWP during 2014 expanded on previous studies of pallid sturgeon reproductive ecology in the Yellowstone River. The objectives included the following: (1) ascertain the instances and temporal periodicity of pallid sturgeon migrations to Intake Dam, (2) identify the location(s) and timing of pallid sturgeon 
spawning events, (3) characterize and quantify habitat conditions (depth, velocity, substrate) at spawning sites, and (4) verify successful incubation and egg hatch based on collections of pallid sturgeon free embryos and larvae. Continuity of research activities in 2014 provided the opportunity to examine replicability of pre-spawn migrations, spawn-site selection, hatch success, and consistency of patterns and trends under a suite of environmental conditions different from previous years of investigation.

\section{Methods}

The research population in 2014 consisted of 44 individuals implanted with radio transmitters, including 43 wild pallid sturgeon (4 gravid females, 1 nongravid female, 38 males) and 1 pallid sturgeon $\times$ shovelnose sturgeon hybrid (code 178 ). The telemetered population included individuals implanted with radio-telemetry transmitters in previous years, individuals that were reimplanted with new transmitters because old transmitters expired or approached expiration, and new individuals that had not been previously implanted with a transmitter. The signal from each radio-telemetry transmitter is encoded with a digital identification code (code). New radio-telemetry transmitters used at reimplantation have a different code than the expired transmitters they replaced. Pallid sturgeon reimplanted multiple times will have multiple codes through time. Three female pallid sturgeon captured in May 2014 were determined as spawn candidates based on reproductive assessments, including weight, presence of black eggs, egg PI, estradiol (E2), and testosterone (T): code 30 (May 14, weight $=18.4 \mathrm{~kg}$, mean $\mathrm{PI}=0.13$, E2=3.92 nanograms per milliliter $[\mathrm{ng} / \mathrm{mL}], \mathrm{T}=32.65 \mathrm{ng} / \mathrm{ml}$ ), code 35 (May 7, weight $=28.0 \mathrm{~kg}$, mean $\mathrm{PI}=0.11, \mathrm{E} 2=3.85 \mathrm{ng} / \mathrm{ml}, \mathrm{T}=58.10 \mathrm{ng} /$ $\mathrm{ml}$ ), and code 36 (May 8 , weight $=17.2 \mathrm{~kg}$, mean $\mathrm{PI}=0.09$, $\mathrm{E} 2=10.34 \mathrm{ng} / \mathrm{ml}, \mathrm{T}=68.07 \mathrm{ng} / \mathrm{ml})$. These three females were also the focus of spawning studies during 2012. A nontransmittered female pallid sturgeon was netted on June 11 in the Lower Yellowstone River (RM 5.0) and was subsequently identified as a spawn candidate based on the presence of mature, black oocytes in biopsy samples (weight $=17.5 \mathrm{~kg}$, PI not available, E2=3.88 ng/ml, T=51.73 ng/ml). This female was implanted with code 39 . Collectively, the four telemetered females composed the known population of spawn-candidate females for 2014.

Tracking by boat on the Yellowstone River and Missouri River downstream from the confluence with the Yellowstone River began in April. Pallid sturgeon locations and associated environmental point attributes were recorded on a customized mobile mapping and electronic data-collection application. Automated ground-based logging stations were deployed at five locations in the main stem Yellowstone River between the Yellowstone-Missouri River confluence and Intake Dam (RM 0.75, 7.0, 39.0, 67.0, and 72.8). Two additional logging stations were placed near the downstream (RM 71.0) and upstream (RM 75.0) ends of the natural high-flow side channel (HFSC; fig. 12) that circumvents Intake Dam. Logging stations also were placed in the Missouri River (see the "FieldBased Biotic Assessments of Migration and SpawningUpper Missouri River and Milk River" section) to complement manual tracking and obtain additional information on migrations and movements among river reaches. As pallid sturgeon migrations persisted upstream from Intake Dam, logging stations were also deployed at four locations upstream from Intake Dam including RM 98.0 (near Glendive, Mont.), RM 124.3 (near Fallon, Mont.), RM 149.1 (Powder-Yellowstone River confluence) and RM 15.0 (in the Powder River).

Sampling for pallid sturgeon free embryos and larvae in the Yellowstone River began June 5 between RM 4.3 and 5.6. Most sampling happened at RM 4.3, but other locations within the reach were also sampled as discharge changed through time and spawning sites were identified. The sampling apparatus consisted of a 3.0-m long tapered rectangular net (1-mm mesh) affixed to a rectangular net-mouth frame (0.75-m width, 0.5-m height) supporting two 4.5-kg sounding weights. Two nets were simultaneously deployed to the river bed following methods outlined in Braaten and others (2010). Because of pallid sturgeon migration and spawning activity, the Powder River was sampled for free embryos and larvae beginning on June 19. The net apparatus was similar to that described previously in this paragraph, but only a single net was deployed in the Powder River. For the Yellowstone and Powder Rivers, sample contents were transferred to black pans where Acipenseriformes (Scaphirhynchus spp. and paddlefish [Polyodon spathula]) eggs, embryos, free embryos, and larvae were extracted from the detritus and preserved immediately in 95-percent nondenatured ethanol. In the laboratory, Acipenseriformes free embryos and larvae were tentatively identified as sturgeon, paddlefish, or undetermined (that is, damaged beyond definitive recognition because of smashed bodies or missing body parts); and measured (to the nearest $0.1 \mathrm{~mm}$ total length [TL]). Specimens were sent for genetic analysis (Eichelberger and others, 2014) to confirm species identity as paddlefish, shovelnose sturgeon, or pallid sturgeon.

\section{Progress}

\section{Hydrologic Conditions}

Hydrologic conditions in the Yellowstone River during April through August 2014 (figs. 5 and 13) exceeded the recorded 1911-2013 long-term trends. Mean daily discharge in April $\left(17,690 \mathrm{ft}^{3} / \mathrm{s}\right)$, May $\left(31,600 \mathrm{ft}^{3} / \mathrm{s}\right)$, June $\left(45,490 \mathrm{ft}^{3} / \mathrm{s}\right)$, and July $\left(22,540 \mathrm{ft}^{3} / \mathrm{s}\right)$ were $172,173,119$ and 117 percent, respectively, of the long-term trends. Discharge during 2014 gradually increased between April and early May to 30,900 $\mathrm{ft}^{3} / \mathrm{s}$ on May 11, declined through mid-May, increased substantially during late May and early June to an annual maximum of $68,100 \mathrm{ft}^{3} / \mathrm{s}$ on June 2, diminished through late June, and then subsequently increased to $41,100 \mathrm{ft}^{3} / \mathrm{s}$ on July 1 . After July 1, discharge gradually declined through early August. Water temperature fluctuated during mid-April to mid-May, 


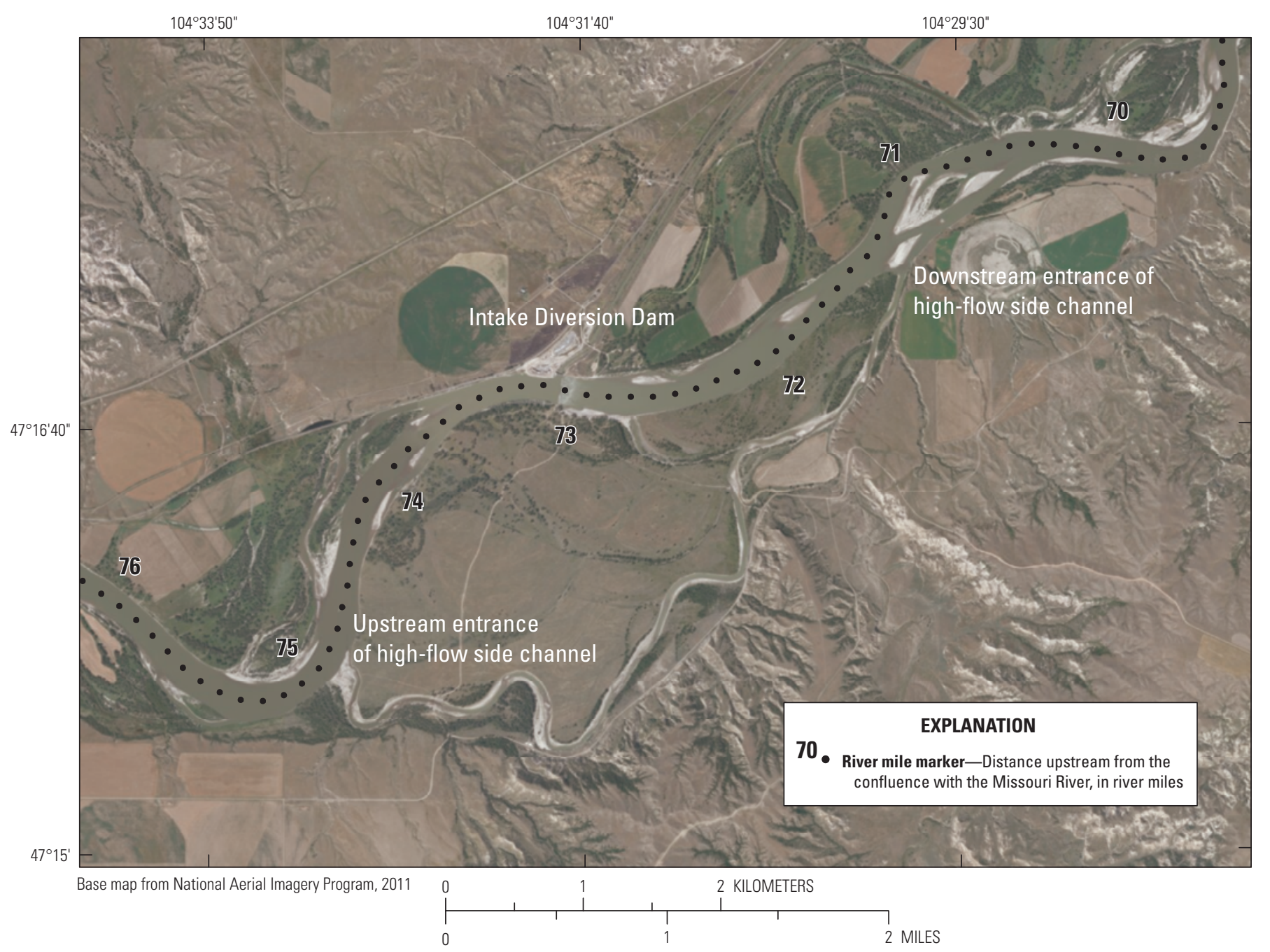

Figure 12. Map of the Yellowstone River near Intake Diversion Dam, including the high-flow side channel.

warmed quickly (approximately $0.7^{\circ} \mathrm{C}$ per day) between May $13\left(10.4{ }^{\circ} \mathrm{C}\right)$ and May $27\left(20.1^{\circ} \mathrm{C}\right)$, declined as discharge tended towards maximum conditions in late May and early June, and then increased to $21.6{ }^{\circ} \mathrm{C}$ on June 27 (fig. 13). After a brief period of declining temperatures during the last few days of June, water temperature increased and remained above $22.0{ }^{\circ} \mathrm{C}$.

Hydrologic conditions in the Powder River during 2014 (fig. 13) followed a trend similar to the Yellowstone River as discharge gradually increased from mid-April to $2,280 \mathrm{ft}^{3} / \mathrm{s}$ on May 11, declined through mid-May, increased through late May to an annual maximum of 3,530 $\mathrm{ft}^{3} / \mathrm{s}$ on June 1, and then declined through mid-June. Discharge in the Powder River during 2014 tended to exceed recorded long-term (1939-2013) trends. Mean discharge in April $\left(760 \mathrm{ft}^{3} / \mathrm{s}\right)$, May $\left(1,790 \mathrm{ft}^{3} / \mathrm{s}\right)$, June $\left(1,390 \mathrm{ft}^{3} / \mathrm{s}\right)$, and July $\left(650 \mathrm{ft}^{3} / \mathrm{s}\right)$ were $101,150,121$ and 118 percent, respectively, of long-term trends. A continuous series of water temperature spanning spring and summer was not available for the Powder River because it was unanticipated that pallid sturgeon would use this river system; however, point measurements of water temperature were recorded in the Powder River in association with radio-telemetry tracking and larval sampling. During June 5-25, point measurements of water temperature ranged from $15.1^{\circ} \mathrm{C}$ recorded on June 7 to $21.9^{\circ} \mathrm{C}$ on June 24 .

\section{Pallid Sturgeon Use of the Yellowstone River}

Pallid sturgeon began early entry into the Yellowstone River during 2014; nearly 50 percent of the telemetered pallid sturgeon population was present in the river by early April (fig. 14). Use of the Yellowstone River gradually increased through April and May with elevated discharge. Maximum use (93 percent of the telemetered population) of the Yellowstone River happened between late May and early June. Use declined from 93 percent on June 9 to 62 percent by June 30 . Downstream movement out of the Yellowstone River during 


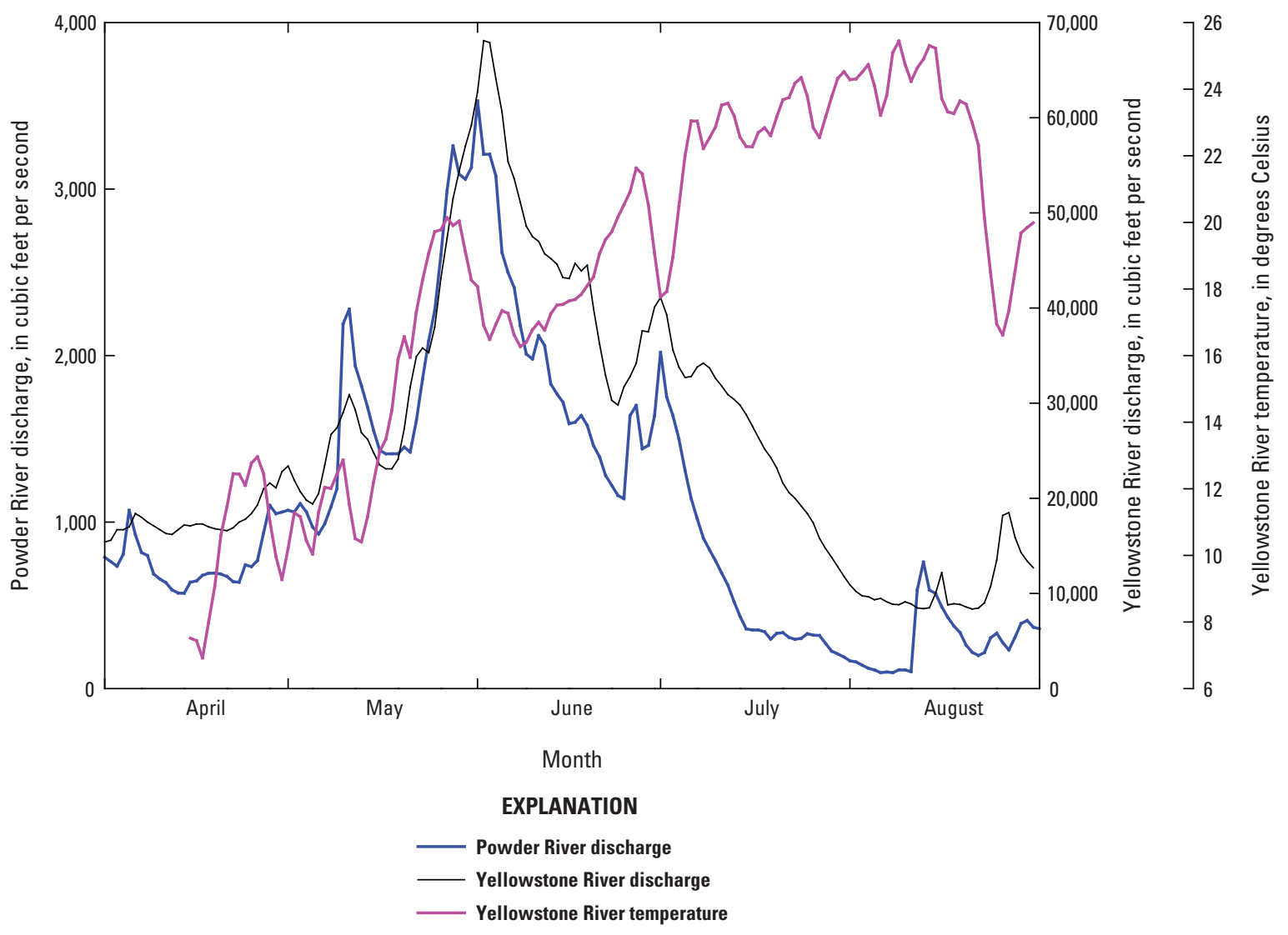

Figure 13. Discharge and water temperature in the Yellowstone River and discharge in the Powder River during April-August 2014.

mid-summer resulted in only about 21 percent of the telemetered population remaining in the Yellowstone River by early August.

\section{Migrations to and Around Intake Dam}

Part of the telemetered pallid sturgeon population in 2014 exhibited extensive upstream migrations that either persisted beyond Intake Dam through use of the HFSC or terminated at Intake Dam. Specifically, manual tracking complemented with logging station detections identified five pallid sturgeon (female code 36; and male codes 49,61, 68, and 76) that completely negotiated the HFSC between May 27 and June 4 (table 2). Female code 36 was the first pallid sturgeon to successfully negotiate the HFSC on May 27. Following passage of code 36, use of and passage through the HFSC happened on May 31 (code 68), June 1 (code 49), June 2 (code 61), and June 4 (code 76). A sixth pallid sturgeon (male code 193) also entered the HFSC and was detected at the downstream logging station in the HFSC on May 29, but this fish did not pass through the entire length of the HFSC as determined from manual tracking and logging station detections. Before negotiating through the HFSC, pallid sturgeon code 49 first exhibited two upstream migrations that were terminated at Intake Dam (May 11 and 28). Across all fish, known use and passage through the HFSC happened at discharges ranging from $47,300 \mathrm{ft}^{3} / \mathrm{s}$ to $68,100 \mathrm{ft}^{3} / \mathrm{s}$ (table 2).

Whereas several pallid sturgeon migrated around Intake Dam through the HFSC, upstream migrations to Intake Dam were noted for seven male pallid sturgeon (codes 48, 49, 72, $76,77,79$, and 179; table 2; fig. 15). Three of seven males exhibited early first arrivals at Intake Dam; code 77 was detected on May 8, code 49 on May 11, and code 179 on May 14. Four pallid sturgeon were first detected at Intake Dam later in the season; code 48 arrived May 29, code 72 on June 1, code 76 on June 27 , and code 79 on July 5 . The detection of code 76 at Intake Dam on June 27 happened after negotiating the HFSC on June 4, migrating back downstream, and subsequently exhibiting a second upstream migration during late June. Residency below Intake Dam before downstream departure varied from a few hours to several days (fig. 15). In addition to the seven male pallid sturgeon at Intake Dam, the hybrid sturgeon (code 178) also migrated to Intake Dam and was first detected below the dam on June 5 . 


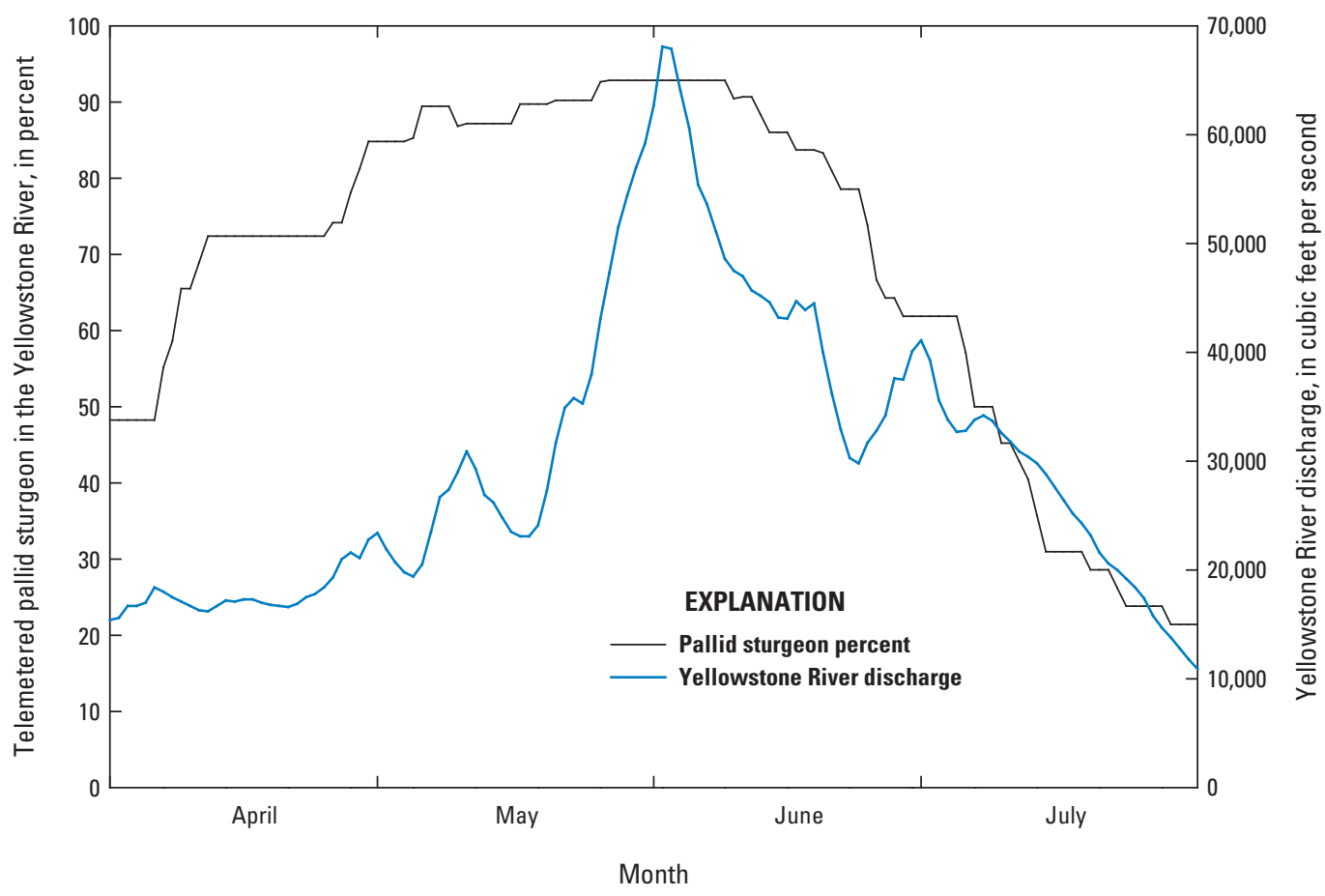

Figure 14. Percentage of telemetered pallid sturgeon in the Yellowstone River and corresponding discharge, April-July 2014.

Table 2. Dates and discharge (from U.S. Geological Survey streamgage 06329500 at Sidney, Montana) when pallid sturgeon passed through the high-flow side channel around Intake Diversion Dam or were detected below Intake Diversion Dam by code and sex, Yellowstone River, Montana, 2014.

[HFSC, high-flow side channel; $\mathrm{ft}^{3} / \mathrm{s}$, cubic foot per second; --, not applicable]

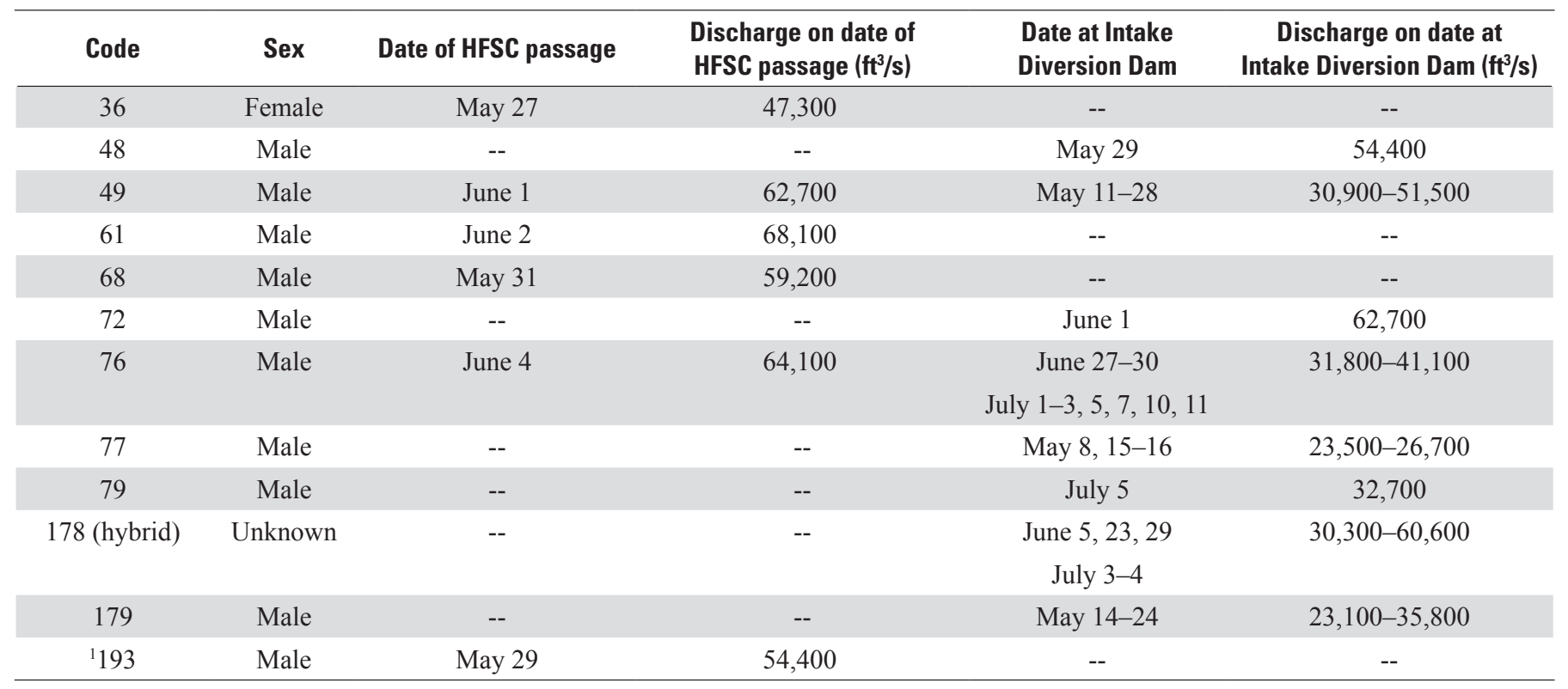

${ }^{1}$ Code 193 was detected only at the lower end of the HFSC and did not negotiate the entire length of the HFSC. 


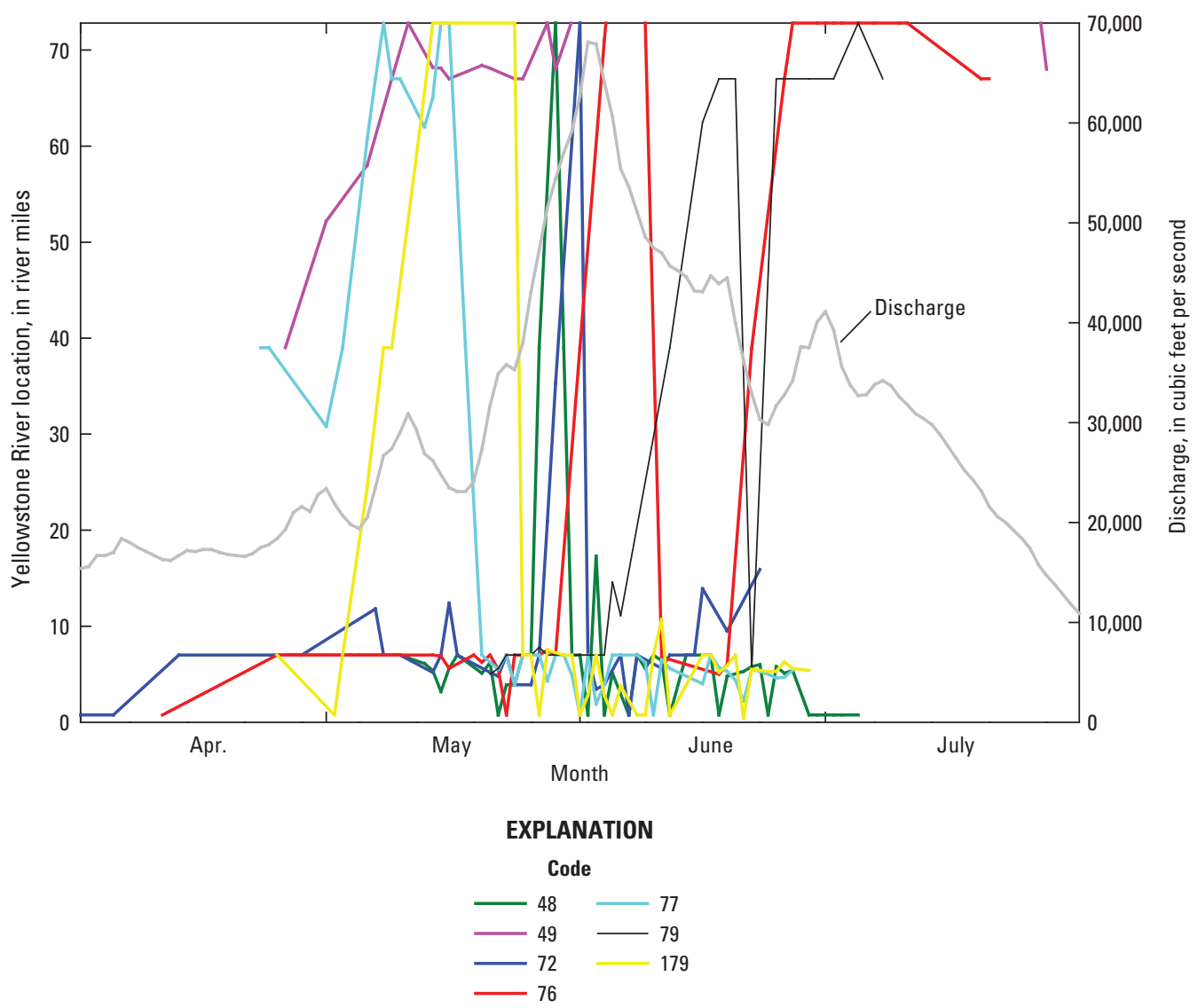

Figure 15. Movements and locations by date of seven telemetered pallid sturgeon migrating to Intake Diversion Dam (located at RM 72.8) on the Yellowstone River and corresponding discharge in April-July 2014.

\section{Male Aggregations and Pallid Sturgeon Spawning Chronology}

As observed in previous years, the location(s) of persistent male aggregations in the Lower Yellowstone River can be used to predict possible pallid sturgeon spawning locations. In 2014, aggregations of male pallid sturgeon were noted throughout much of the May-June timeframe in the Lower Yellowstone River (fig. 16). Groups of 4-6 males were first noted early in the season (May 13-14) between RM 5.4 and 6.1. Although aggregations were observed between RM 0.9 and 11.1, most (65 percent) observed male aggregations happened in the reach including RM 5.0-6.0. These observations presented the hypothesis that spawning may happen within this reach. The largest aggregation of male pallid sturgeon happened on May 22 when 19 pallid sturgeon (50 percent of the implanted male population located in 2014) were observed at RM 5.5-5.6. Male aggregations in mid- to late June were heavily concentrated in the reach including RM 4.6-5.8.

Female code 30 was determined to be a candidate for spawning in 2014 because assessments on May 14 identified reproductive readiness (weight $=18.4 \mathrm{~kg}$, mean $\mathrm{PI}=0.13$,
$\mathrm{E} 2=3.92 \mathrm{ng} / \mathrm{ml}, \mathrm{T}=32.65 \mathrm{ng} / \mathrm{ml})$. Code $30 \mathrm{had}$ migrated to upper reaches of the Lower Yellowstone River by mid-May (maximum extent RM 62.7 on May 14) but returned to the lower reaches of the river by late May (fig. 17). Code 30 exhibited a second pre-spawn upstream migration extending to RM 17.0 on May 28, and then moved downstream by early June. During June 5-11, upstream and downstream migrations of code 30 were localized between the lowermost logging station on the Yellowstone River (RM 0.75) and RM 11.2 (most upstream location point on June 10). The last location of code 30 on June 11 indicated that she was near the lowermost logging station at 9:00 p.m. and intermittently present at this location until about 4:00 a.m. on June 12. Code 30 began migrating upstream during the early morning of June 12; and was at RM 4.4 at 11:34 a.m., RM 7.0 at 3:00 p.m., and RM 10.4 by 7:30 p.m. Attempts were made on June 12 to capture and reproductively assess code 30 ; however, she was not captured. After her ascent to RM 10.4 on June 12, code 30 was not detected in downstream reaches during June 13-15, which suggests that she remained upstream. On June 16, code 30 was in close proximity to her June 12 terminal location (RM 10.3). Code 30 was captured on June 17 at RM 9.7, and reproductive 


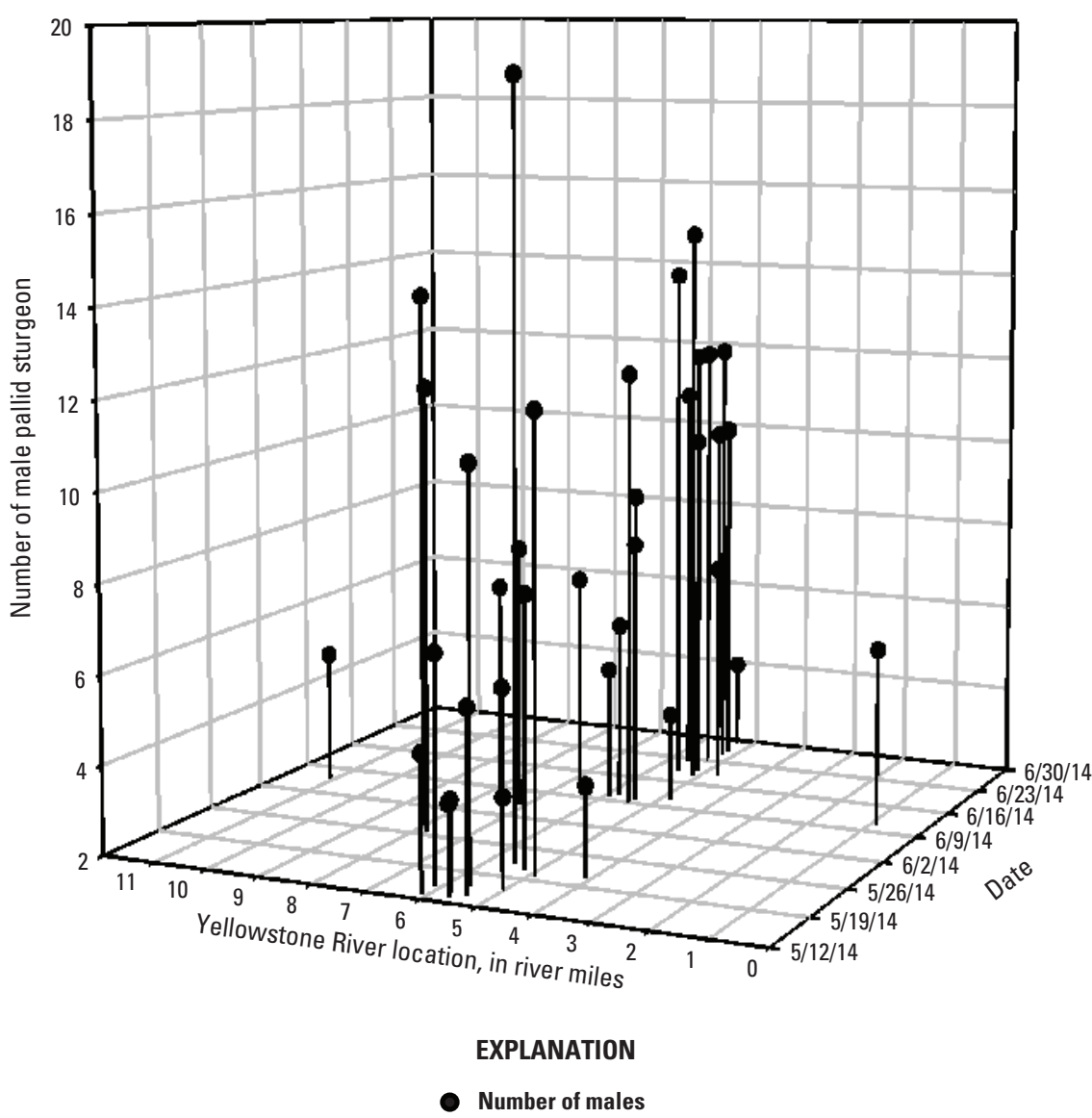

Figure 16. Aggregations of telemetered male pallid sturgeon by river location and date in the Yellowstone River, May-June 2014. assessments indicated that she was in post-spawn condition (weight $=14.0 \mathrm{~kg}, 23.9$-percent loss of pre-spawn body weight, $\mathrm{E} 2=$ nondetectable, $\mathrm{T}=0.47 \mathrm{ng} / \mathrm{mL}$ ). The exact spawn date and location were not determined for code 30 because intensive tracking did not identify that she aggregated with groups of male pallid sturgeon for an extended period of time - similar to typical spawning behavior noted in previous accounts (DeLonay and others, 2014, 2016a, 2016b) of spawning in the Lower Yellowstone River. Although speculative, movement patterns suggest that code 30 may have spawned in the evening of June 11 or perhaps early morning of June 12 in the lower reaches of the Yellowstone River. Specifically, the spatial extent of upstream and downstream movements (a behavioral characteristic typical of pallid sturgeon females just before spawning) diminished during June 6-11. This restricted movement pattern was followed by a short upstream migration on June 12 and localized residency around RM 9.7-11.4 during June 12-29. An extended period of localized residency and limited movements is typical of post-spawn females.

Female code 35 was a second spawning candidate for 2014 based on reproductive assessments on May 7 (weight $=28.0 \mathrm{~kg}$, mean PI=0.11, E2=3.85 ng $/ \mathrm{mL}$,
$\mathrm{T}=58.10 \mathrm{ng} / \mathrm{mL}$ ). Code 35 exhibited pre-spawn migration patterns that were restricted to the lower $30 \mathrm{mi}$ of the Yellowstone River (fig. 17). The maximum upstream extent of migration happened on May 28 as code 35 was relocated at RM 26.3. A second upstream migration happened during early June as code 35 reached RM 14.2 on June 6. On June 10-11, code 35 was detected only in the Lower Yellowstone River at the lowermost logging station (RM 0.75). On June 12, code 35 began migrating upstream as she was detected at 11:51 a.m. at the lowermost logging station and located by tracking boats at RM 1.0 (12:07 p.m.) and RM 2.7 (3:39 p.m.). Code 35 remained upstream from the lowermost logging station during June 13-15. On June 16, code 35 was located at RM 4.5 for several hours with male pallid sturgeon (including, codes 48 , $51,59,77$, and 81 ) being present at RM 4.0-4.9. For the next few days, code 35 remained at RM 4.3-4.4, and several males (including, codes 38, 51, 59, 73, 75, 76, 81, 83, and 193) also occupied the reach spanning RM 4.0-4.9. Code 35 was targeted for capture and reproductive assessment after verifying that code 30 was post-spawn on June 17 (as discussed in the previous paragraph). Capture of code 35 on June 19 indicated that this female was post-spawn (weight $=25.0 \mathrm{~kg}, 10.7$-percent 

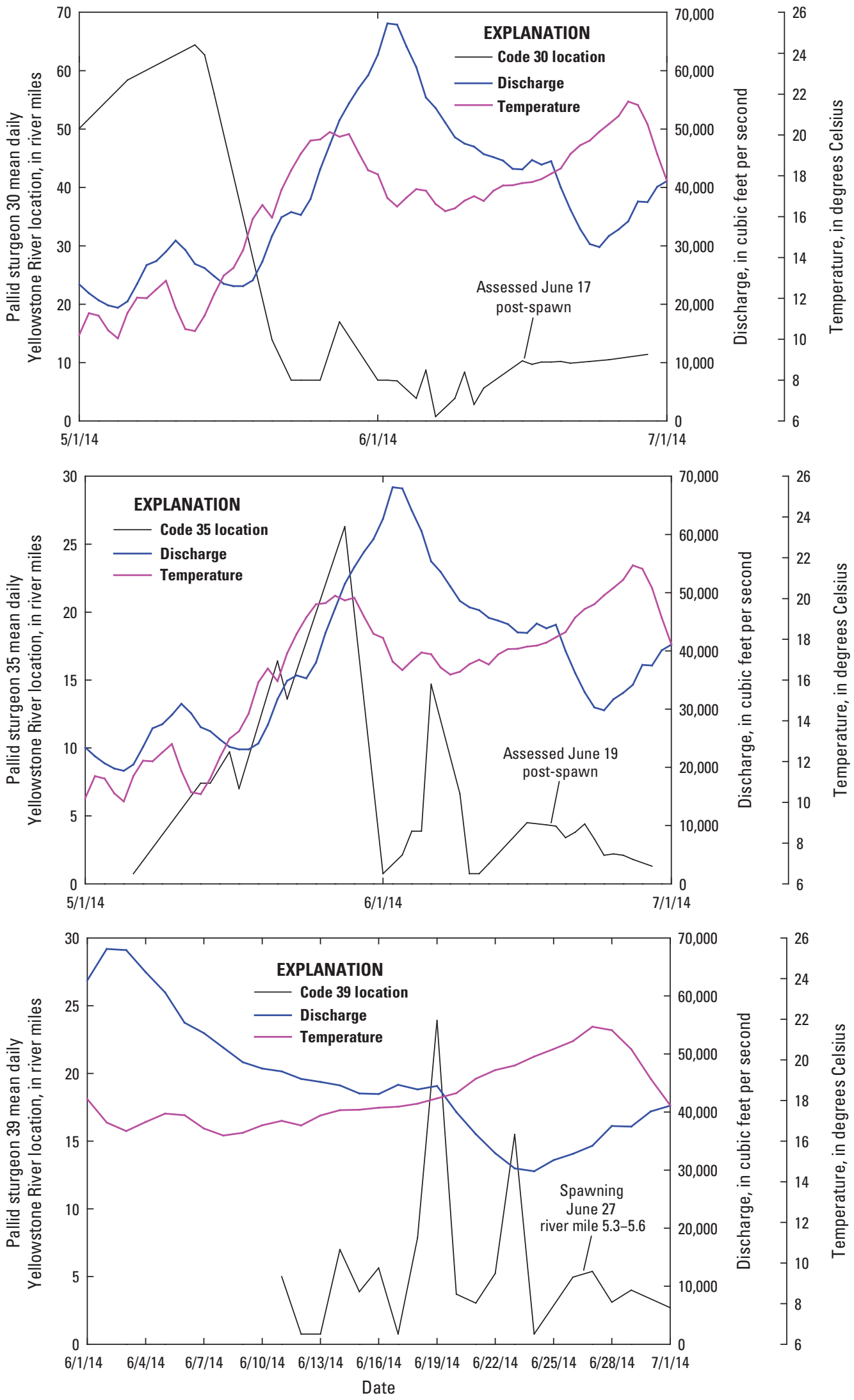

Figure 17. Migrations and mean daily locations of gravid female pallid sturgeon codes 30,35 , and 39 in the Yellowstone River during 2014; and corresponding discharge and temperature. 
Ecological Requirements for Pallid Sturgeon Reproduction and Recruitment in the Missouri River—Annual Report 2014

loss of pre-spawn body weight, gonadal biopsy indicated no eggs present, $\mathrm{E} 2=$ nondetectible, $\mathrm{T}=0.85 \mathrm{ng} / \mathrm{mL}$ ). The exact date and location of the code 35 spawning event were not identified, but it is possible that spawning happened sometime during June 13-16 between RM 4.0 and 4.9, likely in close proximity to RM 4.3-4.5, because she was not detected upstream or downstream from this location during these dates.

Female code 39 was a third spawn candidate for 2014 based on reproductive assessment after first capture on June 11 (weight $=17.5 \mathrm{~kg}$, black eggs, E2=3.88 ng/mL, T=51.73 ng/ $\mathrm{mL}$ ). Between June 11 and June 20, code 39 exhibited upstream and downstream migrations through the primary male aggregation site (RM 5.3); the farthest upstream migration extended to RM 24.7 on June 19 (fig. 17). After her upstream migration through the male aggregation site on June 22, code 39 was captured to verify that she remained in reproductive condition; she remained full of eggs and weighed $17.5 \mathrm{~kg}$. Code 39 persisted migrating upstream and downstream for the next few days. On the morning of June 26 (6:15 a.m.), code 39 was detected at the lowermost logging station on the Yellowstone River (RM 0.75) but moved slowly and progressively upstream towards the male aggregation site throughout the day. She was located at RM 5.8 on June 26 in close proximity to the male aggregation site. On the morning of June 27 and persisting through the day, code 39 and numerous male pallid sturgeon (codes 23, 46, 48, 59, 68, 73, 77, 90, 179 , and 193) were aggregated in suspected spawning activity at RM 5.3-5.6. Spawning activity involved the alternating behaviors of female code 39 swimming into and out of the male aggregation but always remaining in close proximity to the males. This behavior was consistent with previous documented accounts of pallid sturgeon spawning events in the Yellowstone River (DeLonay and others, 2016b). Spawning activity continued until at least 8:41 p.m. on June 27 when assessments of spawning activities were terminated. On the morning of June 28, code 39 was located downstream from the spawning location and subsequently captured for reproductive assessment at RM 3.1. Spawning was complete because she weighed $14.0 \mathrm{~kg}$ (about 20-percent loss of body weight because of deposition of eggs during spawning). Spawning may have begun during the evening of June 26 and was known to persist through the evening of June 27 based on telemetry locations and the aggregation. Hourly water temperature from 8:00 p.m. on June 26 to 8:00 p.m. on June 27 averaged $21.6{ }^{\circ} \mathrm{C}$ (minimum $=21.3{ }^{\circ} \mathrm{C}$, maximum $=22.2^{\circ} \mathrm{C}$ ). Discharge was $32,800 \mathrm{ft}^{3} / \mathrm{s}$ and $34,200 \mathrm{ft}^{3} / \mathrm{s}$ on June 26 and June 27, respectively. Periodic measurements of turbidity on June 27 ranged from 176 to 213 Nephelometric Turbidity Units. Several male pallid sturgeon (codes 48, 68, 77, 179, and 193) aggregated with female code 39 , and other males during the June 27 spawning event had either migrated to or bypassed Intake Dam through the HFSC earlier in the season (table 2).

Female code 36 was captured on May 8 and identified as a spawning candidate after reproductive assessment (weight $=17.2 \mathrm{~kg}$, mean $\mathrm{PI}=0.09, \mathrm{E} 2=10.34 \mathrm{ng} / \mathrm{mL}$,
$\mathrm{T}=68.07 \mathrm{ng} / \mathrm{mL}$ ). Between April 26 and May 20, code 36 exhibited short, upstream and downstream migrations primarily concentrated between the two lowermost logging stations on the Yellowstone River (RM 0.75-7.0; fig. 18). One upstream movement was made to RM 26.5 on May 6 followed by a downstream movement back to RM 7.0. Code 36 exhibited a second upstream movement to RM 16.4 on May 15 but was detected later that day at the logging station at RM 7.0. On May 21, code 36 began a substantial upstream migration and reached the logging station at RM 67.0 on May 27. Code 36 continued migrating upstream past logging stations in the HFSC and bypassed Intake Dam on May 27. Logging stations on the HFSC also documented passage around Intake Dam by male code 68 on May 31, code 49 on June 1, code 61 on June 2, and code 76 on June 4 (fig. 18; table 2). Female code 36 migrated an additional 74.5 RM upstream during the 8 days after bypassing Intake Dam; and reached RM 90.7 by May 29, RM 98.2 by May 30, and RM 149.1 (the Powder River confluence) on June 4. Code 36 entered the Powder River at 12:20 a.m. on June 4 and continued to move upstream but at a decreased rate. Meanwhile, male code 68 and 61 moved up the Yellowstone River at a similar rate as female code 36 but 1 to 3 days later than the female code 36. Male code 68 and code 61 entered the Powder River on June 5 and June 9, respectively; and, similar to female code 36, their rate of upstream migration decreased after entering the Powder River. In contrast to male codes 61 and 68, male code 49 remained near RM 75.0 (just upstream from Intake Dam) through July 27 and male code 76 reached his most upstream location at RM 91.8 on June 6 (fig. 18). The extent of upstream migration for code 68 was RM 8.4 on June 9 and for code 61 was RM 5.0 on June 17. Male code 68 moved downstream, near male code 61 , to RM 4.0 on June 16. Female code 36 moved upstream in the Powder River to RM 15.0 where she was recaptured on June 7 and determined to remain in pre-spawn condition (weight $=17.2 \mathrm{~kg}$ ). Code 36 continued upstream after being released and reached RM 20.5, the apex of her upstream migration, on June 10. The female remained near RM 20.0 through June 13. Early in the morning (3:50 a.m.) of June 15, code 36 was detected moving downstream past a temporary logging station at RM 15.0 and stopping at RM 11.0. She remained between RM 10.0-11.0 on June 17 through at least 1:10 p.m. Code 36 exited the Powder River at 3:17 a.m. on June 18 along with male codes 61 and 68 that had previously remained downstream from the female (in the Powder River). Attempts to capture code 36 immediately upon her exiting the Powder River were unsuccessful because of netting difficulties in high-water velocities. Code 36 was recaptured in the Yellowstone River on June 20 at RM 141.3 and was determined to have spawned because she weighed $15.4 \mathrm{~kg}$, which was approximately a 10.5 -percent loss of body weight because of spawning and egg deposition (E2=nondetectable, $\mathrm{T}=0.38 \mathrm{ng} / \mathrm{mL}$ ). The specific date and location of the code 36 spawning event were not determined; however, evidence from pre-spawn and post-spawn 


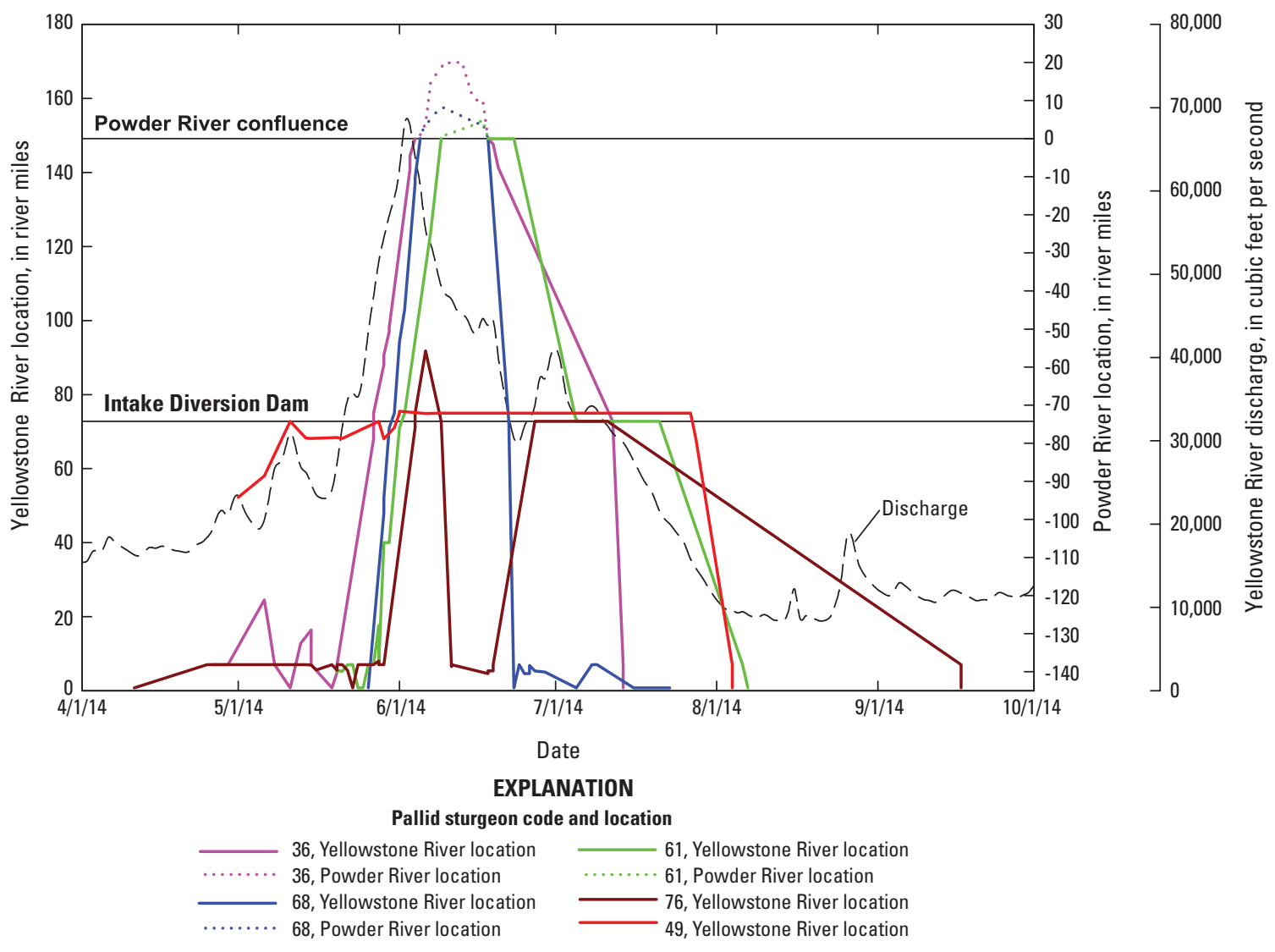

Figure 18. Migrations and locations of pallid sturgeon female code 36; and male codes 49, 61, 68, and 76 in the Yellowstone and Powder Rivers during April-0ctober 2014; and corresponding discharge.

reproductive assessments unequivocally define the spawning window as June 7-20. Residency in the Powder River for all but 3 days during this time (June 18-20 when she was moving downstream) strongly suggests that she spawned in the Powder River, likely during June 10-17.

Pallid sturgeon in the Yellowstone and Powder Rivers exhibited variable downstream movement patterns after spawning activities were completed; for example, female code 36 remained upstream from Intake Dam for several days, moved downstream over Intake Dam on July 12, and was detected at the Lower Yellowstone River logging station (RM 0.75 ) on July 14 . Male code 68 moved rapidly downstream after exiting the Powder River on June 17, passed over Intake Dam on June 22, and was in the lower $7 \mathrm{mi}$ of the Yellowstone River by June 23. On June 27, male code 68 was part of the male aggregation that spawned with female code 39 at RM 5.3-5.6. After exiting the Powder River on June 17, male code 61 remained near the Powder River confluence (RM 149.1) through June 23 and then moved downstream over Intake Dam on July 5. After passing over Intake Dam, code 61 remained in the area directly below the dam through July 21 and was later detected in the lower $7 \mathrm{mi}$ of the Yellowstone River on August 6-7.
Verification of Hatch and Drift Entry of Acipenseriformes Free Embryos and Larvae

During 2011-13, MFWP and USGS crews exhibited joint sampling efforts for Acipenseriformes free embryos and larvae primarily in the lower reaches of the Yellowstone River because spawning activity was concentrated in this area. In 2014, sampling crews were split for much of the sampling season because MFWP crews focused sampling effort in the Powder River, and USGS crews focused sampling effort in the lower reaches of the Yellowstone River. The Yellowstone River was sampled for Acipenseriformes free embryos and larvae on 16 days between early June and early July, which yielded a total of 194 samples (table 3). Collectively, 243 Acipenseriformes eggs and embryos and 466 drifting free embryos and larvae were sampled from the Yellowstone River. The Powder River was sampled for progeny of female code 36 on 7 days between June 19 and June 25. The Powder River sampling regime yielded 47 samples and 139 Acipenseriformes free embryos and larvae. Specimens were tentatively identified in the laboratory as paddlefish, sturgeon, or unknown (because of specimens being mashed, broken, torn or missing body parts). 
Table 3. Samples and numbers of Acipenseriformes eggs, embryos, free embryos, and larvae sampled in the Yellowstone and Powder Rivers by date in June-July 2014.

[--, not applicable]

\begin{tabular}{llccc}
\hline \multicolumn{1}{c}{ Date } & Location & Samples & $\begin{array}{c}\text { Acipenseriformes eggs } \\
\text { and embryos }\end{array}$ & $\begin{array}{c}\text { Acipenseriformes free } \\
\text { embryos and larvae }\end{array}$ \\
\hline June 5 & Yellowstone River & 4 & 6 & 2 \\
June 9 & Yellowstone River & 4 & 3 & 2 \\
June 10 & Yellowstone River & 12 & 12 & 6 \\
June 12 & Yellowstone River & 6 & 9 & 13 \\
June 16 & Yellowstone River & 6 & 11 & 42 \\
June 18 & Yellowstone River & 12 & 20 & 49 \\
June 19 & Yellowstone River & 6 & 5 & 24 \\
June 20 & Yellowstone River & 6 & 9 & 9 \\
June 21 & Yellowstone River & 18 & 22 & 36 \\
June 22 & Yellowstone River & 6 & 11 & 10 \\
June 23 & Yellowstone River & 10 & 25 & 56 \\
June 24 & Yellowstone River & 14 & 15 & 77 \\
June 26 & Yellowstone River & 32 & 49 & 106 \\
June 29 & Yellowstone River & 14 & 15 & 9 \\
June 30 & Yellowstone River & 16 & 15 & 12 \\
July 1 & Yellowstone River & 28 & 16 & 7 \\
June 19 & Powder River & 5 & -- & 12 \\
June 20 & Powder River & 9 & -- & 40 \\
June 21 & Powder River & 3 & -- & 43 \\
June 22 & Powder River & 3 & -- & 19 \\
June 23 & Powder River & 15 & -- & 4 \\
June 24 & Powder River & 9 & -- & \\
June 25 & Powder River & 3 & -- & \\
\hline
\end{tabular}

Genetic testing on free embryos and larvae was completed following methods in Eichelberger and others (2014) to differentiate specimens as paddlefish, shovelnose sturgeon, or pallid sturgeon. Genetic results (Dr. Edward Heist, Southern Illinois University, written commun., 2015) indicated that no pallid sturgeon free embryos or larvae were genetically identified in the Lower Yellowstone River samples. The samples were 63 percent paddlefish and 37 percent shovelnose sturgeon. All specimens from the Powder River were genetically identified as shovelnose sturgeon.

\section{Discussion}

Focused investigations of the reproductive ecology of pallid sturgeon in the Yellowstone River during 2014 provided the means to examine replicability of patterns and trends observed in earlier years (2005-2013) in different environmental conditions and additional information related to habitat restoration efforts in the Yellowstone River. Through this work, several trends similar to earlier investigations were noted; however, work in 2014 also provided substantial new information on pre-spawn migratory characteristics and spawning of pallid sturgeon in the Yellowstone River system.

Use of the Yellowstone River by pallid sturgeon was similar to previous years of investigation. Specifically, after over-wintering primarily in the Missouri River, pallid sturgeon began early and persistent migrations into the Yellowstone River. Nearly 50 percent of the telemetered population occupied the Yellowstone River by early April, and about 90 percent of the population was present in the river by late May and early June. Early first entry and high use of the Yellowstone River have also been documented in previous studies (Fuller and others, 2008; Fuller and Braaten, 2012; Braaten and others, 2014; DeLonay and others, 2014, 2016b), although the proportion of the telemetered population using the Yellowstone River has varied among years. 
After entering the Yellowstone River, part of the telemetered pallid sturgeon population exhibited upstream migrations terminating at Intake Dam. In 2014, about 16 percent of the telemetered pallid sturgeon were documented directly downstream from Intake Dam; first arrival at the dam was between early May and early July. In previous years, 26 percent (2011), 12 percent (2012), and 15 percent (2013) of the telemetered population migrated to Intake Dam with first arrivals at the dam happening primarily during early May through late June (Braaten and others, 2014; DeLonay and others, 2014, 2016a). These results suggest that pallid sturgeon migrate to Intake Dam each year, but the proportion of pallid sturgeon migrating to the dam varies among years; moreover, it is clear that several pallid sturgeon within the telemetered population may exhibit an affinity to migrate to the upper reaches of the Yellowstone River. Six pallid sturgeon, for example, documented at or above Intake Dam in 2014 (codes 61, 68, 72, 76, 79 , and 179; note that some individuals carried a telemetry transmitter with a different code in earlier years) have been detected at Intake Dam in previous years.

Whereas the pre-spawn migrations of several pallid sturgeon terminated at Intake Dam, migrations of five pallid sturgeon (female code 36; and males codes 49, 61, 68, and 76) progressed upstream from Intake Dam through the HFSC. Before 2014, fixed logging stations had not been deployed in the HFSC to potentially detect passage around Intake Dam; therefore, it cannot be unequivocally determined if adult pallid sturgeon have used the HFSC in past years. Definitive information on factors contributing to use of the HFSC and the environmental conditions that facilitate successful passage cannot be determined based on 1 year of pallid sturgeon passage data through the HFSC; rather, inferences are restricted to conditions that happened in 2014. The HFSC starts to exhibit discernable flowing conditions when total discharge in the Yellowstone River exceeds about 30,000 ft $3 / \mathrm{s}$ (U.S. Bureau of Reclamation and U.S. Army Corps of Engineers, 2014), but detailed information on hydraulic conditions through a range of discharges within the HFSC is lacking. Use of and passage through the HFSC by migrating pallid sturgeon was documented at Yellowstone River discharges of $47,300-68,100 \mathrm{ft}^{3} / \mathrm{s}$, thus, establishing that discharges of at least $47,300 \mathrm{ft}^{3} / \mathrm{s}$ provide conditions suitable for upstream passage in the HFSC; however, as observed in 2014, a baseline discharge of $47,300 \mathrm{ft}^{3} / \mathrm{s}$ in the main stem river cannot be used as a sufficient condition to determine that pallid sturgeon will use and negotiate the HFSC. Male code 49, for example, was detected at Intake Dam on May 28 when the main stem river had a discharge of $51,500 \mathrm{ft}^{3} / \mathrm{s}$, but this fish did not ascend the HFSC until June 1 when the discharge was $62,700 \mathrm{ft}^{3} / \mathrm{s}$. Code 72 did not use or negotiate the HFSC at a discharge of $62,700 \mathrm{ft}^{3} / \mathrm{s}$ because this fish was detected at Intake Dam on June 1. Similarly, code 178 (hybrid) was at the confluence of the main stem river and HFSC on June 4 when discharge $\left(64,100 \mathrm{ft}^{3} / \mathrm{s}\right)$ was sufficient for entry and passage by other adult pallid sturgeon through the HFSC; however, code 178 did not use or ascend the HFSC because this fish was later detected at Intake Dam.

Inconsistencies in pallid sturgeon use of the HFSC in 2014 may be because of a combination of factors, including suitability of discharge and associated hydraulic conditions, motivation to ascend the HFSC, and the migration pathways exhibited by pallid sturgeon as they approach the river reach containing the HFSC; for example, the downstream entrance of the HFSC is located along the south bank of the main stem Yellowstone River (fig. 12). Pallid sturgeon migrating upstream could negotiate this complex reach in multiple ways, including moving along the north bank of the river, skirting margins of the midchannel island, or moving along the south bank of the river. The likelihood of detecting and entering the HFSC would be greater for fish migrating along the south bank of the river rather than migrations in other regions of the river. Although migration pathways for all pallid sturgeon in the reach containing the HFSC entrance were not observed, observations of one pallid sturgeon supports this hypothesis. On June 4, male code 76 was first located (1:01 p.m.) migrating upstream along the south bank of the river just downstream from the south-bank entrance of the HFSC. Code 76 was later documented in the HFSC (2:36 p.m.) and eventually fully negotiated the HFSC; however, migration pathways that place pallid sturgeon in close proximity to the HFSC entrance (for example, code 178) or within the lower portion of the HSFC (for example, code 193) will not always result in passage through the HFSC (table 2). Despite variability in use and nonuse of the HFSC, results from 2014 indicate that wild adult pallid sturgeon will use and fully negotiate the long (greater than $4.0 \mathrm{mi}$ ) HFSC. Braaten and others (2014) documented passage in the Yellowstone River only through shorter natural side channels (for example, less than $2.4 \mathrm{mi}$ ).

Replicated work on pre-spawn migratory behavior of female pallid sturgeon codes 30, 35, and 36 during 2012 and 2014 identified consistencies and inconsistencies among years; for example, code 30 exhibited a pre-spawn upstream migration in the Yellowstone River extending to RM 63.8 in 2012 and RM 62.7 in 2014. Pre-spawn migrations of code 35 extended to RM 37.0 in 2012 and RM 26.3 in 2014. In contrast, the pre-spawn migration for code 36 differed substantially between years because this female persisted only to RM 37.2 in 2012 but beyond RM 149.0 (Powder River confluence) and into the Powder River in 2014. Similar to use of the HFSC, these results further illustrate consistency and variation in pallid sturgeon reproductive ecology.

Spawning by the four telemetered female pallid sturgeon (codes 30, 35, 36, and 39) was verified in 2014, but the spatiotemporal dynamics of spawning events varied among the females. Although the exact spawn locations and dates were not unequivocally defined for female codes 30 and 35 , these two females spawned in the lower river reaches of the Yellowstone River likely during mid-June. For comparison, the known spawning event for female code 39 was at RM 5.3-5.6 on June 27. Fuller and others (2008) reported that one female pallid sturgeon likely spawned during June 13-16 
near RM 7.5 based on an aggregation of multiple males and the spawn candidate female. In 2012, female code 30 spawned on June 19-20 at RM 6.7-7.1 (DeLonay and others, 2016b). In 2013, one female spawned on June 20-21 at RM 6.7-7.7, and another female spawned on June 25 at RM 5.7-5.9 (DeLonay and others, 2016a). Replicated accounts of known pallid sturgeon spawning events in the Lower Yellowstone River during multiple years in different hydrologic conditions clearly establish the reach spanning RM 5.3-7.7 as a critical spawning reach for pallid sturgeon. Work in future years will continue to evaluate use of this reach as a spawning area for pallid sturgeon.

In contrast to spawning events in the Lower Yellowstone River, evidence strongly suggests that female code 36 spawned in the Powder River likely during June 10-17. This observation lends substantial new information related to the reproductive ecology of pallid sturgeon in the Upper Missouri River Basin. First, spawning by pallid sturgeon in a small tributary had not been documented because previous accounts of pallid sturgeon spawning have been restricted to observations in main stem habitats of larger rivers. Second, the pre-spawn behavior and spawning characteristics exhibited by code 36 differed greatly from that of other females in the Yellowstone River. Specifically, female pallid sturgeon that spawn in the Lower Yellowstone River typically exhibit a pre-spawn roaming behavior that includes multiple upstream and downstream migrations in the Yellowstone and Missouri Rivers before spawning. The upstream and downstream prespawn roaming behavior terminates at a spawn location in the Lower Yellowstone River. In contrast to this pattern, code 36 exhibited a substantial unidirectional upstream pre-spawn migration during late May and early June that terminated at or close to the spawning location in the Powder River. In this case, spawning happened at or close to the upstream migration apex. The behavior of spawning at or close to the upstream migration apex exhibited by female code 36 is unique to date (2015) among Yellowstone River pallid sturgeon but comparable to patterns observed in the channelized Lower Missouri River (DeLonay and others, 2010) where pallid sturgeon exhibit continuous upstream pre-spawn migrations. In the case of code 36, use of the HFSC facilitated a continuous upstream migration unimpeded by Intake Dam. Third, whereas there is a tendency for male pallid sturgeon in the Lower Yellowstone River to begin early and persistent aggregations at the spawning locations before female arrival, female code 36 began migration into and residency at the Powder River spawning site before male arrival; however, it is unknown if nontelemetered male pallid sturgeon were present in the Powder River before arrival of code 36 .

In addition to providing new insights into the reproductive ecology of pallid sturgeon in the Yellowstone River system, migration and spawning of male and female pallid sturgeon upstream from Intake Dam provide valuable information to assess the likelihood for success of proposed passage alternatives for the reach affected by Intake Dam. The success of the Intake Dam passage project is based on a sequential series of hypotheses: (1) the designed HFSC passage structure will successfully facilitate upstream passage for reproductive adults, (2) suitable spawning areas exist upstream from Intake Dam, (3) pallid sturgeon will spawn in reaches upstream from the dam, and ultimately (4) progeny from spawning events upstream from Intake Dam will survive in sufficient numbers to provide recruits necessary for a self-sustaining wild population (PBS\&J, 2009; U.S. Bureau of Reclamation and U.S. Army Corps of Engineers, 2010). Results from 2014 validated that at least one spawning area exists upstream from Intake Dam and that pallid sturgeon can spawn upstream from Intake Dam. Building on these validations, additional work is necessary to determine the extent that areas upstream from Intake Dam are used for spawning in subsequent years and the environmental conditions that promote spawning in upstream reaches of the Yellowstone River; for example, these questions should be addressed: If reproductive pallid sturgeon negotiate the HFSC or a designed passage structure in future years, will part of the reproductive population of pallid sturgeon annually or periodically spawn in the Powder River under a range of hydrologic regimes or are elevated discharge conditions as observed in 2014 necessary to promote spawning in the Powder River? In addition to the Powder River, will spawning happen in the main stem Yellowstone River upstream from Intake Dam?

Collections of free embryos and larvae from below known and suspected spawning sites in the Yellowstone River and Powder River yielded hundreds of Acipenseriformes specimens; however, genetic analysis of the specimens did not identify any pallid sturgeon free embryos or larvae. Genetic testing of free embryos sampled below known and suspected spawning sites in the Lower Yellowstone River during 2012 and 2013 identified pallid sturgeon free embryos (Eichelberger and others, 2014), which verified functionality of the complete reproductive process, including fertilization, embryonic survival, hatch, and drift entry of pallid sturgeon free embryos. Although no pallid sturgeon were determined genetically in the free-embryo sampling downstream from the Powder River, future sampling may verify reproductive functionality of that river system. Given the upstream distance from the Powder River spawning location, there is the potential that some pallid sturgeon free embryos drifting more than $200 \mathrm{mi}$ during ontogenetic development may develop into larvae, settle, and survive in the riverine part of the Missouri River below the Yellowstone River confluence.

\section{Field-Based Biotic Assessments of Factors Affecting Migration and Spawning-Upper Missouri River and Milk River}

The Lower Yellowstone River and Missouri River between Fort Peck Dam and Lake Sakakawea is inhabited by a wild adult population of pallid sturgeon. Over the last two decades (1993-2014), pallid sturgeon in this section of the Upper Missouri River Basin have been the focus of several 
studies examining movements, migrations, and habitat use (for example, Bramblett and White, 2001; Fuller and others, 2008; Fuller and Braaten, 2012).

The USGS and MFWP collaborated on studies during 2011-14, which focused on examining migrations, habitat use, and spawning of pallid sturgeon in the Yellowstone River. A similar approach is used for the Upper Missouri River and Milk River area. Information is collected to determine what discharges are associated with migrations and spawning of pallid sturgeon in the Missouri River downstream from Fort Peck Dam. This study will evaluate use, migrations, and spawning of pallid sturgeon in the Milk and Missouri Rivers downstream from Fort Peck Dam.

The objectives of this work were to (1) assess pallid sturgeon migrations and use of the Milk and Missouri Rivers between Fort Peck Dam and the Yellowstone River confluence, (2) quantify reproductive products (eggs, free embryos, larvae) and potential spawning reaches in the Milk and Missouri Rivers below Fort Peck Dam, and (3) assess and quantify settlement of pallid sturgeon larvae from the drift based on collections of young-of-year pallid sturgeon in lower reaches of the Missouri River.

\section{Methods}

The Upper Missouri River study section extends from Fort Peck Dam at RM 1,770.0 downstream to RM 1,553.5 (near Williston, North Dakota; fig. 19). The study area also included the lower $185 \mathrm{~km}$ of the Milk River from Vandalia Dam to the confluence with the Missouri River.

Pallid sturgeon were sampled using drifted trammel nets and implanted with radio-telemetry transmitters (MCFT-3L tags, $16 \times 73 \mathrm{~mm}$, air weight=26 g, 2,929-day longevity, 5-s pulse interval, 149.760 megahertz, Lotek Wireless Incorporated, New Market, Ontario, Canada). The signal emitted by each radio-telemetry transmitter is digitally coded to facilitate identification of individual fish. New radio-telemetry transmitters used at reimplantation have different codes than the expired transmitters they replaced. Pallid sturgeon reimplanted multiple times will have multiple codes through time. Surgical procedures followed methods outlined in Braaten and Fuller (2005). Most pallid sturgeon were collected in previous years during broodstock collection near the confluence of the Missouri and Yellowstone Rivers.

Manual tracking of pallid sturgeon by boat during 2014 began in April. The Missouri River between Fort Peck Dam and Wolf Point, Mont. (70 mi), was tracked from April through October. The Milk River was only manually tracked when the ground-based telemetry station, located near the mouth, detected a pallid sturgeon. One radio frequency (149.760 megahertz) was monitored during the boat-tracking run using a 4-element Yagi antennae. Several variables including radio frequency, code, latitude, longitude, and time of day were recorded when a pallid sturgeon was located.

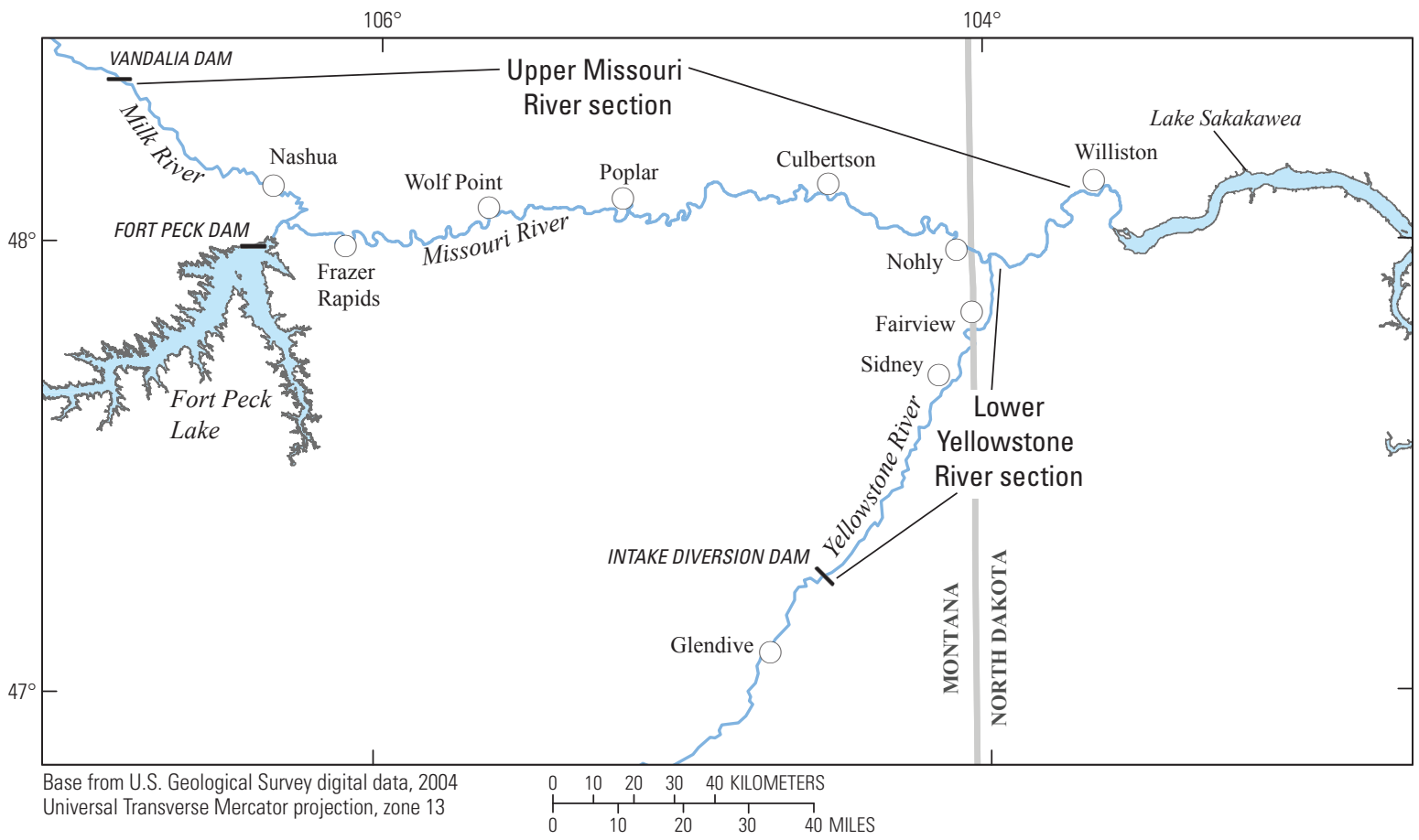

Figure 19. Study sections of the Upper Missouri River, Milk River, and Lower Yellowstone River. 
Stationary telemetry logging stations were deployed in April 2014 at four sites on the Missouri River (Nickels, RM 1,760; near Wolf Point, Mont., RM 1,720; near Culbertson, Mont., RM 1,618; at RM 1,584 just upstream from the Yellowstone River confluence) and one site on the Milk River (RM 2.5). Additionally, there were several telemetry logging stations on the Yellowstone River, which are discussed in the "Field-Based Biotic Assessments of Migration and Spawning-Yellowstone River" section of this report. The telemetry logging stations were placed on shore with two 4-element Yagi antennae, one facing upstream and one downstream. Each telemetry logging station was equipped with a battery-powered receiver (Lotek SRX-400), solar panel, an environmental enclosure kit containing dual 12-volt batteries, and an antenna switchbox. Data recorded by the telemetry logging stations were downloaded to a laptop computer twice per month between April and October. Coupled with manual tracking efforts, the array of telemetry logging stations facilitated detection of dates and times of movement events between and within rivers and river reaches.

The Lower Milk and Missouri Rivers near Wolf Point, Mont., was sampled for Acipenseriformes free embryos and larvae following methods outlined in Braaten and others (2010). Samples were collected twice per week at multiple locations. After sampling was completed, net contents were transferred to black rubber trays where Acipenseriformes (sturgeon and paddlefish) free embryos were extracted from the detritus. Extracted Acipenseriformes free embryos were then immediately placed in 95-percent nondenatured ethanol in preparation for genetic analysis. Specimens were sent for genetic analysis following methods outlined in Eichelberger and others (2014).
Targeted sampling for larval and young-of-year pallid sturgeon followed trawling methods outlined in Braaten and others (2007). Samples were collected every week from late July through early September. Sampling for young-of-year sturgeon (Scaphirhynchus spp.) were collected using a benthic (beam) trawl in the Missouri River above the confluence and below the confluence with the Yellowstone River. Four replicate sampling locations were established at each site where each replicate consisted of an inside bend, outside bend, and channel crossover habitat complex associated with a river bend. Fin clips were obtained for all sturgeon species collected and stored in 95-percent ethanol. The larvae and young-ofyear samples were sent for genetic analysis to distinguish individuals as pallid sturgeon or shovelnose sturgeon. If an identified specimen was a pallid sturgeon, further analysis was completed to determine parentage.

\section{Progress}

\section{Hydrologic Conditions}

Discharge from the Yellowstone River averaged $15,000 \mathrm{ft}^{3} / \mathrm{s}$ greater in the April-May pre-spawn migration season compared to the Upper Missouri River in 2014 (figs. 5 and 20). There was minimal contribution from the Milk River during this time; however, the Milk River augmented regulated releases from Fort Peck Dam during late August and early September resulting from rainfall in the Milk River Basin. This was reflected in elevated discharge conditions at Wolf Point and Culbertson, Mont. (fig. 20). Water temperature warmed with increasing distance from Fort Peck Dam because

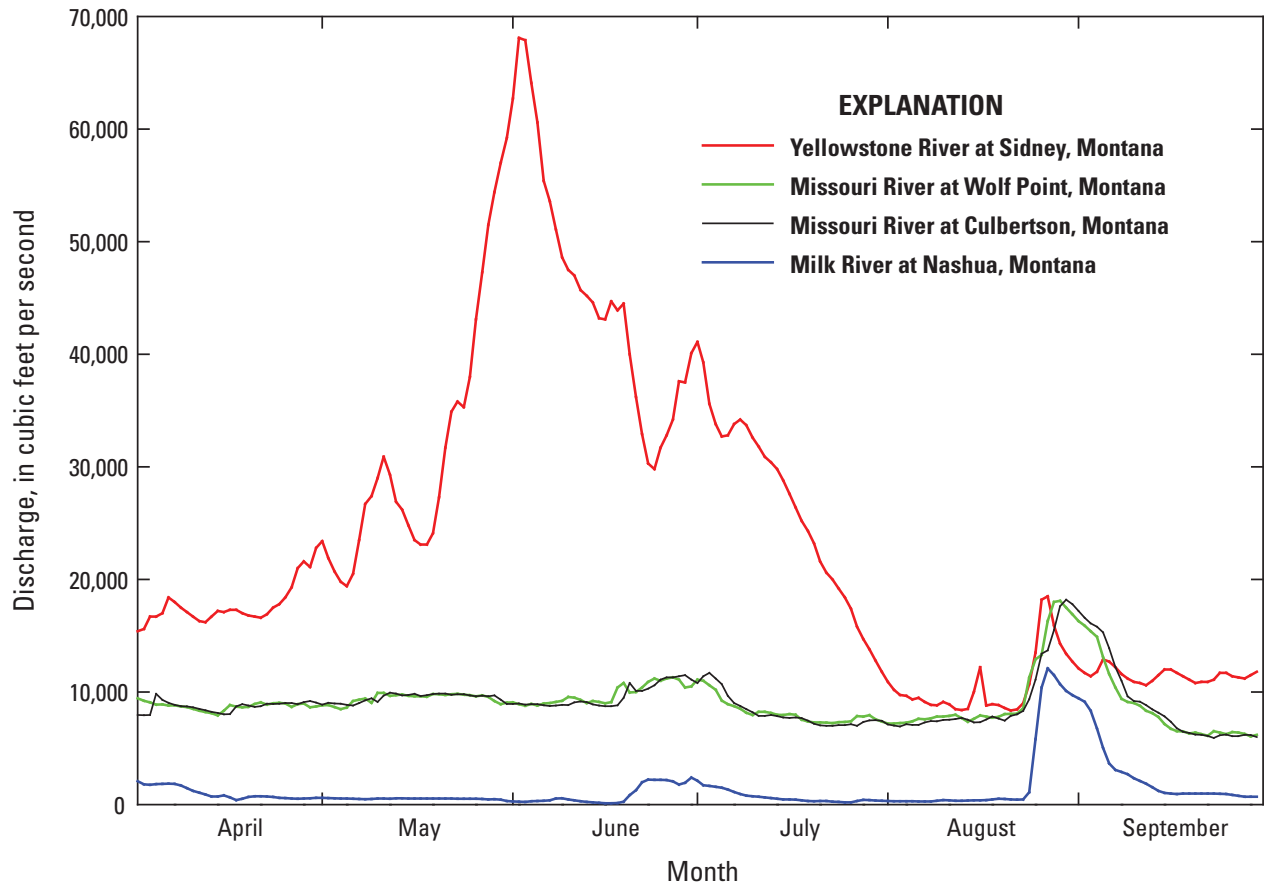

Figure 20. Hydrograph of the Missouri River at Culbertson, Montana (streamgage 06185500); Missouri River at Wolf Point, Montana (streamgage 06177000); in the Milk River at Nashua, Montana (streamgage 06174500); and in the Lower Yellowstone River at Sidney, Montana (streamgage 06329500), during April-September 2014. 
of tributary inputs and increased exposure to ambient temperature (fig. 21). Water temperature averaged $4.3{ }^{\circ} \mathrm{C}$ warmer at Wolf Point, Mont., and $7.8^{\circ} \mathrm{C}$ warmer at Culbertson, Mont., than temperatures recorded at a site $5 \mathrm{mi}$ downstream from Fort Peck Dam (below Fort Peck Dam) from April 15 to August 31. While a downstream warming trend with distance from the dam was evident in the Upper Missouri River, water temperatures recorded at Culbertson, Mont., remained about $1.5^{\circ} \mathrm{C}$ cooler than the Yellowstone River. Temperature in Fort Peck Lake averaged $20.5^{\circ} \mathrm{C}$ from June 15 to July 15 (time of spawning and larval drift), which is $10.4{ }^{\circ} \mathrm{C}$ warmer than temperatures recorded below Fort Peck Dam during that time.

\section{Migration Patterns}

Telemetered wild adult pallid sturgeon $(n=43)$ were manually tracked in the Upper Missouri River above the confluence with the Yellowstone River to Fort Peck Dam. Of these pallid sturgeon, 4 were gravid females, 1 was a nongravid female, and 38 were males. The Upper Missouri River above the confluence with the Yellowstone River had minimal use during 2014 (fig. 22).

Similar to most years, the Upper Missouri River above the confluence with the Yellowstone River was used very little during the spawning season 2014. During June, one pallid sturgeon (approximately 2.5 percent) was present in the Upper Missouri River above the confluence with the Yellowstone River near Culbertson, Mont. (RM 1,618). Use of the Upper Missouri River above the confluence with the Yellowstone River increased in July, similar to other years, as pallid sturgeon completed spawning in the Yellowstone River and migrated to post-spawn areas in the Upper Missouri River above the confluence and below the confluence with the Yellowstone River where most would eventually over-winter.

Most forays into the Upper Missouri River above the confluence with the Yellowstone River were in lower parts of the river. A total of eight pallid sturgeon migrated beyond the Culbertson, Mont., ground station (about $25 \mathrm{mi}$ ), and only two pallid sturgeon migrated beyond the Wolf Point, Mont., ground station (about $140 \mathrm{mi}$ ). Seven of these eight pallid sturgeon made their upstream migration late in the season after telemetry-tagged, female pallid sturgeon had completed spawning in the Yellowstone River (see the "Field-Based Biotic Assessments of Factors Affecting Migration and Spawning - Yellowstone River Yellowstone River" section). The greatest use happened in mid-September because of an increase in discharge after a large rain event (fig. 23).

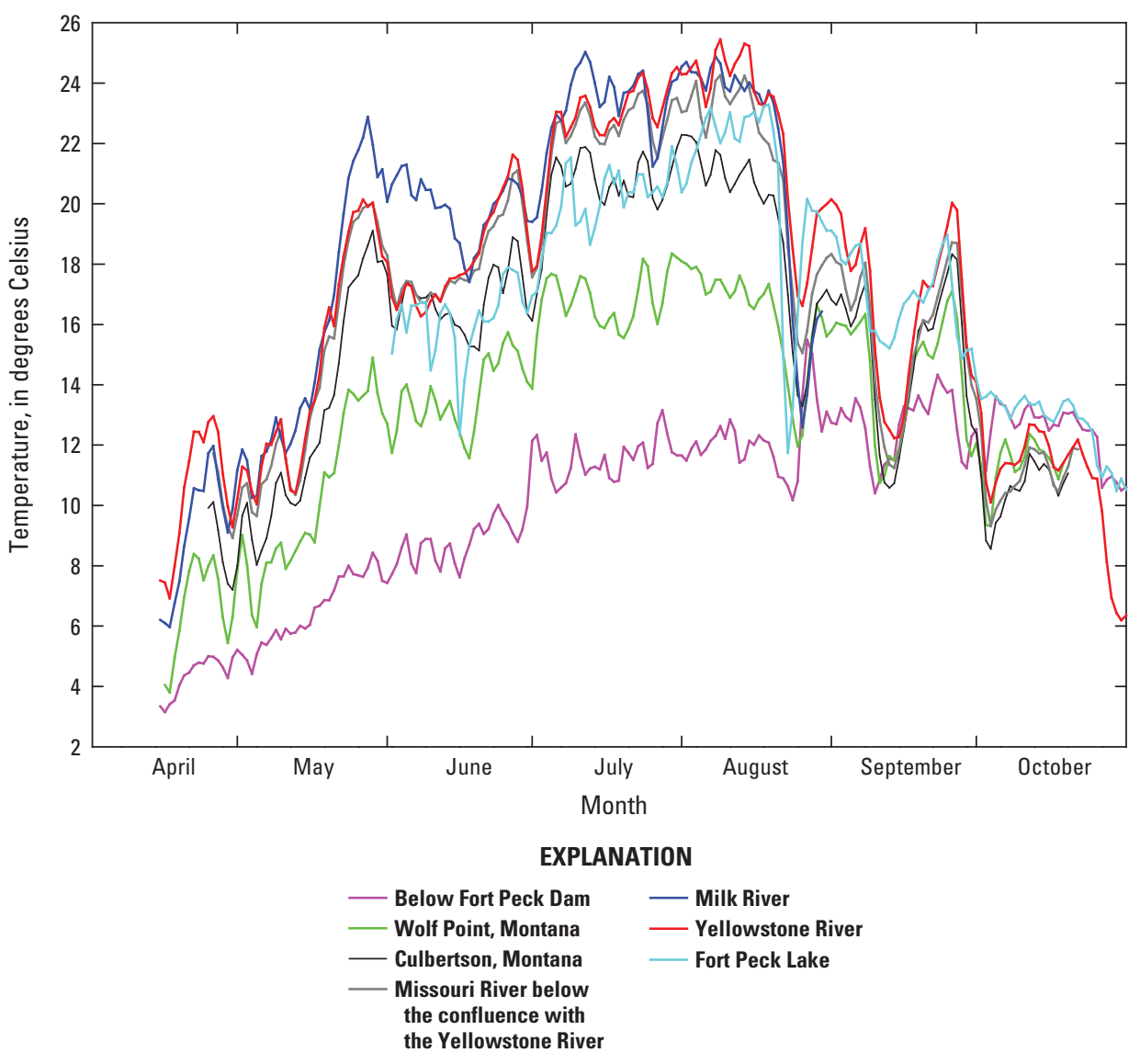

Figure 21. Water temperature for Missouri River sites-below Fort Peck Dam; Wolf Point, Montana; Culbertson, Montana; Missouri River below the confluence with the Yellowstone River; Milk River; Lower Yellowstone River; and Fort Peck Lake_-during April-October 2014. 


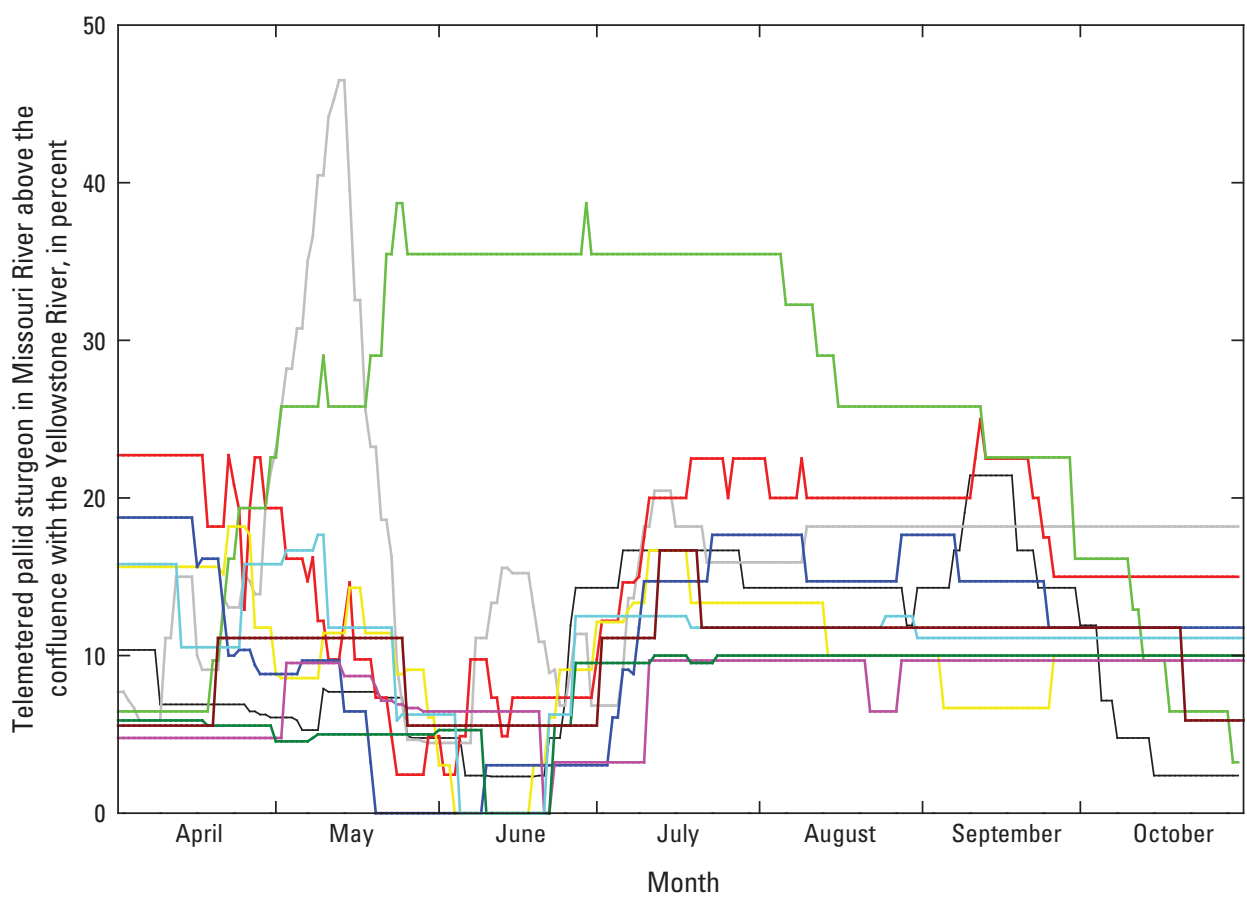

EXPLANATION

( $n$ is the total number of telemetered pallid sturgeon)

$2014(n=43) \quad 2009(n=34)$

$2013(n=46) \longrightarrow 2008(n=31)$

$2012(n=41) \quad 2007(n=22)$

$2011(n=31) \quad 2006(n=19)$

$2010(n=33) \quad 2005(n=18)$
Figure 22. Percentage of telemetered adult pallid sturgeon located in the Missouri River above the confluence with the Yellowstone River by date from 2005 to 2014 in April-0ctober.

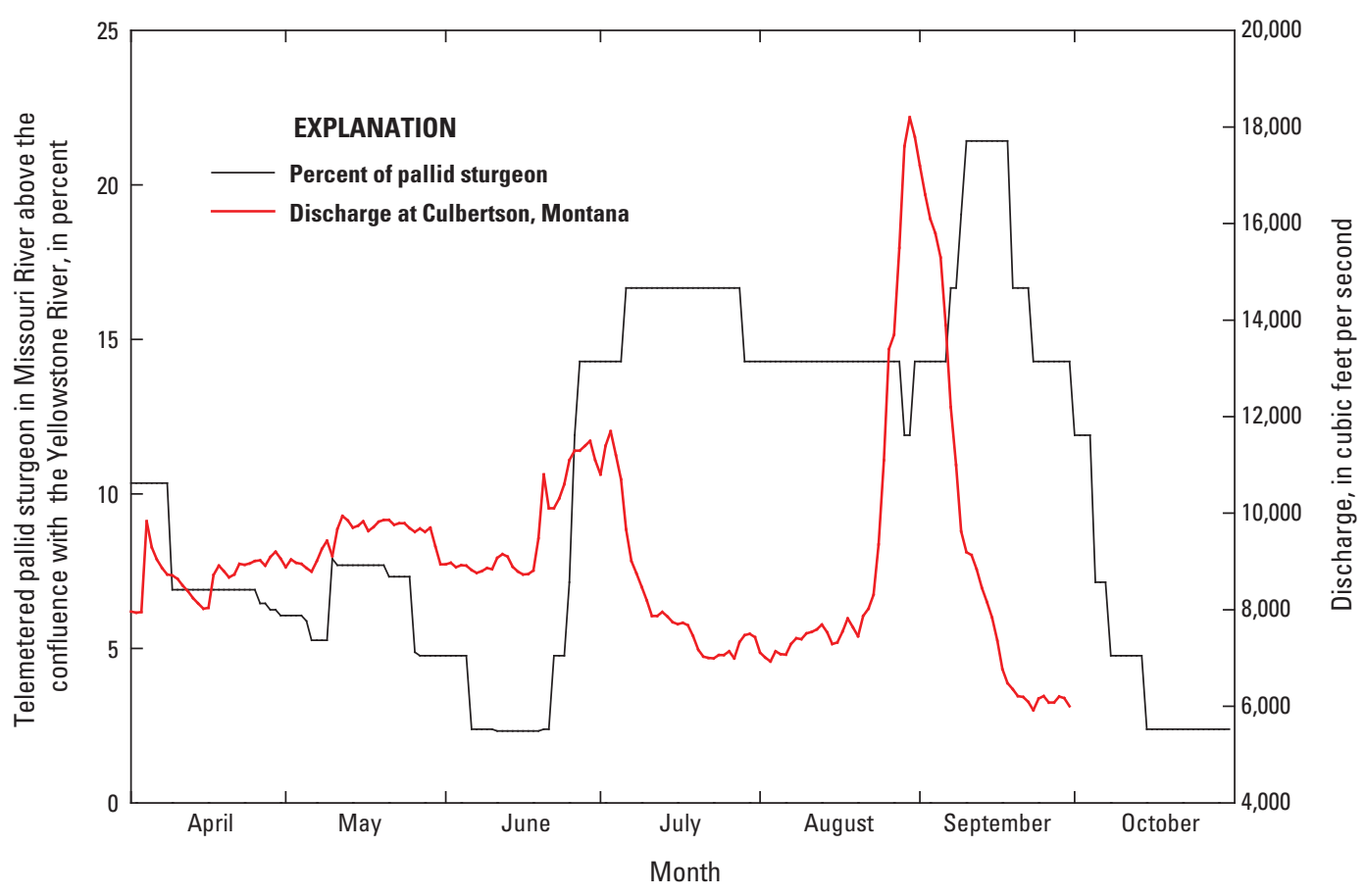

Figure 23. Percentage of telemetered adult pallid sturgeon located in the Missouri River above the confluence with the Yellowstone River and discharge at Culbertson, Montana, in April-0ctober 2014. 


\section{Free-Embryo Sampling}

The Milk River was sampled for free embryos during 13 events spanning from June 2 through July 17, 2014. Only one paddlefish free embryo was collected (July 3 ), and no sturgeon free embryos were collected.

The Upper Missouri River near Wolf Point, Mont., was sampled for free embryos during 21 events from June 3 through August 14, 2014. A total of nine paddlefish and nine shovelnose sturgeon free embryos were collected (table 4). No pallid sturgeon were identified using genetic analysis (Dr. Edward Heist, University of Illinois Carbondale, written commun., 2015).

\section{Larvae and Young-Of-Year Sampling}

Beam trawling for young-of-year sturgeon was done weekly from July 23 through September 10, 2014. Channel catfish (Ictalurus punctatus), sturgeon chub (Macrhybopsis gelida), and sicklefin chub (Macrhybopsis meeki) made up $65.3,13.9$, and 5.4 percent of the catch, respectively (table 5). A total of 141 young-of-year shovelnose sturgeon (4th most abundant) was collected in the Missouri River below the confluence with the Yellowstone River, whereas one young-ofyear shovelnose sturgeon was collected in the Missouri River above the confluence with the Yellowstone River. There was a wide range of cohorts indicating that there was a prolonged spawn likely from the Upper Missouri River (table 6). Additionally, several large, earlier spawned individuals were collected and are likely of Yellowstone or Powder River origin. A total of 134 sturgeon (Scaphirhynchus spp.) samples was sent to Southern Illinois University Carbondale (SIU) for genetic analysis. All sturgeon were identified as shovelnose sturgeon. No free embryo or larval pallid sturgeon were collected (Dr. Edward Heist, University of Illinois Carbondale, written commun., 2015).

\section{Discussion}

Because of present (2015) hydrologic conditions in the Upper Missouri River, very few wild adult pallid sturgeon use the Upper Missouri River downstream from Fort Peck Dam, particularly during the spawning season. As in most previous years, higher discharge in the Yellowstone River triggered pre-spawn migrations upstream into the Yellowstone River, and fish maintained residency there throughout May and June 2014. Milk River discharge was low, and there was no use of the Milk River by adult pallid sturgeon this year. Given the low number of Acipenseriformes free embryos collected, the lack of warm turbid inputs of the Milk River likely had a negative effect on paddlefish and shovelnose sturgeon production as well.

Documentation of use, spawning, and reproduction in the Upper Missouri River in 2011 indicates that the Upper Missouri River may be used by pallid sturgeon under some hydrologic conditions regardless of water temperature (DeLonay and others, 2016b). Temperature is still a very important variable because it could shorten embryonic development time, result in shorter drift distance, as well as increase the overall productivity of this dam-affected section of the Upper Missouri River. Verification of successful reproduction by wild pallid sturgeon in 2011 demonstrated that spawning, fertilization, egg survival, and hatch can happen in the Upper Missouri River when discharge deviates from conventional reservoir operations (DeLonay and others, 2016a). Additional information may develop understanding of how water releases (discharge) from Fort Peck Dam could be managed to increase attraction and retention of pallid sturgeon into this section without flooding. Since very few sexually mature adult pallid sturgeon have been observed in the Upper Missouri River to date (2014), limited data exist to specify the flow parameters required to stimulate wild pallid sturgeon migrations and spawning.

\section{Field-Based Habitat Assessments of Habitats Supporting Spawning, Embryo Incubation, and Hatch}

Gravid female pallid sturgeon have been tracked each spring from 2008 to 2013 through migrations to probable spawning, incubation, and hatch sites on the Lower Missouri River in Missouri, Kansas, Iowa, and Nebraska; and from 2012 to 2014 on the Upper Missouri and Lower Yellowstone Rivers on the Montana and North Dakota border (table 7) (DeLonay and others, 2009, 2014, 2016a, 2016b). Field assessments attempted to characterize the habitat at spawning sites where spawning behavior and egg deposition happened within the larger river reach.

Characteristics of 10 spawning sites, for 10 individual female pallid sturgeon were mapped on the Lower Missouri River from 2008 to 2013, and 3 spawning sites used by 4 females were mapped in 2013 and 2014 on the Yellowstone River for spawning events that happened from 2012 to 2014 (table 7). Known spawning sites on the Lower Missouri River are scattered on revetted bends on hundreds of miles of river, which is a situation that contrasts with the Upper Missouri and Yellowstone Rivers where most known spawning is concentrated in a several kilometer-long, dominantly sand-bedded reach of the Lower Yellowstone River near Fairview, N. Dak. (table 7) (DeLonay and others, 2016b). Other spawning events have been inferred on the Upper Missouri or Milk Rivers in 2011 (through recapture of pallid sturgeon larvae) and on the Powder River (through telemetry) in 2014. On the Lower Missouri River, pallid sturgeon spawning sites are deep high-velocity zones on outside revetted bends that can be near bedrock outcrops (DeLonay and others, 2009, 2012, 2014, 2016a, 2016b).

Although gravid female pallid sturgeon have been documented in multiple years spawning on the Lower Missouri and Yellowstone Rivers (table 7), the precise locations of egg release and incubation are still unknown. Spawning sites on the Lower Missouri River present a challenging research 
Table 4. Numbers of Acipenseriformes free embryos collected by date in the Upper Missouri River near Wolf Point, Montana, in June-August 2014.



Table 5. Fish collected with the benthic trawl in the Missouri River above and below the confluence with the Yellowstone River and total catch from July 23 to September 10, 2014.

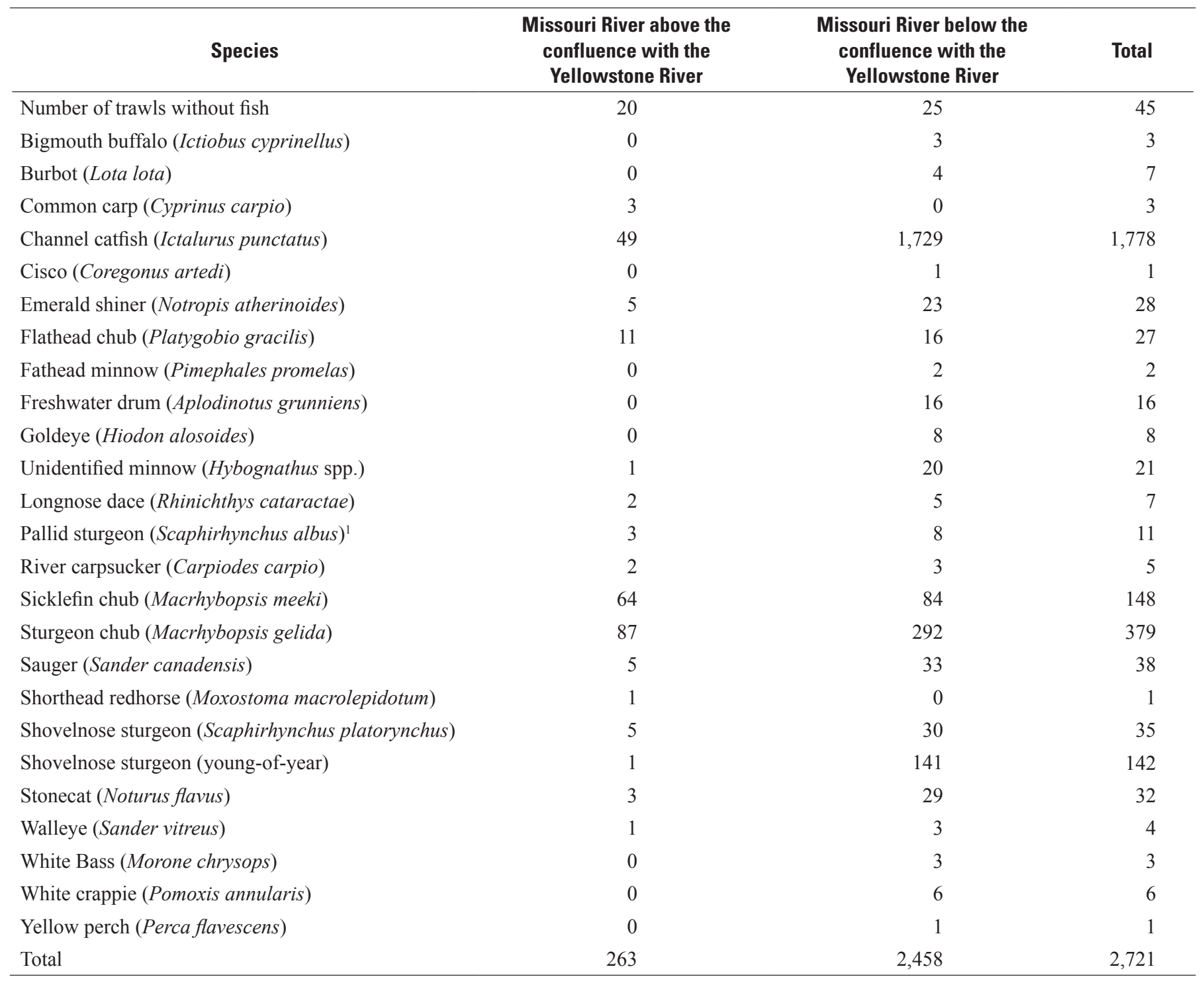

\footnotetext{
${ }^{1}$ Nonwild, hatchery-origin.
} 
Table 6. Number of larval and young-of-year sturgeon collected in standard trawls, targeted trawls, minimum length, maximum length, and mean length by date in July-September 2014.

[NA, not applicable]

\begin{tabular}{|c|c|c|c|c|c|c|}
\hline Date & Total number & Standard trawls & Targeted trawls & $\begin{array}{l}\text { Minimum length } \\
\text { (millimeter) }\end{array}$ & $\begin{array}{l}\text { Maximum length } \\
\text { (millimeter) }\end{array}$ & $\begin{array}{l}\text { Mean length } \\
\text { (millimeter) }\end{array}$ \\
\hline $7 / 23 / 2014$ & 4 & 3 & 1 & 31 & 67 & 46.3 \\
\hline $8 / 6 / 2014$ & 44 & 15 & 29 & 30 & 97 & 43.4 \\
\hline $8 / 12 / 2014$ & 35 & 5 & 30 & 33 & 103 & 57.8 \\
\hline $9 / 3 / 2014$ & 6 & 4 & 2 & 56 & 128 & 79.3 \\
\hline $9 / 9 / 2014$ & 0 & 0 & 0 & NA & NA & NA \\
\hline
\end{tabular}

environment with depths generally greater than $6 \mathrm{~m}$, high turbidity (no visibility in the water column), and high current velocities commonly in excess of 1.5 meters per second $(\mathrm{m} / \mathrm{s})$ (DeLonay and others, 2016b). In addition to the challenging physical conditions for measurement, Lower Missouri River spawning sites are on or adjacent to coarse substrate (revetment or bedrock), which can cause signals from acoustictelemetry transmitters implanted in pallid sturgeon to echo off the hard surfaces and make it difficult to locate sturgeon precisely in the river bend.

On the Upper Missouri and Yellowstone River systems pallid sturgeon are tracked using radio-telemetry transmitters, which allows for efficient, extensive tracking on hundreds of miles but presents a challenge for documenting pallid sturgeon locations in the river as precisely as acoustic-telemetry transmitters (DeLonay and others, 2016a, 2016b). In addition, the large number of telemetered adult sturgeon, and the nature of male aggregations makes it difficult to discriminate unique signals and locate individual pallid sturgeon to an area less than $0.1 \mathrm{RM}$; therefore, the locations of spawning sites on the Yellowstone River are inferred from fish positions recorded by crews throughout the day during the presumed spawning event while taking into consideration the uncertainty associated with telemetry locations (DeLonay and others, 2016a).

Water-hardened pallid sturgeon embryos are about $3 \mathrm{~mm}$ in diameter, become sticky or adhesive in 1 to 3 min after fertilization, and are presumed to adhere to hard substrates shortly after they become adhesive (Dettlaff and others, 1993; DeLonay and others, 2016b). Embryos are hypothesized to remain adhered to or in the substrate for several days. Time to hatch varies with temperature (DeLonay and others, 2016b) but is generally within 3-8 days. There is a hypothesized need for a stable substrate during this incubation period, which provided the motivation for new assessments of physical habitat within this task in 2014. Worldwide, most sturgeon species spawn on coarse substrates (Parsley and Beckman, 1994; Krykhtin and Svirskii, 1997; Sulak and Clugston, 1998; Perrin and others, 2003; Du and others, 2011), and it is believed that sand substrates provide poor habitat for the survival of eggs and larvae (Paragamian and others, 2001; Kock and others, 2006). It is presumed that eggs and larvae would be buried in mobile sand dunes, and although there is some evidence that some sturgeon species spawn over sandy substrates, the survival of embryos and larvae spawned over sandy and mobile substrates is likely to be lower than on coarse substrates (Kock and others, 2006). White sturgeon embryos, for example, were shown in laboratory experiments to have reduced survival rates and delayed hatch at even moderate burial rates $(2 \mathrm{~mm})$, and these results suggest that sediment deposition in spawning areas may be responsible for high early life stage mortality for white sturgeon in the Kootenai River (Kock and others, 2006). On the Lower Missouri River, we have investigated stability of substrate at previously known spawning locations using repeat bathymetric mapping. On the Yellowstone River, we have completed repeat measurements of bed and bedform morphology at and around spawning sites during the time the males were aggregating in the site before the spawning event.

\section{Methods}

Habitat assessments used previously documented methods to map depth, velocity, and substrate (Elliott and others, 2004; Reuter and others, 2008; DeLonay and others, 2009). A multibeam echosounder (MBES) survey system was used to map depths and visualize substrates on the Lower Missouri River using a real-time kinematic (RTK) global positioning system (GPS). On the Lower Missouri River, emphasis in 2014 was on assessment of habitat dynamics, bed stability, and bedform movement at previously known spawning sites. Single-pass longitudinal profiles were also analyzed from previously collected MBES bathymetry in Lower Missouri River spawning sites to document bed conditions and bedform size at spawning sites. 


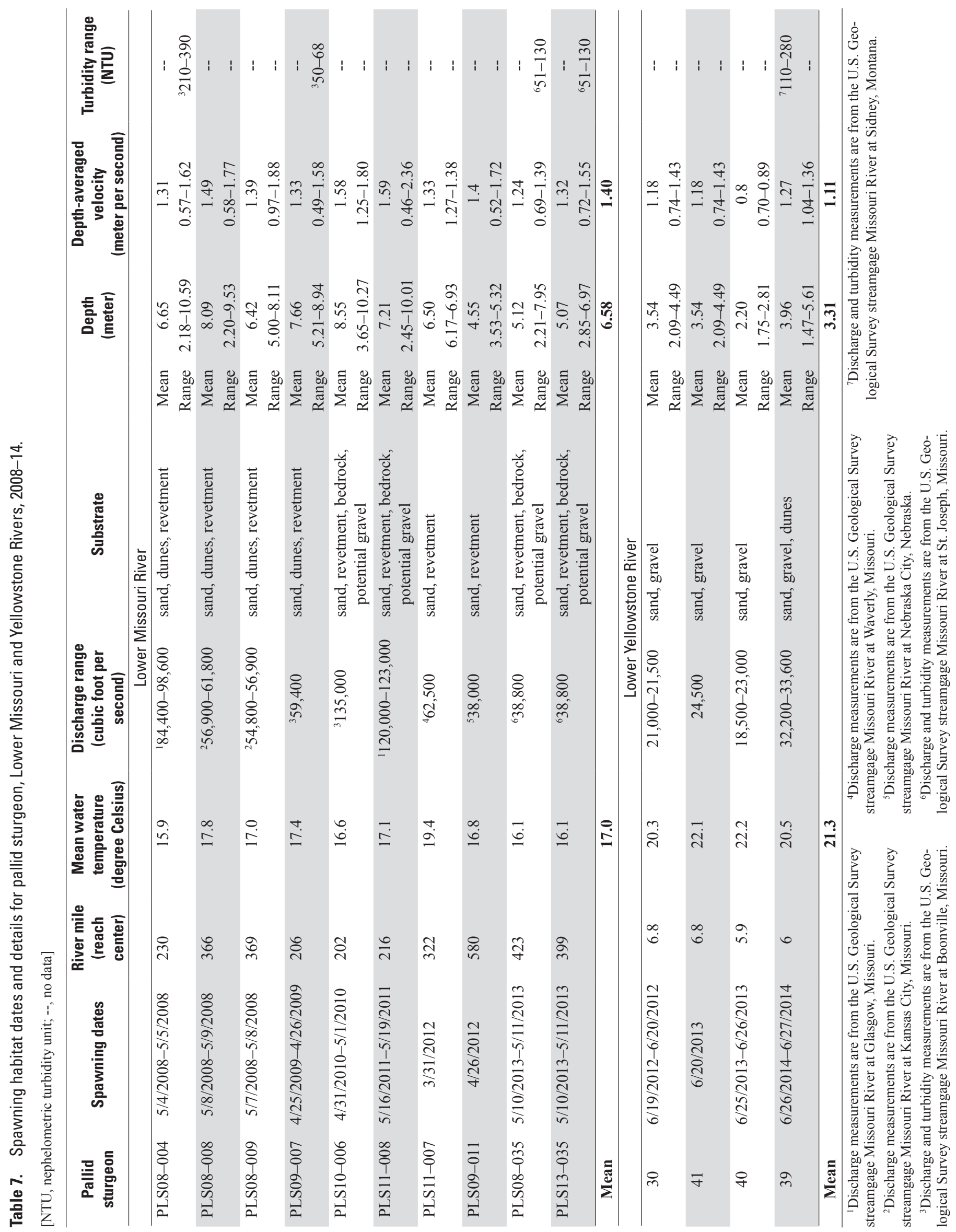


New fieldwork in 2014 on the Lower Missouri River was completed using repeat MBES mapping at three spawning sites documented in 2009, 2010, and 2013 (table 8). In late summer 2014, GPS positioning for the MBES was improved by an upgrade of GPS equipment to include the additional satellites provided by the extended Global Navigation Satellite System (GNSS) network (which includes Russian and other international satellites) and the adoption of post-processed kinematic GPS positioning, which increases GPS positioning accuracy for repeat bathymetric measurements. The post-processed kinematic GNSS positioning uses a smooth best-estimated trajectory correction in post-processing for water-surface elevations and provides an additional degree of positioning accuracy, which is particularly useful in river environments near banks; or bridges where overhanging trees, bluffs, or bridges may block parts of the satellite constellation needed for precise real-time GNSS positioning.

Depths were mapped in the spawning reach on the Lower Yellowstone River using a 1,200 kHz Rio Grande acoustic Doppler current profiler (ADCP) and RTK GPS for precise positioning and water-surface elevation measurements (table 9). Velocity flow fields at all sites were mapped using an ADCP. Repeat longitudinal profiles (parallel to flow) were measured on the Lower Yellowstone River using the vertical beam of a $600 \mathrm{kHz}$ RiverRay ADCP with center transducer in 2014 to assess the stability of the substrate and bedform movement within the suspected spawning site and the surrounding reach (table 10). These profiles were collected on multiple dates for a range of available discharges. Repeat measurements were made for segments of the survey line on three different dates (table 10).

Substrate assessments on Lower Missouri and Lower Yellowstone Rivers used sidescan sound and navigation ranging (sonar). Additional substrate sampling was completed on the Yellowstone River in 2014 using a BM-54 bed material sampler (Edwards and Glysson, 1999) and an underwater microscope (Rubin and others, 2007; DeLonay and others, 2014) (table 9). Bed material and digital grain-size samples were taken from an anchored boat at about the same locations; sampling positions were recorded using differential GPS. Locations sampled were within the suspected spawning site shortly after spawning was presumed to happen as well as in locations of known coarse substrates identified from sidescan sonar surveys within the surrounding 4-kilometer $(\mathrm{km})$ spawning reach. Physical sediment samples were sent to the soil characterization laboratory in the Department of Engineering at the University of Missouri, Columbia for sieve analysis. Digital underwater microscope photographic samples from the underwater microscope were analyzed using digital grain-size analysis methods (Buscombe, 2013). Sidescan sonar data were collected using extensive and intensive surveys at 400 and $800 \mathrm{kHz}$ to survey substrates along the Lower Yellowstone River spawning reach. Repeat surveys were completed within spawning sites and over known coarse substrates within the spawning reach.

\section{Progress}

Probable pallid sturgeon spawning habitat on the channelized Lower Missouri River happens on outside revetted bends in relatively deep and high-velocity conditions over an extended area (600 mi of river). Substrate does vary somewhat by spawning site; some sites contained varying degrees of bedrock exposure and apparent patches of gravels. Bank revetment and closely adjacent sand dunes are present at all Lower Missouri River spawning sites. The Lower Yellowstone River has a braided channel with regions; active channel migration and spawning is hypothesized to happen in a range of depths in regions of higher velocity with some degree of gravel and sand substrate present.

\section{Lower Missouri River}

Studies on the Lower Missouri River in 2014 focused on the habitat dynamics of previously known spawning sites (table 7). We focused primarily on three spawning sites: one near Atchison, Kansas, at RM 422.7; and two near Boonville, Mo., near RM 202 and 206. Additional bathymetric mapping was completed in two locations on the Lower Missouri River to calibrate equipment and to explore and develop methods to monitor bedload movement and transport rates for application at spawning sites in the future (table 8).

Near Atchison, Kans., a MBES dataset collected by Huizinga (2013) coincided with the downstream-most extent of the 2013 spawning site for pallid sturgeon PLS08-035. We acquired this dataset for comparison to assess geomorphic dynamics and the longer-term ( $>1$ year) stability of substrates in a Lower Missouri River spawning reach (table 8) (DeLonay and others, 2016a). The MBES dataset included surveys completed before, during, and after bridge construction; and was collected using similar MBES and RTK GPS instrumentation for a range of discharges (Huizinga, 2013). Five datasets were collected that ranged in discharge from 35,600 to $70,900 \mathrm{ft}^{3} / \mathrm{s}$ (at the USGS streamgaging station at St. Joseph, Mo.). The Huizinga (2013) dataset overlapped with the downstream end of the suspected spawning sites mapped by CSRP crews within a few days of the May 10-11, 2013, spawning dates (DeLonay and others, 2016a), thereby allowing for temporal comparison (fig. 24). Cross sections and longitudinal profiles show a range of bedform sizes that generally increase in length and amplitude with increasing discharge, particularly in the regions related to the dike scour hole and dike-related sandbar on the left descending bank of the channel (figs. 24 and 25). The thalweg region near the center of the channel and sandybedded area adjacent to the revetment experienced about a meter of bed aggradation between 2010 and 2013. Small scale dunes of about 0.20 to $0.30 \mathrm{~m}$ in height and $5 \mathrm{~m}$ in dune length were present in the spawning reach near the vicinity of the fish locations at the spawning discharge and in the weeks preceding the spawning event based on the April and May 2013 survey data (fig. 25). Little to no measureable change happened in the region of bank revetment during the survey period from 2009 to 2013 (fig. 25). 


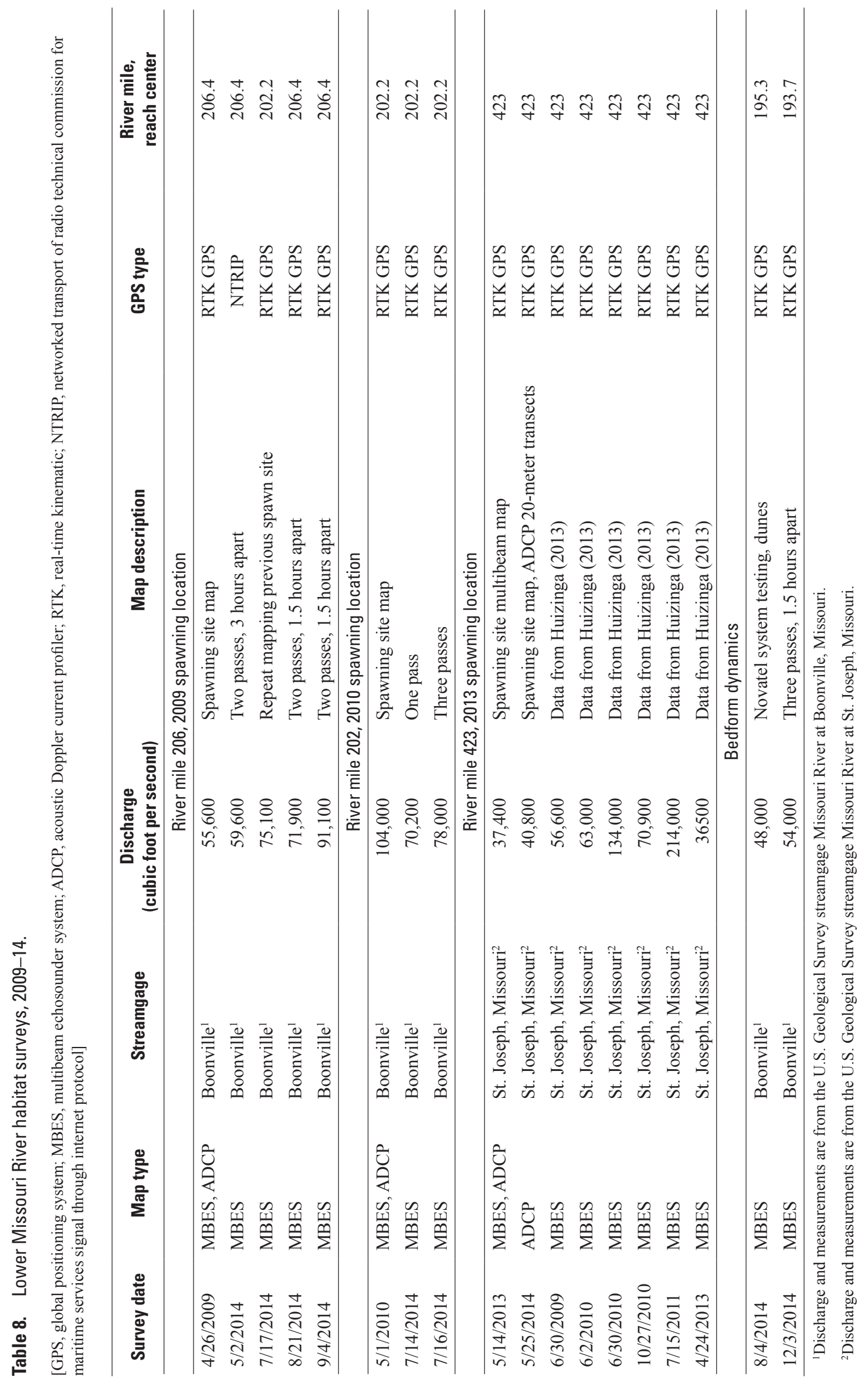




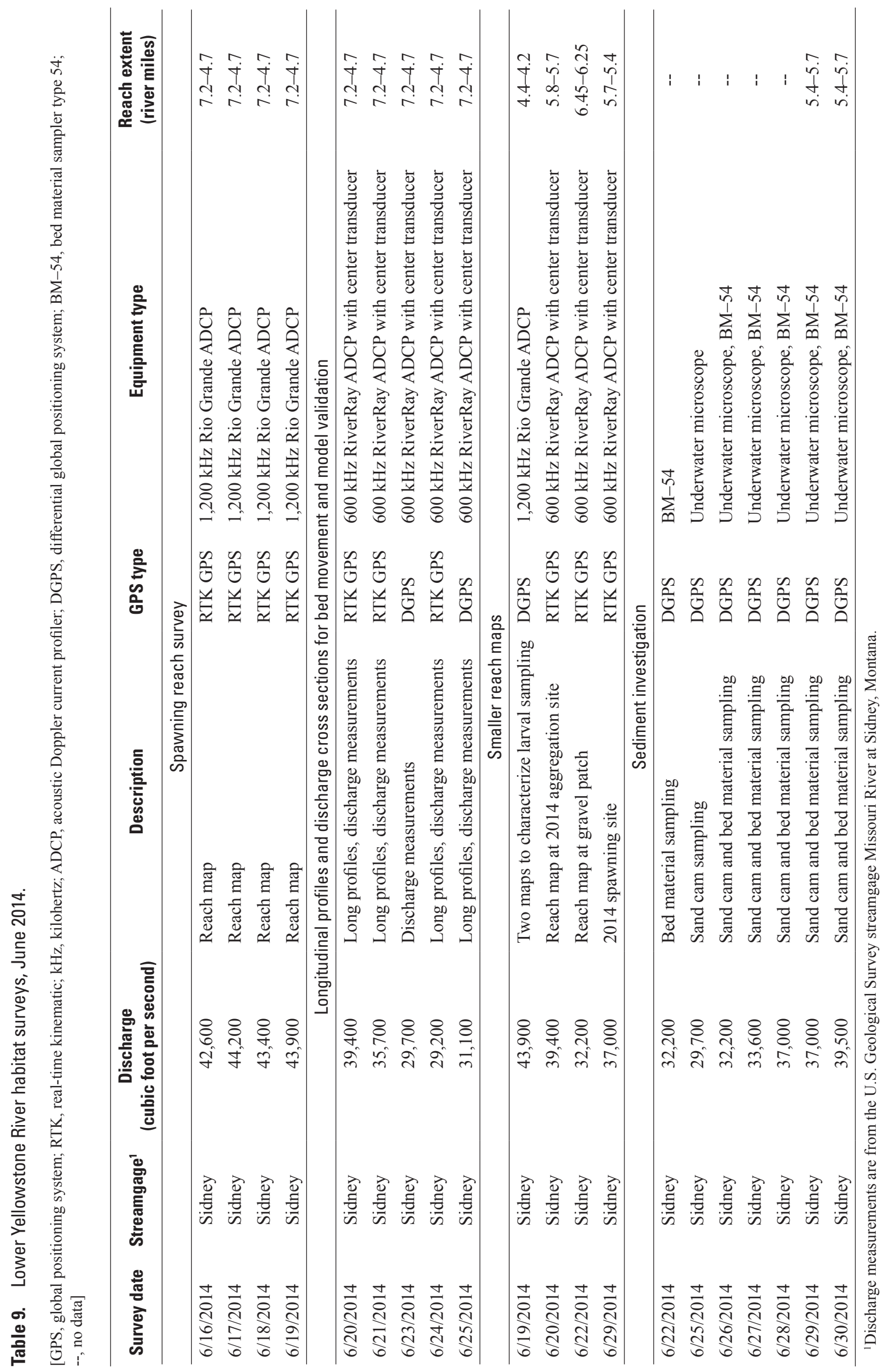


Table 10. Longitudinal bed profiles on the Lower Yellowstone River, June 2014.

$[--$, no data $]$

\begin{tabular}{|c|c|c|c|c|c|c|c|}
\hline Date & Time & Streamgage $^{1}$ & $\begin{array}{l}\text { Discharge } \\
\text { (cubic foot per } \\
\text { second) }\end{array}$ & $\begin{array}{l}\text { Hours between } \\
\text { repeat transects }\end{array}$ & $\begin{array}{l}\text { Dune velocity }{ }^{2} \\
\text { (meter per hour) }\end{array}$ & $\begin{array}{l}\text { Deformation flux }{ }^{2} \\
\text { (percent) }\end{array}$ & $\begin{array}{c}\text { Bed material flux }{ }^{2} \\
\text { (square meter } \\
\text { per hour) }\end{array}$ \\
\hline \multirow[t]{2}{*}{$6 / 20 / 2014$} & 12:17 p.m. & Sidney & 39,400 & -- & -- & -- & -- \\
\hline & 02:03 p.m. & Sidney & 39,400 & 2 & -- & -- & -- \\
\hline $6 / 21 / 2014$ & 12:15 p.m. & Sidney & 35,700 & -- & -- & -- & -- \\
\hline $6 / 24 / 2014$ & 07:00 p.m. & Sidney & 29,200 & 6 & -- & -- & -- \\
\hline \multirow[t]{3}{*}{$6 / 25 / 2014$} & 12:25 p.m. & Sidney & 31,100 & -- & 1.25 & 0.12 & 0.60 \\
\hline & 02:44 p.m. & Sidney & 31,100 & 2 & -- & -- & -- \\
\hline & 04:19 p.m. & Sidney & 31,100 & 2 & -- & -- & -- \\
\hline
\end{tabular}

${ }^{1}$ Discharge measurements are from the U.S. Geological Survey streamgage Yellowstone River at Sidney, Montana.

${ }^{2}$ Dune velocity, deformation flux, and bed material flux calculated in the 2014 suspected spawning site using the methods of McElroy and Mohrig (2009).

Repeat MBES bathymetric surveys were completed at the 2009 spawning site for pallid sturgeon PLS09-007. The spawning event was documented on April 25, 2009, near RM 206.5 at a discharge of $59,400 \mathrm{ft}^{3} / \mathrm{s}$ at the USGS streamgaging station at Boonville, Mo. (DeLonay and others, 2012, 2016b) (table 7). Surveys were completed in 2014 on May 2, August 21, and September 4 at discharges ranging from $59,600 \mathrm{ft}^{3} / \mathrm{s}$ to $91,100 \mathrm{ft}^{3} / \mathrm{s}$ (table 8 , fig. 26). Surveys in 2014 on these 3 days consisted of mapping the reach twice with the MBES to assess bed stability and bedform movement during a time interval of less than 4 hours. Results of this mapping show a variety of bedform sizes present in this reach during the 3 days (fig. 26), including fairly large $1.5-\mathrm{m}$ height and 40-m long dunes that were moving in the thalweg in May 2014. Dunes were markedly smaller (0.78 and $1.04 \mathrm{~m}$ high with wavelengths of around $10 \mathrm{~m}$ ) on the August and September survey dates at considerably higher discharges, suggesting complexity in the relations between sediment transport, discharge, and bedform dynamics on the Lower Missouri River (fig. 26). Differencing of 0.25 -cm gridded maps from these datasets show that the dunes present in the spawning reach are moving at all three of the survey discharges and that there are zones of relative stability during the survey timeframes on and adjacent to the coarse substrates present in the reach and near the pallid sturgeon telemetry points for pallid sturgeon PLS09-007 (fig. 27). These data suggest that zones of relative substrate stability can be present at Lower Missouri River pallid sturgeon spawning sites. Additional surveys were completed in 2015 to quantify these zones of relative stability in more locations during timeframes and discharges relevant to pallid sturgeon spawning conditions and to assess bedload dynamics and transport rates at spawning sites.

\section{Lower Yellowstone River}

On the Lower Yellowstone River, four female pallid sturgeon (codes 30, 39, 40, and 41) have been tracked using radiotelemetry transmitters to probable spawning sites within one large reach located between RM 7 and 5 in June 2012, 2013, and 2014 (table 7, fig. 28). These spawning sites are associated with aggregations of 3-12 males, which are usually present at a spawning site for several days to weeks before spawning. Two females (codes 30 and 41) spawned in the channel thalweg near RM 6.8 over a gravel patch in 2012 and 2013 (table 7 , fig. 28). One female (code 40) spawned in a shallower location near river mile 5.9 in 2013. In 2014, a female was tracked to a probable spawning site near RM 5.4 (fig. 28).

Repeat mapping in 2013 and 2014 documented that Yellowstone River spawning sites are not static. Surveys determined that the depths, velocities, and substrates at specific spawning sites in the Lower Yellowstone River are highly dynamic and that bed morphology and substrate change on intra- and inter-annual timeframes with changes in discharge (figs. 29-31). The reach surveyed in 2013 did not include RTK GPS elevation control; therefore, habitat mapping in 2013 only included depths and velocities and cannot be directly compared with the 2014 survey. Qualitative comparisons from cross sections from 2013 and 2014 at two different discharges (about 22,000 ft $3 / \mathrm{s}$ in 2013 and 43,000 ft $3 / \mathrm{s}$ in 2014) show that the spawning reach and site are dynamic and that depths and velocities vary between the years (fig. 29). Elevation control is available for the water surface in the 2014 survey and allows for comparison with an April 2012 1,000-foot cross section interval survey by the USACE (figs. 30 and 31). A total of 13 cross sections from the 2012 survey overlap with the 2014 CSRP survey and, when compared, document substantial shifting of the thalweg and migration of sandbars throughout 

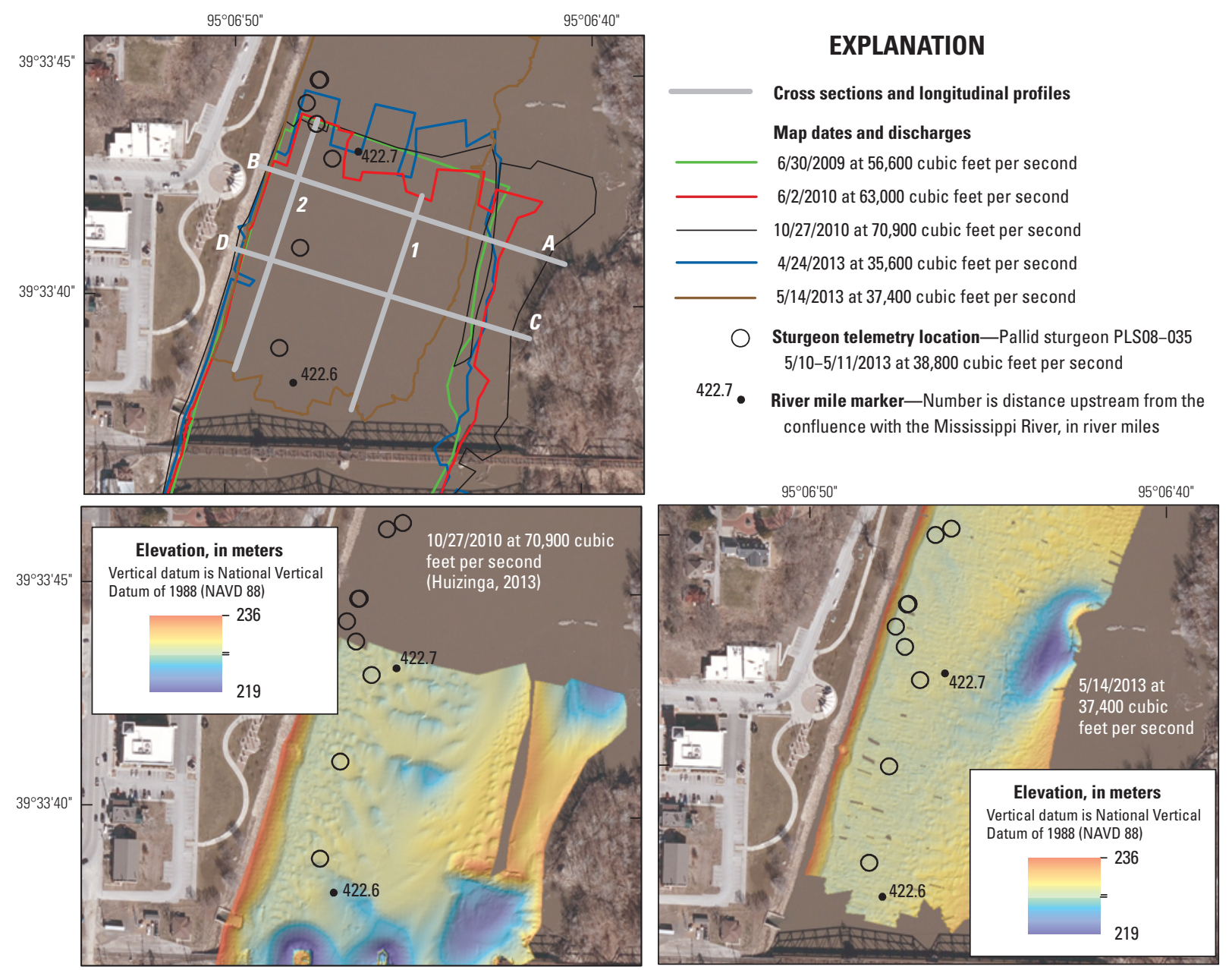

Digital imagery from U.S. Department of Agriculture National Agriculture Imagery Program digital data, 2012



Figure 24. Repeat mapping of pallid sturgeon PLS08-035 2013 spawning site near river mile 422.7 and Atchison, Kansas, and location of cross sections and longitudinal profiles.

the 4-km long reach (figs. 30 and 31). It is notable that there is minimal bank erosion in this reach between 2012 and 2014. On the other hand, the locations of deep and shallow places in the reach varied considerably, and it would be expected that sites suitable for spawning change every year on the Lower Yellowstone River as well.

Longitudinal surveys were completed along the approximate line of the thalweg for the entire reach on 4 days during discharges ranging from $29,200 \mathrm{ft}^{3} / \mathrm{s}$ to $39,400 \mathrm{ft}^{3} / \mathrm{s}$ (figs. 30 and 32). Changes in dune bedforms were characterized over the 6-day period close to the spawning date; these data demonstrate the dynamic moving habitat present in some parts of the spawning site (fig. 32). Bedform size generally increased with discharge although there was a wide variety of dune sizes along the longitudinal profile trace (fig. 32). Small bedforms (heights of $0.2-0.3 \mathrm{~m}$ and lengths of around $5 \mathrm{~m}$ ) were present in the upstream site where spawning happened in 2012 and 2013 near RM 6.7 (fig. 32). Larger dunes were present in a region near RM 6.5 and adjacent to the 2014 spawning site (near RM 5.5) with heights of $0.6-0.8 \mathrm{~m}$ and dune lengths of around $10 \mathrm{~m}$ (fig. 32). Repeat bed depth profiling in 2013 through a male spawning aggregation between RM 5.3 and 5.5 documented the presence and migration of dunes over the course of as little as $1.5 \mathrm{~h}$ (tables 9 and 10; fig. 33). These dunes are on average $0.63-0.70 \mathrm{~m}$ in height and about $7-8 \mathrm{~m}$ long. Dune velocity and bed transport rates calculated using the methods of McElroy and Mohrig (2009) indicate bed material flux rates of 0.60 and 0.82 square meter per hour and dune velocities (bed movement rates) of 1.25 and 1.44 meters per hour on June 25 and June 24 at discharges of 31,100 and $29,200 \mathrm{ft}^{3} / \mathrm{s}$, respectively (table 10 ). 

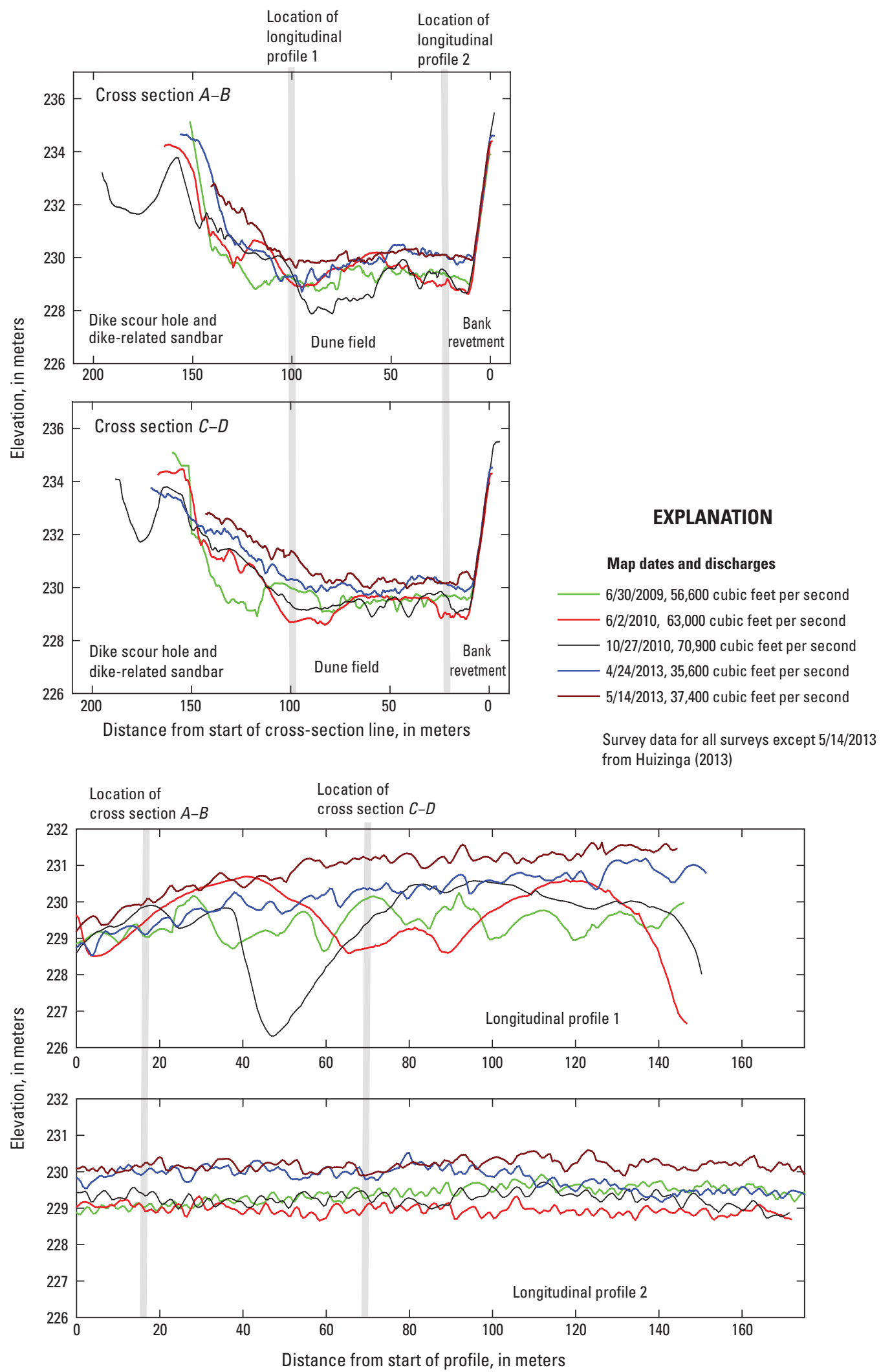

Figure 25. Elevation of cross sections and longitudinal profiles for repeat mapping of pallid sturgeon PLS08-035 2013 spawning site near river mile 422.7 and Atchison, Kansas. 

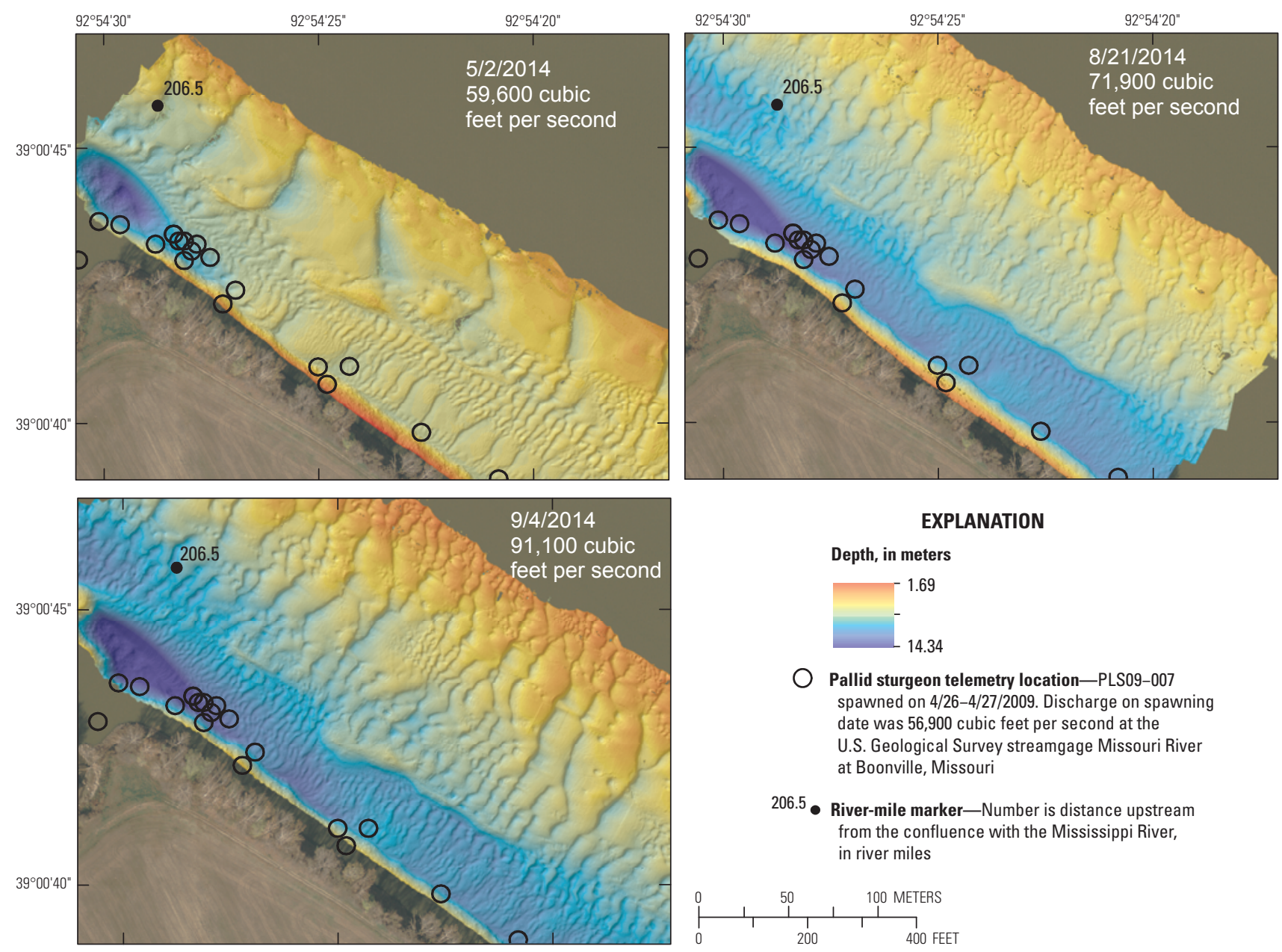

Digital imagery from U.S. Department of Agriculture National Agriculture Imagery Program digital data, 2012

Figure 26. Repeat mapping of pallid sturgeon PLS09-007 spawning site near river mile 206 and Boonville, Missouri, on three days in 2014.

Substrate within the larger Lower Yellowstone River spawning reach and at specific spawning sites documented through sidescan sonar surveys is dominantly sand with patches of gravel (DeLonay and others, 2016a). Bed-material sampling, and photographs of the bed taken with the underwater microscope, document dominance of sand $(0.0625-2 \mathrm{~mm})$ with some coarse pebble- to cobble-sized (16-256 mm) sediment at spawning sites (fig. 34). The size and extent of these gravel patches is highly variable. Some gravel patches within the larger spawning reach are tens of meters in size, and others are present in very small discrete lenses (less than $5 \mathrm{~m}$ in size) within fields of sand dunes (DeLonay and others, 2016a). Bed-material sampling and underwater microscope digital grain-size results from the spawning site show the sand components of the substrate to be in the range of very fine to very coarse sand (figs. 35 and 36). Notwithstanding the presence of scattered small pebbles and gravel, grain-size sieve analysis documented medians for all 10 samples were within the fine sand class ( 0.125 to $0.25 \mathrm{~mm}$ ) (fig. 35).

Sidescan sonar surveys in 2014 documented large patches of sand present in several locations within the larger 4-km long reach, and the region where spawning is inferred to have happened is also sandy (fig. 37). Comparisons with sidescan data from 2013 indicate that the locations and sizes of exposed gravel patches changed within the spawning reach between 2013 and 2014. Underwater microscope, DIDSON acoustic imagery, and probing of the bed indicate the presence of patches of coarse substrates in the spawning reach despite the prevalence of sand dunes on sidescan imagery of the spawning site (fig. 37). Spawning sites above the confluence of less than 20 square meters $\left(\mathrm{m}^{2}\right)$ in area have been difficult to map with current instruments deployed on the Lower Yellowstone River. Technological improvements in the assessment of bed material are planned for the 2015 field season. 

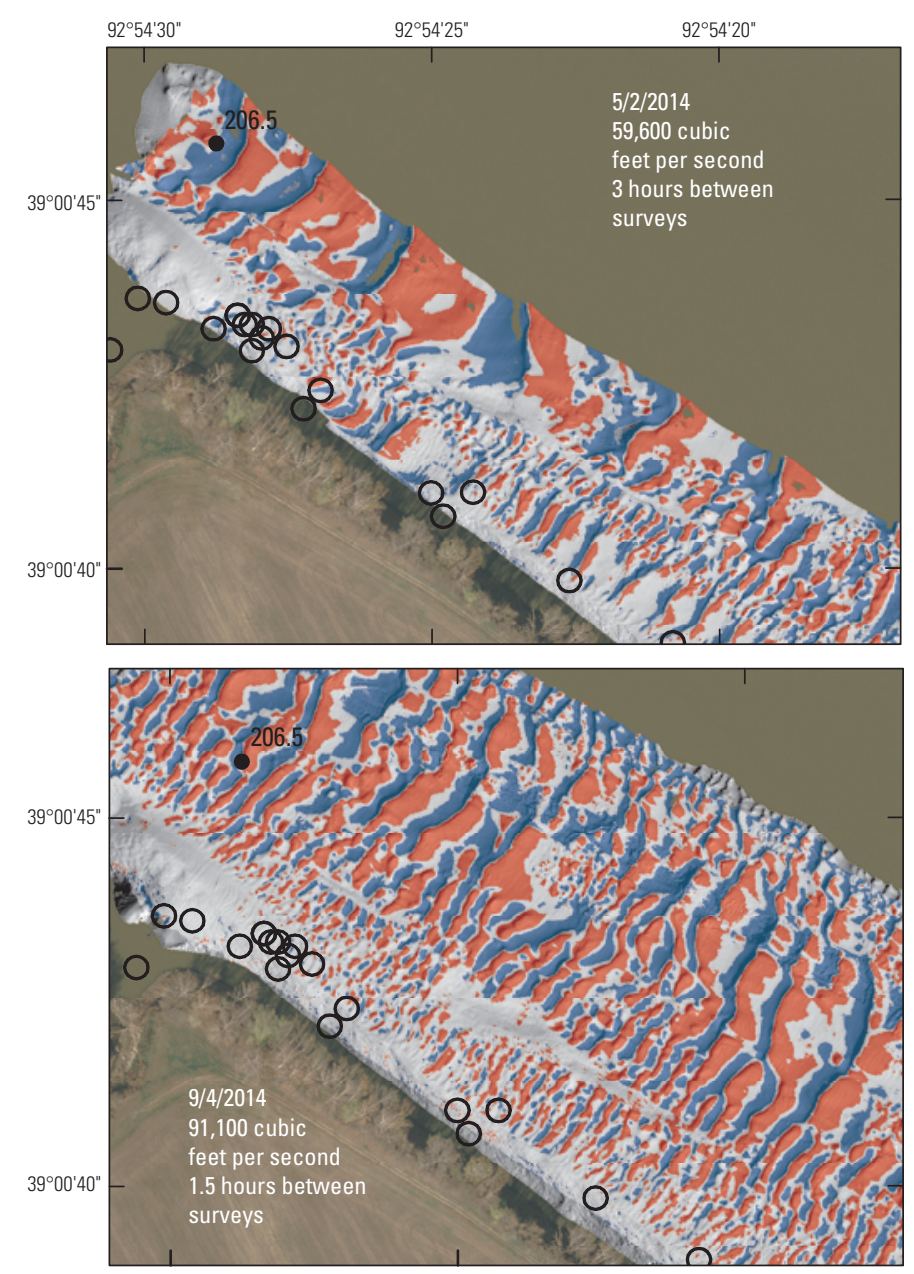

Digital imagery from U.S. Department of Agriculture

National Agriculture Imagery Program digital data, 2012

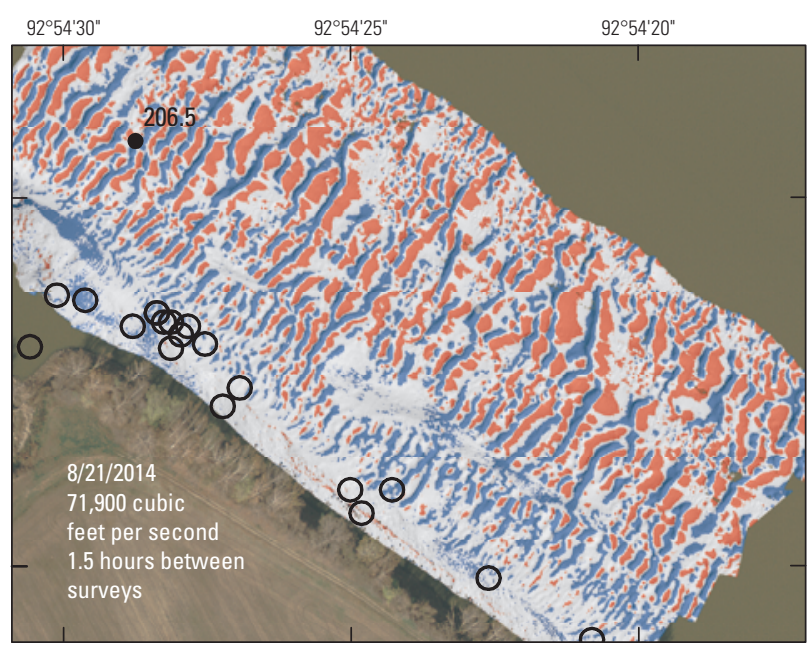

EXPLANATION

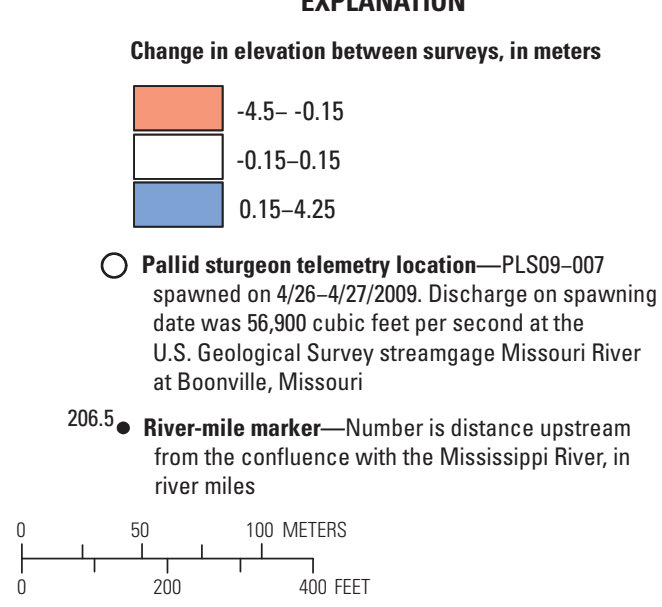

Figure 27. Bedform differencing from repeat mapping of pallid sturgeon PLS09-007 spawning site near river mile 206 and Boonville, Missouri, on three days in 2014.

\section{Discussion}

A cluster of spawning events has happened on the Lower Missouri and Lower Yellowstone Rivers in a 4-km long reach near the downstream end of the Yellowstone River on the Montana-North Dakota border. Four documented (and several suspected) spawning events have happened in this reach, which is characterized by patches of gravel scattered within a dominantly sand bed with variable bedforms (table 10; bottom right panel, fig. 38). Depths of Lower Yellowstone River spawning sites ranged from 1.47 to $5.61 \mathrm{~m}$ with a mean depth of $3.31 \mathrm{~m}$ (table 7). Lower Yellowstone River spawning sites are characterized by relatively high velocity ranging from 0.74 to $1.43 \mathrm{~m} / \mathrm{s}$ and a mean velocity of $1.11 \mathrm{~m} / \mathrm{s}$ (fig. 39; table 7). Within this fairly short reach there has been variable use of spawning sites from year to year. The morphology of the spawning reach, and spawning sites within the reach, are sensitive to discharge variation; therefore, habitat patch structure changes on inter- and intra-annual timeframes.

In contrast, locations of documented spawning in the Lower Missouri River range over 600 RM. The downstream extent of documented spawning events on the Lower Missouri River is near RM 200, and the upstream-most location is near RM 811 (table 1). Evidence of spawning has also been documented on the Platte River, but discrete locations have not been identified, and spawning habitat has not been mapped on the Platte River (DeLonay and others, 2014). Repeat mapping of spawning sites on the Lower Missouri River indicates that depths and velocities are insensitive to discharge variation and are likely to be similar from year to year. Although individual depths at spawning sites have a fairly wide range (from 2.18 to $10.59 \mathrm{~m}$ ), mean depth at spawning sites is $6.58 \mathrm{~m}$ (table 7; fig. 40). The mean depth-averaged velocity for Lower Missouri River spawning telemetry sites is $1.40 \mathrm{~m} / \mathrm{s}$ (range from 

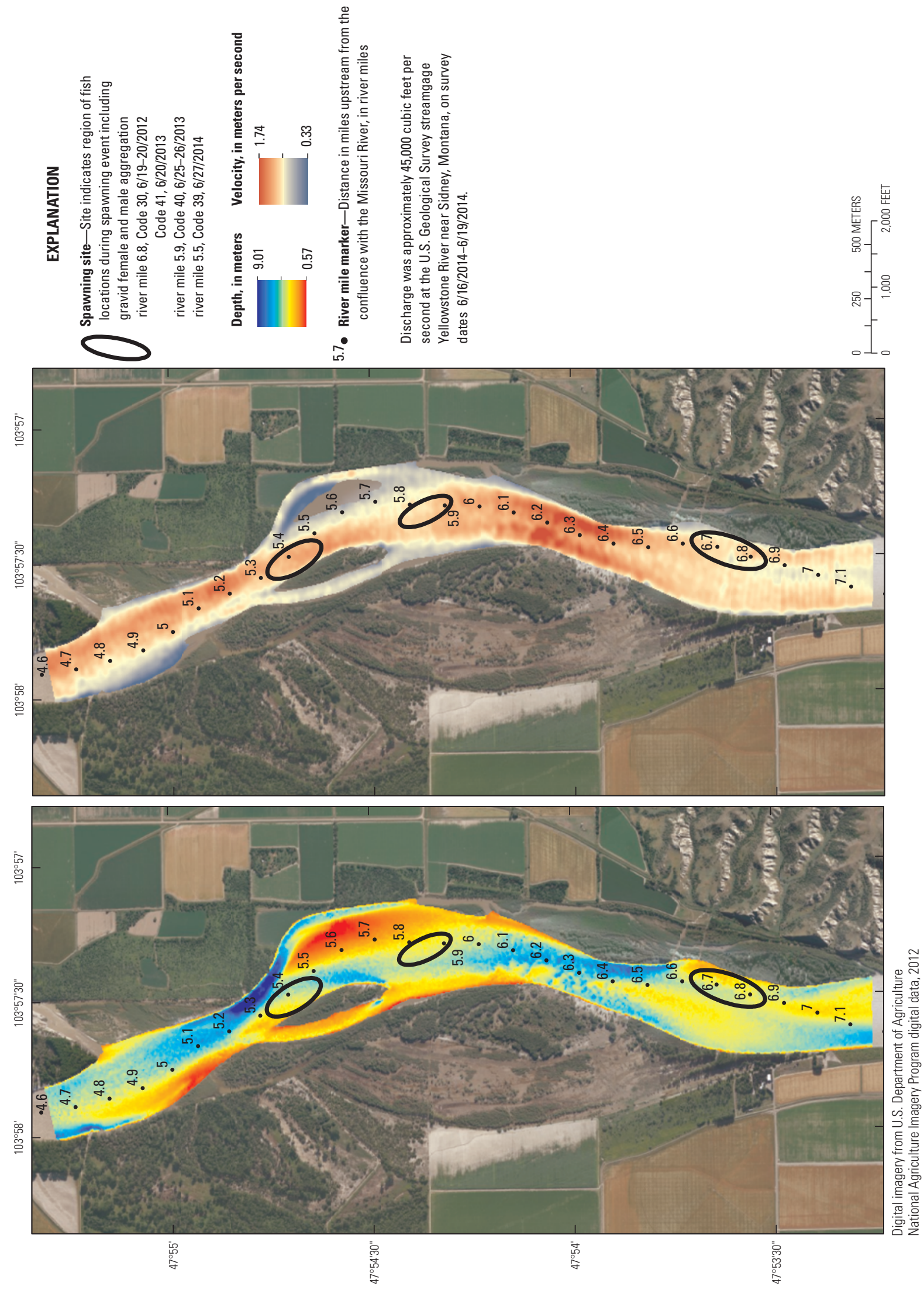

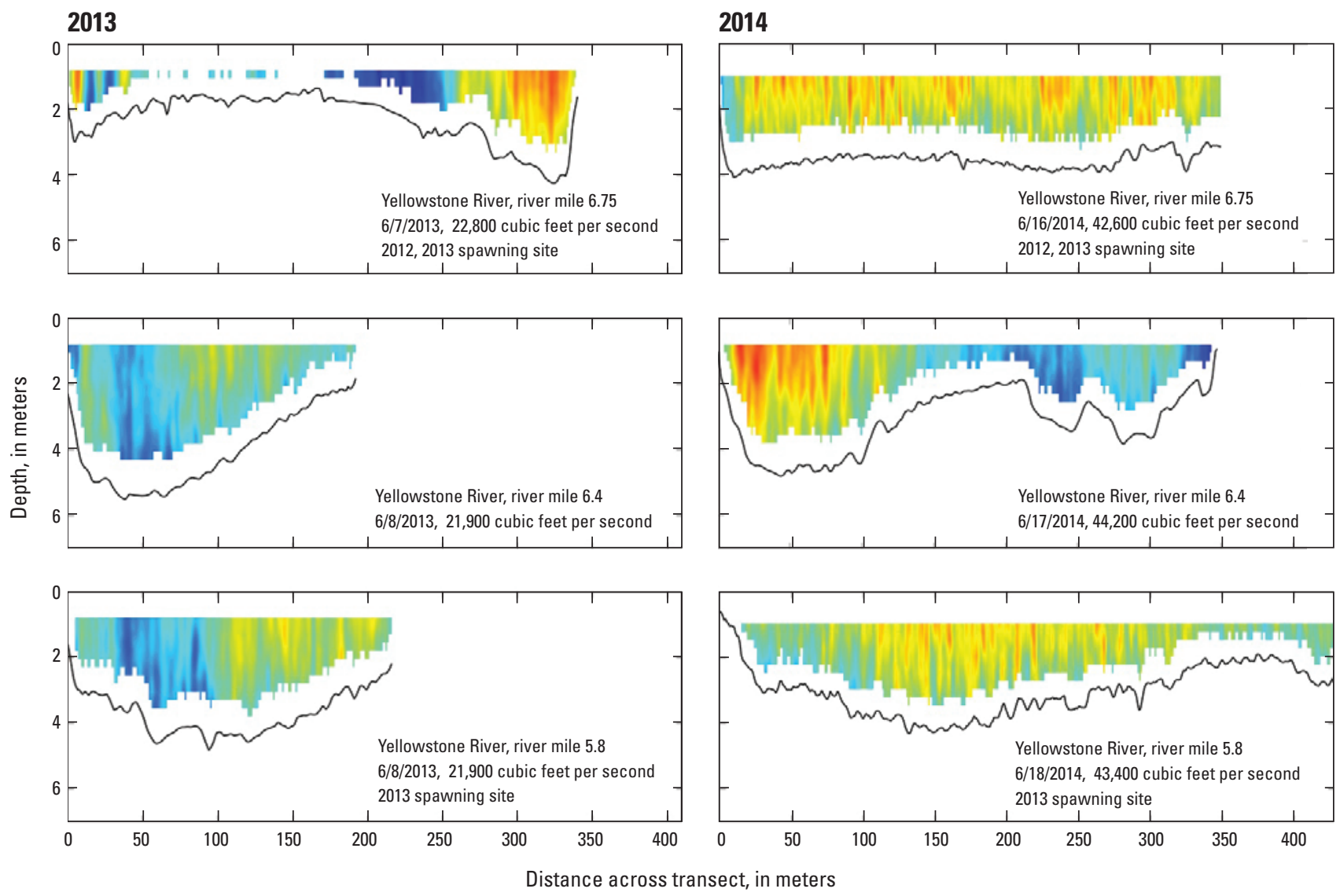

EXPLANATION

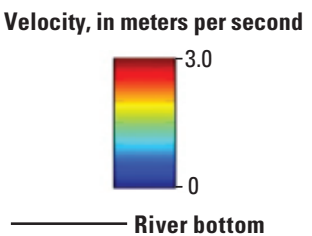

Figure 29. Velocity cross sections of the Lower Yellowstone River near Fairview, North Dakota, from 2013 and 2014 in a known pallid sturgeon spawning reach.

0.46 to $2.36 \mathrm{~m} / \mathrm{s}$ ), which is considerably faster than many adjacent environments in the Lower Missouri River (table 7; fig. 24). All 10 of the spawning sites mapped on the Lower Missouri River were in or adjacent to the thalweg on outside bends armored with coarse bank revetment rock or underlain by bedrock (table 7).

Although the exact locations of egg release at spawning sites on the Lower Missouri River are not known, all spawning sites have coarse substrate in close proximity to moving sand dunes. The MBES bathymetry and sidescan sonar mapping show that several of the Lower Missouri River spawning sites (near RM 202 and 216, table 7) contain large limestone bedrock outcrops and exhibit complex topography that may contain gravel deposits on the channel bed. Two additional spawning sites (near RM 399 and 423) contain small bedrock exposures and natural gravel deposits. All Lower Missouri River spawning sites have coarse bank revetment and the potential for gravel deposits to form at the base of the revetment and margin of sand dunes in the channel. Repeat singlebeam echosounder bedform measurements (Elliott and others, 2009) and MBES dune mapping suggest that large dunes are moving in the channel thalweg at most discharges on the Missouri River and would not remain static over the time scale of egg deposition to embryo hatch (several days). Bank revetments and bedrock substrates at Missouri River spawning sites, in contrast, seem to be stable during periods of days to years. 

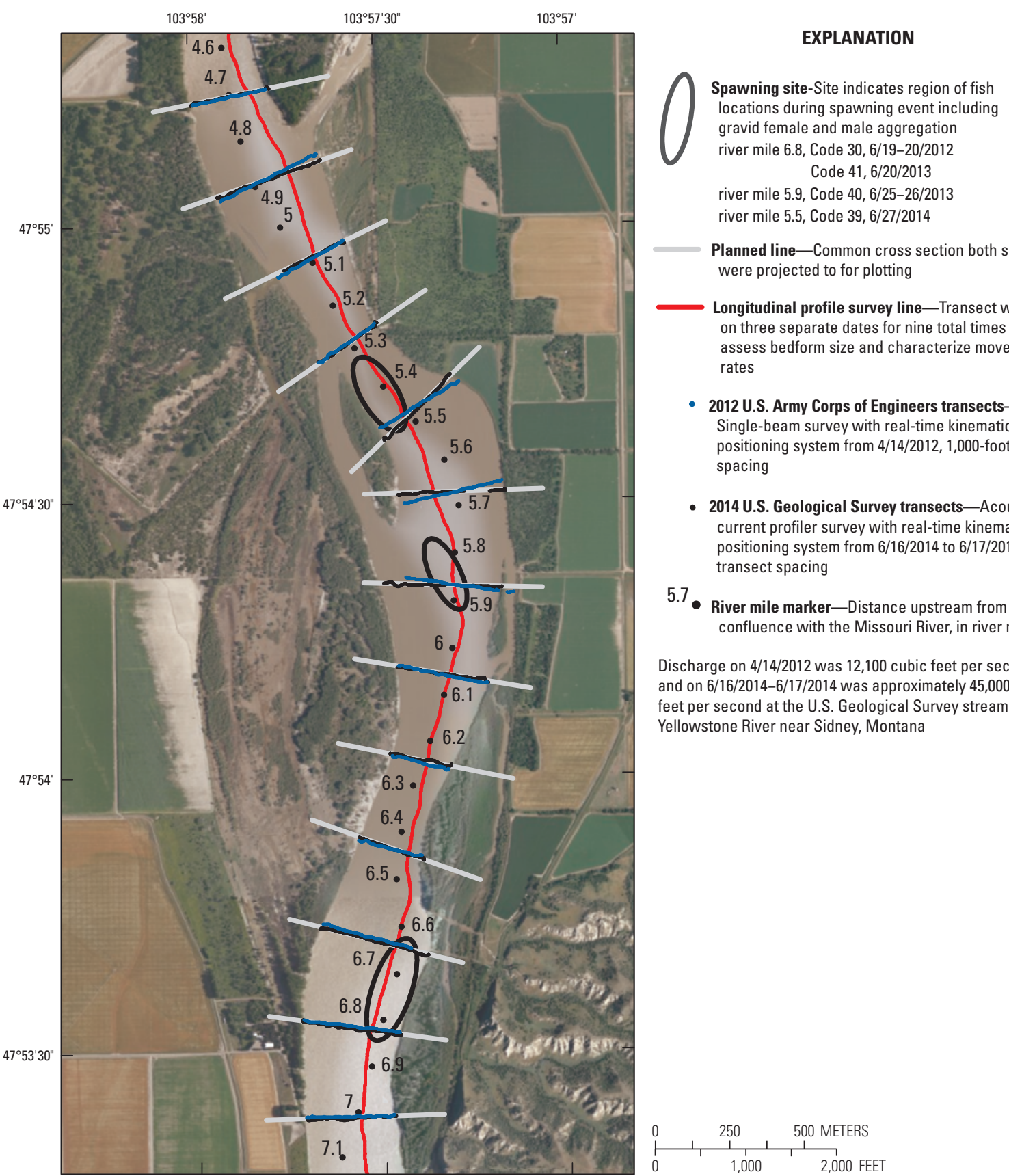

river mile 5.9 , Code $40,6 / 25-26 / 2013$

river mile 5.5 , Code $39,6 / 27 / 2014$

Planned line-Common cross section both surveys were projected to for plotting

Longitudinal profile survey line-Transect was driven on three separate dates for nine total times to assess bedform size and characterize movement rates

- 2012 U.S. Army Corps of Engineers transectsSingle-beam survey with real-time kinematic global positioning system from 4/14/2012, 1,000-foot transect spacing

- 2014 U.S. Geological Survey transects-Acoustic Doppler current profiler survey with real-time kinematic global positioning system from 6/16/2014 to 6/17/2014, 20-meter transect spacing

River mile marker-Distance upstream from the confluence with the Missouri River, in river miles

Discharge on 4/14/2012 was 12,100 cubic feet per second and on 6/16/2014-6/17/2014 was approximately 45,000 cubic feet per second at the U.S. Geological Survey streamgage Yellowstone River near Sidney, Montana

Digital imagery from U.S. Department of Agriculture

National Agriculture Imagery Program digital data, 2012

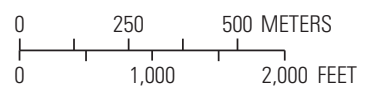

Figure 30. 2012 U.S. Army Corps of Engineers transects, 2014 U.S. Geological Survey transects, and longitudinal profile survey lines in the Lower Yellowstone River near Fairview, North Dakota, in a known pallid sturgeon spawning reach. 

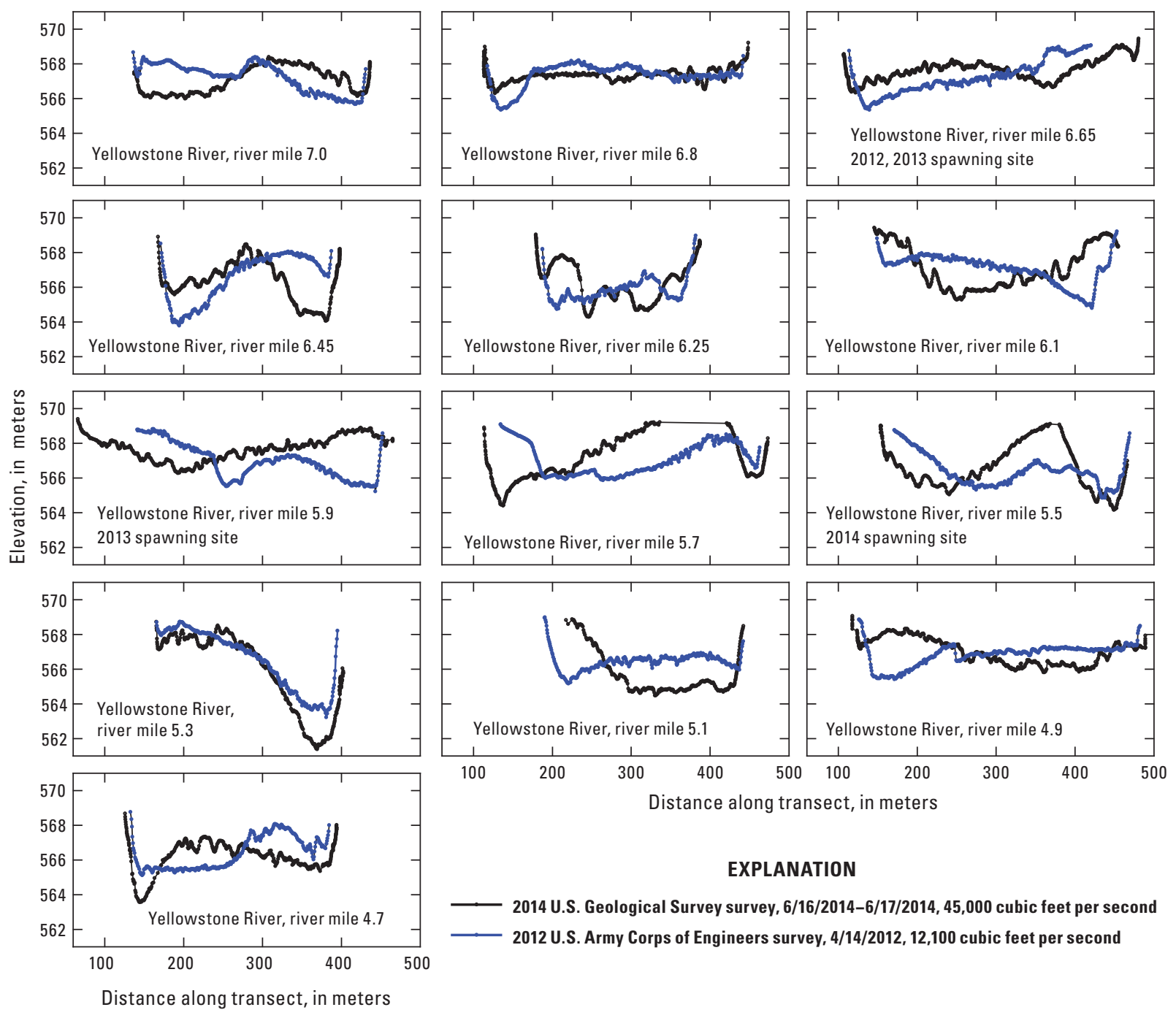

\section{EXPLANATION}

2014 U.S. Geological Survey survey, 6/16/2014-6/17/2014, 45,000 cubic feet per second

2012 U.S. Army Corps of Engineers survey, 4/14/2012, 12,100 cubic feet per second

Figure 31. Cross sections from 2012 U.S. Army Corps of Engineers transects and 2014 U.S. Geological Survey transects surveyed in the Lower Yellowstone River near Fairview, North Dakota, in a known pallid sturgeon spawning reach.

\section{Laboratory Assessments of Abiotic and Biotic Aspects of Spawning and Egg Deposition}

Recent (2014) improvements to CERC pond and culture facilities have provided the ability to hold and bring adult pallid sturgeon to reproductive condition. The CERC facilities are now capable of holding large sturgeon in mesocosms where flow, substrate, and structure can be manipulated. The USGS CERC has demonstrated substantial expertise in the culture and husbandry of numerous sturgeon species, including shovelnose and pallid sturgeon. Under the CSRP we have pioneered the use of noninvasive techniques to assess reproductive maturity and stage and have experimented extensively with spawning induction and early life history rearing conditions (Wildhaber and others, 2007b; Bryan and others, 2007; Candrl and others, 2010; DeLonay and others, 2012). Only with recent improvements at CERC and the increasing availability of adult pallid sturgeon, excess to the PSCAP is it possible to do controlled laboratory and mesocosm studies with reproductive pallid sturgeon. This study component was added in 2014 to take advantage of these new opportunities to advance our understanding of pallid sturgeon reproductive ecology.

This study component began in a stepwise, progressive manner. Objectives were to first overcome technical impediments to attempting research with reproductive pallid sturgeon in a controlled setting and then to progress to understanding and characterizing spawning behavior. Finally, the objective was to develop tools and technology that can be applied in the field to study reproductive behavior, precisely examine substrate selection and egg deposition, and evaluate factors that may contribute to spawning success in the river. Activities under this research component can be broadly categorized into three types that include (1) refining the use of artificial 

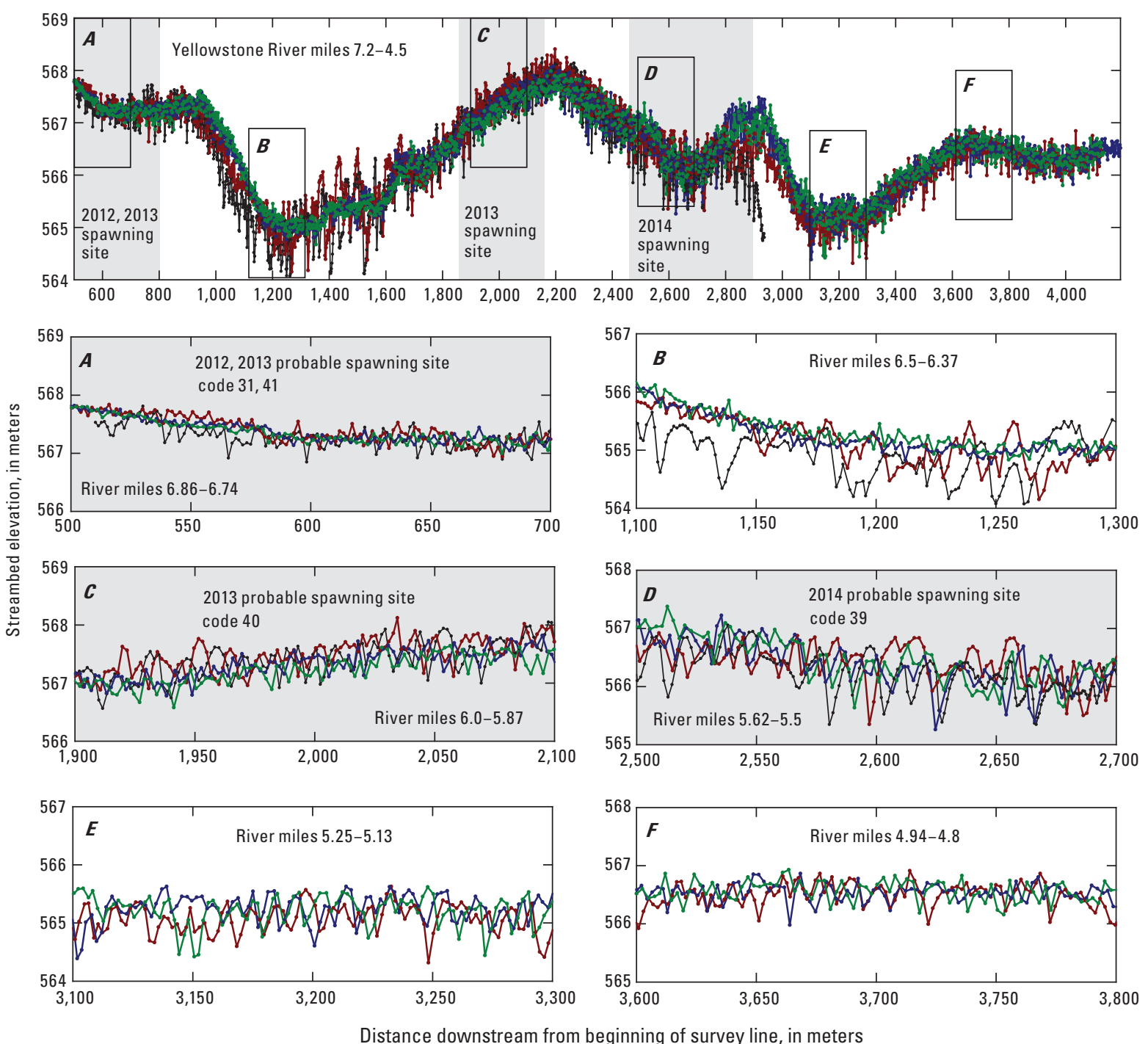

\section{EXPLANATION}

Yellowstone River longitudinal profile survey dates and discharge

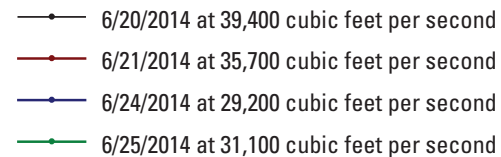

Figure 32. Longitudinal profiles of the 4-kilometer pallid sturgeon spawning reach on the Lower Yellowstone River near Fairview, North Dakota, from June 20-25, 2014. 

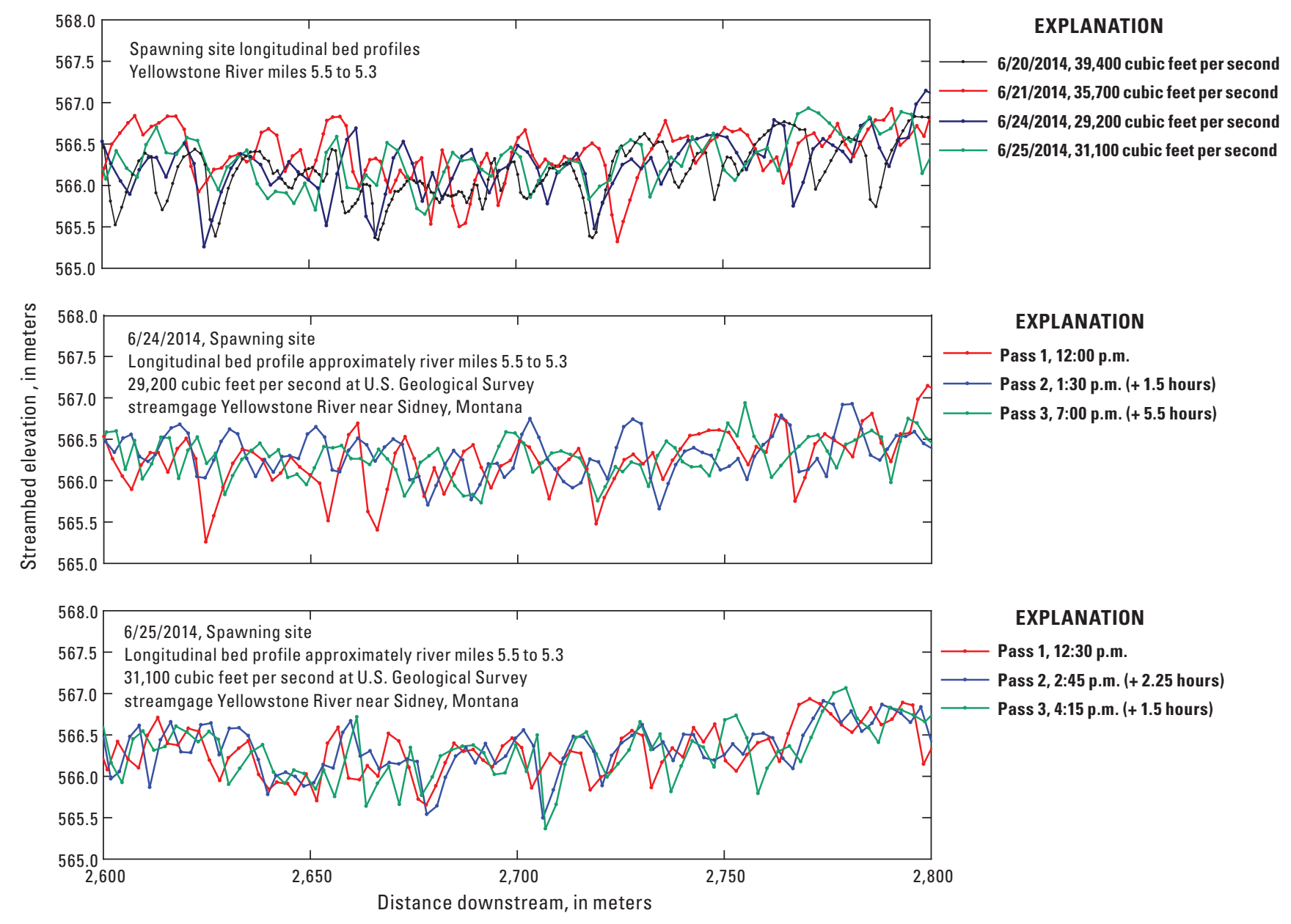

Figure 33. Repeat longitudinal profiles of sand dunes near the suspected 2014 pallid sturgeon spawning site on the Lower Yellowstone River near river mile 5.4 and Fairview, North Dakota.

propagation technologies for pallid sturgeon to provide for reliable induction of ovulation and spermiation and preservation of reproductive products for laboratory research studies, (2) consistently eliciting the behavioral spawning sequence in a controlled setting to document behaviors using technologies that can be applied in the field, and (3) identifying candidate behaviors for the development of detectable biological event signatures and development of tagging technologies for the logging of critical biological events. Beginning studies were completed to address the first two of the three study activities in 2014.

\section{Methods}

Improved Methods for Induction of Female and Male Pallid Sturgeon and Shovelnose Sturgeon

To artificially spawn pallid sturgeon in captivity, reproductively ready broodstock are induced to ovulate (females) or spermiate (males) by the administration of hormone injections. Standard induction protocols for pallid sturgeon prescribe induction using luteinizing hormone releasing hormone analog (LHRHa). Females are generally induced to ovulate by administering two doses of LHRHa through intramuscular injection (Conte and others, 1988). The first primer dose is separated from the second resolving dose by about 12 hours. Ovulation is generally expected within 14-18 hours after administering the resolving dose. Males are induced to spermiate by administering a single dose of LHRHa. Spermiation is generally expected within 24 hours. The amount of hormone administered is based directly on weight of each individual sturgeon. Successful induction rates for both pallid sturgeon and shovelnose sturgeon can be low using this protocol, especially for females. Low induction rates limit the ability of hatcheries to produce viable progeny for population augmentation and limit facilities like CERC when artificially spawning sturgeon for early life-history research. Between 2002 and 2012 at CERC, 13 of 25 (52 percent) shovelnose sturgeon females ovulated successfully when induced by 

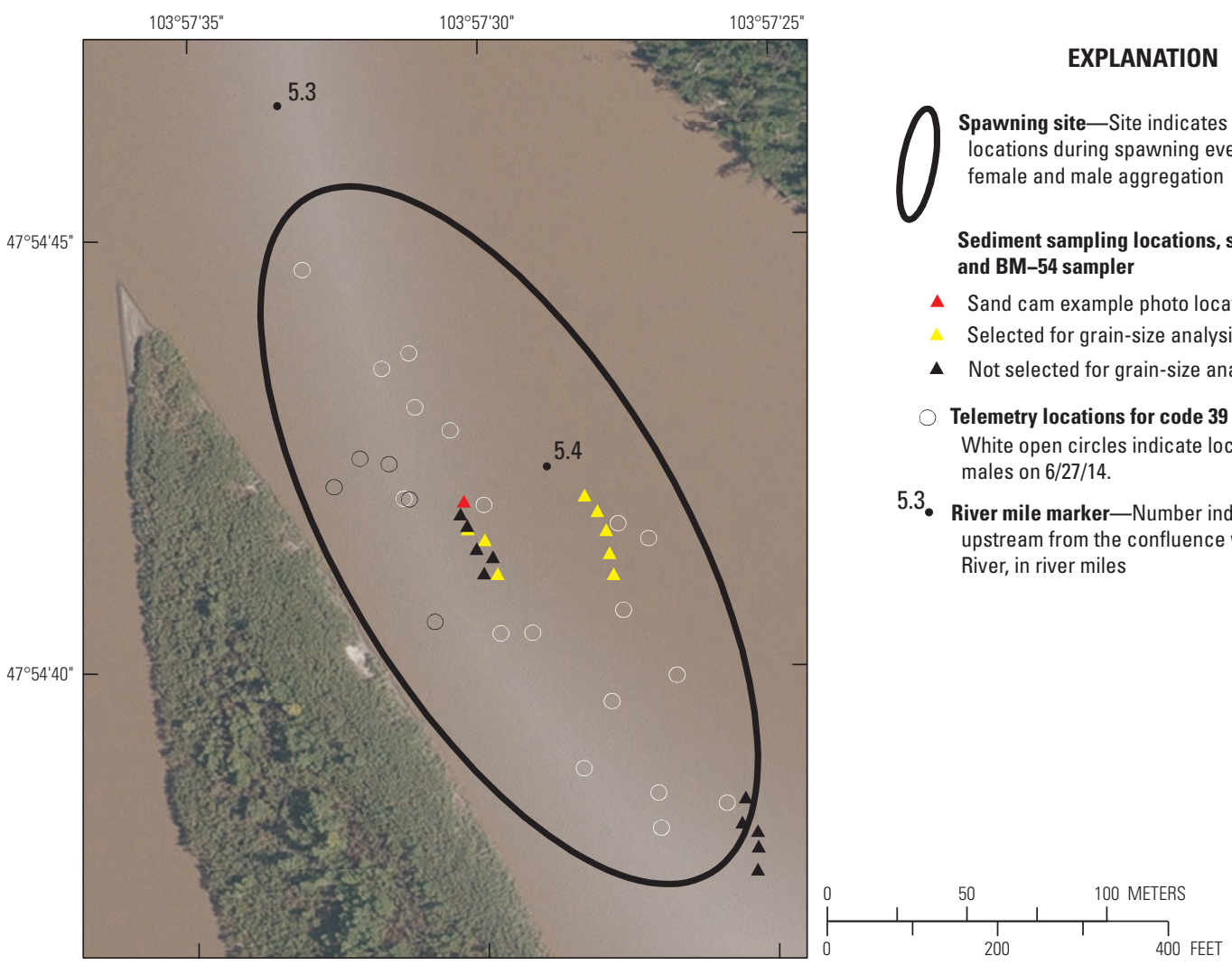

Digital imagery from U.S. Department of Agriculture

National Agriculture Imagery Program digital data, 2012
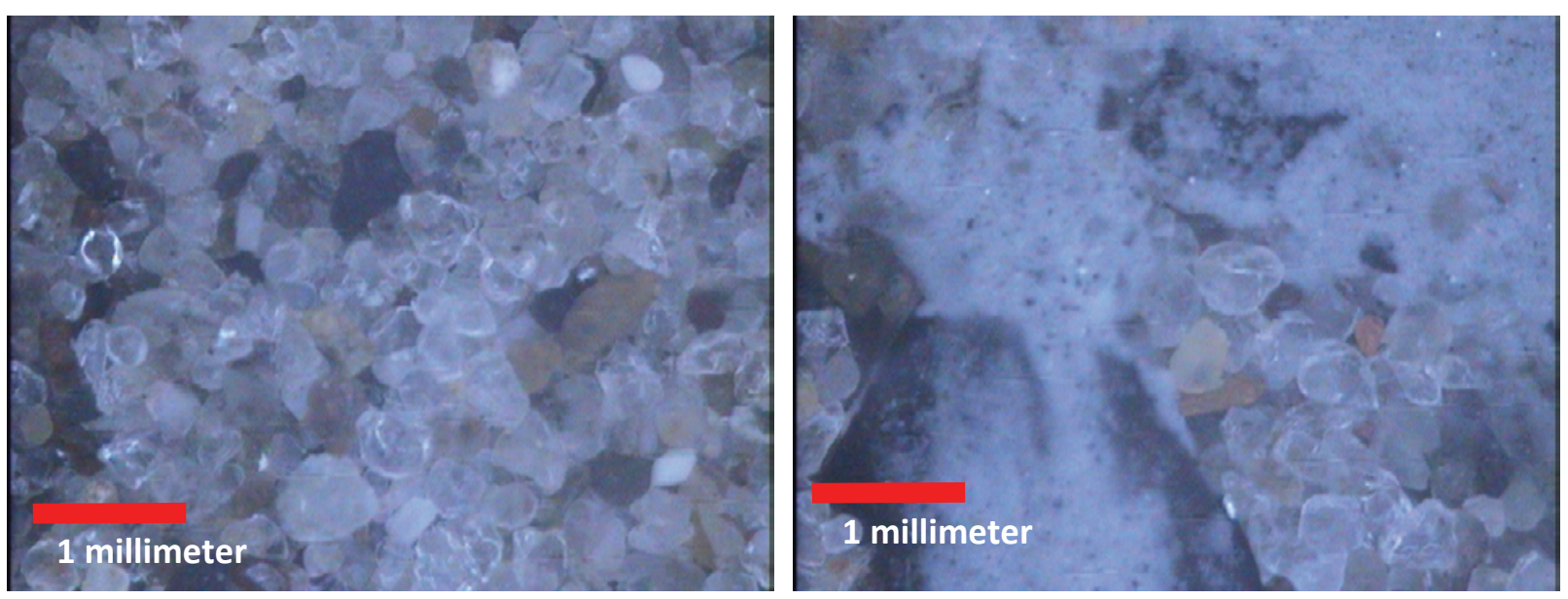

Figure 34. Locations and types of sediment sampling in the 2014 suspected pallid sturgeon spawning site near river mile 5.4 and Fairview, North Dakota, on the Lower Yellowstone River; and digital photographs of bed material taken with the underwater microscope. 


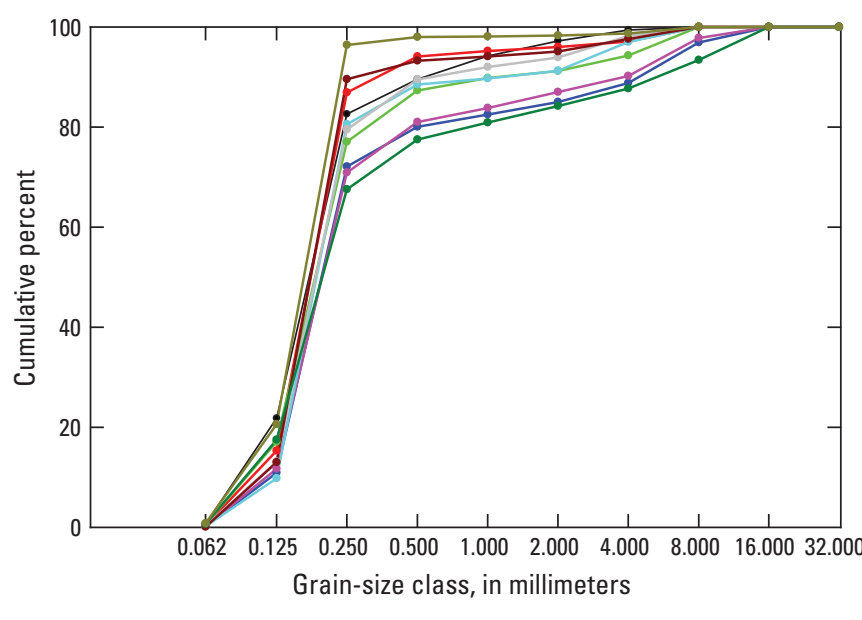

\section{EXPLANATION}

Sediment samples from

Yellowstone River spawning

site, river mile 5.4

6/28/2014

- - BS-16

$\longrightarrow$ BS-17

$6 / 29 / 2014$

$\longrightarrow$ BS-2

$\longrightarrow$ BS-3

$\longrightarrow$ BS-5

$\longrightarrow$ BS-6

$\because$ BS-7

$\longrightarrow$ BS-8

$\longrightarrow$ BS-9
Figure 35. Grain-size distributions from sieve results from 10 sites sampled using a BM-54 bed-material sampler. Sampled region is within the 2014 suspected pallid sturgeon spawning site near river mile 5.4 and Fairview, North Dakota, on the Lower Yellowstone River.

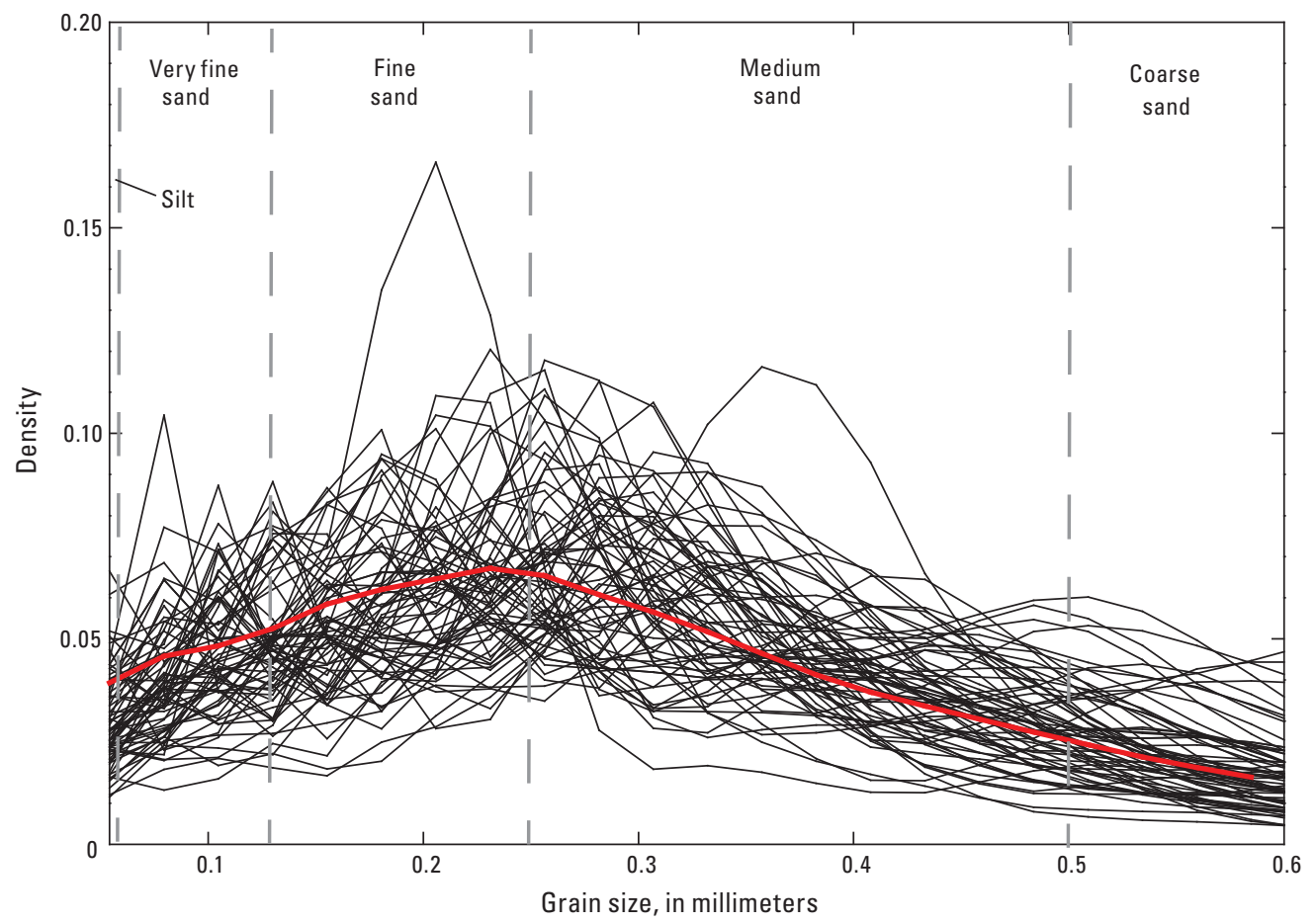

EXPLANATION

— Digital grain-size distribution from 67 digital photographs at spawning site 6/29/2014

Mean grain-size distribution

Figure 36. Grain-size distributions from digital grain-size analysis results from 67 sites sampled using an underwater microscope. Sampled region is within the 2014 suspected pallid sturgeon spawning site near river mile 5.4 and Fairview, North Dakota, on the Lower Yellowstone River. 

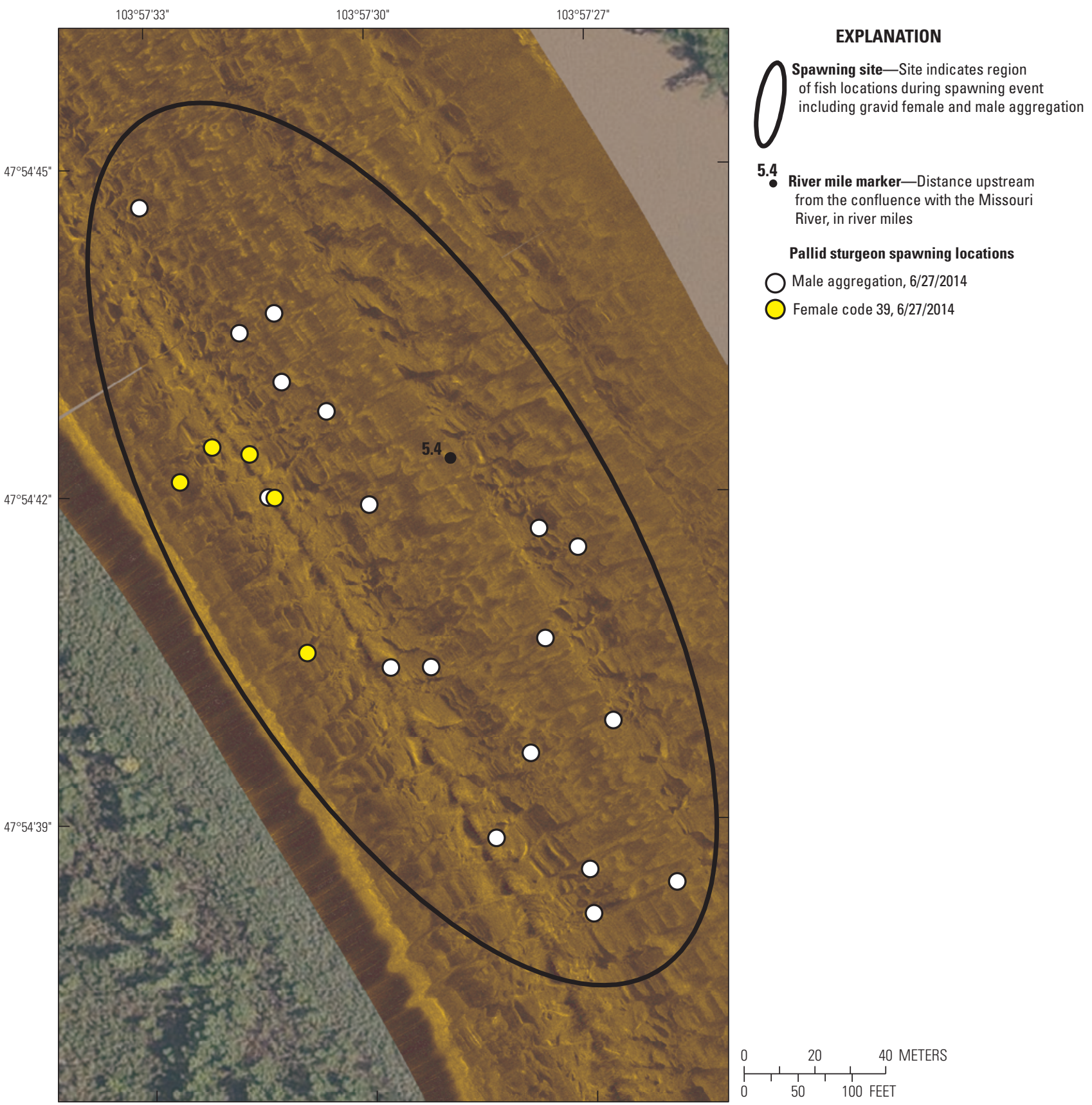

Digital imagery from U.S. Department of Agriculture

National Agriculture Imagery Program digital data, 2012

Figure 37. Sidescan sonar mapping in the 2014 suspected pallid sturgeon spawning site near river mile 5.4 and Fairview, North Dakota, on the Lower Yellowstone River. 


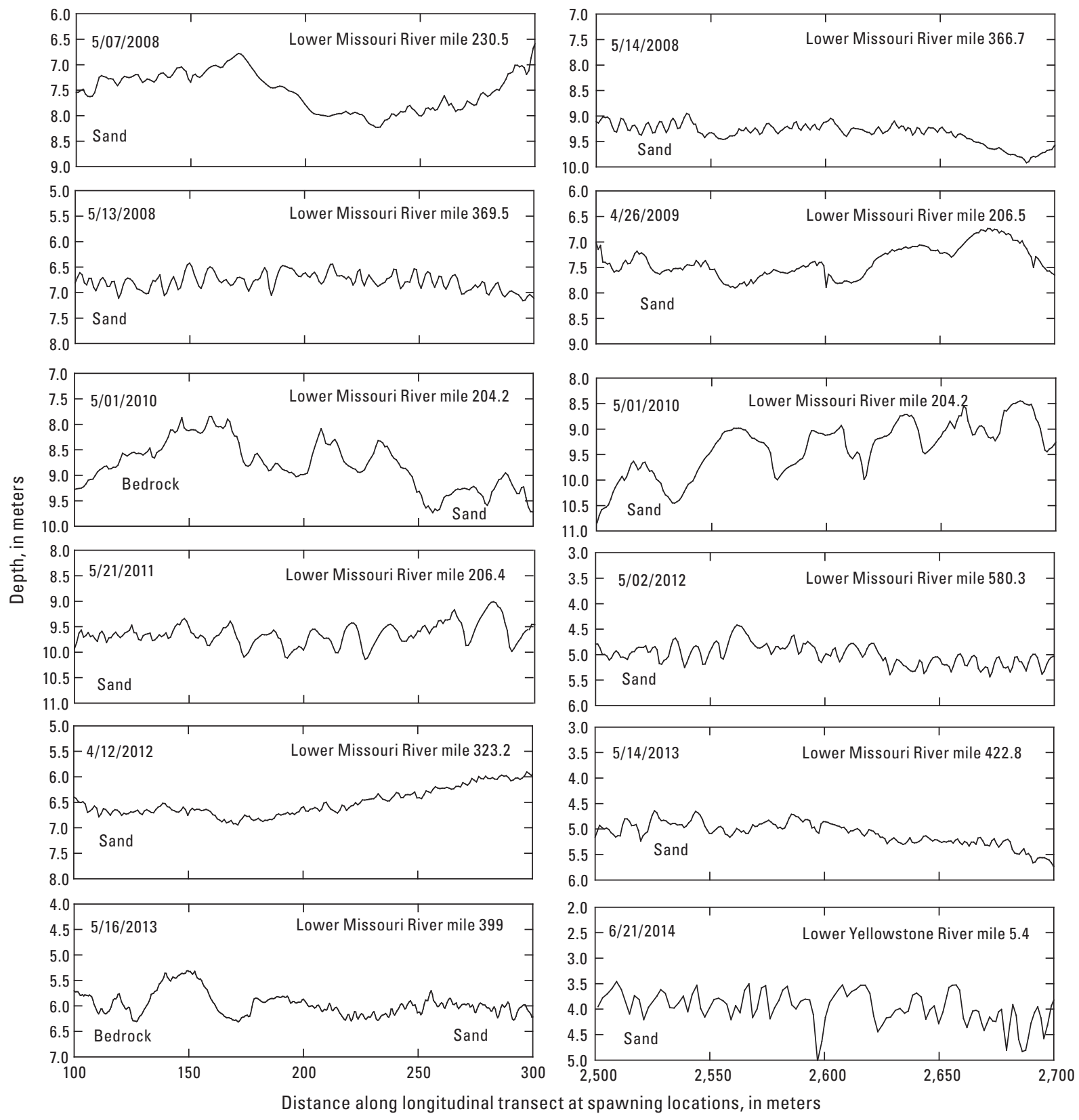

Figure 38. Longitudinal profiles in and adjacent to known pallid sturgeon spawning sites on the Lower Missouri and Lower Yellowstone Rivers. 

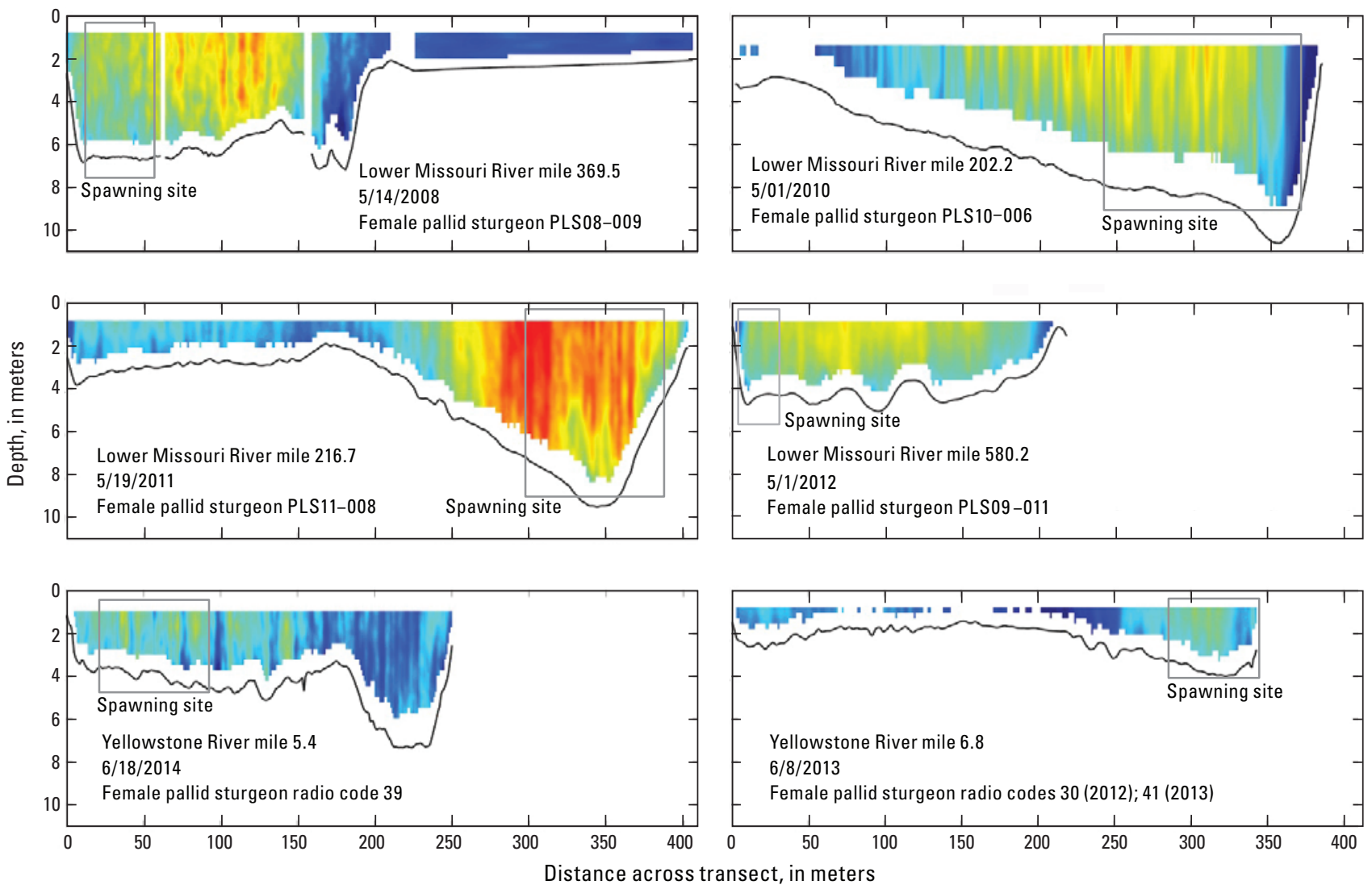

EXPLANATION

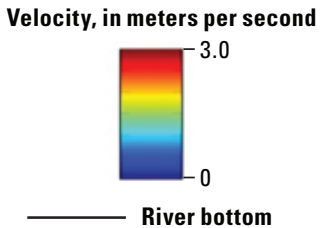

Figure 39. Cross sections showing velocity distributions at known pallid sturgeon spawning sites on the Lower Missouri and Lower Yellowstone Rivers.

LHRHa procedures (U.S. Fish and Wildlife Service, 2005). Between 2008 and 2012 at CERC, 12 female pallid sturgeon were induced to ovulate using LHRHa; only four (33 percent) of these females ovulated successfully (James Candrl, U.S. Geological Survey, written commun., 2014). Studies in 2014 at CERC experimented with alterations in the induction protocol to improve the reliability of induction among sturgeon males and females collected from disparate sources and held under varying conditions.

During late April and May 2014 adult shovelnose sturgeon (13 females and 8 males) were collected from the Missouri River near Hermann and New Haven, Mo., at the confluence with the Big Sioux River near Sioux City, Iowa, and at the confluence with the James River near St. Helena, Nebr. (table 11). Shovelnose sturgeon were transported to CERC on the day of capture and held in circular tanks or ponds until induction. Adult HOPS (10 females and 8 males) also were selected from the captive broodstock population maintained at the CERC. All adult broodstock held at CERC are the progeny of wild-captured adults from the Yellowstone and Upper Missouri Rivers that have been reared in captivity. Sturgeon of both species were maintained either in outdoor ponds or in indoor, temperature-controlled circular tanks until induction.

\section{Females}

Females of pallid sturgeon and shovelnose sturgeon were selected for spawning induction based on ultrasound examination and confirmation of readiness with oocyte biopsies and oocyte PIs (Candrl and others, 2010). Females were induced to ovulate by administering two separate hormone injections. The 

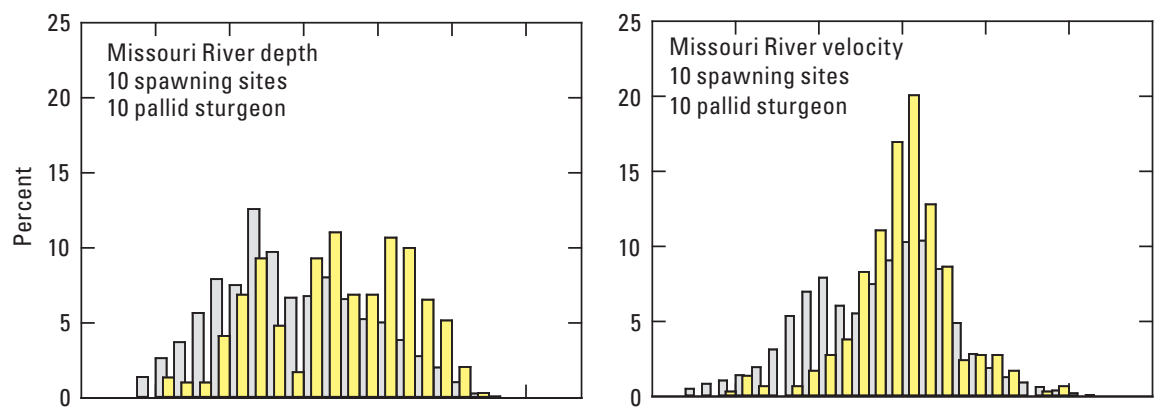

EXPLANATION
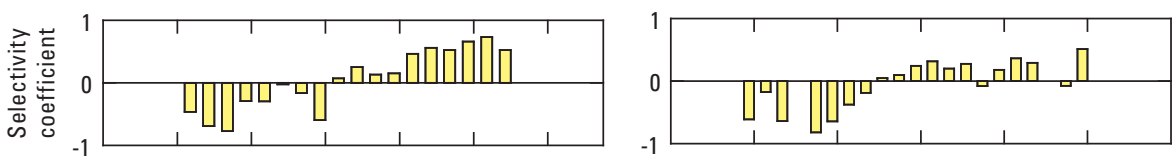

All habitat measurements

in spawning reach
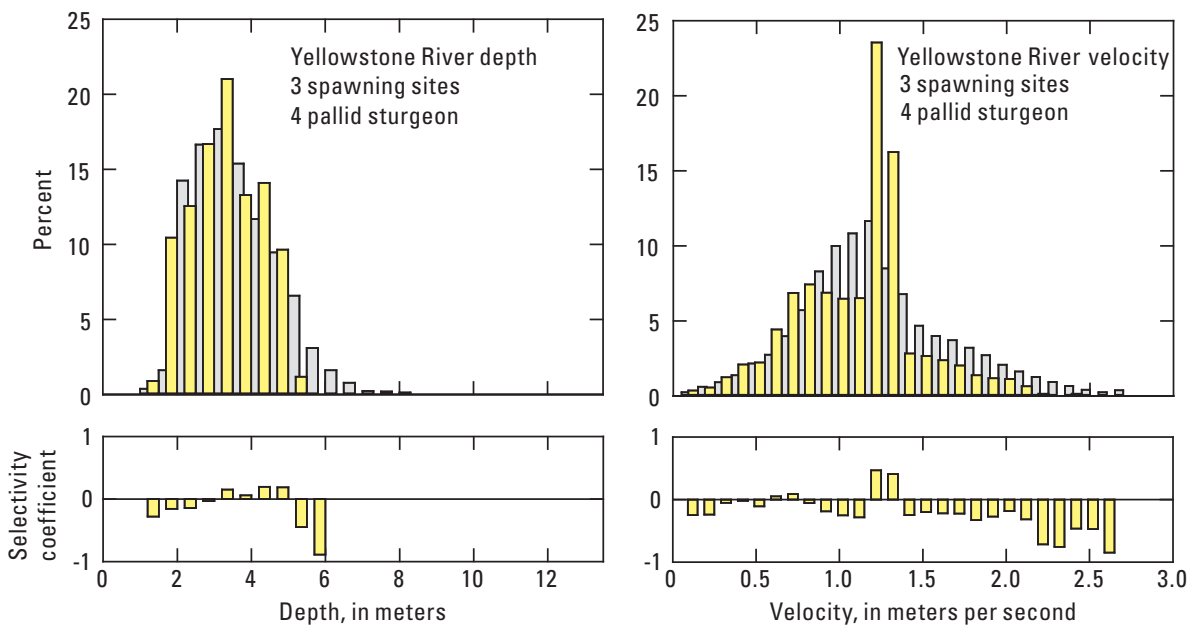

Figure 40. Histograms showing the distributions of available and used depths and velocities at known pallid sturgeon spawning sites on the Lower Missouri and Lower Yellowstone Rivers.

first dose was an intramuscular injection of LHRHa (Syndell Labratories, Vancouver, British Columbia) at a dosage of 50 micrograms per $\mathrm{kg}(\mu \mathrm{g} / \mathrm{kg})$ of body weight. The second injection was an intramuscular injection of white sturgeon pituitary extract (WSPE) at a dose of 2 milligrams per $\mathrm{kg}$ $(\mathrm{mg} / \mathrm{kg})$ body weight given 12 hours after the first injection (Eenennaam and others, 2012). The expected ovulation time was about 14-18 hours after the second injection. Eggs were collected from female pallid sturgeon using one of two methods: minimally invasive surgical technique or caesarean section (Štěch and others, 1999). Eggs were collected from shovelnose sturgeon after the fish was euthanized. Eggs from each female sturgeon were maintained separately throughout the study. The degree of ovulation (the release of oocytes from follicular tissues in the ovarian folds) for females of both species was determined during egg collection. The eggs of pallid sturgeon and shovelnose sturgeon were fertilized in the laboratory for other CSRP studies examining hatch and dispersal.
The fertilization rates for the eggs of each female sturgeon were determined by estimating the percent of eggs fertilized and reaching second cleavage, resulting in four discernable blastomeres at about 5 hours postfertilization (Conte and others, 1988).

Males

Males of pallid sturgeon and shovelnose sturgeon were induced to spermiate by administering one of two hormone injection protocols. The first protocol used was a single intramuscular injection of LHRHa at a dosage of $100 \mu \mathrm{g} / \mathrm{kg}$ of body weight administered about 24 hours before expected milt collection. The second protocol used consisted of two separate intramuscular injections administered at the same time about 24 hours before expected milt collection. One injection was using LHRHa at a dosage of $50 \mu \mathrm{g} / \mathrm{kg}$ of body weight, whereas the second injection was using WSPE at a dosage of $1 \mathrm{mg} / \mathrm{kg}$ body weight (Eenennaam and others, 2012). 


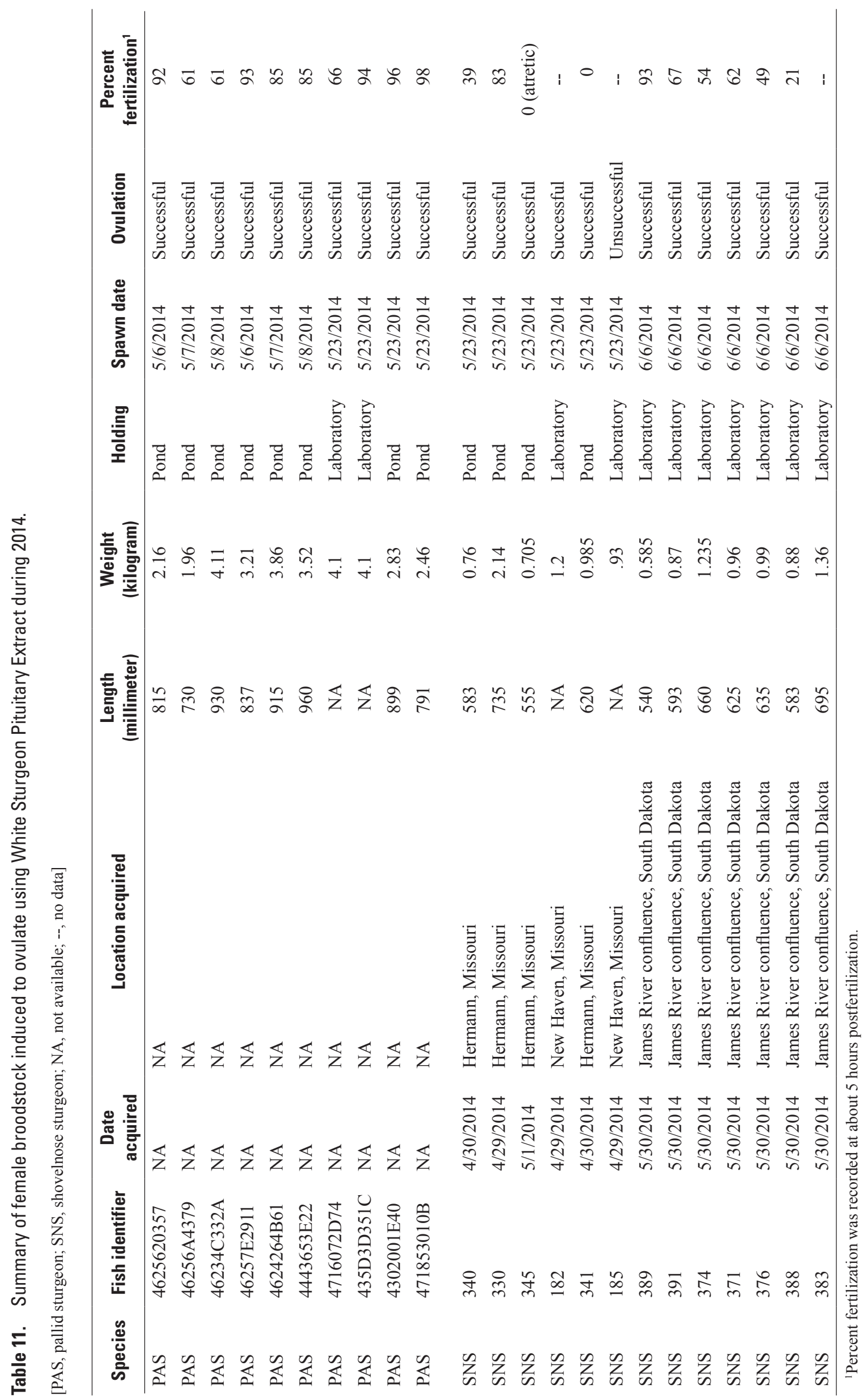


Sturgeon milt must be collected without contacting water because the sperm are water-activated and only have energy reserves for motility of about 2 to 5 minutes after activation. Milt was collected using a flexible piece of polyvinyl chloride (PVC) tubing attached to the end of a 10-milliliter $(\mathrm{mL})$ syringe. The sturgeon was positioned on a stretcher in a water bath, ventral side up. The tubing end was inserted into the urogenital vent of the sturgeon and gentle suction applied. After collection, milt was transferred into a dry $250-\mathrm{mL}$ glass beaker and placed into a cooler with an ice pack. Milt from each male sturgeon was maintained separately throughout the study. Collected milt was promptly evaluated using a milt grading chart developed at the CERC based on appearance, density, percent activation, and forward motility. Once the milt was evaluated, it was either cryopreserved for long-term storage ( $>1$ month), or it was prepared for short-term storage $(<2$ weeks) and subsequent use. Short-term storage of milt consists of mixing the whole milt with an extender solution (Park and Chapman, 2005) at a ratio of three parts extender to one part milt. Extended milt was placed into oxygenated plastic bags, sealed, and refrigerated until ready for use. Only males with good quality milt were used for fertilization.

\section{Elicitation of the Behavioral Spawning Sequence in a Controlled Setting}

Studies begun in 2014 used the wild-caught shovelnose sturgeon and the captive pallid sturgeon population at CERC to study spawning by adult sturgeon. Studies attempted to induce sturgeon to begin and complete the behavioral sequence that results in egg deposition and fertilization (spawning) in manipulated mesocosms. In separate trials, adult pallid sturgeon and shovelnose sturgeon were assessed for reproductive readiness and induced to spermiate and ovulate using the modified LHRHa and WSPE protocol described in the "Improved Methods for Induction of Female and Male Pallid Sturgeon and Shovelnose Sturgeon" section above. Adult sturgeon were released into a 0.125 -acre mesocosm (research pond with maximum depth $2 \mathrm{~m}$ ). Three circulators ( 2 horsepower each) were placed in the mesocosm to create a current (maximum $1.5 \mathrm{~m} / \mathrm{s}$ ). The bottom of the mesocosms was sand, and the sides were lined in rock (10-20 cm in diameter). A patch of 2-5 cm gravel substrate $\left(10 \mathrm{~m}^{2}\right)$ was placed on the bottom of the mesocosm in front of the circulators to attract spawning females. A total of 20 fibrous mats $\left(0.25 \mathrm{~m}^{2}\right)$ were anchored to the bottom to collect adhesive eggs. During the first week of May, three female and three male adult shovelnose sturgeon were induced and released into the mesocosm. The spawning substrate was continuously monitored using a DIDSON camera for $48 \mathrm{~h}$ after induction and release. After the observation period, the mesocosm was drained, and the females were examined for the presence of eggs. The substrate of the mesocosm and anchored egg mats were searched for fertilized eggs. The mesocosm was reset and refilled with water during the second week of May. Two female and three male pallid sturgeon were induced and released into the mesocosm. The spawning substrate was continuously monitored using a DIDSON camera for $48 \mathrm{~h}$ after induction and release of the pallid sturgeon. After the observation period, the mesocosm was drained, and the females were examined for the presence of eggs. The substrate of the mesocosm and anchored egg mats were again searched for fertilized eggs.

\section{Progress}

\section{Improved Methods for Induction of Female and Male Pallid Sturgeon and Shovelnose Sturgeon}

Induction of female pallid sturgeon and shovelnose sturgeon using WSPE protocol was considered successful. Of the 10 female pallid sturgeon induced with the WSPE protocol, all 10 successfully ovulated (table 11). All eight of the males produced viable sperm. The mean fertilization rate of the eggs produced by the 10 female pallid sturgeon recorded at about $5 \mathrm{~h}$ postfertilization was 83 percent and ranged from 61 to 98 percent (table 11). Of the 13 female shovelnose sturgeon with the WSPE protocol, 12 successfully ovulated (92.3 percent), and 1 female failed to ovulate ( 7.7 percent). All eight of the males produced viable sperm. Eggs produced by the shovelnose sturgeon were recorded for 10 of the 12 successfully induced females. The mean fertilization rate for the eggs of the 10 female shovelnose sturgeon was 52 percent and ranged from 0 to 93 percent. Fertilization rates for eggs from two female shovelnose sturgeon (182 and 383) were not measured at $5 \mathrm{~h}$ postfertilization, but estimates for these two females based on back calculations made from observations at later developmental stages estimated fertilization at 16 and 18 percent, respectively. One female (345) successfully ovulated; however, the oocytes had already become atretic before induction and were not viable.

\section{Elicitation of the Behavioral Spawning Sequence in a Controlled Setting}

Two of three female shovelnose sturgeon ovulated completely but did not expel their eggs. The third female only partially ovulated and expelled only a small part of her eggs. Collection of expelled eggs from the mesocosm substrate and egg mats did not result in any viable, fertilized eggs. Necropsy of the females indicated that the oviducts of each of the females were affected with ovulated eggs making expulsion of the eggs after the 48-h observation period unlikely. Preliminary evaluation of the DIDSON footage did not show any behavior immediately identifiable as spawning. In the absence of spawning behavior (physical interactions of males and females) it seems that females may not be able to expel their eggs.

Pallid sturgeon females, likewise, also ovulated, but did not expel their eggs. No eggs were collected from the substrate or egg mats. Examination of DIDSON imagery did not reveal any spawning behavior during the 48-h observation period. 
In both experiments, the availability and quality of males in 2014 were poor. Laboratory studies were of higher priority, and males were induced and used first for laboratory studies before being induced a second time for behavior studies in mesocosms. It is likely that the lack of spawning behavior responses coincident with induction may have been affected by prior induction in males. Future studies should be repeated with naïve adults of both sexes more closely timed with physiological readiness to spawn.

\section{Discussion}

Improved Methods for Induction of Female and Male Pallid Sturgeon and Shovelnose Sturgeon

Pallid and shovelnose sturgeon females showed a strong response to the WSPE induction procedure with 100 and 92.3 percent successful ovulation, respectively. Mean fertilization rates of the 10 female pallid sturgeon was higher (83 percent) than that of the 12 female shovelnose sturgeon (52 percent). The pallid sturgeon were long-term, captive broodstock maintained under controlled conditions at CERC, either indoors or research ponds, before induction of gamete maturation. Shovelnose sturgeon, in contrast, were collected and transported to CERC within 4 weeks before the induction procedure. It is likely that being captured from the Missouri River late in the spawning season and transported to the laboratory was stressful for these fish and may have affected their response to the induction hormone and reduced egg viability. Shovelnose sturgeon are also known to be capable of delaying spawning until the fall, and despite having late-stage oocytes, some females used in this study may not have been cued to spawn in spring 2014. These factors may explain why the female pallid sturgeon seemed to have somewhat higher ovulation and fertilization rates than the shovelnose sturgeon. Regardless of the differences in fertilization rates, induction of females using the modified WSPE protocol resulted in a reliably high rate of ovulation among females from a wide range of sources and holding conditions.

Existing artificial induction protocols used for sturgeon seem to be most effective for adult sturgeon that are captured from the river near the end of their migration within days of spawning or for adult sturgeon that are held in controlled conditions that can be manipulated to optimize final maturation. Conservation propagation and research programs for the pallid sturgeon in the Lower Missouri River are hampered by high rates of failed artificial induction in the hatchery environment (Jake Colehour, Missouri Department of Conservation, written commun., 2014). Broodstock for the Lower Missouri River are commonly captured from the wild and transported to hatchery facilities with markedly different environmental conditions or less than optimal environmental controls. This may disrupt reproductive maturation and reduce the efficacy of artificial induction protocols. Research studies are also limited by the narrow window of reproductive activity for pallid sturgeon that prevents replication. There is a need for more effective induction techniques for reproductive adults for a wide range of conditions and during a longer time period. There is also a need for the distribution and dissemination of cryopreservation techniques to more facilities to extend the reproductive period of adults and ensure the ready availability of male reproductive products when female sturgeon do ovulate. These improvements in artificial induction are necessary to increase the efficacy of the propagation program and productivity of research studies.

\section{Elicitation of the Behavioral Spawning Sequence in a Controlled Setting}

Despite technological advances in telemetry and underwater remote sensing, substantial challenges remain in characterizing conditions that trigger spawning; specific criteria used by sturgeon to select spawning locations; and the dynamics of spawning behavior, egg deposition, and fertilization. Manipulation and observation of spawning sturgeon under controlled laboratory conditions in this study will aid in determining if substrates available for spawning in the river are conducive to egg deposition and survival to hatch. The dynamics of spawning behavior will provide insight into the adaptive mating strategies used by pallid sturgeon, including how males and females interact, the social cues that elicit appropriate spawning behavior, where in the water column spawning happens in relation to the substrate, and mechanisms that may affect the rate of hybridization.

Although field components of the CSRP have been successful in tracking adult sturgeon to their spawning locations for several years, the precise location of egg deposition at spawning sites in the Lower Missouri River are currently (2015) unknown. The exact composition of suitable spawning substrates is similarly elusive. Additional methods and technology are required to more precisely locate and characterize areas selected by pallid sturgeon for egg deposition to appropriately assess the suitability of available habitat and evaluate survival of developing embryos. Further studies of spawning and egg deposition under controlled conditions will improve understanding and aid in the development of technologies to provide more precise characterizations.

\section{Assessments of Factors Affecting Embryo Incubation, Hatch, and First Drift}

Pallid sturgeon are presumably litho-pelagophiles (Frimpong and Angermeier, 2010) and ecologically intermediate r-K strategists (based on Klimley and others, 2006). In part, we know the pallid reproductive strategy is to live and spawn over many years, mature late at a large body size, and produce a large number of gametes on an annual or longer cycle so that spawning is coincident with environmental conditions 
suitable for offspring development. Survival of eggs from deposition through to hatching is naturally variable and low. Population viability analyses for sturgeon suggest that even slight increases in survival rates of the earliest life stages may have pronounced effects on population recruitment and status (Bajer and Wildhaber, 2007; Jager and others, 2010).

\section{Laboratory Assessments of Incubation, Hatch, and Beginning of Drift}

The CERC telemetry studies on female pallid sturgeon in the Lower Missouri River have determined that the behavioral and physiological tactics to complete reproduction include solitary, deliberate upstream migrations in springtime when temperatures begin to rise (DeLonay and others, 2009, 2010). Movements are along inside bends with spawning happening at the upstream apex over or adjacent to coarse substrate when water temperatures are $16-22{ }^{\circ} \mathrm{C}$. Observations of spawning by pallid sturgeon in the Yellowstone River indicate the selection of similar but not identical habitats (DeLonay and others, 2012). It is not clear from previous studies what the specific substrate and hydraulic conditions are at the site of egg deposition, how specific sturgeon are in their selection criteria, and how the conditions selected may affect survival through hatch (DeLonay and others, 2010, 2012, 2014). Because the depths and velocities where spawning happens on the Lower Missouri River make studies in the river difficult, preliminary studies for this life stage are being completed in the laboratory. This

Table 12. Mean particle size and interstitial volume for materials used within substrate patches of the experimental stream.

$[<$, less than $]$

\begin{tabular}{lcc}
\hline Material & $\begin{array}{c}\text { Mean particle size } \\
\text { (millimeter) }\end{array}$ & $\begin{array}{c}\text { Percent } \\
\text { interstitial volume }\end{array}$ \\
\hline Sand & $<2.4$ & -- \\
Gravel & 28.1 & 43.9 \\
Cobble & 67.8 & 47.7 \\
\hline
\end{tabular}

task addresses laboratory studies intended to elucidate how abiotic and biotic factors affect the earliest life stages of pallid sturgeon, better characterize developmental stages, and inform advection and dispersion models for dispersing free embryos.

\section{Methods}

\section{Hatch and Initial Drift (in an Artificial Stream)}

This study took place within two 1-m wide concrete artificial streams at the CERC. Each stream was partitioned into three 10-m long experimental sections and lined with 45 mil rubber liners (Pondliner.com, Shawnee, Oklahoma). The downstream end of the liner within each section was attached to a $20-\mathrm{cm}$ diameter PVC pipe fitted with 750-micron ichthyoplankton nets, which fished continuously throughout the experiment (Aquatic Research Instruments, Hope, Idaho). At the upstream end of each section, we constructed a 4.9-m long by $10-\mathrm{cm}$ deep substrate patch with a randomly assigned material size. Substrate treatments consisted of either sand, gravel, or cobble (table 12; Capital Sand Company, Jefferson City, Mo.) with two replicates of each material (fig. 41).

Each stream was covered with a polyethylene tarp supported by a steel A-frame to control experimental conditions, buffer water temperature, and minimize light intensity. In addition, 90-percent shade cloth (The Natural Home Building Source, Silverthorne, Colorado) was stretched over the study area. Water temperature and DO were recorded every 15 min throughout the experiment using a HOBO DO logger (Onset Computer Corporation, Bourne, Massachusetts). Water samples were collected daily to measure conductivity, $\mathrm{pH}$, alkalinity, and hardness. Water depth and velocity were measured at three equidistant points over each substrate patch using a Marsh-McBirney Flo-Mate 2000 (Marsh-McBirney Inc., Frederick, Maryland) and a Rickly top-setting wading rod (Rickly Hydrological Company, Columbus, Ohio). Radiant light intensity was measured at 10 equidistant points across the length of each section using a Macam UV203 radiometer (Macam Photometrics Ltd., Livingston, Scotland).

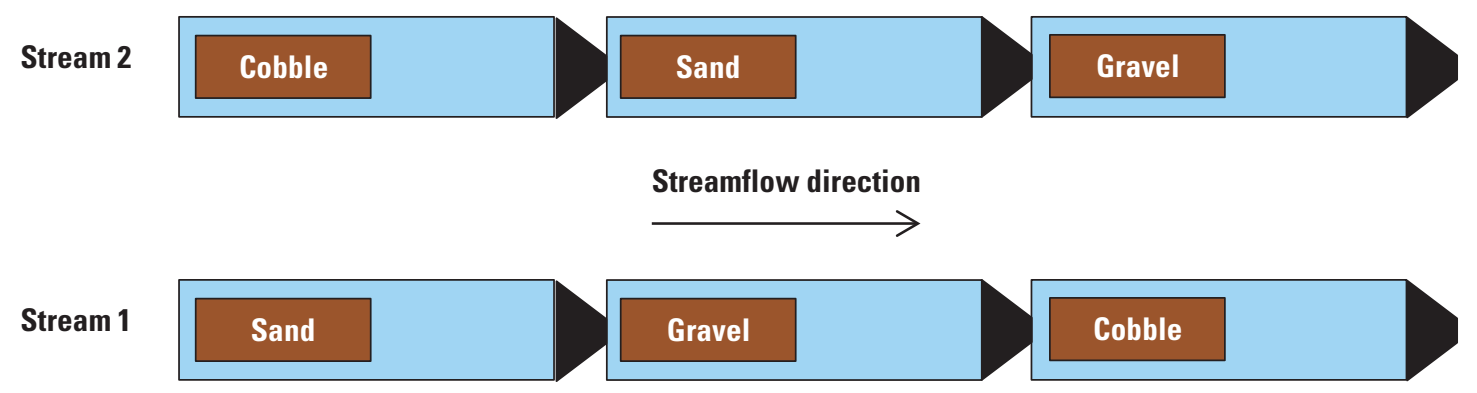

Figure 41. Diagram of experimental streams showing the orientation of substrate treatments. 
Trial 1.-Starting on May 5, 2014, one of three females and three male pallid sturgeon from the HOPS population maintained at CERC were induced to ovulate (female) and spermiate (males) as described in the previous task. Milt was extracted from males as it became available and maintained as necessary (see the "Laboratory Assessments of Abiotic and Biotic Aspects of Spawning and Egg Deposition" section). The remaining two females were induced to ovulate on sequential dates, resulting in one female that ovulated on May 6 and one on May 8. A total of $10 \mathrm{~g}$ of eggs were then mixed with a milt:water solution containing equal parts from each of the three male pallid sturgeon ( $1 \mathrm{~mL}$ milt:100 g eggs) and diluted with water $(1,000 \mathrm{~mL}$ water: $1 \mathrm{~mL}$ milt). The mixture was then stirred for $3 \mathrm{~min}$. The eggs were seeded onto a $60 \times 60 \mathrm{~cm}$ stainless steel wire cloth with $2-\mathrm{mm}$ mesh and were placed in a water bath. Additional lots of embryos were collected and maintained in the laboratory to quantify rates of fertilization and survival. This was repeated for a total of six cloths per female and one cloth per experimental stream section. Cloths remained in the water bath and were monitored for survival, removing nonviable embryos, until 4 days postfertilization. On May 10, it was determined that only embryos originating from the female spawned May 6 attained fertilization and survival rates sufficient to use in the experiments and were acclimated to experimental stream conditions. The viable eggs on each wire cloth were enumerated, and wire cloths were randomly placed within a section at the upstream margin of the constructed substrate patch.

Trial 2.-On May 22, 2014, four female and two male pallid sturgeon were induced using the methods described in the "Laboratory Assessments of Abiotic and Biotic Aspects of Spawning and Egg Deposition" section. Eggs were extracted from all females on May 23 from 9:30 a.m. to 2 p.m. using one of two methods: minimally invasive surgical technique or caesarean section (Štěch and others, 1999). All extracted eggs from each female were mixed with a milt:water solution containing equal parts from each male pallid sturgeon $(1 \mathrm{~mL}$ milt:100 g eggs) and diluted with water $(1000 \mathrm{~mL}$ water: $1 \mathrm{~mL}$ milt). This mixture was stirred for $3 \mathrm{~min}$, combined with fuller's earth, and stirred for an additional $20 \mathrm{~min}$. Eggs from all four females $(1,261 \mathrm{~g})$ were then placed in separate McDonald-type jars until about 4 days postfertilization. Watersource temperature was monitored using a combination of TidbiT v2 Water Temperature and HOBO Water Temperature Pro v2 data loggers (Onset Computer Corporation, Bourne, Massachusetts). On May 27, eggs were examined microscopically to determine viability, and 700 viable eggs from three females were acclimated to experimental stream conditions and randomly assigned to a section. Eggs were spread evenly across two $30 \times 60 \mathrm{~cm}$ open-top trays with a $2-\mathrm{mm}$ stainless steel mesh bottom and filled with the appropriate substrate from the respective section.

Trial 3.- On June 5, seven female and three male shovelnose sturgeon were artificially induced using the methods described in the "Laboratory Assessments of Abiotic and Biotic Aspects of Spawning and Egg Deposition” section.
On June 6, all females ovulated, upon which time they were euthanized and eggs were collected from 9:30 a.m. to 5 p.m. Eggs were fertilized and maintained similar to the eggs fertilized on May 23, except milt from the three males was mixed at a 2:1:1 volume ratio to adjust for differences in sperm motility - one male with lower motility was added at twice the volume of two males with greater motility. On June 10, eggs were examined microscopically to determine viability, and 350 eggs from six females were acclimated to experimental stream conditions and randomly assigned to a section. Again, eggs were spread evenly across two $30 \times 60 \mathrm{~cm}$ open-top trays with a $2-\mathrm{mm}$ stainless steel mesh bottom and filled with the appropriate substrate from the respective section.

For each experimental trial, samples were collected from the ichthyoplankton nets at the downstream end of each section at 2-h intervals after placement. Collected larvae were counted and preserved in 10-percent neutral buffered formalin (NBF). In the lab, preserved larvae were measured for TL and examined for developmental characteristics to estimate age. In addition, we collected water temperature and both percent and milligrams per liter of DO using a YSI 556 (YSI Incorporated, Yellow Springs, Ohio) at each 2-h interval. Collections were stopped once larval collections remained at zero for 2 days and most viable larvae had been collected. At the conclusion of each experiment, the egg source (wire cloth or open-top tray) was removed, and remaining eggs and larvae were counted. In addition, each experimental section was thoroughly cleaned, flushed, and drained to remove any remaining eggs and larvae within the system. Flushed eggs and larvae were captured in the ichthyoplankton nets and enumerated.

\section{Developmental Series}

To better document and characterize ontogenetic development of sturgeon from the experiments in the artificial stream environment and specimens collected in the field (see "FieldBased Biotic Assessments of Factors Affecting Migration and Spawning" sections), a minimum of three free embryos was collected at regularly-spaced intervals from each sturgeon family lot from trials 2 and 3 (sturgeon spawned on May 23 and June 6 , respectively) reared in the laboratory. Fertilized eggs and developing embryos were maintained in separate family lots throughout the study; fertilized eggs were maintained in McDonald-type hatching jars. Shortly after hatching (on the day of hatching), embryos were transferred to acrylic baskets fitted with 250-micron nylon screens to allow for water flow and retain hatched embryos. Water was continuously delivered to the baskets through a series of tubes. After most developing embryos in each family lot had expelled the yolk plug, the embryos were transferred to stainless steel bowls, each fitted with a water delivery and aeration tube on day 20 and 14 for embryos from trial 2 and 3, respectively.

Collected specimens were preserved in 10-percent NBF. Beginning on the day of hatch, free embryos were collected and preserved at a 2-h interval, which yielded 12 collection intervals per day. Successive developmental stages required 
greater amounts of developmental time; therefore, the frequency of specimen collection was assessed and adjusted to adequately capture transitions between developmental stages without oversampling. Collection of specimens was reduced to every $4 \mathrm{~h}$ (six collection intervals per day) on day 5 for trials 1 and 2 of the hatch and initial drift experiments. The sampling interval was reduced to $12 \mathrm{~h}$ ( 2 collection intervals per day) on day 16 after all family lots had exceeded 50-percent yolk plug expulsion. Sampling was reduced to one collection of a minimum of three specimens at an interval of once daily on day 30 . Once the yolk plug expulsion was estimated as greater than 50 percent of randomly sampled individuals from each family lot, fish were fed either frozen or live brine shrimp at alternating feedings to excess at a minimum of twice daily. Collections for the developmental series continued until fish were no longer available from the family lots.

\section{Passive Settling Rate}

To provide parameters for advection and dispersion models, methods were developed to estimate the passive settling rates of sturgeon eggs and endogenously feeding free embryos because these parameter estimates are needed to parameterize advection and dispersion models. Each of 25 unfertilized eggs from 4 pallid and 9 shovelnose sturgeon females (trials 2 and 3 described in the previous "Hatch and Initial Drift (in an Artificial Stream)" section) was measured at 2 perpendicular axes using a Nikon SMZ1500 (Nikon Instruments Inc., Melville, New York) at 10x magnification with NIS Elements software. The passive settling rate of the unfertilized sturgeon eggs was measured by releasing a single unfertilized egg into an experimental column and measuring the time required to sink a known distance. The experimental column was constructed of glass and was approximately $122 \mathrm{~cm}$ tall and $5.5 \mathrm{~cm}$ in diameter and filled to approximately $121-\mathrm{cm}$ height with deionized (DI) water. The experimental column was marked with a $20-\mathrm{cm}$ acceleration zone to allow the egg to reach terminal velocity, and a $40-\mathrm{cm}$ measurement zone. Water temperature in the experimental column was measured at 5-min intervals using a HOBO Water Temperature Pro v2 Data Logger (Onset Computer Corporation, Bourne, Massachusetts) deployed at the bottom of the experimental column well below the $40-\mathrm{cm}$ measurement zone. Each egg was placed just below the water surface in the middle of the column. Sinking rate was measured by timing the descent of the egg through the $40-\mathrm{cm}$ measurement zone. A stopwatch was started when the egg crossed the top mark of the measurement zone and stopped when it crossed the bottom mark of the measurement zone.

Similar to the previously described (in the preceding paragraph), the passive settling rate of a minimum of 20 endogenously feeding free embryos from 5 shovelnose sturgeon family lots was measured by releasing anesthetized free embryos in the center of an experimental column and measuring the time required for the free embryos to sink to a known distance. Free embryos were anesthetized with tricaine methanesulfonate. Standard length of each free embryo was measured with a Nikon SMZ1500 (Nikon Instruments Inc., Melville, New York) at 10x magnification with NIS Elements software before being released into the experimental column. The experimental column was constructed of plexiglass and was approximately $91 \mathrm{~cm}$ tall and $29 \mathrm{~cm}$ in diameter and was filled to a height of approximately $90 \mathrm{~cm}$ with DI water. The experimental column was marked with a $20-\mathrm{cm}$ acceleration zone to allow the free embryo to reach terminal velocity and a 40-cm measurement zone. Water temperature was measured at 5-min intervals using a HOBO Water Temperature Pro v2 Data Logger deployed at the bottom of the drop tube. Each free embryo was placed just below the water surface in the middle of the experimental column, and the passive settling rate was measured by timing the descent of the free embryo through the $40-\mathrm{cm}$ measurement zone. Length and passive settling rate for 20 randomly selected free embryos from each of the 5 shovelnose sturgeon family lots were recorded daily beginning on the day of hatch until yolk plug expulsion of most individuals in the family lot (12-14 days post-hatch [dph]).

\section{Progress}

\section{Hatch and Initial Drift (in an Artificial Stream)}

Throughout all three experiments within the artificial streams, water temperature averaged 17.36 plus or minus $( \pm)$ $0.1{ }^{\circ} \mathrm{C}$ (ranged from 16.04 to $19.30^{\circ} \mathrm{C}$ ), and DO averaged $9.19 \pm 0.00$ milligrams per liter $(\mathrm{mg} / \mathrm{L})$ (ranged from 8.17 to $9.74 \mathrm{mg} / \mathrm{L}$; table 13 ). Water depth and velocity averaged $15.6 \pm 0.46 \mathrm{~cm}$ and $0.07 \pm 0.004 \mathrm{~m} / \mathrm{s}$, respectively, among experimental sections in all experiments. Radiant light intensity was $0.60 \pm 0.208$ milliwatt per meter throughout the experiments.

From the first experiment using pallid sturgeon eggs fertilized on May 6 (table 14), embryos were collected in ichthyoplankton nets among treatments from 116 to $164 \mathrm{~h}$ postfertilization; the largest number of embryos was collected at $128 \mathrm{~h}$ postfertilization (fig. 42). No substantial difference was observed in the timing of embryo collection or drift; however, embryos have not been aged and, thus, may contain as much as $48 \mathrm{~h}$ of variation in drift timing based on age. At a finer scale, embryos appeared in the collection from sections with sand substrate $4-8 \mathrm{~h}$ earlier than gravel and cobble treatments. A total of 966 pallid sturgeon embryos, of the original 4,056 viable eggs contained on the wire cloths, was collected in ichthyoplankton nets (table 14) with no viable embryos contained in the experimental sections (that is, within the substrate) at the conclusion of the experiment. Embryo recovery and (or) survival was low (966 embryos or 24 percent) and highly variable among treatments (ranged from 9.4 to 52.8 percent) largely because of variability in the number of viable fertilized embryos remaining on the wire cloths at 4 days postfertilization (beginning of artificial stream experiment); furthermore, although most, if not all, unviable eggs were removed from the wire cloths before placing them into artificial streams, a large number of eggs died, decayed, and 
Table 13. Mean and standard error of measured water-quality properties for experiments within outdoor artificial streams in May and June 2014.

[Numbers in parentheses represent the standard error]

\begin{tabular}{lcccccc}
\hline Experiment & $\begin{array}{c}\text { Water temperature } \\
\text { (degree Celsius) }\end{array}$ & $\begin{array}{c}\text { Dissolved oxygen } \\
\text { (milligram } \\
\text { per liter) }\end{array}$ & $\begin{array}{c}\text { Conductivity } \\
\text { (microsiemen per } \\
\text { centimeter at } \\
\text { 25 degrees Celsius) }\end{array}$ & $\begin{array}{c}\text { pH } \\
\text { (standard unit) }\end{array}$ & $\begin{array}{c}\text { Alkalinity } \\
\text { (milligram } \\
\text { per liter) }\end{array}$ & $\begin{array}{c}\text { Hardness } \\
\text { (milligram } \\
\text { per liter) }\end{array}$ \\
\hline May 6 & $17.48(0.03)$ & $9.24(0.01)$ & $663.7(2.5)$ & $8.13(0.01)$ & $250.5(3.0)$ & $293.3(2.3)$ \\
May 23 & $17.47(0.01)$ & $9.17(0.00)$ & $675.0(1.4)$ & $8.04(0.01)$ & $247.1(2.8)$ & $293.8(2.8)$ \\
June 6 & $17.08(0.01)$ & $9.13(0.00)$ & $679.7(1.4)$ & $8.05(0.01)$ & $250.8(2.4)$ & $299.7(2.5)$ \\
\hline
\end{tabular}

Table 14. Number of fertilized pallid sturgeon eggs used and the number of embryos collected from ichthyoplankton nets for each treatment using eggs fertilized on May 6, 2014.

\begin{tabular}{lccc}
\hline \multicolumn{1}{c}{ Treatment } & $\begin{array}{c}\text { Number of } \\
\text { fertilized eggs }\end{array}$ & $\begin{array}{c}\text { Number of } \\
\text { embryos collected }\end{array}$ & $\begin{array}{c}\text { Recovery rate } \\
\text { (percent) }\end{array}$ \\
\hline 1-Sand & 732 & 69 & 9.4 \\
2-Sand & 686 & 362 & 52.8 \\
1-Gravel & 786 & 106 & 13.5 \\
2-Gravel & 444 & 233 & 52.5 \\
1-Cobble & 713 & 91 & 12.8 \\
2-Cobble & 695 & 105 & 15.1 \\
\hline
\end{tabular}

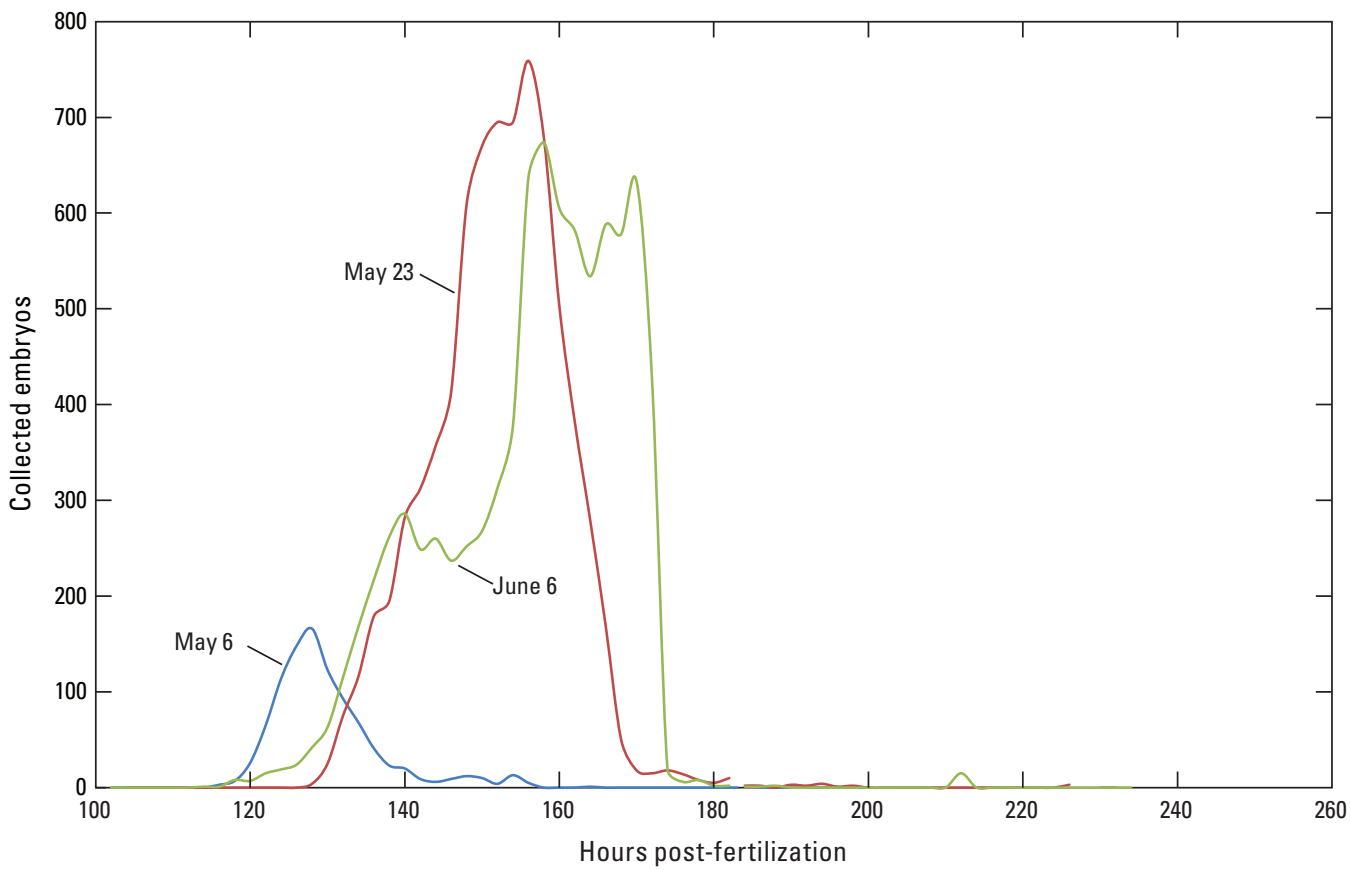

Figure 42. Number of pallid sturgeon (May 6 and May 23) and shovelnose sturgeon (June 6) embryos collected per hour postfertilization for each experiment within outdoor artificial streams in 2014. 
remained on the wire cloths at the conclusion of the experiment. Alternatively, laboratory controls for pallid sturgeon embryos fertilized on May 6 achieved 91.011.0-percent fertilization and 77 \pm 4.7-percent survival in McDonald-type jars at $18.1 \pm .01{ }^{\circ} \mathrm{C}$ (table 15$)$. Wire cloths were not used in subsequent experiments because of poor recovery and (or) survival of embryos.

Pallid sturgeon embryos from eggs fertilized on May 23 were collected in ichthyoplankton nets from 128 to $226 \mathrm{~h}$ postfertilization among treatments; the largest number of embryos was collected at $156 \mathrm{~h}$ postfertilization (fig. 42). Of the original 12,600 viable eggs ( 2,100 per section; table 16$)$, a total of 7,555 pallid sturgeon embryos was collected in ichthyoplankton nets. No viable embryos were collected from the substrate at the conclusion of the experiment; however, a total of 2,896 embryos (454 eggs and 2,442 free embryos) remained in the open-top trays at the head of the experimental section. Overall, these methods substantially improved total embryo recovery and (or) survival in all streams and substrates combined (82.9 percent) and reduced variability among treatments (ranged from 75.2 to 94.2 percent). Laboratory controls for pallid sturgeon embryos fertilized May 23 achieved 93.2 \pm 1.1 -percent fertilization and 91.9 \pm 1.4 -percent survival in

Table 15. Mean and standard error of fertilization and survival rates for control pallid sturgeon (May 6 and May 23) and shovelnose sturgeon (June 6) embryos from each experiment spawned in 2014.

[Numbers in parentheses represent the standard error]

\begin{tabular}{lccc}
\hline Experiment & $\begin{array}{c}\text { Fertilization } \\
\text { (percent) }\end{array}$ & $\begin{array}{c}\text { Survival } \\
\text { (percent) }\end{array}$ & $\begin{array}{c}\text { Water temperature } \\
\text { (degrees Celsius) }\end{array}$ \\
\hline May 6 & $91.0(1.0)$ & $77.0(4.7)$ & $18.1(0.1)$ \\
May 23 & $93.2(1.1)$ & $91.9(1.4)$ & $17.5(0.1)$ \\
June 6 & $59.3(9.2)$ & $90.6(3.0)$ & $17.7(0.1)$ \\
\hline
\end{tabular}

McDonald-type jars at $17.5 \pm .01{ }^{\circ} \mathrm{C}$ (table 15). Embryos in the section with sand substrate had greater recovery and survival, fewer embryos remaining in the open-top containers, and appeared in collections $2-4 \mathrm{~h}$ sooner compared to gravel and cobble treatments. Again, embryos have not been aged and, thus, may contain as much as $98 \mathrm{~h}$ of variation in drift timing based on age.

Shovelnose sturgeon embryos from eggs fertilized June 6 were collected in ichthyoplankton nets, among treatments, from 114 to $212 \mathrm{~h}$ postfertilization; the largest number of embryos was collected at $158 \mathrm{~h}$ postfertilization (fig. 42). Of the original 12,600 viable shovelnose sturgeon eggs $(2,100$ per section), 8,498 embryos were collected in ichthyoplankton nets (table 16). Again, no viable embryos were collected from the substrate at the conclusion of the experiment; however, a total of 3,298 embryos (1,522 eggs and 1,776 free embryos) remained in the open-top trays at the head of the experimental section. Again, we improved embryo recovery and survival (average 93.6 percent; ranged from 88.8 to 97.4 percent). Alternatively, laboratory controls for shovelnose sturgeon embryos fertilized June 6 achieved 59.3 \pm 9 .2-percent fertilization and 90.6 \pm 3.0 -percent survival in McDonald-type jars at $17.7 \pm .01{ }^{\circ} \mathrm{C}$ (table 15). Similar to pallid sturgeon embryos, shovelnose sturgeon embryos in sections with sand substrate had fewer embryos remaining in the open-top containers and appeared in collections 6-10 h sooner compared to gravel and cobble treatments. Conversely, sand and cobble treatments had similar rates of recovery and survival of shovelnose sturgeon embryos. Embryos have not been aged and, thus, may contain as much as $98 \mathrm{~h}$ of variation in drift timing based on age.

\section{Developmental Series}

During the rearing of sturgeon (from trials 2 and 3) for the developmental series, mean daily water temperature ranged from 17.6 to $19.9^{\circ} \mathrm{C}$ and 17.4 to $19.8^{\circ} \mathrm{C}$, respectively. A minimum of three specimens per sampling interval was collected from four pallid sturgeon family lots from trial 2 for a minimum of $30 \mathrm{dph}$ and a maximum of $51 \mathrm{dph}$. Shovelnose

Table 16. Total number of pallid sturgeon (May 23) and shovelnose sturgeon (June 6) embryos recovered (of the 2,100 fertilized eggs), percent recovered in ichthyoplankton nets, and percent recovered from the source (open-top containers) for each experiment by treatment in 2014.

\begin{tabular}{|c|c|c|c|c|c|c|}
\hline \multirow[b]{2}{*}{ Treatment } & \multicolumn{3}{|c|}{ May 23} & \multicolumn{3}{|c|}{ June 6} \\
\hline & $\begin{array}{c}\text { Total } \\
\text { recovered }\end{array}$ & $\begin{array}{c}\text { Percent from } \\
\text { ichthyoplankton nets }\end{array}$ & $\begin{array}{l}\text { Percent from } \\
\text { source }\end{array}$ & $\begin{array}{c}\text { Total } \\
\text { recovered }\end{array}$ & $\begin{array}{c}\text { Percent from } \\
\text { ichthyoplankton nets }\end{array}$ & $\begin{array}{l}\text { Percent from } \\
\text { source }\end{array}$ \\
\hline 1-Sand & 1,918 & 76.9 & 23.1 & 1,968 & 82.7 & 17.3 \\
\hline 2-Sand & 1,979 & 93.3 & 6.7 & 2,046 & 83.7 & 16.3 \\
\hline 1-Gravel & 1,746 & 58.8 & 41.2 & 1,865 & 60.2 & 39.8 \\
\hline 2-Gravel & 1,579 & 54.1 & 45.9 & 1,891 & 70.8 & 29.2 \\
\hline 1-Cobble & 1,643 & 68.4 & 31.6 & 1,987 & 71.1 & 28.9 \\
\hline 2-Cobble & 1,586 & 77.5 & 22.5 & 2,039 & 63.0 & 37.0 \\
\hline
\end{tabular}


sturgeon specimens were collected from seven family lots from trials 2 and 3 for a minimum of $7 \mathrm{dph}$ and a maximum of $56 \mathrm{dph}$. More than 1,800 samples were collected during the developmental study. Microscopic examination of preserved specimens began during fall 2014 and has not been completed at the time of this report.

\section{Passive Settling Rate}

Water temperature in the experimental column was maintained between $22.5^{\circ} \mathrm{C}$ and $22.3^{\circ} \mathrm{C}$ during trials. During the development of methods to measure the passive settling rate of sturgeon eggs, the passive settling rate of a minimum of 25 unfertilized eggs from each of 4 pallid sturgeon and 9 shovelnose sturgeon were recorded. During the development of methods to measure the passive settling rate of sturgeon free embryos, the passive settling rate of a minimum of 20 endogenously feeding free embryos from each of 5 shovelnose sturgeon family lots were recorded daily for a minimum of $12 \mathrm{dph}$. Analyses of data collected during the development of passive settling rate estimation methods of pallid sturgeon and shovelnose sturgeon eggs and shovelnose sturgeon free embryos are pending.

\section{Discussion}

Pallid and shovelnose sturgeon embryos exhibited similar drift characteristics under similar conditions in artificial streams. Both appeared in ichthyoplankton net collection as early as $114-116 \mathrm{~h}$ postfertilization and were present in collections for about $98 \mathrm{~h}$, with the exception of embryos fertilized on May 6 (trial 1), which only appeared in collections for $48 \mathrm{~h}$. We believe the drift duration of embryos fertilized on May 6 was shortened because of mortality. Embryos from both species were collected earlier and at relatively greater numbers in sand treatments compared to gravel and cobble. Given the relatively small difference in collection times among substrate treatment, we suspect the difference is attributable to channel roughness among substrates with sand having the lowest roughness coefficient; thus, a passive particle would more readily traverse sand substrate. Disparity in the age of collected embryos, however, could lead to different conclusions. The presence of embryos in the open-top trays at the conclusion of experiments may indicate selection because open-top trays did contain substrate; however, given that no viable embryos were found in the substrate patch at the conclusion of the experiment, it is probable that the open-top trays were to some extent a barrier to dispersal.

\section{Assessments of Factors Affecting Free- Embryo Drift Survival}

Very few genetically confirmed larval and young-ofyear pallid sturgeon have been collected from the Missouri River; however, CSRP studies did collect pallid $\times$ shovelnose sturgeon hybrid free embryos during 2013. The low numbers of young-of-year pallid sturgeon in Missouri River samples may be explained by limited spawning, hybridization, lack of successful spawning, poor fertilization, high mortality, ineffective sampling methods, inadequate sampling of drift and settling locations, or rapid dispersal and washout of sturgeon free embryos and larvae from the Missouri River into the Mississippi River. Documentation of spawning by pallid sturgeon is a critical first step towards assessing population status and recovery; however, successful spawning does not ensure successful recruitment to the juvenile or adult life stages. Many sturgeons have evolved a downstream dispersal strategy, which transports early life stages from the spawning and hatch locations to downstream rearing areas (Kynard and others, 2007); however, little is known about the dispersal, behavior, and survival of pallid and shovelnose sturgeon early life stages. Biotic and abiotic factors operating during the free-embryo life stage (hatch to endogenous feeding) may limit survival and population growth (Dettlaff and others, 1993). Because of decreased mobility and sensory ability, and increased vulnerability to anthropogenic environmental alteration, this life stage commonly functions as a recruitment bottleneck for fishes (Scheidegger and Bain, 1995; Humphries and others, 2002). This task combines field-based habitat and biotic studies with controlled laboratory studies to determine how abiotic and biotic factors affect the transport, behavior, and fate of endogenously feeding (yolk-sac) free embryos. The field-based studies were designed to develop and refine hydrodynamic models to simulate dispersion and advection of drifting free embryos; and characterize the timing, distribution, and genetics of Acipenseriformes collected in the Lower Missouri River where drift distances are expected to be long enough for completion of ontogenetic development to settling. The laboratory studies were designed to develop an understanding of Scaphirhynchus sturgeon behavior from hatch through first feeding to better guide future research of dispersal dynamics of sturgeon.

\section{Field-Based Biotic Assessments of Embryo and Larval Dispersal, Distribution, and Habitat Use}

Acipenseriformes, specifically pallid sturgeon, shovelnose sturgeon, and paddlefish, are long lived, reach sexual maturity late (5-15 years), and do not reproduce annually (Billard and Lecointre, 2001). These species each have adhesive eggs inferred to be deposited in the current over coarse substrate and a protracted free-embryo life stage that drifts for several days after hatching. Although the species may differ, the comparative examination of the early life stages of the three species may provide insights into factors controlling year-class strength, patterns of abundance, or rarity. The distance that sturgeon and paddlefish free embryos drift during ontogenetic development is dependent on water velocity, localized hydraulic conditions, and temperature (Kynard and others, 2007; Braaten and others, 2008). Free embryos may require a 
long section of free-flowing river to complete the ontogenetic drift and dispersal cycle in the Missouri River if localized hydraulics do not result in retention of free embryos in channel margins. The probability of retention in channel margins, rather than direct downstream transport in the thalweg, is an unknown but critical factor in determining total drift distance. The number of sturgeon free embryos and larvae produced in the Lower Missouri River, the proportion retained, and the proportion contributed from primary tributaries is unknown. Locations along the channel where drifting free embryos are retained or larvae settle, and the availability of suitable habitat for early feeding, may be critical for survival and recruitment.

The broad objectives of this study were to (1) detect and verify successful spawning, fertilization, hatch, and drift of pallid sturgeon in the Lower Missouri and Platte Rivers; (2) determine the timing and spatial extent of Acipenseriformes spawning in the Lower Missouri and Platte Rivers; (3) assess the species composition of Acipenseriformes embryos in the Lower Missouri and Platte Rivers; and (4) assess the probability of drifting sturgeon to be entrained in shallow-water habitats based on the cross-sectional channel distribution and developmental stage of sturgeon collected.

\section{Methods}

Methods used in 2014 closely follow those developed and used by the CSRP during previous years (DeLonay and others, 2016a). To assess recruitment and drift dynamics of sturgeon in the Lower Missouri River and the contribution of primary tributaries, we systematically sampled for Acipenseriformes free embryos at two sites in Nebraska (fig. 43). One site was in the main stem Lower Missouri River upstream from the confluence with the Platte River near RM 599.5. The second site was in the Platte River less than 1 mile upstream from the confluence with the Lower Missouri River. At the Lower Missouri River site, we established a transect of four equidistant sampling stations (stations 10,11, 12, and 13) to assess crosssectional distribution of drifting free embryos (fig. 43). Three sampling stations (numbers 14, 15, and 16) were established in the Platte River. Sites were intended to be systematically sampled for free-drifting embryos 3 days per week from April 15 through July. Field crews were still collecting sturgeon free embryos at the end of July; therefore, sampling efforts were extended through the month of August.

As during previous years, stations were sampled with paired $0.5-\mathrm{m}$ diameter conical ichthyoplankton nets (750-micron mesh) equipped with General Oceanics velocity meters and attached to 100 -pound $(45.4 \mathrm{~kg}$ ) Columbusstyle sounding weights. Sampling nets were deployed from an anchored 8-m research vessel outfitted with paired booms and winches (port and starboard). Samples were collected at two depths at each station: just above the river bottom and at midwater column unless water depth was less than $2 \mathrm{~m}$. We assumed there was a negligible difference between bottom and midcolumn samples at water depths less than $2 \mathrm{~m}$. Sample duration was intended to be 10 min but varied depending on the suspended load of coarse organic material and debris during the sampling effort. Paired samples were collected in replicate at each sampled station and depth. Ichthyoplankton samples were sorted on board the research vessel shortly after collection. All Acipenseriformes free embryos identified as either sturgeon (Scaphirhynchus spp.) or paddlefish (Polyodon spathula) were preserved in 70-percent ethanol for identification to genus in the laboratory. All specimens identified as potential sturgeon free embryos were prepared and sent for species determination by genetic analysis at SIU. For the purpose of summary and analysis contained in this report, the paired port and starboard samples were pooled for each depth.

\section{Progress}

Field crews sampled for Acipenseriformes free embryos at two sites: one in the Lower Missouri River and one in the Platte River during a total of 52 and 55 sampling days, respectively, from April 15 through August 28, 2014 (table 17). Discharge ranged from 29,600 to $97,200 \mathrm{ft}^{3} / \mathrm{s}$ in the Lower Missouri River (06610000 Missouri River at Omaha, Nebr.) and 1,890 to $54,200 \mathrm{ft}^{3} / \mathrm{s}$ in the Platte River (06805500 Platte River at Louisville, Nebr.). In the interest of safety, samples were not collected at the Lower Missouri River stations on June 4, 17, and 18; and July 2 because of high discharges and heavy debris loads. Samples were not collected on August 14 in the Platte River because of low discharge.

A total of 433 sturgeon free embryos and larvae was collected during 2014 sampling efforts (table 17). Of the sturgeon free-embryo specimens collected, genetic analysis identified 430 shovelnose sturgeon, 3 confirmed pallid sturgeon, and 1 possible pallid sturgeon. The 1 specimen identified as possible pallid sturgeon was degraded and only scoreable on 13 of the 19 microsatellite markers used to confirm species identity. Although the analysis indicates that the specimen was consistent with a pure pallid sturgeon, the large amount of data missing precluded the determination of species with a high degree of certainty. The three specimens identified as pallid sturgeon were captured in the main channel of the Lower Missouri River at stations 10 and 11 on May 30. The one specimen identified as a possible pallid sturgeon was collected from the main channel of the Lower Missouri River at station 11 on June 3 . The confirmed pallid sturgeon specimens ranged in length from 9.59 to $10.42 \mathrm{~mm}$ and were estimated to be between 1 and 3 days old based on ambient river temperatures and the developmental stage of the specimens.

Of all free embryos identified as sturgeon, 430 (99.3 percent) were collected in the Lower Missouri River in the main channel and outside bend at stations 10-12, and none were collected at station 13 (tables 17-21). Sturgeon free embryos first appeared in Lower Missouri River samples on May 28 at stations 10-12 and ranged in length from $7.55 \mathrm{~mm}$ (less than $1 \mathrm{dph}$ ) to $11.39 \mathrm{~mm}$ (estimated as $2-3 \mathrm{dph}$ ). The last sturgeon free embryo was collected on August 28 at station 11 and was estimated as 2-3 dph (tables 18-20). Discrete water temperatures at Lower Missouri River stations during sampling efforts 


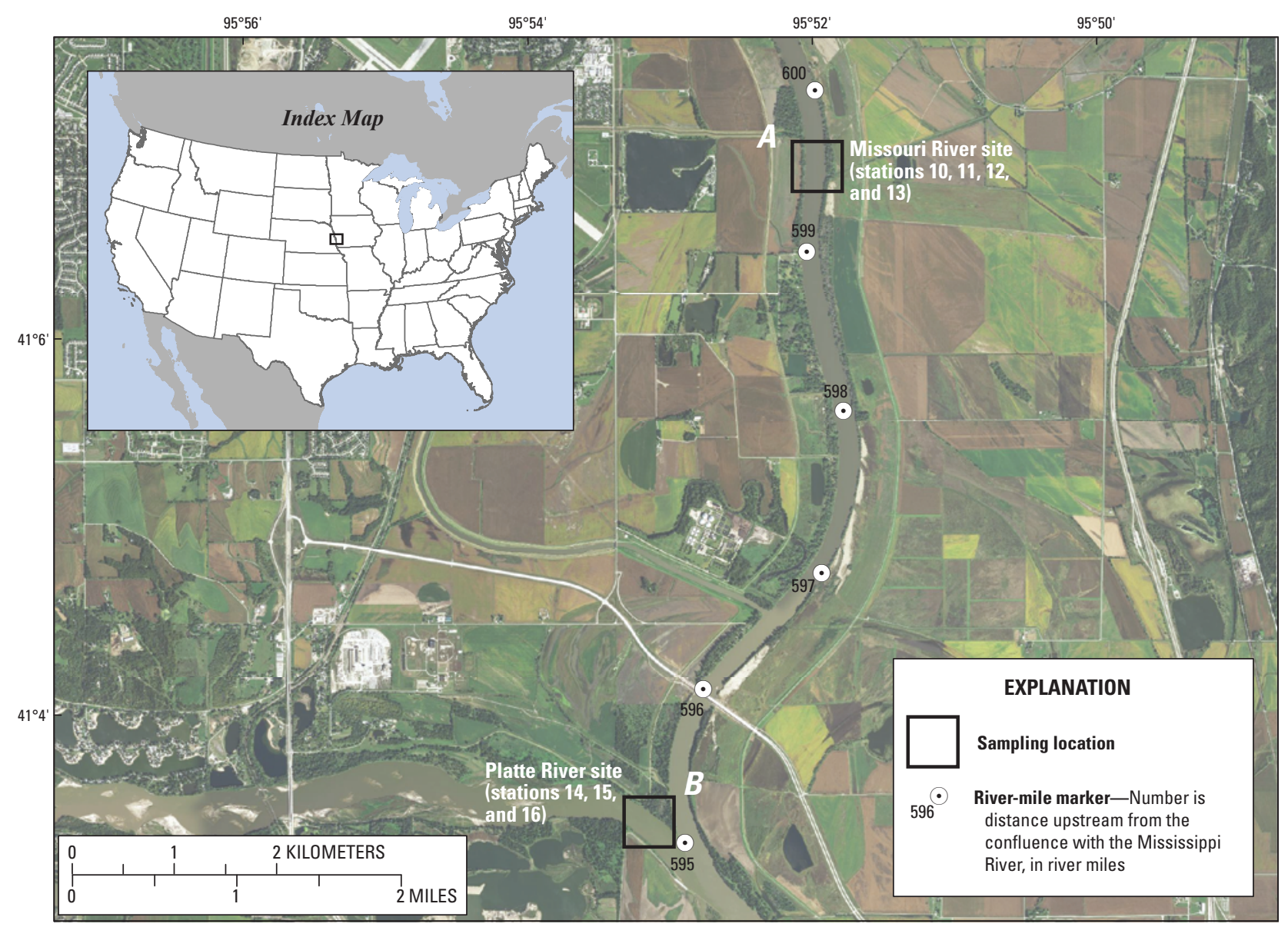

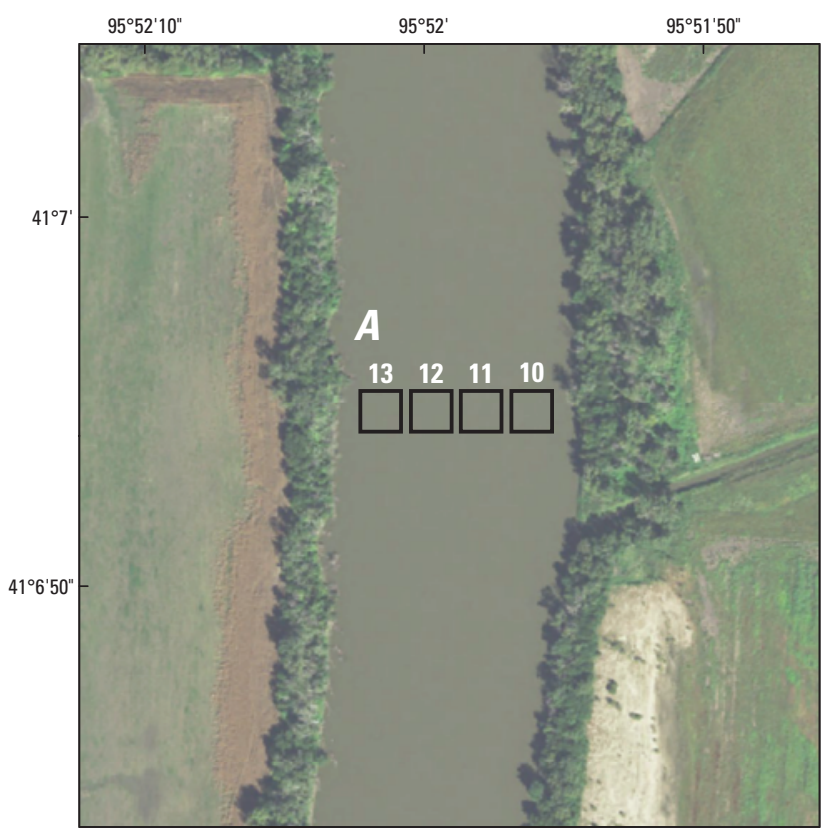

Digital imagery from U.S. Department of Agriculture National Agriculture Imagery Program digital data, 2014

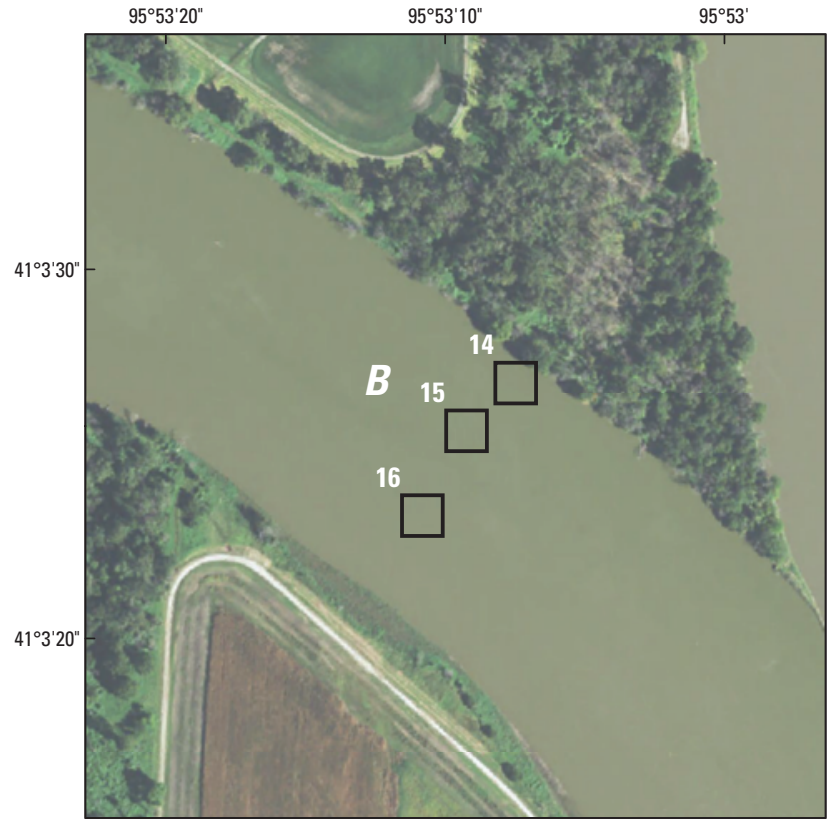

River miles from U.S. Army Corps of Engineers, 1960

Figure 43. Free-embryo and larval sampling locations in the Lower Missouri River and the Platte River. 
Table 17. Sampling period, number of sampling days, mean water volume sampled, number and density of sturgeon (Scaphirhynchus spp.) and paddlefish (Polyodon spathula) free embryos and larvae collected during 2014.

\begin{tabular}{clcccccccc}
\hline $\begin{array}{c}\text { Station } \\
\text { number }\end{array}$ & $\begin{array}{c}\text { Station } \\
\text { location }\end{array}$ & $\begin{array}{c}\text { First date } \\
\text { sampled }\end{array}$ & $\begin{array}{c}\text { Last date } \\
\text { sampled }\end{array}$ & $\begin{array}{c}\text { Number } \\
\text { of days } \\
\text { sampled }\end{array}$ & $\begin{array}{c}\text { Mean volume of } \\
\text { water sampled } \\
\text { (cubic meter) }\end{array}$ & $\begin{array}{c}\text { Number of } \\
\text { sturgeon } \\
\text { larvae } \\
\text { collected }\end{array}$ & $\begin{array}{c}\text { Number of } \\
\text { paddlefish } \\
\text { larvae } \\
\text { collected }\end{array}$ & $\begin{array}{c}\text { Mean density } \\
\text { of sturgeon } \\
\text { collected }\end{array}$ & $\begin{array}{c}\text { Mean density } \\
\text { of paddlefish } \\
\text { collected }\end{array}$ \\
\hline 10 & Missouri River & $4 / 15 / 2014$ & $8 / 28 / 2014$ & 52 & 187.7 & 209 & 233 & 0.57 & 0.86 \\
11 & Missouri River & $4 / 15 / 2014$ & $8 / 28 / 2014$ & 52 & 179.5 & 212 & 136 & 0.62 & 0.47 \\
12 & Missouri River & $4 / 15 / 2014$ & $8 / 28 / 2014$ & 52 & 174.9 & 9 & 16 & 0.03 & 0.06 \\
13 & Missouri River & $4 / 15 / 2014$ & $8 / 28 / 2014$ & 52 & 155.0 & 0 & 5 & 0.00 & 0.02 \\
14 & Platte River & $4 / 15 / 2014$ & $8 / 28 / 2014$ & 55 & 88.4 & 2 & 0 & 0.02 & 0.00 \\
15 & Platte River & $5 / 13 / 2014$ & $7 / 16 / 2014$ & 18 & 58.5 & 1 & 0 & 0.04 & 0.00 \\
16 & Platte River & $5 / 13 / 2014$ & $7 / 3 / 2014$ & 9 & 39.0 & 0 & 0 & 0.00 & 0.00 \\
\hline
\end{tabular}

ranged from $20.3{ }^{\circ} \mathrm{C}$ on May 28 to $26.5^{\circ} \mathrm{C}$ on August 20. The length of sturgeon free embryos collected during sampling efforts ranged from 6.0 to $14.82 \mathrm{~mm}$; however, a number of specimens were damaged yielding length measurements that were less than TL (fig. 44; tables 18-21). The largest of the sturgeon specimens collected were estimated at about $7-8 \mathrm{dph}$. Three sturgeon free embryos were collected in the Platte River at stations 14 and 15 on June 12 and 11, respectively (tables 22-24). The length of the three sturgeon specimens ranged from 7.99 to $8.43 \mathrm{~mm}$; the embryos were estimated as being less than $1 \mathrm{dph}$ (fig. 45; tables 22-24). Discrete water temperatures at stations 14 and 15 in the Platte River on June 11 and 12 ranged from 20.7 to $22.6{ }^{\circ} \mathrm{C}$.

Numbers and mean density of sturgeon free embryos varied among sampling stations (tables 17 and 25). Across all sampling dates in the Lower Missouri River $(n=52)$, stations 10 and 11 contained the highest numbers, 212 and 209, respectively, as well as the highest mean density of free embryos, 0.58 and 0.63 free embryos per 100 cubic meters $\left(\mathrm{m}^{3}\right)$, respectively (tables 17 and 25). Mean density of free-embryo sturgeon at station 12 in the Lower Missouri River was low $\left(0.03\right.$ free embryos $\left./ 100 \mathrm{~m}^{3}\right)$ because only nine free embryos were collected. No sturgeon free embryos were collected at station 13 in the Lower Missouri River. Mean density of sturgeon free embryos was also low at stations 14 and 15 in the Platte River (0.02 and 0.04 free embryos $/ 100 \mathrm{~m}^{3}$, respectively) where three specimens were collected (tables 17 and 25). No sturgeon free embryos were collected at station 16 in the Platte River during 9 days of sampling. The periodicity and densities of free embryos sampled during 2014 varied among sampling sites and dates (table 25). Mean densities of freeembryo sturgeon peaked during late May through mid-June in the Lower Missouri River with stations in or near the thalweg having the highest densities. Specifically, the greatest density of free-embryo sturgeon happened on June 10 at station 10 with densities of 5.66 free embryos $/ 100 \mathrm{~m}^{3}$.

A total of 390 paddlefish free embryos was collected during 2014 sampling efforts (table 17). Three paddlefish free embryos were preliminarily assigned to genus but were damaged by sampling gear such that a definitive confirmation would need to be confirmed through genetic analysis. All 390 specimens identified as paddlefish free embryos were collected in Lower Missouri River stations 10-13 (tables 18-22). Paddlefish free embryos appeared in samples from May 7 through June 12. Discrete water temperatures at Lower Missouri River stations during this period ranged from 12.8 to $22.7^{\circ} \mathrm{C}$. The length of paddlefish free embryos collected during sampling efforts ranged from 4.77 to $14.89 \mathrm{~mm}$; however, a number of specimens were damaged yielding length measurements that were less than TL (fig. 46; tables 18-21). The largest paddlefish specimens collected were estimated at about 7-8 dph. No paddlefish free embryos were collected in the Platte River.

Paddlefish free-embryo numbers and mean density also varied among sampling stations (table 26). Across all sampling dates in the Lower Missouri River, the highest number $(n=238)$ and mean density $\left(0.87\right.$ free embryos $\left./ 100 \mathrm{~m}^{3}\right)$ of paddlefish free embryos were collected at station 10, followed by station 11 where 136 free embryos were collected and mean density was 0.48 free embryos $/ 100 \mathrm{~m}^{3}$. Mean density of paddlefish free embryos was low at stations 12 and 13 at the Lower Missouri River site (0.06 and 0.02 free embryos $/ 100 \mathrm{~m}^{3}$, respectively). Mean density of paddlefish free embryos collected peaked during late May at the Lower Missouri River site (tables 18-22 and 26). No paddlefish free embryos were collected at stations 14,15 , or 16 at the Platte River site.

\section{Discussion}

During 2014, paddlefish free embryos were collected during mid-May to mid-June in the Lower Missouri River; no paddlefish free embryos were located in the Platte River. Sturgeon free embryos were collected from May 28 through August 28 (tables 22-26) at the Lower Missouri River site and 
Table 18. Number, mean length, minimum length, and maximum length of free-embryo and larval sturgeon (Scaphirhynchus spp.) and paddlefish (Polyodon spathula) collected in the Missouri River at station 10.

[mm, millimeter; --, no data]

\begin{tabular}{|c|c|c|c|c|c|c|c|c|}
\hline \multirow[b]{2}{*}{$\begin{array}{l}\text { Collection } \\
\text { date }\end{array}$} & \multicolumn{4}{|c|}{ Sturgeon } & \multicolumn{4}{|c|}{ Paddlefish } \\
\hline & $\begin{array}{l}\text { Number } \\
\text { collected }\end{array}$ & $\begin{array}{c}\text { Mean } \\
\text { length } \\
(\mathrm{mm})\end{array}$ & $\begin{array}{l}\text { Minimum } \\
\text { length } \\
(\mathrm{mm})\end{array}$ & $\begin{array}{c}\text { Maximum } \\
\text { length } \\
(\mathrm{mm})\end{array}$ & $\begin{array}{l}\text { Number } \\
\text { collected }\end{array}$ & $\begin{array}{c}\text { Mean } \\
\text { length } \\
(\mathrm{mm})\end{array}$ & $\begin{array}{l}\text { Minimum } \\
\text { length } \\
(\mathrm{mm})\end{array}$ & $\begin{array}{l}\text { Maximum } \\
\text { length } \\
\text { (mm) }\end{array}$ \\
\hline $4 / 15 / 2014$ & -- & -- & -- & -- & -- & -- & -- & -- \\
\hline $4 / 16 / 2014$ & -- & -- & -- & -- & -- & -- & -- & -- \\
\hline $4 / 17 / 2014$ & -- & -- & -- & -- & -- & -- & -- & -- \\
\hline $4 / 22 / 2014$ & -- & -- & -- & -- & -- & -- & -- & -- \\
\hline $4 / 23 / 2014$ & -- & -- & -- & -- & -- & -- & -- & -- \\
\hline $4 / 24 / 2014$ & -- & -- & -- & -- & -- & -- & -- & -- \\
\hline $4 / 29 / 2014$ & -- & -- & -- & -- & -- & -- & -- & -- \\
\hline $4 / 30 / 2014$ & -- & -- & -- & -- & -- & -- & -- & -- \\
\hline $5 / 1 / 2014$ & -- & -- & -- & -- & -- & -- & -- & -- \\
\hline $5 / 6 / 2014$ & -- & -- & -- & -- & -- & -- & -- & -- \\
\hline $5 / 7 / 2014$ & -- & -- & -- & -- & -- & -- & -- & -- \\
\hline $5 / 8 / 2014$ & -- & -- & -- & -- & -- & -- & -- & -- \\
\hline $5 / 13 / 2014$ & -- & -- & -- & -- & 1 & 8.86 & 8.86 & 8.86 \\
\hline $5 / 14 / 2014$ & -- & -- & -- & -- & -- & -- & -- & -- \\
\hline $5 / 15 / 2014$ & -- & -- & -- & -- & -- & -- & -- & -- \\
\hline $5 / 20 / 2014$ & -- & -- & -- & -- & 21 & 9.14 & 6.03 & 11.06 \\
\hline $5 / 21 / 2014$ & -- & -- & -- & -- & 23 & 9.60 & 7.30 & 12.00 \\
\hline $5 / 22 / 2014$ & -- & -- & -- & -- & 51 & 9.14 & 6.17 & 11.92 \\
\hline $5 / 28 / 2014$ & 1 & 8.73 & 8.73 & 8.73 & 11 & 10.22 & 8.93 & 11.92 \\
\hline $5 / 29 / 2014$ & -- & -- & -- & -- & 23 & 10.38 & 6.34 & 12.06 \\
\hline $5 / 30 / 2014$ & 10 & 9.55 & 8.48 & 10.73 & 83 & 10.92 & 5.61 & 13.44 \\
\hline $6 / 3 / 2014$ & 14 & 9.57 & 7.49 & 12.65 & 7 & 9.74 & 8.31 & 11.87 \\
\hline $6 / 5 / 2014$ & 2 & 11.07 & 10.64 & 11.49 & 2 & 13.17 & 11.44 & 14.89 \\
\hline $6 / 10 / 2014$ & 37 & 10.97 & 7.92 & 14.82 & 6 & 10.00 & 7.95 & 11.98 \\
\hline $6 / 11 / 2014$ & 8 & 9.13 & 7.14 & 11.19 & 3 & 10.89 & 7.92 & 13.42 \\
\hline $6 / 12 / 2014$ & 5 & 8.43 & 6.21 & 11.92 & 2 & 10.87 & 10.66 & 11.08 \\
\hline $7 / 1 / 2014$ & -- & -- & -- & -- & -- & -- & -- & -- \\
\hline $7 / 3 / 2014$ & -- & -- & -- & -- & -- & -- & -- & -- \\
\hline $7 / 8 / 2014$ & -- & -- & -- & -- & -- & -- & -- & -- \\
\hline 7/9/2014 & -- & -- & -- & -- & -- & -- & -- & -- \\
\hline $7 / 10 / 2014$ & -- & -- & -- & -- & -- & -- & -- & -- \\
\hline $7 / 15 / 2014$ & -- & -- & -- & -- & -- & -- & -- & -- \\
\hline $7 / 16 / 2014$ & -- & -- & -- & -- & -- & -- & -- & -- \\
\hline $7 / 17 / 2014$ & -- & -- & -- & -- & -- & -- & -- & -- \\
\hline $7 / 22 / 2014$ & 6 & 9.75 & 8.35 & 12.04 & -- & -- & -- & -- \\
\hline $7 / 23 / 2014$ & 3 & 11.28 & 10.25 & 12.67 & -- & -- & -- & -- \\
\hline $7 / 24 / 2014$ & -- & -- & -- & -- & -- & -- & -- & -- \\
\hline $7 / 29 / 2014$ & -- & -- & -- & -- & -- & -- & -- & -- \\
\hline $7 / 30 / 2014$ & -- & -- & -- & -- & -- & -- & -- & -- \\
\hline
\end{tabular}


Table 18. Number, mean length, minimum length, and maximum length of free-embryo and larval sturgeon (Scaphirhynchus spp.) and paddlefish (Polyodon spathula) collected in the Missouri River at station 10.-Continued

[mm, millimeter; --, no data]

\begin{tabular}{|c|c|c|c|c|c|c|c|c|}
\hline \multirow[b]{2}{*}{$\begin{array}{c}\text { Collection } \\
\text { date }\end{array}$} & \multicolumn{4}{|c|}{ Sturgeon } & \multicolumn{4}{|c|}{ Paddlefish } \\
\hline & $\begin{array}{l}\text { Number } \\
\text { collected }\end{array}$ & $\begin{array}{l}\text { Mean } \\
\text { length } \\
(\mathrm{mm})\end{array}$ & $\begin{array}{l}\text { Minimum } \\
\text { length } \\
\text { (mm) }\end{array}$ & $\begin{array}{l}\text { Maximum } \\
\text { length } \\
(\mathrm{mm})\end{array}$ & $\begin{array}{l}\text { Number } \\
\text { collected }\end{array}$ & $\begin{array}{l}\text { Mean } \\
\text { length } \\
(\mathrm{mm})\end{array}$ & $\begin{array}{l}\text { Minimum } \\
\text { length } \\
(\mathrm{mm})\end{array}$ & $\begin{array}{l}\text { Maximum } \\
\text { length } \\
(\mathrm{mm})\end{array}$ \\
\hline $7 / 31 / 2014$ & 2 & 8.35 & 8.11 & 8.58 & -- & -- & -- & -- \\
\hline $8 / 5 / 2014$ & 5 & 11.59 & 10.04 & 12.40 & -- & -- & -- & -- \\
\hline $8 / 6 / 2014$ & 3 & 11.71 & 10.41 & 13.21 & -- & -- & -- & -- \\
\hline 8/7/2014 & 1 & 9.04 & 9.04 & 9.04 & -- & -- & -- & -- \\
\hline $8 / 12 / 2014$ & 27 & 8.78 & 6.05 & 12.54 & -- & -- & -- & -- \\
\hline $8 / 13 / 2014$ & 41 & 10.17 & 6.68 & 12.73 & -- & -- & -- & -- \\
\hline $8 / 14 / 2014$ & 25 & 10.59 & 6.49 & 12.97 & -- & -- & -- & -- \\
\hline $8 / 19 / 2014$ & 7 & 9.48 & 7.23 & 11.01 & -- & -- & -- & -- \\
\hline $8 / 20 / 2014$ & 3 & 10.58 & 8.33 & 11.84 & -- & -- & -- & -- \\
\hline $8 / 21 / 2014$ & 8 & 9.09 & 6.61 & 12.95 & -- & -- & -- & -- \\
\hline $8 / 26 / 2014$ & -- & -- & -- & -- & -- & -- & -- & -- \\
\hline $8 / 27 / 2014$ & 1 & 13.30 & 13.30 & 13.30 & -- & -- & -- & -- \\
\hline $8 / 28 / 2014$ & -- & -- & -- & -- & -- & -- & -- & -- \\
\hline
\end{tabular}

on June 11 and 12 at the Platte River site. Three confirmed and one possible pallid sturgeon were collected from the Lower Missouri River. No pallid sturgeon were collected from the Platte River. From free-embryo specimens collected during 2014, it seems that most sturgeon spawned in the Lower Missouri River from mid-May into August, whereas sturgeon spawned in the Platte River during mid-June. As during previous years, the highest number and densities of free-embryo sturgeon collected during 2014 were located drifting in and near the thalweg of the Lower Missouri River where velocities are highest. These findings support the hypothesis (DeLonay and others, 2009) that sturgeon free embryos may drift long distances and have the potential to drift out of the Lower Missouri River into the Mississippi River.

Despite documentation of spawning by female pallid sturgeon (DeLonay and others, 2009, 2010, 2012), the success of spawning and subsequent hatch in the Lower Missouri River remain largely unknown. This study collected three confirmed pallid sturgeon free embryos in the Lower Missouri River. These are the first genetically identified free-embryo sturgeon collected in the Lower Missouri River. Other agencies monitoring the Lower Missouri River also collected three exogenously feeding larval sturgeon (Joe Bonneau, U.S. Army Corps of Engineers, oral commun., 2015). These larval sturgeon are also the first genetically identified larval pallid sturgeon collected in the Lower Missouri River. Subsequent evaluation of genetic relatedness of the pallid sturgeon free embryos and larvae collected by all agencies in 2014 indicate that the three free embryos were not from the same two parents and that the free embryos were unrelated to the three larval pallid sturgeon collected by other agencies (Dr. Edward Heist, University of Illinois Carbondale, written commun., 2015). These results indicate that pallid sturgeon discovered suitable spawning habitat and that multiple adults spawned successfully in 2014. Despite collecting pallid sturgeon free embryos in 2014, the relatively small number of pallid sturgeon collected given the amount of effort in 2012-14 indicate that natural spawning and hatch, or both, are rare.

\section{Field-Based Habitat Assessments of Hydrology and Hydraulics Affecting Transport, Retention, and Fate of Drifting Free Embryos to Exogenously Feeding Larvae}

The transport and fate of free embryos post-hatch is largely unknown. Free embryos may drift for 9-17 days, depending on temperature-mediated development rate, before depleting their yolk sac and "settling" into feeding environments (Kynard and others, 2002; Braaten and others, 2008, 2012). During this time, they develop some ability to move on their own, and field experiments suggest that they tend to concentrate in the thalweg (Braaten and others, 2010) and drift at velocities slightly slower than mean water velocity (Braaten and others, 2008). Studies in the Upper Missouri River indicate that older larvae tend to drift slower as they settle or orient to benthic habitats (Braaten and others, 2012), but the degree to which free embryos engage in volitional swimming 
Table 19. Number, mean length, minimum length, and maximum length of free-embryo and larval sturgeon (Scaphirhynchus spp.) and paddlefish (Polyodon spathula) collected in the Missouri River at station 11.

[mm, millimeter; --, no data]

\begin{tabular}{|c|c|c|c|c|c|c|c|c|}
\hline \multirow[b]{2}{*}{$\begin{array}{l}\text { Collection } \\
\text { date }\end{array}$} & \multicolumn{4}{|c|}{ Sturgeon } & \multicolumn{4}{|c|}{ Paddlefish } \\
\hline & $\begin{array}{l}\text { Number } \\
\text { collected }\end{array}$ & $\begin{array}{l}\text { Mean } \\
\text { length } \\
(\mathrm{mm})\end{array}$ & $\begin{array}{l}\text { Minimum } \\
\text { length } \\
\text { (mm) }\end{array}$ & $\begin{array}{c}\text { Maximum } \\
\text { length } \\
(\mathrm{mm})\end{array}$ & $\begin{array}{l}\text { Number } \\
\text { collected }\end{array}$ & $\begin{array}{c}\text { Mean } \\
\text { length } \\
(\mathrm{mm})\end{array}$ & $\begin{array}{l}\text { Minimum } \\
\text { length } \\
\text { (mm) }\end{array}$ & $\begin{array}{l}\text { Maximum } \\
\text { length } \\
\text { (mm) }\end{array}$ \\
\hline $4 / 15 / 2014$ & -- & -- & -- & -- & -- & -- & -- & -- \\
\hline $4 / 16 / 2014$ & -- & -- & -- & -- & -- & -- & -- & -- \\
\hline $4 / 17 / 2014$ & -- & -- & -- & -- & -- & -- & -- & -- \\
\hline $4 / 22 / 2014$ & -- & -- & -- & -- & -- & -- & -- & -- \\
\hline $4 / 23 / 2014$ & -- & -- & -- & -- & -- & -- & -- & -- \\
\hline $4 / 24 / 2014$ & -- & -- & -- & -- & -- & -- & -- & -- \\
\hline $4 / 29 / 2014$ & -- & -- & -- & -- & -- & -- & -- & -- \\
\hline $4 / 30 / 2014$ & -- & -- & -- & -- & -- & -- & -- & -- \\
\hline $5 / 1 / 2014$ & -- & -- & -- & -- & -- & -- & -- & -- \\
\hline $5 / 6 / 2014$ & -- & -- & -- & -- & -- & -- & -- & -- \\
\hline $5 / 7 / 2014$ & -- & -- & -- & -- & -- & -- & -- & -- \\
\hline $5 / 8 / 2014$ & -- & -- & -- & -- & -- & -- & -- & -- \\
\hline $5 / 13 / 2014$ & -- & -- & -- & -- & -- & -- & -- & -- \\
\hline $5 / 14 / 2014$ & -- & -- & -- & -- & 3 & 11.53 & 11.29 & 11.70 \\
\hline $5 / 15 / 2014$ & -- & -- & -- & -- & -- & -- & -- & -- \\
\hline $5 / 20 / 2014$ & -- & -- & -- & -- & 19 & 8.99 & 7.45 & 9.87 \\
\hline $5 / 21 / 2014$ & -- & -- & -- & -- & 14 & 9.40 & 8.56 & 11.47 \\
\hline $5 / 22 / 2014$ & -- & -- & -- & -- & 37 & 9.66 & 6.64 & 11.72 \\
\hline $5 / 28 / 2014$ & 1 & 11.39 & 11.39 & 11.39 & 3 & 9.04 & 8.54 & 9.32 \\
\hline $5 / 29 / 2014$ & 3 & 9.63 & 8.67 & 10.55 & 19 & 10.13 & 4.77 & 12.83 \\
\hline $5 / 30 / 2014$ & 1 & 9.59 & 9.59 & 9.59 & 9 & 12.04 & 10.56 & 13.57 \\
\hline $6 / 3 / 2014$ & 30 & 9.77 & 7.45 & 13.01 & 12 & 11.04 & 8.07 & 13.09 \\
\hline $6 / 5 / 2014$ & 8 & 10.96 & 7.93 & 13.38 & 12 & 12.40 & 10.54 & 14.56 \\
\hline $6 / 10 / 2014$ & 17 & 11.21 & 8.57 & 14.09 & 2 & 14.02 & 13.33 & 14.71 \\
\hline $6 / 11 / 2014$ & 24 & 9.45 & 6.33 & 12.80 & 3 & 10.11 & 8.90 & 10.83 \\
\hline $6 / 12 / 2014$ & 9 & 8.95 & 7.45 & 12.53 & 3 & 10.62 & 9.84 & 12.08 \\
\hline $7 / 1 / 2014$ & -- & -- & -- & -- & -- & -- & -- & -- \\
\hline $7 / 3 / 2014$ & -- & -- & -- & -- & -- & -- & -- & -- \\
\hline $7 / 8 / 2014$ & -- & -- & -- & -- & -- & -- & -- & -- \\
\hline 7/9/2014 & 1 & 10.47 & 10.47 & 10.47 & -- & -- & -- & -- \\
\hline $7 / 10 / 2014$ & -- & -- & -- & -- & -- & -- & -- & -- \\
\hline $7 / 15 / 2014$ & 1 & 9.80 & 9.80 & 9.80 & -- & -- & -- & -- \\
\hline $7 / 16 / 2014$ & -- & -- & -- & -- & -- & -- & -- & -- \\
\hline $7 / 17 / 2014$ & -- & -- & -- & -- & -- & -- & -- & -- \\
\hline $7 / 22 / 2014$ & 4 & 8.83 & 6.04 & 10.53 & -- & -- & -- & -- \\
\hline $7 / 23 / 2014$ & -- & -- & -- & -- & -- & -- & -- & -- \\
\hline $7 / 24 / 2014$ & 3 & 10.71 & 8.86 & 13.25 & -- & -- & -- & -- \\
\hline $7 / 29 / 2014$ & 3 & 8.18 & 7.49 & 9.42 & -- & -- & -- & -- \\
\hline $7 / 30 / 2014$ & 5 & 7.80 & 7.37 & 8.30 & -- & -- & -- & -- \\
\hline
\end{tabular}


Table 19. Number, mean length, minimum length, and maximum length of free-embryo and larval sturgeon (Scaphirhynchus spp.) and paddlefish (Polyodon spathula) collected in the Missouri River at station 11.-Continued

[mm, millimeter; --, no data]

\begin{tabular}{|c|c|c|c|c|c|c|c|c|}
\hline \multirow[b]{2}{*}{$\begin{array}{l}\text { Collection } \\
\text { date }\end{array}$} & \multicolumn{4}{|c|}{ Sturgeon } & \multicolumn{4}{|c|}{ Paddlefish } \\
\hline & $\begin{array}{l}\text { Number } \\
\text { collected }\end{array}$ & $\begin{array}{c}\text { Mean } \\
\text { length } \\
(\mathrm{mm})\end{array}$ & $\begin{array}{l}\text { Minimum } \\
\text { length } \\
\text { (mm) }\end{array}$ & $\begin{array}{l}\text { Maximum } \\
\text { length } \\
\text { (mm) }\end{array}$ & $\begin{array}{l}\text { Number } \\
\text { collected }\end{array}$ & $\begin{array}{c}\text { Mean } \\
\text { length } \\
(\mathrm{mm})\end{array}$ & $\begin{array}{l}\text { Minimum } \\
\text { length } \\
\text { (mm) }\end{array}$ & $\begin{array}{c}\text { Maximum } \\
\text { length } \\
(\mathrm{mm})\end{array}$ \\
\hline $7 / 31 / 2014$ & 2 & 9.26 & 8.94 & 9.57 & -- & -- & -- & -- \\
\hline $8 / 5 / 2014$ & 6 & 10.97 & 9.99 & 11.93 & -- & -- & -- & -- \\
\hline $8 / 6 / 2014$ & 1 & 9.74 & 9.74 & 9.74 & -- & -- & -- & -- \\
\hline $8 / 7 / 2014$ & 4 & 12.07 & 9.80 & 13.38 & -- & -- & -- & -- \\
\hline $8 / 12 / 2014$ & 25 & 9.01 & 7.36 & 11.03 & -- & -- & -- & -- \\
\hline $8 / 13 / 2014$ & 11 & 10.39 & 8.68 & 12.81 & -- & -- & -- & -- \\
\hline $8 / 14 / 2014$ & 21 & 11.12 & 7.11 & 12.80 & -- & -- & -- & -- \\
\hline $8 / 19 / 2014$ & 10 & 9.27 & 3.97 & 11.72 & -- & -- & -- & -- \\
\hline $8 / 20 / 2014$ & 4 & 12.46 & 9.89 & 13.83 & -- & -- & -- & -- \\
\hline $8 / 21 / 2014$ & 16 & 10.02 & 7.41 & 13.00 & -- & -- & -- & -- \\
\hline $8 / 26 / 2014$ & -- & -- & -- & -- & -- & -- & -- & -- \\
\hline $8 / 27 / 2014$ & 1 & 9.65 & 9.65 & 9.65 & -- & -- & -- & -- \\
\hline $8 / 28 / 2014$ & 1 & 10.01 & 10.01 & 10.01 & -- & -- & -- & -- \\
\hline
\end{tabular}

in the high velocities of the Lower Missouri River is unknown. Additionally, mean water velocities in the Lower Missouri River suggest larvae may drift hundreds of kilometers per day (DeLonay and others, 2009), but it is unknown how complex hydraulics along the river may interact with progressive larval development to determine actual drift distances, where larvae may be retained, and if retention sites provide necessary food resources and protection from predation. Poor recruitment to young-of-year sturgeon suggests that drift and retention processes may be critical in determining growth and survival of pallid sturgeon.

In previous years, we focused on quantifying the use and availability of physical habitat selected by pallid sturgeon for reproductive migrations and spawning on the Missouri and Yellowstone Rivers. Effort to document and describe habitat was strongly coordinated with the tracking of adult sturgeon. During 2013, we shifted emphasis toward data collection for the purpose of characterizing habitat used during hatch, drift, and settling life stages (DeLonay and others, 2016a). Understanding these early life stages necessarily includes tracking reproductive adults to their spawning locations to address conditions for egg deposition, fertilization, and hatch; and to identify origins of drifting free embryos. Key questions for the drifting phase of ontogenetic development include duration of drift, drift velocity (relative to current velocity), control of cumulative drift distance, distribution of free embryos within the channel, and conditions that affect the probability of free embryos moving from the thalweg into marginal retention areas (settling). These factors interact with developmental stage and the geomorphology and hydraulics of the channel to determine where along the river free embryos are retained and begin to feed or if, instead, they continue to be transported past the point of starvation.

In 2013, we developed one-dimensional advectiondispersion models for segments of the Lower Missouri River using hydroacoustic data to characterize dispersion parameters (for example, Carr and Rehmann, 2007; Kim, 2012). We also did a statistical analysis of ADCP-derived dispersion coefficients throughout the Lower Missouri River to compare the relative retention and dispersion characteristics among river segments (DeLonay and others, 2016a). These analyses built on previous work (Bazzetta, 2010) and provided new insights into the effects of channel morphology and hydrologic regime on the dispersion and retention of drifting free embryos (Erwin and Jacobson, 2015).

In 2014, we developed two-dimensional hydrodynamic models of select reaches in the Lower Missouri River. These more detailed and computationally intensive models simulate processes not captured by a one-dimensional approach that exert a primary control on the transport and fate of drifting free embryos (Korman and others, 2004). Reach-scale numerical modeling provides further insight into the complex interactions between channel hydraulics and morphology that determine the drift, distribution, and fate of drifting free embryos within the Missouri and Yellowstone Rivers. 
Table 20. Number, mean length, minimum length, and maximum length of free-embryo and larval sturgeon (Scaphirhynchus spp.) and paddlefish (Polyodon spathula) collected in the Missouri River at station 12.

[mm, millimeter; --, no data]

\begin{tabular}{|c|c|c|c|c|c|c|c|c|}
\hline \multirow[b]{2}{*}{$\begin{array}{c}\text { Collection } \\
\text { date }\end{array}$} & \multicolumn{4}{|c|}{ Sturgeon } & \multicolumn{4}{|c|}{ Paddlefish } \\
\hline & $\begin{array}{l}\text { Number } \\
\text { collected }\end{array}$ & $\begin{array}{l}\text { Mean } \\
\text { length } \\
\text { (mm) }\end{array}$ & $\begin{array}{c}\text { Minimum } \\
\text { length } \\
\text { (mm) }\end{array}$ & $\begin{array}{c}\text { Maximum } \\
\text { length } \\
\text { (mm) }\end{array}$ & $\begin{array}{l}\text { Number } \\
\text { collected }\end{array}$ & $\begin{array}{c}\text { Mean } \\
\text { length } \\
\text { (mm) }\end{array}$ & $\begin{array}{c}\text { Minimum } \\
\text { length } \\
\text { (mm) }\end{array}$ & $\begin{array}{c}\text { Maximum } \\
\text { length } \\
\text { (mm) }\end{array}$ \\
\hline $4 / 15 / 2014$ & -- & -- & -- & -- & -- & -- & -- & -- \\
\hline $4 / 16 / 2014$ & -- & -- & -- & -- & -- & -- & -- & -- \\
\hline $4 / 17 / 2014$ & -- & -- & -- & -- & -- & -- & -- & -- \\
\hline $4 / 22 / 2014$ & -- & -- & -- & -- & -- & -- & -- & -- \\
\hline $4 / 23 / 2014$ & -- & -- & -- & -- & -- & -- & -- & -- \\
\hline $4 / 24 / 2014$ & -- & -- & -- & -- & -- & -- & -- & -- \\
\hline $4 / 29 / 2014$ & -- & -- & -- & -- & -- & -- & -- & -- \\
\hline $4 / 30 / 2014$ & -- & -- & -- & -- & -- & -- & -- & -- \\
\hline $5 / 1 / 2014$ & -- & -- & -- & -- & -- & -- & -- & -- \\
\hline $5 / 6 / 2014$ & -- & -- & -- & -- & -- & -- & -- & -- \\
\hline $5 / 7 / 2014$ & -- & -- & -- & -- & 1 & 9.72 & 9.72 & 9.72 \\
\hline $5 / 8 / 2014$ & -- & -- & -- & -- & -- & -- & -- & -- \\
\hline $5 / 13 / 2014$ & -- & -- & -- & -- & -- & -- & -- & -- \\
\hline $5 / 14 / 2014$ & -- & -- & -- & -- & -- & -- & -- & -- \\
\hline $5 / 15 / 2014$ & -- & -- & -- & -- & -- & -- & -- & -- \\
\hline $5 / 20 / 2014$ & -- & -- & -- & -- & 2 & 9.04 & 8.36 & 9.71 \\
\hline $5 / 21 / 2014$ & -- & -- & -- & -- & 2 & 9.13 & 8.04 & 10.22 \\
\hline $5 / 22 / 2014$ & -- & -- & -- & -- & 1 & 9.71 & 9.71 & 9.71 \\
\hline $5 / 28 / 2014$ & 1 & 7.55 & 7.55 & 7.55 & 5 & 9.89 & 7.26 & 13.17 \\
\hline $5 / 29 / 2014$ & -- & -- & -- & -- & 2 & 8.25 & 7.52 & 8.98 \\
\hline $5 / 30 / 2014$ & -- & -- & -- & -- & 2 & 6.82 & 6.50 & 7.14 \\
\hline $6 / 3 / 2014$ & -- & -- & -- & -- & 1 & 11.39 & 11.39 & 11.39 \\
\hline $6 / 5 / 2014$ & -- & -- & -- & -- & -- & -- & -- & -- \\
\hline $6 / 10 / 2014$ & -- & -- & -- & -- & -- & -- & -- & -- \\
\hline $6 / 11 / 2014$ & 3 & 8.63 & 7.21 & 10.94 & -- & -- & -- & -- \\
\hline $6 / 12 / 2014$ & -- & -- & -- & -- & -- & -- & -- & -- \\
\hline $7 / 1 / 2014$ & -- & -- & -- & -- & -- & -- & -- & -- \\
\hline $7 / 3 / 2014$ & -- & -- & -- & -- & -- & -- & -- & -- \\
\hline $7 / 8 / 2014$ & -- & -- & -- & -- & -- & -- & -- & -- \\
\hline $7 / 9 / 2014$ & -- & -- & -- & -- & -- & -- & -- & -- \\
\hline $7 / 10 / 2014$ & -- & -- & -- & -- & -- & -- & -- & -- \\
\hline $7 / 15 / 2014$ & -- & -- & -- & -- & -- & -- & -- & -- \\
\hline $7 / 16 / 2014$ & -- & -- & -- & -- & -- & -- & -- & -- \\
\hline $7 / 17 / 2014$ & -- & -- & -- & -- & -- & -- & -- & -- \\
\hline $7 / 22 / 2014$ & -- & -- & -- & -- & -- & -- & -- & -- \\
\hline $7 / 23 / 2014$ & 1 & 12.37 & 12.37 & 12.37 & -- & -- & -- & -- \\
\hline $7 / 24 / 2014$ & -- & -- & -- & -- & -- & -- & -- & -- \\
\hline $7 / 29 / 2014$ & -- & -- & -- & -- & -- & -- & -- & -- \\
\hline $7 / 30 / 2014$ & 1 & 7.55 & 7.55 & 7.55 & -- & -- & -- & -- \\
\hline $7 / 31 / 2014$ & -- & -- & -- & -- & -- & -- & -- & -- \\
\hline
\end{tabular}


Table 20. Number, mean length, minimum length, and maximum length of free-embryo and larval sturgeon (Scaphirhynchus spp.) and paddlefish (Polyodon spathula) collected in the Missouri River at station 12.-Continued

[mm, millimeter; --, no data]

\begin{tabular}{|c|c|c|c|c|c|c|c|c|}
\hline \multirow[b]{2}{*}{$\begin{array}{c}\text { Collection } \\
\text { date }\end{array}$} & \multicolumn{4}{|c|}{ Sturgeon } & \multicolumn{4}{|c|}{ Paddlefish } \\
\hline & $\begin{array}{l}\text { Number } \\
\text { collected }\end{array}$ & $\begin{array}{c}\text { Mean } \\
\text { length } \\
(\mathrm{mm})\end{array}$ & $\begin{array}{l}\text { Minimum } \\
\text { length } \\
\text { (mm) }\end{array}$ & $\begin{array}{l}\text { Maximum } \\
\text { length } \\
\text { (mm) }\end{array}$ & $\begin{array}{l}\text { Number } \\
\text { collected }\end{array}$ & $\begin{array}{c}\text { Mean } \\
\text { length } \\
(\mathrm{mm})\end{array}$ & $\begin{array}{l}\text { Minimum } \\
\text { length } \\
\text { (mm) }\end{array}$ & $\begin{array}{c}\text { Maximum } \\
\text { length } \\
\text { (mm) }\end{array}$ \\
\hline $8 / 5 / 2014$ & -- & -- & -- & -- & -- & -- & -- & -- \\
\hline $8 / 6 / 2014$ & -- & -- & -- & -- & -- & -- & -- & -- \\
\hline $8 / 7 / 2014$ & -- & -- & -- & -- & -- & -- & -- & -- \\
\hline $8 / 12 / 2014$ & 1 & 11.65 & 11.65 & 11.65 & -- & -- & -- & -- \\
\hline $8 / 13 / 2014$ & -- & -- & -- & -- & -- & -- & -- & -- \\
\hline $8 / 14 / 2014$ & 1 & 12.88 & 12.88 & 12.88 & -- & -- & -- & -- \\
\hline $8 / 19 / 2014$ & -- & -- & -- & -- & -- & -- & -- & -- \\
\hline $8 / 20 / 2014$ & -- & -- & -- & -- & -- & -- & -- & -- \\
\hline $8 / 21 / 2014$ & -- & -- & -- & -- & -- & -- & -- & -- \\
\hline $8 / 26 / 2014$ & -- & -- & -- & -- & -- & -- & -- & -- \\
\hline $8 / 27 / 2014$ & 1 & 12.44 & 12.44 & 12.44 & -- & -- & -- & -- \\
\hline $8 / 28 / 2014$ & -- & -- & -- & -- & -- & -- & -- & -- \\
\hline
\end{tabular}

\section{Methods}

Hydrodynamic models were developed for two sites on the Lower Missouri River (fig. 47A) to evaluate drift potential: Lisbon-Jameson (fig. 47B) and Miami (fig. 47C) (table 27). The Lisbon-Jameson and Miami reaches represent end-member conditions; the Miami reach reflects typical characteristics of the channelized Lower Missouri River, whereas the LisbonJameson reach contains what is considered the best available habitat on the Lower Missouri River.

The Lisbon-Jameson hydrodynamic model was developed after an extensive field campaign in spring and summer 2014. The Miami model was originally developed by the USGS in 2006-7 to evaluate the effects of Gavins Point Dam release modifications on pallid sturgeon habitat dynamics. Methods used in the construction of the Lisbon-Jameson hydrodynamic model are described in the "Hydrodynamic Modeling" section, and methods used in the construction of the Miami model are described in detail by Jacobson and others (2009).

\section{Data Collection}

Topographic data for the hydrodynamic models were generated by integrating data from hydroacoustic surveys, topographic ground surveys, and existing aerial light and detection ranging surveys. Hydroacoustic surveys were completed using methods established by the USGS (Reuter and others, 2008, 2009). Hydroacoustic surveys were completed using a $200 \mathrm{kHz}$ single-beam echosounder with an 8-degree transducer coupled with RTK GPS equipment to provide precise positioning. The echosounder was calibrated for draft and sound velocity using a bar check. Hydroacoustic data were supplemented by RTK GPS ground surveys of subaerially exposed sandbars. Floodplain and bank topography was provided by aerial light and detection ranging surveys collected in 2007 (National Elevation Dataset; http://ned.usgs.gov).

Water-surface profiles were surveyed during a range of discharges for model calibration. Velocity data for model validation were acquired using 600 and $1,200 \mathrm{kHz}$ Teledyne RDI Rio Grande ADCP units integrated with RTK GPS positioning.

\section{Hydrodynamic Modeling}

We developed two-dimensional, depth-averaged hydrodynamic models to predict water-surface elevations, depths, and depth-averaged velocity throughout both study areas. Modeling was completed using TUFLOW (BMT Group Ltd., Brisbane, Australia) and implemented within the Surfacewater Modeling System (Aquaveo LLC, Provo, Utah). The TUFLOW solves the vertically averaged, two-dimensional shallow-water equations by means of the finite difference method on a Cartesian grid. The Miami model was originally developed and calibrated using an alternate hydrodynamic modeling program (Jacobson and others, 2009) and was converted to TUFLOW as part of this analysis to facilitate comparison with the Lisbon-Jameson model. For the current application, the Miami model domain was extended to include overbank areas. Topographic and bathymetric data were used to generate a computational grid for each modeling domain. We calibrated the models to measured water-surface elevations by iteratively adjusting channel roughness. 
Table 21. Number, mean length, minimum length, and maximum length of free-embryo and larval sturgeon (Scaphirhynchus spp.) and paddlefish (Polyodon spathula) collected in the Missouri River at station 13.

[mm, millimeter; --, no data]

\begin{tabular}{|c|c|c|c|c|c|c|c|c|}
\hline \multirow[b]{2}{*}{$\begin{array}{c}\text { Collection } \\
\text { date }\end{array}$} & \multicolumn{4}{|c|}{ Sturgeon } & \multicolumn{4}{|c|}{ Paddlefish } \\
\hline & $\begin{array}{l}\text { Number } \\
\text { collected }\end{array}$ & $\begin{array}{c}\text { Mean } \\
\text { length } \\
(\mathbf{m m})\end{array}$ & $\begin{array}{c}\text { Minimum } \\
\text { length } \\
(\mathrm{mm})\end{array}$ & $\begin{array}{l}\text { Maximum } \\
\text { length } \\
(\mathrm{mm})\end{array}$ & $\begin{array}{l}\text { Number } \\
\text { collected }\end{array}$ & $\begin{array}{c}\text { Mean } \\
\text { length } \\
(\mathrm{mm})\end{array}$ & $\begin{array}{c}\text { Minimum } \\
\text { length } \\
(\mathrm{mm})\end{array}$ & $\begin{array}{l}\text { Maximum } \\
\text { length } \\
(\mathrm{mm})\end{array}$ \\
\hline $4 / 15 / 2014$ & -- & -- & -- & -- & -- & -- & -- & -- \\
\hline $4 / 16 / 2014$ & -- & -- & -- & -- & -- & -- & -- & -- \\
\hline $4 / 17 / 2014$ & -- & -- & -- & -- & -- & -- & -- & -- \\
\hline $4 / 22 / 2014$ & -- & -- & -- & -- & -- & -- & -- & -- \\
\hline $4 / 23 / 2014$ & -- & -- & -- & -- & -- & -- & -- & -- \\
\hline $4 / 24 / 2014$ & -- & -- & -- & -- & -- & -- & -- & -- \\
\hline 4/29/2014 & -- & -- & -- & -- & -- & -- & -- & -- \\
\hline $4 / 30 / 2014$ & -- & -- & -- & -- & -- & -- & -- & -- \\
\hline $5 / 1 / 2014$ & -- & -- & -- & -- & -- & -- & -- & -- \\
\hline $5 / 6 / 2014$ & -- & -- & -- & -- & -- & -- & -- & -- \\
\hline $5 / 7 / 2014$ & -- & -- & -- & -- & -- & -- & -- & -- \\
\hline $5 / 8 / 2014$ & -- & -- & -- & -- & 2 & 9.12 & 9.03 & 9.20 \\
\hline $5 / 13 / 2014$ & -- & -- & -- & -- & -- & -- & -- & -- \\
\hline $5 / 14 / 2014$ & -- & -- & -- & -- & 1 & 9.30 & 9.30 & 9.30 \\
\hline $5 / 15 / 2014$ & -- & -- & -- & -- & -- & -- & -- & -- \\
\hline $5 / 20 / 2014$ & -- & -- & -- & -- & 1 & 7.30 & 7.30 & 7.30 \\
\hline $5 / 21 / 2014$ & -- & -- & -- & -- & -- & -- & -- & -- \\
\hline $5 / 22 / 2014$ & -- & -- & -- & -- & -- & -- & -- & -- \\
\hline $5 / 28 / 2014$ & -- & -- & -- & -- & -- & -- & -- & -- \\
\hline $5 / 29 / 2014$ & -- & -- & -- & -- & 1 & 8.27 & 8.27 & 8.27 \\
\hline $5 / 30 / 2014$ & -- & -- & -- & -- & -- & -- & -- & -- \\
\hline 6/3/2014 & -- & -- & -- & -- & -- & -- & -- & -- \\
\hline 6/5/2014 & -- & -- & -- & -- & -- & -- & -- & -- \\
\hline 6/10/2014 & -- & -- & -- & -- & -- & -- & -- & -- \\
\hline $6 / 11 / 2014$ & -- & -- & -- & -- & -- & -- & -- & -- \\
\hline $6 / 12 / 2014$ & -- & -- & -- & -- & -- & -- & -- & -- \\
\hline 7/1/2014 & -- & -- & -- & -- & -- & -- & -- & -- \\
\hline $7 / 3 / 2014$ & -- & -- & -- & -- & -- & -- & -- & -- \\
\hline 7/8/2014 & -- & -- & -- & -- & -- & -- & -- & -- \\
\hline 7/9/2014 & -- & -- & -- & -- & -- & -- & -- & -- \\
\hline 7/10/2014 & -- & -- & -- & -- & -- & -- & -- & -- \\
\hline $7 / 15 / 2014$ & -- & -- & -- & -- & -- & -- & -- & -- \\
\hline $7 / 16 / 2014$ & -- & -- & -- & -- & -- & -- & -- & -- \\
\hline 7/17/2014 & -- & -- & -- & -- & -- & -- & -- & -- \\
\hline $7 / 22 / 2014$ & -- & -- & -- & -- & -- & -- & -- & -- \\
\hline $7 / 23 / 2014$ & -- & -- & -- & -- & -- & -- & -- & -- \\
\hline $7 / 24 / 2014$ & -- & -- & -- & -- & -- & -- & -- & -- \\
\hline 7/29/2014 & -- & -- & -- & -- & -- & -- & -- & -- \\
\hline $7 / 30 / 2014$ & -- & -- & -- & -- & -- & -- & -- & -- \\
\hline
\end{tabular}


Table 21. Number, mean length, minimum length, and maximum length of free-embryo and larval sturgeon (Scaphirhynchus spp.) and paddlefish (Polyodon spathula) collected in the Missouri River at station 13.-Continued

[mm, millimeter; --, no data]

\begin{tabular}{|c|c|c|c|c|c|c|c|c|}
\hline \multirow[b]{2}{*}{$\begin{array}{c}\text { Collection } \\
\text { date }\end{array}$} & \multicolumn{4}{|c|}{ Sturgeon } & \multicolumn{4}{|c|}{ Paddlefish } \\
\hline & $\begin{array}{l}\text { Number } \\
\text { collected }\end{array}$ & $\begin{array}{l}\text { Mean } \\
\text { length } \\
(\mathrm{mm})\end{array}$ & $\begin{array}{l}\text { Minimum } \\
\text { length } \\
\text { (mm) }\end{array}$ & $\begin{array}{l}\text { Maximum } \\
\text { length } \\
\text { (mm) }\end{array}$ & $\begin{array}{l}\text { Number } \\
\text { collected }\end{array}$ & $\begin{array}{l}\text { Mean } \\
\text { length } \\
(\mathrm{mm})\end{array}$ & $\begin{array}{l}\text { Minimum } \\
\text { length } \\
(\mathrm{mm})\end{array}$ & $\begin{array}{l}\text { Maximum } \\
\text { length } \\
(\mathrm{mm})\end{array}$ \\
\hline $7 / 31 / 2014$ & -- & -- & -- & -- & -- & -- & -- & -- \\
\hline 8/5/2014 & -- & -- & -- & -- & -- & -- & -- & -- \\
\hline 8/6/2014 & -- & -- & -- & -- & -- & -- & -- & -- \\
\hline 8/7/2014 & -- & -- & -- & -- & -- & -- & -- & -- \\
\hline $8 / 12 / 2014$ & -- & -- & -- & -- & -- & -- & -- & -- \\
\hline 8/13/2014 & -- & -- & -- & -- & -- & -- & -- & -- \\
\hline $8 / 14 / 2014$ & -- & -- & -- & -- & -- & -- & -- & -- \\
\hline 8/19/2014 & -- & -- & -- & -- & -- & -- & -- & -- \\
\hline $8 / 20 / 2014$ & -- & -- & -- & -- & -- & -- & -- & -- \\
\hline $8 / 21 / 2014$ & -- & -- & -- & -- & -- & -- & -- & -- \\
\hline $8 / 26 / 2014$ & -- & -- & -- & -- & -- & -- & -- & -- \\
\hline $8 / 27 / 2014$ & -- & -- & -- & -- & -- & -- & -- & -- \\
\hline $8 / 28 / 2014$ & -- & -- & -- & -- & -- & -- & -- & -- \\
\hline
\end{tabular}

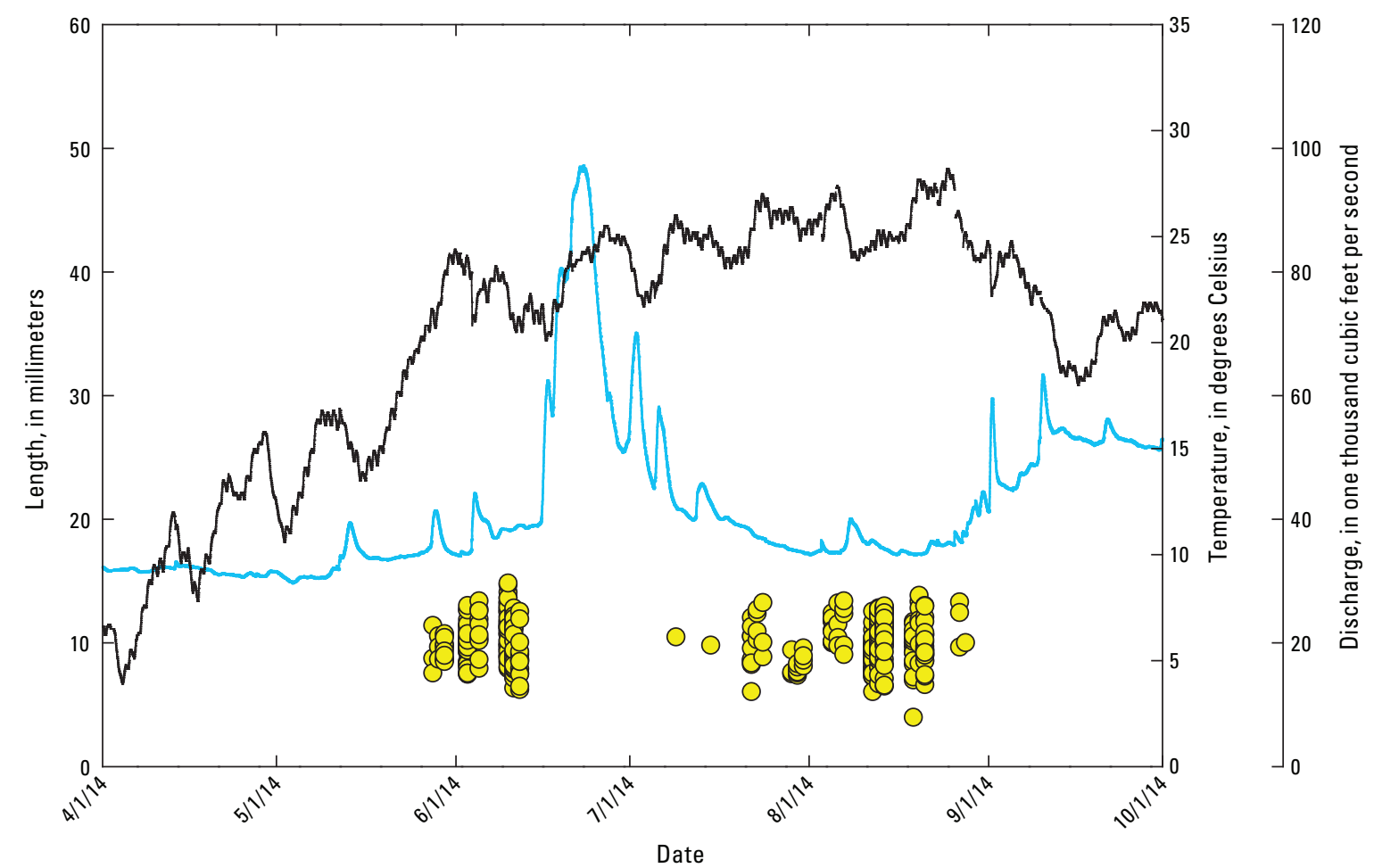

EXPLANATION

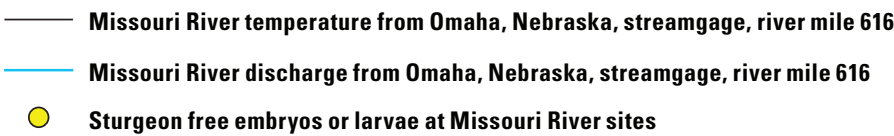

Figure 44. Length of sturgeon (Scaphirhynchus spp.) free embryos and larvae collected at the Missouri River site during AprilOctober 2014. Mean hourly temperature and discharge from the U.S. Geological Survey streamgage near Omaha, Nebraska. 
Table 22. Number, mean length, minimum length, and maximum length of free-embryo and larval sturgeon (Scaphirhynchus spp.) and paddlefish (Polyodon spathula) collected in the Platte River at station 14.

[mm, millimeter; --, no data]

\begin{tabular}{|c|c|c|c|c|c|c|c|c|}
\hline \multirow[b]{2}{*}{$\begin{array}{c}\text { Collection } \\
\text { date }\end{array}$} & \multicolumn{4}{|c|}{ Sturgeon } & \multicolumn{4}{|c|}{ Paddlefish } \\
\hline & $\begin{array}{l}\text { Number } \\
\text { collected }\end{array}$ & $\begin{array}{l}\text { Mean } \\
\text { length } \\
(\mathrm{mm})\end{array}$ & $\begin{array}{l}\text { Minimum } \\
\text { length } \\
(\mathrm{mm})\end{array}$ & $\begin{array}{l}\text { Maximum } \\
\text { length } \\
(\mathrm{mm})\end{array}$ & $\begin{array}{l}\text { Number } \\
\text { collected }\end{array}$ & $\begin{array}{c}\text { Mean } \\
\text { length } \\
(\mathrm{mm})\end{array}$ & $\begin{array}{l}\text { Minimum } \\
\text { length } \\
(\mathrm{mm})\end{array}$ & $\begin{array}{c}\text { Maximum } \\
\text { length } \\
(\mathrm{mm})\end{array}$ \\
\hline $4 / 15 / 2014$ & -- & -- & -- & -- & -- & -- & -- & -- \\
\hline $4 / 16 / 2014$ & -- & -- & -- & -- & -- & -- & -- & -- \\
\hline $4 / 17 / 2014$ & -- & -- & -- & -- & -- & -- & -- & -- \\
\hline $4 / 22 / 2014$ & -- & -- & -- & -- & -- & -- & -- & -- \\
\hline 4/23/2014 & -- & -- & -- & -- & -- & -- & -- & -- \\
\hline 4/24/2014 & -- & -- & -- & -- & -- & -- & -- & -- \\
\hline 4/29/2014 & -- & -- & -- & -- & -- & -- & -- & -- \\
\hline 4/30/2014 & -- & -- & -- & -- & -- & -- & -- & -- \\
\hline $5 / 1 / 2014$ & -- & -- & -- & -- & -- & -- & -- & -- \\
\hline $5 / 6 / 2014$ & -- & -- & -- & -- & -- & -- & -- & -- \\
\hline $5 / 7 / 2014$ & -- & -- & -- & -- & -- & -- & -- & -- \\
\hline $5 / 8 / 2014$ & -- & -- & -- & -- & -- & -- & -- & -- \\
\hline $5 / 13 / 2014$ & -- & -- & -- & -- & -- & -- & -- & -- \\
\hline $5 / 14 / 2014$ & -- & -- & -- & -- & -- & -- & -- & -- \\
\hline $5 / 15 / 2014$ & -- & -- & -- & -- & -- & -- & -- & -- \\
\hline $5 / 20 / 2014$ & -- & -- & -- & -- & -- & -- & -- & -- \\
\hline $5 / 21 / 2014$ & -- & -- & -- & -- & -- & -- & -- & -- \\
\hline $5 / 22 / 2014$ & -- & -- & -- & -- & -- & -- & -- & -- \\
\hline $5 / 28 / 2014$ & -- & -- & -- & -- & -- & -- & -- & -- \\
\hline $5 / 29 / 2014$ & -- & -- & -- & -- & -- & -- & -- & -- \\
\hline $5 / 30 / 2014$ & -- & -- & -- & -- & -- & -- & -- & -- \\
\hline 6/3/2014 & -- & -- & -- & -- & -- & -- & -- & -- \\
\hline 6/4/2014 & -- & -- & -- & -- & -- & -- & -- & -- \\
\hline 6/5/2014 & -- & -- & -- & -- & -- & -- & -- & -- \\
\hline 6/10/2014 & -- & -- & -- & -- & -- & -- & -- & -- \\
\hline $6 / 11 / 2014$ & -- & -- & -- & -- & -- & -- & -- & -- \\
\hline $6 / 12 / 2014$ & 2 & 8.21 & 7.99 & 8.43 & -- & -- & -- & -- \\
\hline 6/17/2014 & -- & -- & -- & -- & -- & -- & -- & -- \\
\hline $6 / 18 / 2014$ & -- & -- & -- & -- & -- & -- & -- & -- \\
\hline $7 / 1 / 2014$ & -- & -- & -- & -- & -- & -- & -- & -- \\
\hline 7/2/2014 & -- & -- & -- & -- & -- & -- & -- & -- \\
\hline $7 / 3 / 2014$ & -- & -- & -- & -- & -- & -- & -- & -- \\
\hline 7/8/2014 & -- & -- & -- & -- & -- & -- & -- & -- \\
\hline 7/9/2014 & -- & -- & -- & -- & -- & -- & -- & -- \\
\hline $7 / 10 / 2014$ & -- & -- & -- & -- & -- & -- & -- & -- \\
\hline $7 / 15 / 2014$ & -- & -- & -- & -- & -- & -- & -- & -- \\
\hline $7 / 16 / 2014$ & -- & -- & -- & -- & -- & -- & -- & -- \\
\hline $7 / 17 / 2014$ & -- & -- & -- & -- & -- & -- & -- & -- \\
\hline 7/22/2014 & -- & -- & -- & -- & -- & -- & -- & -- \\
\hline
\end{tabular}


Table 22. Number, mean length, minimum length, and maximum length of free-embryo and larval sturgeon (Scaphirhynchus spp.) and paddlefish (Polyodon spathula) collected in the Platte River at station 14.-Continued

[mm, millimeter; --, no data]

\begin{tabular}{|c|c|c|c|c|c|c|c|c|}
\hline \multirow[b]{2}{*}{$\begin{array}{l}\text { Collection } \\
\text { date }\end{array}$} & \multicolumn{4}{|c|}{ Sturgeon } & \multicolumn{4}{|c|}{ Paddlefish } \\
\hline & $\begin{array}{l}\text { Number } \\
\text { collected }\end{array}$ & $\begin{array}{l}\text { Mean } \\
\text { length } \\
(\mathrm{mm})\end{array}$ & $\begin{array}{l}\text { Minimum } \\
\text { length } \\
(\mathrm{mm})\end{array}$ & $\begin{array}{l}\text { Maximum } \\
\text { length } \\
(\mathrm{mm})\end{array}$ & $\begin{array}{l}\text { Number } \\
\text { collected }\end{array}$ & $\begin{array}{l}\text { Mean } \\
\text { length } \\
(\mathrm{mm})\end{array}$ & $\begin{array}{l}\text { Minimum } \\
\text { length } \\
(\mathrm{mm})\end{array}$ & $\begin{array}{l}\text { Maximum } \\
\text { length } \\
(\mathrm{mm})\end{array}$ \\
\hline $7 / 23 / 2014$ & -- & -- & -- & -- & -- & -- & -- & -- \\
\hline $7 / 24 / 2014$ & -- & -- & -- & -- & -- & -- & -- & -- \\
\hline $7 / 29 / 2014$ & -- & -- & -- & -- & -- & -- & -- & -- \\
\hline $7 / 30 / 2014$ & -- & -- & -- & -- & -- & -- & -- & -- \\
\hline $7 / 31 / 2014$ & -- & -- & -- & -- & -- & -- & -- & -- \\
\hline $8 / 5 / 2014$ & -- & -- & -- & -- & -- & -- & -- & -- \\
\hline 8/6/2014 & -- & -- & -- & -- & -- & -- & -- & -- \\
\hline 8/7/2014 & -- & -- & -- & -- & -- & -- & -- & -- \\
\hline $8 / 12 / 2014$ & -- & -- & -- & -- & -- & -- & -- & -- \\
\hline $8 / 13 / 2014$ & -- & -- & -- & -- & -- & -- & -- & -- \\
\hline $8 / 19 / 2014$ & -- & -- & -- & -- & -- & -- & -- & -- \\
\hline $8 / 20 / 2014$ & -- & -- & -- & -- & -- & -- & -- & -- \\
\hline $8 / 21 / 2014$ & -- & -- & -- & -- & -- & -- & -- & -- \\
\hline $8 / 26 / 2014$ & -- & -- & -- & -- & -- & -- & -- & -- \\
\hline $8 / 27 / 2014$ & -- & -- & -- & -- & -- & -- & -- & -- \\
\hline $8 / 28 / 2014$ & -- & -- & -- & -- & -- & -- & -- & -- \\
\hline
\end{tabular}

We implemented a particle tracking algorithm within the Surface-water Modeling System to estimate residence times of passively drifting particles in each model domain (Aquaveo LLC, 2013). On a cell-by-cell basis, velocity vectors and magnitudes were used to generate flow paths through the model domains. Each simulation was seeded with 10,000 particles whose starting positions were uniformly distributed along a transect, perpendicular to flow, across the thalweg near the upstream boundary of each reach. To allow comparison of calculated residence times between the two modeling reaches, values were normalized: (1) discharge was normalized by median discharge for each reach; and (2) residence time was normalized by mean reach length, as measured along the channel centerline throughout the model domain.

\section{Progress}

Hydroacoustic data were collected at the Lisbon-Jameson reach on 21 days from May 7 to September 13 (table 28). Bathymetric transects in the main channel were surveyed at regularly spaced $50-\mathrm{m}$ increments along the entire $14.6-\mathrm{km}$ reach (fig. 48). In the Lisbon Bottoms and Jameson Island chutes, transects were surveyed in 20-m increments. Six main stem water-surface profiles were surveyed at discharges ranging from 1,135 to 5,974 cubic meters per second $\left(\mathrm{m}^{3} / \mathrm{s}\right)$. Bathymetric and topographic data were integrated to generate a $10 \times 10 \mathrm{~m}$ orthogonal model mesh. Efforts are ongoing to generate a higher-resolution mesh for the Lisbon-Jameson model reach. After calibrating the model to measured watersurface profiles, we generated steady-state simulations for discharges ranging from base flow to overbank floods in 200$\mathrm{m}^{3} / \mathrm{s}$ increments ranging from 600 to $7,000 \mathrm{~m}^{3} / \mathrm{s}$. Simulations for the Miami reach were generated in $200-\mathrm{m}^{3} / \mathrm{s}$ increments ranging from 550 to $6,150 \mathrm{~m}^{3} / \mathrm{s}$.

Preliminary maps of inundation and velocity generated by flow simulations depict markedly different flow patterns in the two reaches. At Miami, simulated depth-averaged velocities during base flows display relatively little cross-stream variability because of confined flow, relatively uniform channel width, and low sinuosity (fig. 49). Similar patterns happen during bankfull flows; depth-averaged velocities are greater throughout the model domain, and eddies that are downstream from dikes become less prominent (fig. 49). Overbank flows are contained within a relatively narrow corridor along the channel because of extensive levees along the reach (fig. 49). For the entire range of discharges simulated, the primary sources of hydraulic variability within the active channel are rock dikes used to maintain the navigation channel. 
Table 23. Number, mean length, minimum length, and maximum length of free-embryo and larval sturgeon (Scaphirhynchus spp.) and paddlefish (Polyodon spathula) collected in the Platte River at station 15.

[mm, millimeter; --, no data]

\begin{tabular}{|c|c|c|c|c|c|c|c|c|}
\hline \multirow[b]{2}{*}{$\begin{array}{c}\text { Collection } \\
\text { date }\end{array}$} & \multicolumn{4}{|c|}{ Sturgeon } & \multicolumn{4}{|c|}{ Paddlefish } \\
\hline & $\begin{array}{l}\text { Number } \\
\text { collected }\end{array}$ & $\begin{array}{l}\text { Mean } \\
\text { length } \\
(\mathrm{mm})\end{array}$ & $\begin{array}{l}\text { Minimum } \\
\text { length } \\
(\mathrm{mm})\end{array}$ & $\begin{array}{l}\text { Maximum } \\
\text { length } \\
(\mathrm{mm})\end{array}$ & $\begin{array}{l}\text { Number } \\
\text { collected }\end{array}$ & $\begin{array}{l}\text { Mean } \\
\text { length } \\
(\mathbf{m m})\end{array}$ & $\begin{array}{c}\text { Minimum } \\
\text { length } \\
\text { (mm) }\end{array}$ & $\begin{array}{l}\text { Maximum } \\
\text { length } \\
\text { (mm) }\end{array}$ \\
\hline $5 / 13 / 2014$ & -- & -- & -- & -- & -- & -- & -- & -- \\
\hline $5 / 14 / 2014$ & -- & -- & -- & -- & -- & -- & -- & -- \\
\hline $5 / 15 / 2014$ & -- & -- & -- & -- & -- & -- & -- & -- \\
\hline 6/4/2014 & -- & -- & -- & -- & -- & -- & -- & -- \\
\hline 6/5/2014 & -- & -- & -- & -- & -- & -- & -- & -- \\
\hline $6 / 10 / 2014$ & -- & -- & -- & -- & -- & -- & -- & -- \\
\hline $6 / 11 / 2014$ & 1 & 8.18 & 8.18 & 8.18 & -- & -- & -- & -- \\
\hline $6 / 12 / 2014$ & -- & -- & -- & -- & -- & -- & -- & -- \\
\hline $6 / 17 / 2014$ & -- & -- & -- & -- & -- & -- & -- & -- \\
\hline $6 / 18 / 2014$ & -- & -- & -- & -- & -- & -- & -- & -- \\
\hline 7/1/2014 & -- & -- & -- & -- & -- & -- & -- & -- \\
\hline $7 / 2 / 2014$ & -- & -- & -- & -- & -- & -- & -- & -- \\
\hline 7/3/2014 & -- & -- & -- & -- & -- & -- & -- & -- \\
\hline 7/8/2014 & -- & -- & -- & -- & -- & -- & -- & -- \\
\hline 7/9/2014 & -- & -- & -- & -- & -- & -- & -- & -- \\
\hline $7 / 10 / 2014$ & -- & -- & -- & -- & -- & -- & -- & -- \\
\hline $7 / 15 / 2014$ & -- & -- & -- & -- & -- & -- & -- & -- \\
\hline $7 / 16 / 2014$ & -- & -- & -- & -- & -- & -- & -- & -- \\
\hline
\end{tabular}

Table 24. Number, mean length, minimum length, and maximum length of free-embryo and larval sturgeon (Scaphirhynchus spp.) and paddlefish (Polyodon spathula) collected in the Platte River at station 16.

[mm, millimeter; --, no data]

\begin{tabular}{|c|c|c|c|c|c|c|c|c|}
\hline \multirow[b]{2}{*}{$\begin{array}{l}\text { Collection } \\
\text { date }\end{array}$} & \multicolumn{4}{|c|}{ Sturgeon } & \multicolumn{4}{|c|}{ Paddlefish } \\
\hline & $\begin{array}{l}\text { Number } \\
\text { collected }\end{array}$ & $\begin{array}{c}\text { Mean } \\
\text { length } \\
(\mathrm{mm})\end{array}$ & $\begin{array}{l}\text { Minimum } \\
\text { length } \\
(\mathrm{mm})\end{array}$ & $\begin{array}{l}\text { Maximum } \\
\text { length } \\
(\mathbf{m m})\end{array}$ & $\begin{array}{l}\text { Number } \\
\text { collected }\end{array}$ & $\begin{array}{c}\text { Mean } \\
\text { length } \\
(\mathrm{mm})\end{array}$ & $\begin{array}{c}\text { Minimum } \\
\text { length } \\
(\mathrm{mm})\end{array}$ & $\begin{array}{l}\text { Maximum } \\
\text { length } \\
(\mathrm{mm})\end{array}$ \\
\hline $5 / 13 / 2014$ & -- & -- & -- & - & -- & -- & -- & -- \\
\hline $5 / 14 / 2014$ & -- & -- & -- & -- & -- & -- & -- & -- \\
\hline 6/4/2014 & -- & -- & -- & -- & -- & -- & -- & -- \\
\hline 6/5/2014 & -- & -- & -- & -- & -- & -- & -- & -- \\
\hline 6/17/2014 & -- & -- & -- & -- & -- & -- & -- & -- \\
\hline 6/18/2014 & -- & -- & -- & -- & -- & -- & -- & -- \\
\hline 7/1/2014 & -- & -- & -- & -- & -- & -- & -- & -- \\
\hline 7/2/2014 & -- & -- & -- & -- & -- & -- & -- & -- \\
\hline $7 / 3 / 2014$ & -- & -- & -- & -- & -- & -- & -- & -- \\
\hline
\end{tabular}




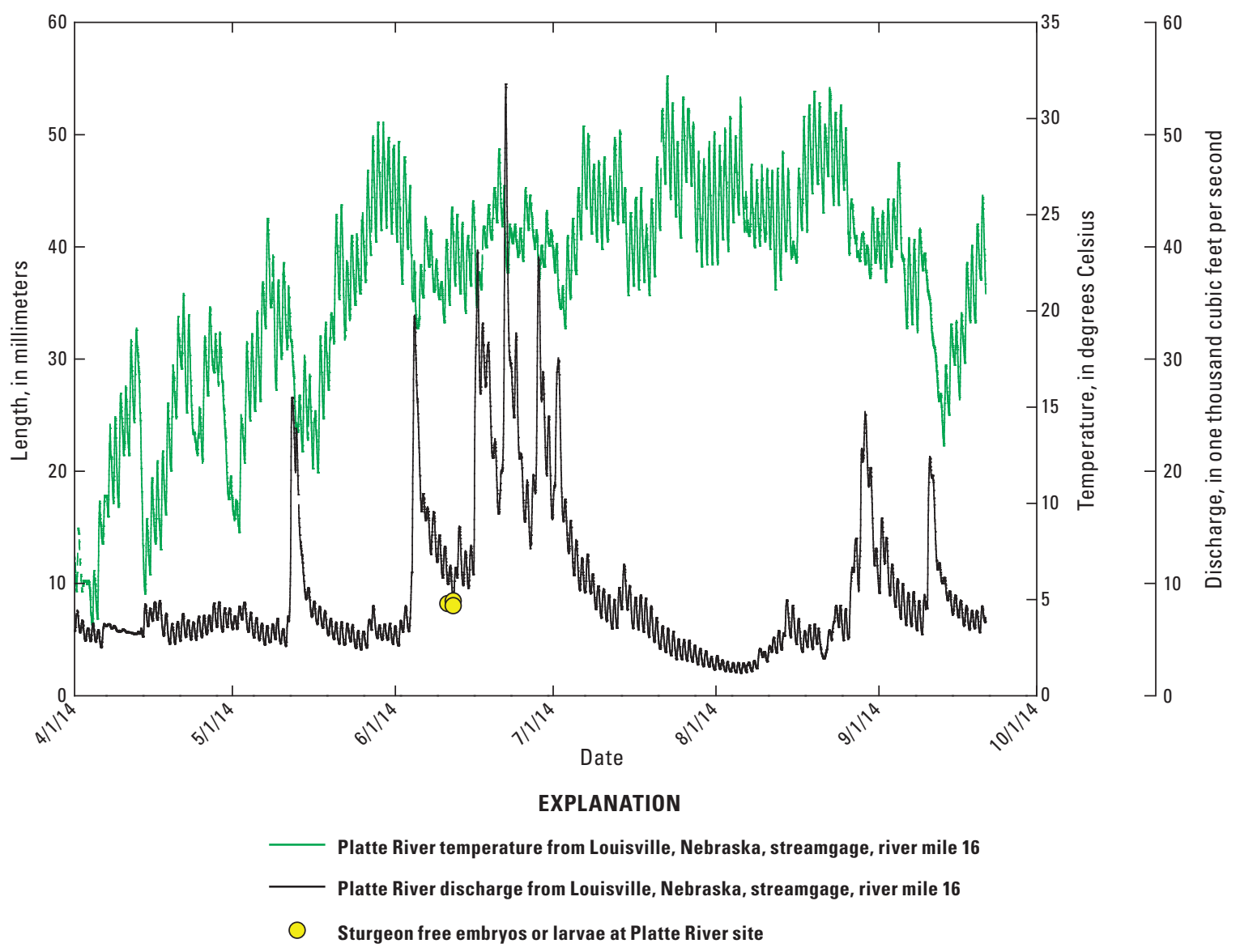

Figure 45. Length of sturgeon (Scaphirhynchus spp.) free embryos and larvae collected at the Platte River site during 2014. Mean hourly temperature and discharge from the U.S. Geological Survey streamgage near Louisville, Nebraska.

The Lisbon-Jameson reach is morphologically and hydraulically complex. Preliminary model results show that at base flows, bars, exposed dikes, and constructed side-channel chutes provide areas of low velocity and backwaters (fig. 50). As discharge approaches bankfull conditions, bars and dikes become inundated, but these features still provide substantial zones of hydraulic refugia (fig. 50). Substantial areas of low velocity are along the channel margins in the upstream and more developed chute at Lisbon Bottom; thus, a wide distribution of velocities is maintained during moderate floods (fig. 51). As discharge overtops channel banks, mean velocities in the main channel and chutes increase, but extensive areas of low velocity happen across the floodplain (fig. 51). Results presented here are preliminary; model solutions may change with refinement of the computation mesh and incorporation of additional calibration data.

The patterns in velocity depicted by the hydrodynamic simulations directly translate into differences in the routing of passively drifting particles through the model domains. For the full range of discharges evaluated, there is much greater variability in particle residence times calculated at LisbonJameson (fig. 52A) as compared to those in Miami (fig. 52B). Mean velocities do not differ substantially between the two reaches because currents in the navigation channel efficiently advect particles downstream; thus, as discharge increases, the median residence time steadily decreases in both reaches. In the Lisbon-Jameson reach, however, there is greater potential for retention within low-velocity environments, which results in the long-tailed distribution of particle residence times observed for all discharges (fig. 52). Additionally, the slight increase in the distribution of residence times at Lisbon-Jameson during large floods reflects the retention of particles on the floodplain that happens during overbank flows. This effect is not observed at Miami because of the limited floodplain connectivity and the overwhelming ability of the navigation channel to convey water downstream. 
Table 25. Mean density of sturgeon (Scaphirhynchus spp.) free embryos and larvae per sampling day.

$[--$, no data $]$

\begin{tabular}{|c|c|c|c|c|c|c|c|}
\hline \multirow{2}{*}{ Date } & \multicolumn{7}{|c|}{ Station number } \\
\hline & 10 & 11 & 12 & 13 & 14 & 15 & 16 \\
\hline $4 / 15 / 2014$ & 0 & 0 & 0 & 0 & 0 & -- & -- \\
\hline $4 / 16 / 2014$ & 0 & 0 & 0 & 0 & 0 & -- & -- \\
\hline $4 / 17 / 2014$ & 0 & 0 & 0 & 0 & 0 & -- & -- \\
\hline $4 / 22 / 2014$ & 0 & 0 & 0 & 0 & 0 & -- & -- \\
\hline $4 / 23 / 2014$ & 0 & 0 & 0 & 0 & 0 & -- & -- \\
\hline $4 / 24 / 2014$ & 0 & 0 & 0 & 0 & 0 & -- & -- \\
\hline $4 / 29 / 2014$ & 0 & 0 & 0 & 0 & 0 & -- & -- \\
\hline $4 / 30 / 2014$ & 0 & 0 & 0 & 0 & 0 & -- & -- \\
\hline $5 / 1 / 2014$ & 0 & 0 & 0 & 0 & 0 & -- & -- \\
\hline $5 / 6 / 2014$ & 0 & 0 & 0 & 0 & 0 & -- & -- \\
\hline $5 / 7 / 2014$ & 0 & 0 & 0 & 0 & 0 & -- & -- \\
\hline $5 / 8 / 2014$ & 0 & 0 & 0 & 0 & 0 & -- & -- \\
\hline $5 / 13 / 2014$ & 0 & 0 & 0 & 0 & 0 & 0 & 0 \\
\hline $5 / 14 / 2014$ & 0 & 0 & 0 & 0 & 0 & 0 & 0 \\
\hline $5 / 15 / 2014$ & 0 & 0 & 0 & 0 & 0 & 0 & -- \\
\hline $5 / 20 / 2014$ & 0 & 0 & 0 & 0 & 0 & -- & -- \\
\hline $5 / 21 / 2014$ & 0 & 0 & 0 & 0 & 0 & -- & -- \\
\hline $5 / 22 / 2014$ & 0 & 0 & 0 & 0 & 0 & -- & -- \\
\hline $5 / 28 / 2014$ & 0.26 & 0.28 & 0.18 & 0 & 0 & -- & -- \\
\hline $5 / 29 / 2014$ & 0 & 0.48 & 0 & 0 & 0 & -- & -- \\
\hline $5 / 30 / 2014$ & 2.51 & 0.24 & 0 & 0 & 0 & -- & -- \\
\hline $6 / 3 / 2014$ & 3.44 & 4.36 & 0 & 0 & 0 & -- & -- \\
\hline $6 / 4 / 2014$ & -- & -- & -- & -- & 0 & 0 & -- \\
\hline 6/5/2014 & 0.56 & 3.55 & 0 & 0 & 0 & 0 & 0 \\
\hline $6 / 10 / 2014$ & 5.66 & 4.39 & 0 & 0 & 0 & 0 & -- \\
\hline $6 / 11 / 2014$ & 1.68 & 3.33 & 0.43 & 0 & 0 & 0.75 & -- \\
\hline $6 / 12 / 2014$ & 0.60 & 1.13 & 0 & 0 & 1.29 & 0 & -- \\
\hline $6 / 17 / 2014$ & -- & -- & -- & -- & 0 & 0 & 0 \\
\hline $6 / 18 / 2014$ & -- & -- & -- & -- & 0 & 0 & 0 \\
\hline $7 / 1 / 2014$ & 0 & 0 & 0 & 0 & 0 & 0 & 0 \\
\hline $7 / 2 / 2014$ & -- & -- & -- & -- & 0 & 0 & 0 \\
\hline $7 / 3 / 2014$ & 0 & 0 & 0 & 0 & 0 & 0 & 0 \\
\hline 7/8/2014 & 0 & 0 & 0 & 0 & 0 & 0 & -- \\
\hline 7/9/2014 & 0 & 0.24 & 0 & 0 & 0 & 0 & -- \\
\hline $7 / 10 / 2014$ & 0 & 0 & 0 & 0 & 0 & -- & -- \\
\hline $7 / 15 / 2014$ & 0 & 0.17 & 0 & 0 & 0 & 0 & -- \\
\hline $7 / 16 / 2014$ & 0 & 0 & 0 & 0 & 0 & 0 & -- \\
\hline $7 / 17 / 2014$ & 0 & 0 & 0 & 0 & 0 & -- & -- \\
\hline $7 / 22 / 2014$ & 0.73 & 0.46 & 0 & 0 & 0 & -- & -- \\
\hline $7 / 23 / 2014$ & 0.40 & 0 & 0.13 & 0 & 0 & -- & -- \\
\hline $7 / 24 / 2014$ & 0 & 0.38 & 0 & 0 & 0 & -- & -- \\
\hline $7 / 29 / 2014$ & 0 & 0.35 & 0 & 0 & 0 & -- & -- \\
\hline
\end{tabular}


Table 25. Mean density of sturgeon (Scaphirhynchus spp.) free embryos and larvae per sampling day.-Continued [--, no data]

\begin{tabular}{|c|c|c|c|c|c|c|c|}
\hline \multirow{2}{*}{ Date } & \multicolumn{7}{|c|}{ Station number } \\
\hline & 10 & 11 & 12 & 13 & 14 & 15 & 16 \\
\hline $7 / 30 / 2014$ & 0 & 0.58 & 0.13 & 0 & 0 & -- & -- \\
\hline $7 / 31 / 2014$ & 0.21 & 0.26 & 0 & 0 & 0 & -- & -- \\
\hline $8 / 5 / 2014$ & 0.57 & 0.75 & 0 & 0 & 0 & -- & -- \\
\hline $8 / 6 / 2014$ & 0.48 & 0.24 & 0 & 0 & 0 & -- & -- \\
\hline 8/7/2014 & 0.23 & 0.48 & 0 & 0 & 0 & -- & -- \\
\hline $8 / 12 / 2014$ & 2.77 & 2.92 & 0.13 & 0 & 0 & -- & -- \\
\hline $8 / 13 / 2014$ & 4.19 & 1.33 & 0 & 0 & 0 & -- & -- \\
\hline $8 / 14 / 2014$ & 3.46 & 2.77 & 0.14 & 0 & -- & -- & -- \\
\hline $8 / 19 / 2014$ & 0.76 & 1.25 & 0 & 0 & 0 & -- & -- \\
\hline $8 / 20 / 2014$ & 0.37 & 0.53 & 0 & 0 & 0 & -- & -- \\
\hline $8 / 21 / 2014$ & 0.82 & 1.95 & 0 & 0 & 0 & -- & -- \\
\hline $8 / 26 / 2014$ & 0 & 0 & 0 & 0 & 0 & -- & -- \\
\hline $8 / 27 / 2014$ & 0.20 & 0.23 & 0.24 & 0 & 0 & -- & -- \\
\hline 8/28/2014 & 0 & 0.24 & 0 & 0 & 0 & -- & -- \\
\hline Mean & 0.58 & 0.63 & 0.03 & 0.00 & 0.02 & 0.04 & 0.00 \\
\hline
\end{tabular}

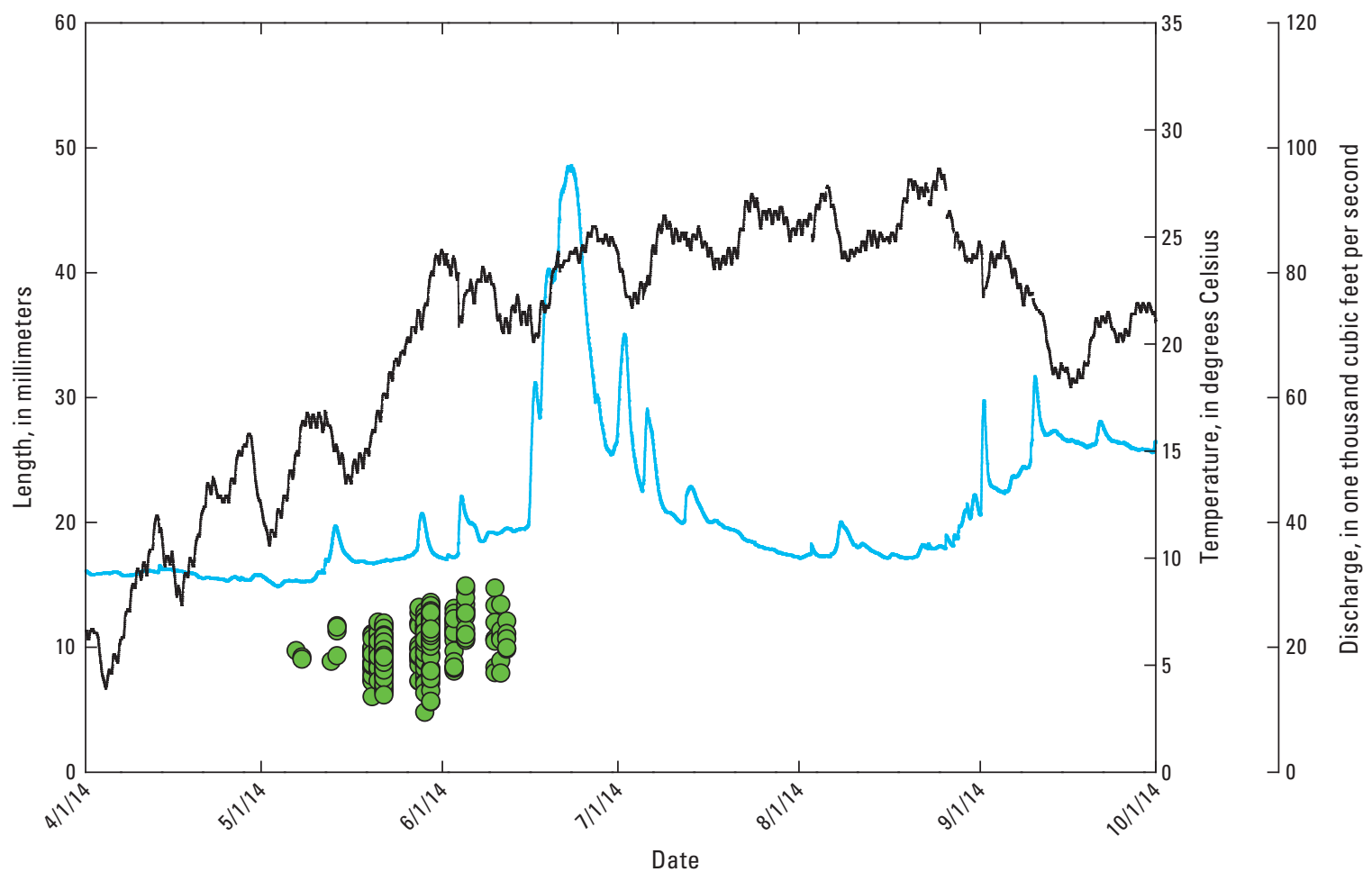

EXPLANATION

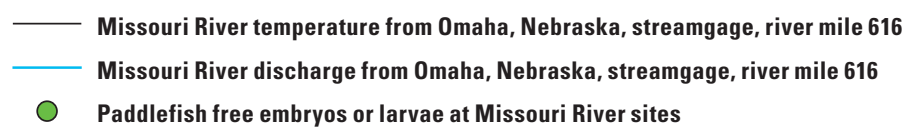

Figure 46. Length of paddlefish (Polyodon spathula) free embryos and larvae collected at the Missouri River site during 2014. Mean hourly temperature and discharge from the U.S. Geological Survey streamgage near Omaha, Nebraska. 
Table 26. Mean density of paddlefish (Polyodon spathula) free embryos and larvae per sampling day.

$[--$, no data $]$

\begin{tabular}{|c|c|c|c|c|c|c|c|}
\hline \multirow{2}{*}{ Date } & \multicolumn{7}{|c|}{ Station number } \\
\hline & 10 & 11 & 12 & 13 & 14 & 15 & 16 \\
\hline $4 / 15 / 2014$ & 0 & 0 & 0 & 0 & 0 & -- & -- \\
\hline $4 / 16 / 2014$ & 0 & 0 & 0 & 0 & 0 & -- & -- \\
\hline $4 / 17 / 2014$ & 0 & 0 & 0 & 0 & 0 & -- & -- \\
\hline $4 / 22 / 2014$ & 0 & 0 & 0 & 0 & 0 & -- & -- \\
\hline $4 / 23 / 2014$ & 0 & 0 & 0 & 0 & 0 & -- & -- \\
\hline $4 / 24 / 2014$ & 0 & 0 & 0 & 0 & 0 & -- & -- \\
\hline 4/29/2014 & 0 & 0 & 0 & 0 & 0 & -- & -- \\
\hline $4 / 30 / 2014$ & 0 & 0 & 0 & 0 & 0 & -- & -- \\
\hline $5 / 1 / 2014$ & 0 & 0 & 0 & 0 & 0 & -- & -- \\
\hline $5 / 6 / 2014$ & 0 & 0 & 0 & 0 & 0 & -- & -- \\
\hline $5 / 7 / 2014$ & 0 & 0 & 0.13 & 0 & 0 & -- & -- \\
\hline $5 / 8 / 2014$ & 0 & 0 & 0 & 0.32 & 0 & -- & -- \\
\hline $5 / 13 / 2014$ & 0.16 & 0 & 0 & 0 & 0 & 0 & 0 \\
\hline $5 / 14 / 2014$ & 0 & 0.48 & 0 & 0.16 & 0 & 0 & 0 \\
\hline $5 / 15 / 2014$ & 0 & 0 & 0 & 0 & 0 & 0 & -- \\
\hline $5 / 20 / 2014$ & 2.41 & 2.99 & 0.26 & 0.17 & 0 & -- & -- \\
\hline $5 / 21 / 2014$ & 2.91 & 2.63 & 0.26 & 0 & 0 & -- & -- \\
\hline $5 / 22 / 2014$ & 7.23 & 5.39 & 0.15 & 0 & 0 & -- & -- \\
\hline $5 / 28 / 2014$ & 2.73 & 0.89 & 1.13 & 0 & 0 & -- & -- \\
\hline $5 / 29 / 2014$ & 4.41 & 3.26 & 0.55 & 0.28 & 0 & -- & -- \\
\hline $5 / 30 / 2014$ & 21.38 & 2.18 & 0.54 & 0 & 0 & -- & -- \\
\hline $6 / 3 / 2014$ & 1.66 & 1.77 & 0.15 & 0 & 0 & -- & -- \\
\hline $6 / 4 / 2014$ & -- & -- & -- & -- & 0 & 0 & -- \\
\hline 6/5/2014 & 0.57 & 4.31 & 0 & 0 & 0 & 0 & 0 \\
\hline $6 / 10 / 2014$ & 0.86 & 0.52 & 0 & 0 & 0 & 0 & -- \\
\hline 6/11/2014 & 0.62 & 0.38 & 0 & 0 & 0 & 0 & -- \\
\hline $6 / 12 / 2014$ & 0.24 & 0.37 & 0 & 0 & 0 & 0 & -- \\
\hline $6 / 17 / 2014$ & -- & -- & -- & -- & 0 & 0 & 0 \\
\hline $6 / 18 / 2014$ & -- & -- & -- & -- & 0 & 0 & 0 \\
\hline 7/1/2014 & 0 & 0 & 0 & 0 & 0 & 0 & 0 \\
\hline $7 / 2 / 2014$ & -- & -- & -- & -- & 0 & 0 & 0 \\
\hline $7 / 3 / 2014$ & 0 & 0 & 0 & 0 & 0 & 0 & 0 \\
\hline 7/8/2014 & 0 & 0 & 0 & 0 & 0 & 0 & -- \\
\hline 7/9/2014 & 0 & 0 & 0 & 0 & 0 & 0 & -- \\
\hline $7 / 10 / 2014$ & 0 & 0 & 0 & 0 & 0 & -- & -- \\
\hline $7 / 15 / 2014$ & 0 & 0 & 0 & 0 & 0 & 0 & -- \\
\hline $7 / 16 / 2014$ & 0 & 0 & 0 & 0 & 0 & 0 & -- \\
\hline $7 / 17 / 2014$ & 0 & 0 & 0 & 0 & 0 & -- & -- \\
\hline $7 / 22 / 2014$ & 0 & 0 & 0 & 0 & 0 & -- & -- \\
\hline $7 / 23 / 2014$ & 0 & 0 & 0 & 0 & 0 & -- & -- \\
\hline $7 / 24 / 2014$ & 0 & 0 & 0 & 0 & 0 & -- & -- \\
\hline $7 / 29 / 2014$ & 0 & 0 & 0 & 0 & 0 & -- & -- \\
\hline
\end{tabular}


Table 26. Mean density of paddlefish (Polyodon spathula) free embryos and larvae per sampling day.-Continued

[--, no data]

\begin{tabular}{|c|c|c|c|c|c|c|c|}
\hline \multirow{2}{*}{ Date } & \multicolumn{7}{|c|}{ Station number } \\
\hline & 10 & 11 & 12 & 13 & 14 & 15 & 16 \\
\hline $7 / 30 / 2014$ & 0 & 0 & 0 & 0 & 0 & -- & -- \\
\hline $7 / 31 / 2014$ & 0 & 0 & 0 & 0 & 0 & -- & -- \\
\hline $8 / 5 / 2014$ & 0 & 0 & 0 & 0 & 0 & -- & -- \\
\hline $8 / 6 / 2014$ & 0 & 0 & 0 & 0 & 0 & -- & -- \\
\hline 8/7/2014 & 0 & 0 & 0 & 0 & 0 & -- & -- \\
\hline $8 / 12 / 2014$ & 0 & 0 & 0 & 0 & 0 & -- & -- \\
\hline $8 / 13 / 2014$ & 0 & 0 & 0 & 0 & 0 & -- & -- \\
\hline $8 / 14 / 2014$ & 0 & 0 & 0 & 0 & -- & -- & -- \\
\hline $8 / 19 / 2014$ & 0 & 0 & 0 & 0 & 0 & -- & -- \\
\hline $8 / 20 / 2014$ & 0 & 0 & 0 & 0 & 0 & -- & -- \\
\hline $8 / 21 / 2014$ & 0 & 0 & 0 & 0 & 0 & -- & -- \\
\hline $8 / 26 / 2014$ & 0 & 0 & 0 & 0 & 0 & -- & -- \\
\hline $8 / 27 / 2014$ & 0 & 0 & 0 & 0 & 0 & -- & -- \\
\hline $8 / 28 / 2014$ & 0 & 0 & 0 & 0 & 0 & -- & -- \\
\hline Mean & 0.87 & 0.48 & 0.06 & 0.02 & 0.00 & 0.00 & 0.00 \\
\hline
\end{tabular}

\section{Discussion}

The hydraulic simulations highlight the geomorphic and channel engineering features that create channel complexity and promote retention of drifting particles within the Lower Missouri River. Typical sections of the Lower Missouri River, represented by the Miami modeling reach, are characterized by relatively uniform channel widths, low morphologic variability, and limited access to the floodplain; thus, drifting particles or organisms are efficiently advected downstream and may not be able to exit the thalweg before the point at which they need to transition to the benthos and begin exogenous feeding. The degree of exchange of free embryos between the thalweg and typical wing-dike structures is unknown. Restored reaches, such as Lisbon-Jameson, provide more complex hydraulic conditions that may transport the larvae into channel-margin habitats. It is hypothesized that such environments provide the food-producing and foraging habitats required for survival of juvenile pallid sturgeon.

Several features of the Lisbon-Jameson reach contribute to hydraulic complexity captured by the model outputs and resulting particle tracking simulations. Heterogeneity in the simulated distribution of velocities results from not only the presence of constructed side-channel chutes but also the relatively large channel width, variability in channel width, and sinuosity that leads to the secondary currents that drive the formation of bars. The reach also displays greater floodplain connectivity than much of the Lower Missouri River. These characteristics of the Lisbon-Jameson reach increase channel complexity and hydraulic heterogeneity and, thus, increase opportunities for drifting free embryos to exit the thalweg and access foraging habitats. Further research is needed to evaluate the relative contributions of these different geomorphic features to the retention of drifting free embryos within the Lower Missouri River to inform ongoing restoration efforts. Additionally, the presence of hydraulic conditions that are more conducive to retention and settling alone does not indicate that larvae will discover conditions supportive of foraging or with adequate food resources. Identifying the habitat requirements of pallid sturgeon during these early life stages remains an area of ongoing research.

\section{Laboratory Assessments of Free-Embryo and Larval Hatch, Dispersal, and Settling Behavior}

Early life stages of sturgeons have evolved a downstream dispersal behavior that transports them from spawning and hatch locations to downstream rearing areas (Kynard and others, 2007). Dispersal behaviors may differ markedly among sturgeon species and among geographic races or subpopulations (Khodorevskaya and others, 2009). Pallid and shovelnose sturgeon are thought to begin dispersal as free embryos immediately after hatch based on previous laboratory observations (Kynard and others, 2007). In contrast, studies of other sturgeon species have documented delayed drift because of a period of interstitial residency (McAdam, 2011, 2012). Because of the lack of field verification of immediate drift 
A. Lower Missouri River

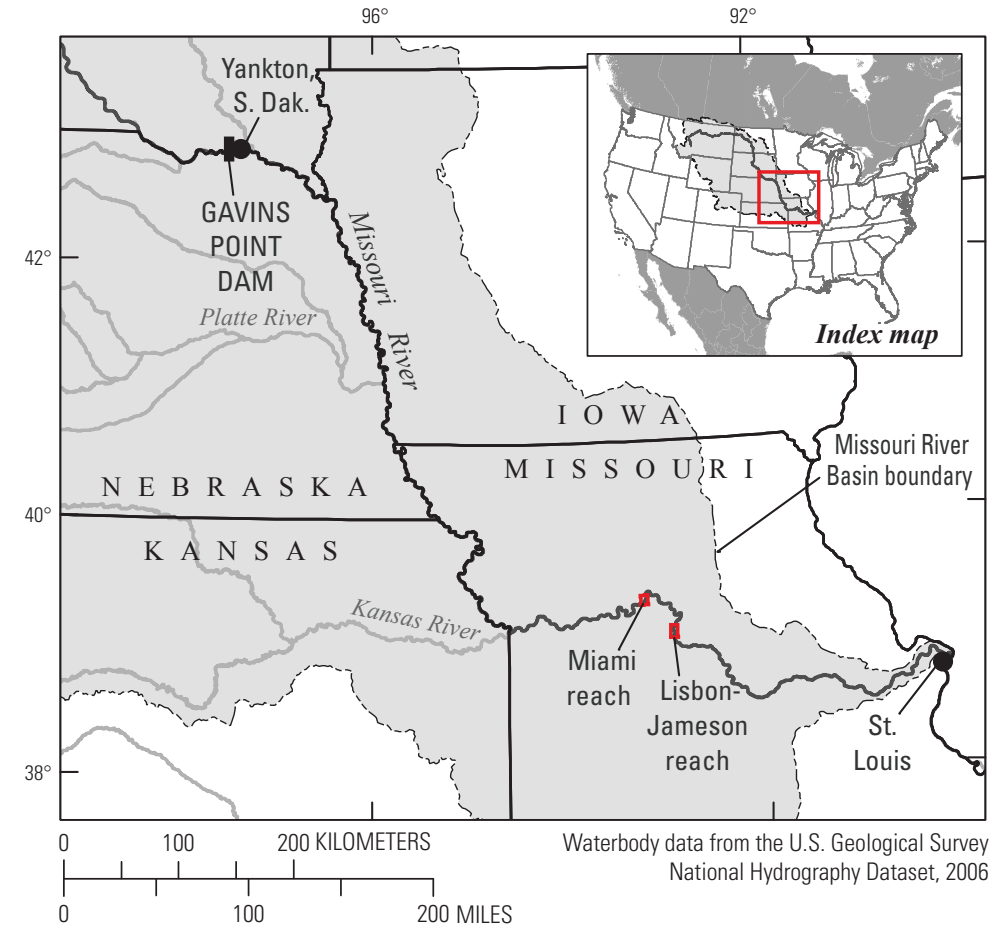

B. Lisbon-Jameson reach

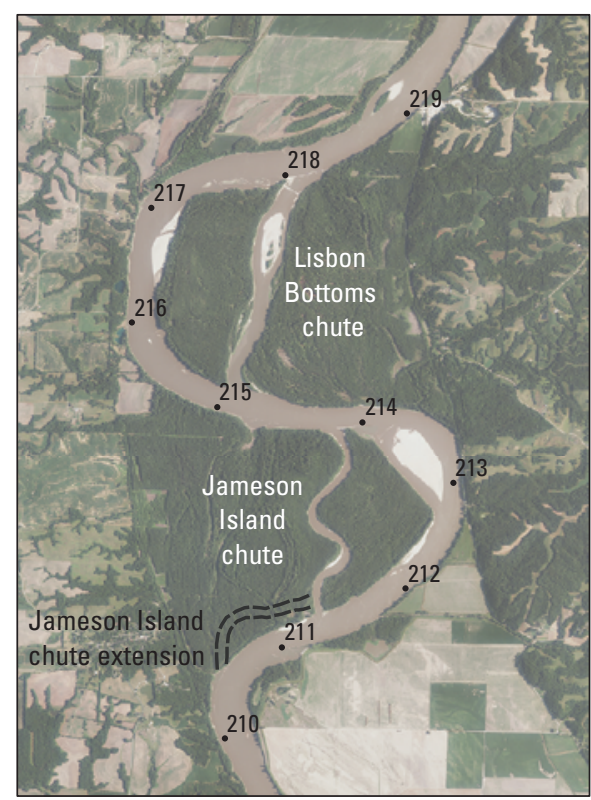

Base data from National Agriculture Imagery Program, 2012 Universal Transverse Mercator projection, zone 15

\section{Miami reach}
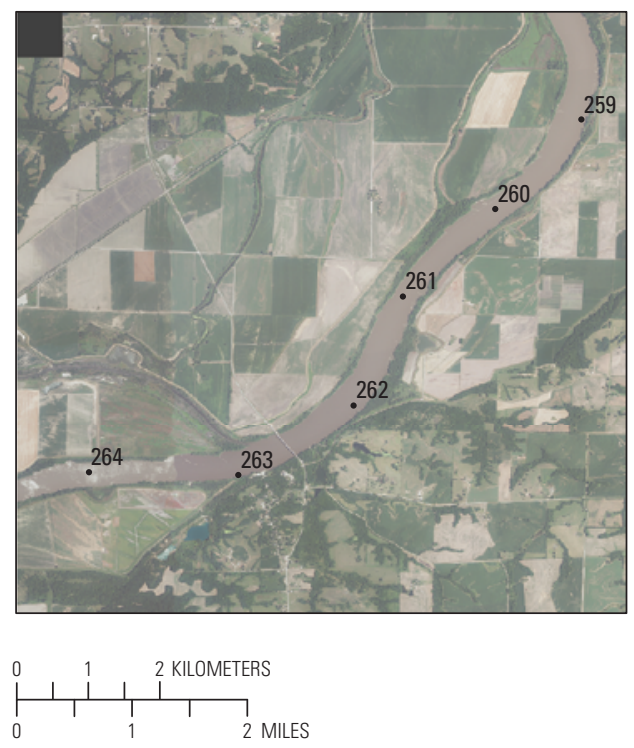

\section{EXPLANATION}

262. River mile marker-Distance upstream from the confluence with the Mississippi River, in river miles

Figure 47. The Miami and Lisbon-Jameson reaches on the Lower Missouri River where two-dimensional hydrodynamic models were developed. $A$, the Lower Missouri River; $B$, the Lisbon-Jameson reach (river miles 210.0-219.1); and, $C$, the Miami reach (river miles 259.6-263.5). 
Table 27. Summary data for Miami and Lisbon-Jameson reaches on the Lower Missouri River where two-dimensional hydrodynamic models were developed.

\begin{tabular}{lclccc}
\hline \multicolumn{1}{c}{ Reach } & River miles & Nearest streamgage & $\begin{array}{c}\text { Length } \\
\text { (meter) }\end{array}$ & $\begin{array}{c}\text { Average bankfull width' } \\
\text { (meter) }\end{array}$ & $\begin{array}{c}\text { Reach slope } \\
\text { (meter per meter) }\end{array}$ \\
\hline Miami, Missouri & $259.2-264.4$ & Waverly, Missouri & 8,400 & 345 & 0.00015 \\
Lisbon-Jameson, Missouri & $210.0-219.1$ & Glasgow, Missouri & 14,600 & 442 & 0.00018 \\
\hline
\end{tabular}

${ }^{1}$ Average bankfull width reported for Lisbon-Jameson reports the average width measured along the main channel, excluding the width of side-channel chutes.

Table 28. Summary of field data collected in 2014 for development of the Lisbon-Jameson hydrodynamic model.

$\left[\mathrm{ft}^{3} / \mathrm{s}\right.$, cubic foot per second]

\begin{tabular}{lrl}
\hline \multicolumn{1}{c}{ Date } & $\begin{array}{c}\text { Discharge } \\
\text { at Glasgow' } \\
\text { (ft's) }\end{array}$ & \multicolumn{1}{c}{ Data collected } \\
\hline $5 / 7 / 2014$ & 45,600 & Water surface profile. \\
$5 / 16 / 2014$ & 77,200 & Water surface profile; velocity transects. \\
$5 / 20 / 2014$ & 51,300 & Bathymetry transects (main channel). \\
$5 / 21 / 2014$ & 49,200 & Bathymetry transects (main channel). \\
$5 / 23 / 2014$ & 46,800 & Bathymetry transects (main channel). \\
$5 / 27 / 2014$ & 46,500 & Topographic ground survey. \\
$5 / 29 / 2015$ & 46,600 & Topographic ground survey. \\
$6 / 3 / 2014$ & 49,200 & Topographic ground survey. \\
$6 / 8 / 2014$ & 155,000 & Water surface profile. \\
$6 / 9 / 2014$ & 158,000 & Bathymetry (Lisbon chute). \\
$6 / 10 / 2014$ & 154,000 & Bathymetry (Lisbon chute). \\
$6 / 11 / 2014$ & 128,000 & Bathymetry (Lisbon and Jameson \\
& & chutes). \\
$6 / 13 / 2014$ & 121,000 & Bathymetry (Jameson chute). \\
$6 / 23 / 2014$ & 115,000 & Bathymetry (main channel). \\
$6 / 24 / 2014$ & 122,000 & Bathymetry (main channel). \\
$6 / 25 / 2014$ & 121,000 & Bathymetry (main channel). \\
$6 / 26 / 2014$ & 121,000 & Bathymetry (main channel). \\
$6 / 27 / 2014$ & 122,000 & Water surface profile. \\
$7 / 9 / 2014$ & 139,000 & Water surface profile; velocity transects. \\
$8 / 20 / 2014$ & 85,000 & Water surface profile; velocity transects. \\
9/13/2014 & 195,000 & Water surface profile; velocity transects. \\
\hline $1515 c h a t g$ & & \\
& &
\end{tabular}

\footnotetext{
${ }^{1}$ Discharge is reported as the mean daily discharge for the corresponding
} date.

and the importance of this information to species recovery, the CSRP is treating immediate and delayed drift as competing hypotheses (see the "Assessments of Factors Affecting Embryo Incubation, Hatch, and Initial Drift" section).

Pallid and shovelnose sturgeon are also thought to differ in the duration of the free-embryo drift stage before transitioning to the benthic larval stage (Kynard and others, 2007;
Braaten and others, 2008). In laboratory and field studies of sturgeon from the Upper Missouri and Yellowstone Rivers, the duration of the drift stage for pallid sturgeon (11-17 days) was about twice as long as that for shovelnose sturgeon (4-6 days) (Kynard and others, 2007; Braaten and others, 2008). These findings indicate that under similar hydraulic conditions, pallid sturgeon require a longer stretch of freeflowing river to complete the ontogenetic drift cycle compared to shovelnose sturgeon.

Little is known about the drift behavior of sturgeon from genetically differentiated subgroups, from downstream parts of the species range, or from pallid $\times$ shovelnose sturgeon hybrids. The downstream subgroups may exhibit different dispersal behaviors than those from the most upstream population, and the hybrids may express intermediate dispersal behaviors.

The overall objectives of this task are to develop an understanding of normal Scaphirhynchus sturgeon behaviors from hatch through first feeding in the laboratory to guide future research on dispersal dynamics of sturgeon in the Missouri River. Our main objectives are to quantify survival and stage-specific dispersal behaviors of newly hatched embryos through first feeding of shovelnose sturgeon and pallid sturgeon, pallid sturgeon subgroups, and paddlefish under the same set of experimental conditions (that is, flow, temperature, and water quality). Paddlefish were included because their early life history is similar to that of Scaphirhynchus sturgeon species; paddlefish free embryos have been documented to begin downstream drift immediately after hatch (Jennings and Zigler, 2009). The goal is to identify morphological and innate behavioral traits that accelerate or reduce downstream drift among Scaphirhynchus sturgeon species, among pallid sturgeon subgroups, and between sturgeon and paddlefish.

\section{Methods}

Fish

Pallid sturgeon eggs were obtained from Blind Pony State Fish Hatchery (BPSFH), Sweet Springs, Mo., and Gavins Point National Fish Hatchery (GPNFH), Yankton, South Dakota. Eggs received from BPSFH (designated as PLS-6) were artificially spawned on May 1, 2014, from Middle 


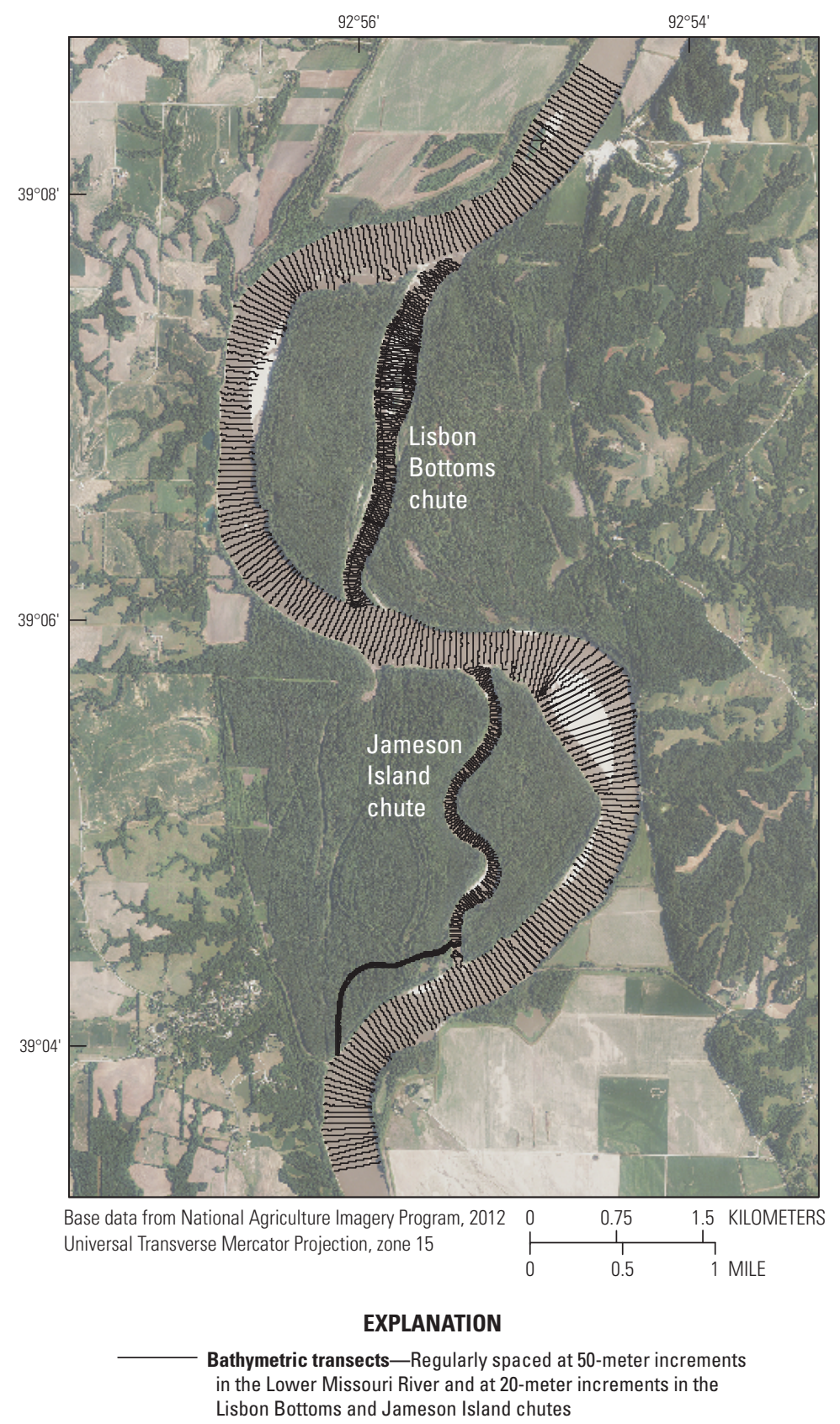

Figure 48. Bathymetric and topographic survey data used to construct the mesh for the Lisbon-Jameson hydrodynamic model.
Missouri River Basin stock and shipped by overnight courier to Yankton Field Research Station (FRS). The two lots of eggs from GPNFH (designated as PLS-8 and PLS-9) were the progeny of Upper Missouri River Basin stock but from different parents. Embryos of lots PLS-8 and PLS-9 were spawned on June 20 and July 2, 2014, respectively, and were transported to the Yankton FRS within 15 min after collection in 1-liter (L) plastic containers filled with aerated hatchery water. Upon arrival at the Yankton FRS, embryos were acclimated to the culture water temperature of $17-19^{\circ} \mathrm{C}$ (PLS-6 at $17{ }^{\circ} \mathrm{C}$; PLS-8 and PLS-9 at $19{ }^{\circ} \mathrm{C}$ ) during a period of $2-5 \mathrm{~h}$ and partly acclimated to the culture water quality by a series of static-renewal water replacements.
One lot of paddlefish eggs (designated as PAH-3) was obtained from GPNFH for interspecies comparisons. The eggs were progeny of wild-caught adults from the Upper Missouri River Basin and were spawned on May 29, 2014. The embryos were transported to the Yankton FRS and acclimated as described in the previous paragraph.

The embryos of all lots were hatched in a miniature egg incubator system constructed by James Candrl at the USGS CERC. The system is based on McDonald or Downing hatching jar devices where water is delivered through a tube to the rounded bottom of jars or cylindrical vessels containing the eggs (Piper and others, 1982). The incubation tubes $(50 \mathrm{~mL} ; 25 \times 200 \mathrm{~mm}$ Pyrex glass) were fitted with a 

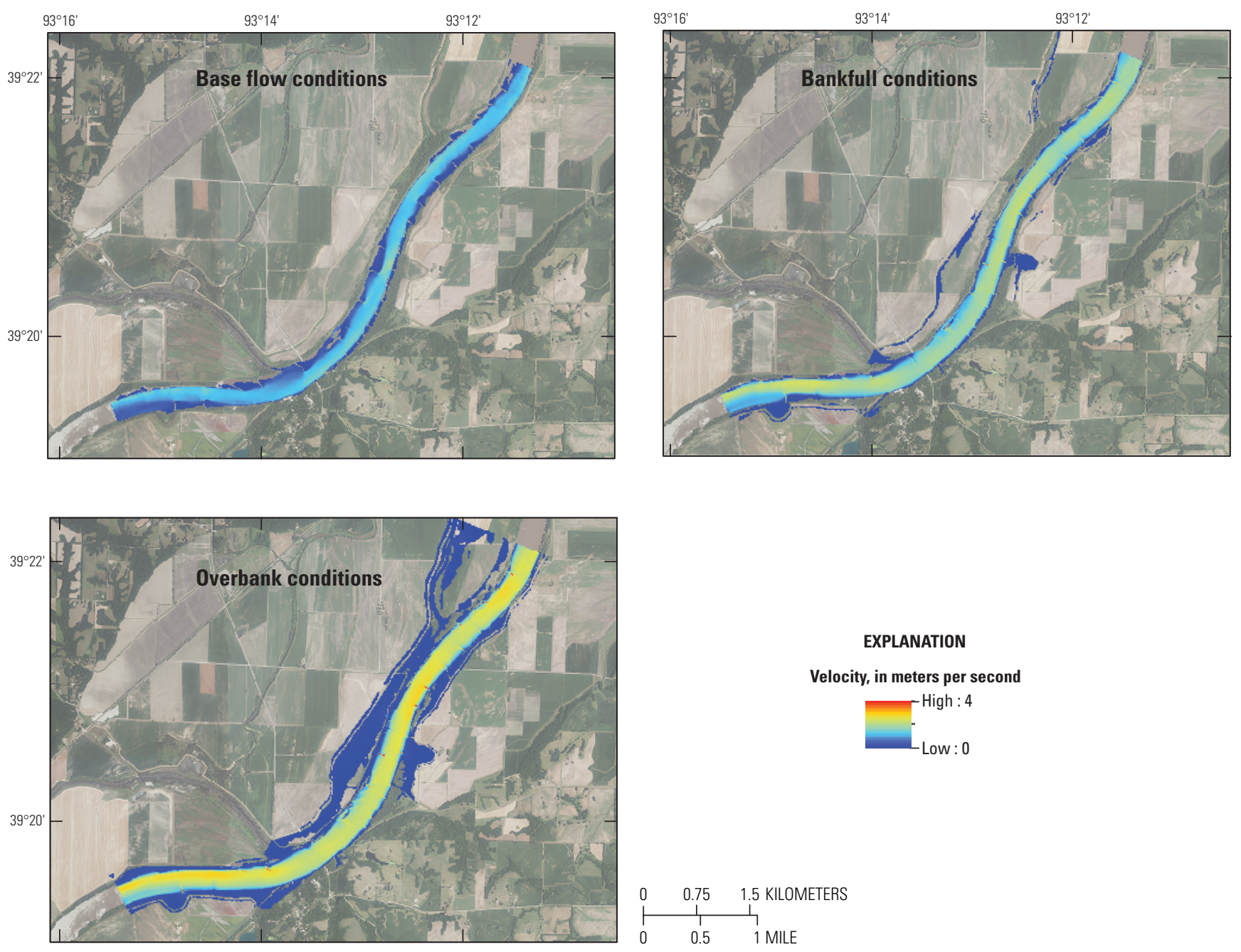

\section{EXPLANATION}

Velocity, in meters per second

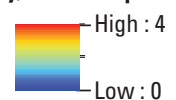

Base data from National Agriculture Imagery Program, 2012

Universal Transverse Mercator projection, zone 15

Figure 49. Simulated depth-averaged velocities for a subset of discharges in the Miami modeling reach representing base flow, bankfull, and overbank conditions.

250-micron nylon screen around the top of the tube to retain the hatched embryos.

Free embryos used in dispersal studies (see the "Dispersal Studies" section) were taken from the incubation tubes. The remaining embryos of a given lot were cultured in incubation tubes for the duration of the experiments except for PLS-8, which were transferred at $8 \mathrm{dph}$ to a polyethylene, cylindrical tank ( $75 \mathrm{~cm}$ in diameter by $61 \mathrm{~cm}$ tall) containing approximately $117 \mathrm{~L}$ of tempered culture water maintained at an average velocity of $0.07 \mathrm{~m} / \mathrm{s}$.

\section{Test Water}

The fish were cultured and tested in a nonstandard reconstituted water (table 29) designed to simulate the primary water-quality characteristics (without trace inorganic contaminants) of the Missouri River near Sioux City, Iowa (about
0.5 mile upstream from the USGS streamgage 06486000; table 30) (Christiansen, 2004). The water-quality data for June were used because pallid sturgeon are presumed to spawn between April and June, and most of larval Scaphirhynchus spp. have been collected from late May through mid-June in this reach of the Missouri River (DeLonay and others, 2009). Alkalinity was not measured by Christiansen (2004) and was estimated from the cation-anion balance as the difference between summed concentrations (in milliequivalents/liter) of cations and anions. The reconstituted water was prepared by adding appropriate amounts of mineral salts (pharmaceutical grade or higher) to DI water in 5,678-L (1,500-gallon) polyethylene tanks equipped with a recirculating pump to mix and aerate the water. Before usage, each tank of water was vigorously aerated for at least 1 day, and a sample was collected for analyses of selected water-quality characteristics using standard methods (American Public Health Association, American 


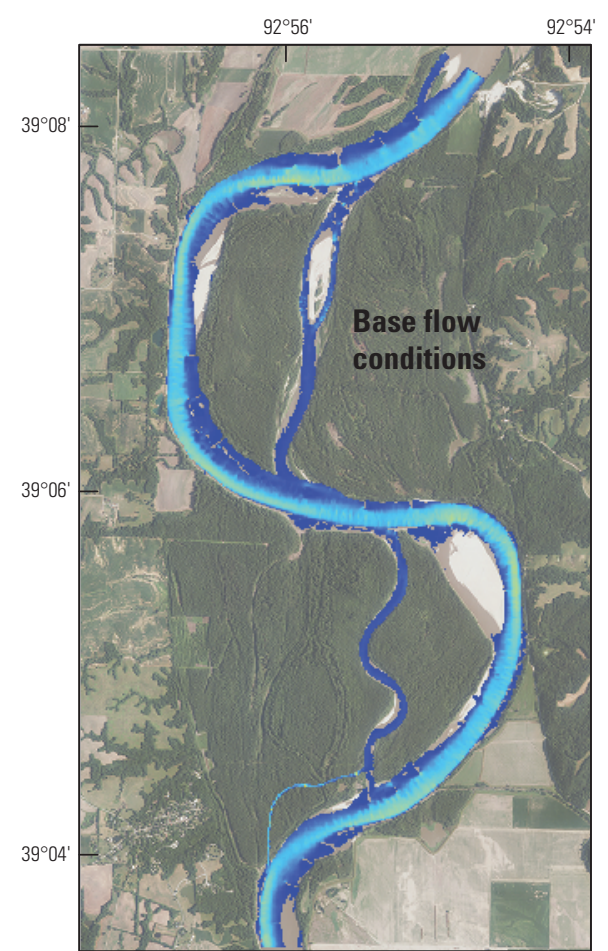

Base data from National Agriculture Imagery Program, 2012 Universal Transverse Mercator projection, zone 15
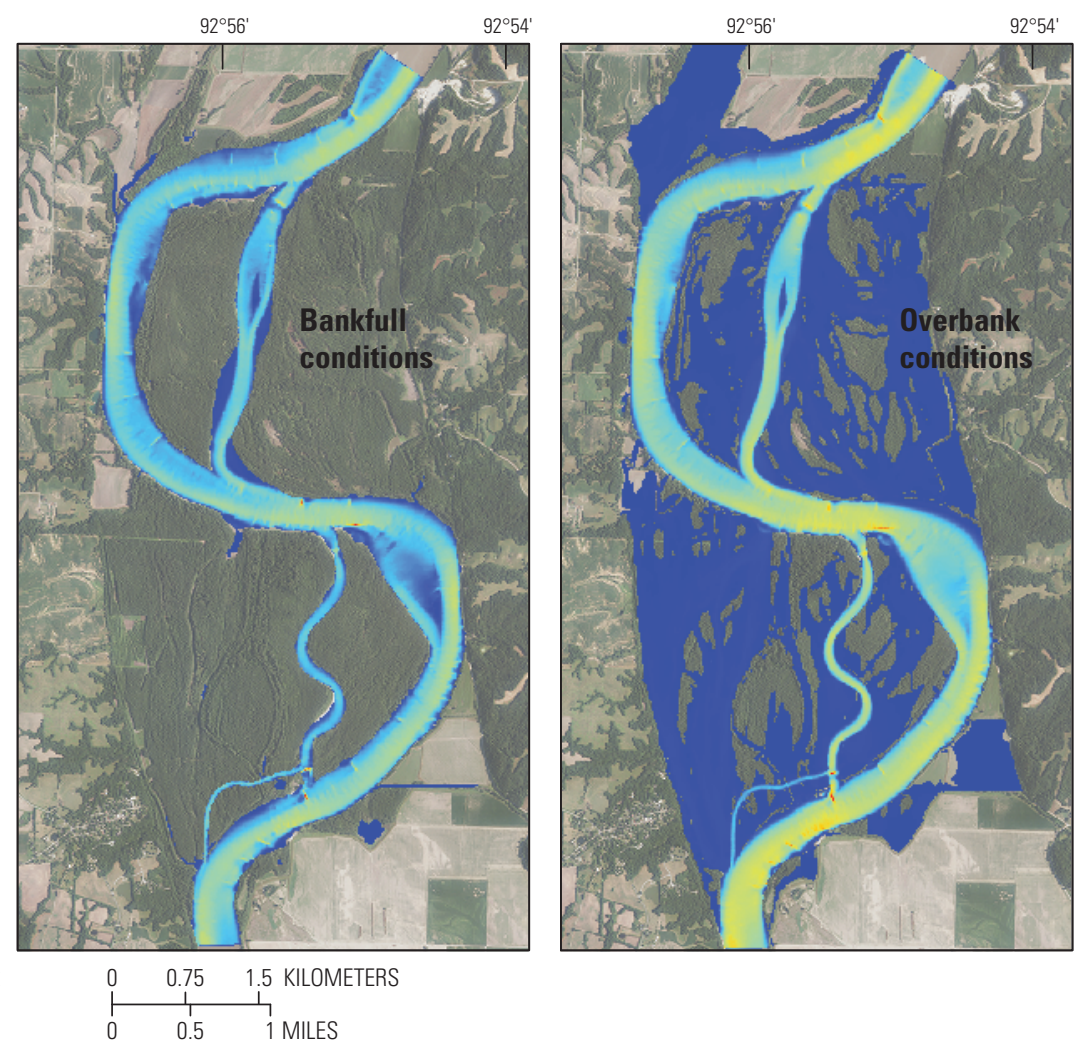

Figure 50. Simulated depth-averaged velocities throughout the Lisbon-Jameson modeling reach for a subset of discharges representing base flow, bankfull, and overbank conditions.

Water Works Association, and Water Environment Federation, 1995). Water quality measured in the blending tanks closely matched that measured in the Missouri River (table 29). Water from the tanks was pumped through a stainless steel heat exchanger placed in a chiller box to cool the water to $17 \pm 1^{\circ} \mathrm{C}$ before flowing to the flumes and culture unit.

\section{Dispersal Studies}

\section{Flume Systems}

The dispersal behavior experiments were completed in two fiberglass oval flume systems. Each flume system consisted of two 1.2-m long straight runs connected to two 180 -degree $\left(^{\circ}\right)$ bends and measured about $4.3 \mathrm{~m}$ in maximum length. The channel was $40 \mathrm{~cm}$ (16 inches [in.]) wide at the top, $38 \mathrm{~cm}$ (15 in.) wide at the bottom, and $50 \mathrm{~cm}$ (20 in.) deep. Water level was maintained at $30 \mathrm{~cm}$ (12 in.) with standpipes placed outside of the flume. The average lap or loop distance (based on circumferences of the inside and outside walls measured at the bottom, $15 \mathrm{~cm}$ and $30 \mathrm{~cm}$ ) was 849 $\mathrm{cm}$. There were two drains on the flume bottom that allowed water to drain into two 473-L reservoir tanks plumbed together below the flume. Water from the reservoir tanks was pumped back into the flume through one horizontal spray bar to create the velocity. Water in the reservoir tanks for both flume systems was constantly circulated through an aquarium chiller unit to maintain the test temperature $\left(19 \pm 1{ }^{\circ} \mathrm{C}\right)$.

The two flumes were nearly identical, except for the water delivery systems. In the first flume system (hereafter referred to as "Flume 1"), water pumped from the reservoir entered the flume through a horizontal spray bar that was attached to a plastic sheet ( $1.2 \mathrm{~m}$ long by $38 \mathrm{~cm}$ wide) placed about $10 \mathrm{~cm}$ above the water surface at the upstream end of the straight section. The plastic sheet served as a ramp to spread the water flow across the width of the channel before entering at the surface, thereby minimizing the shear forces of microcurrents created by a spreader bar and physical trauma to fish passing through this section of the flume. 


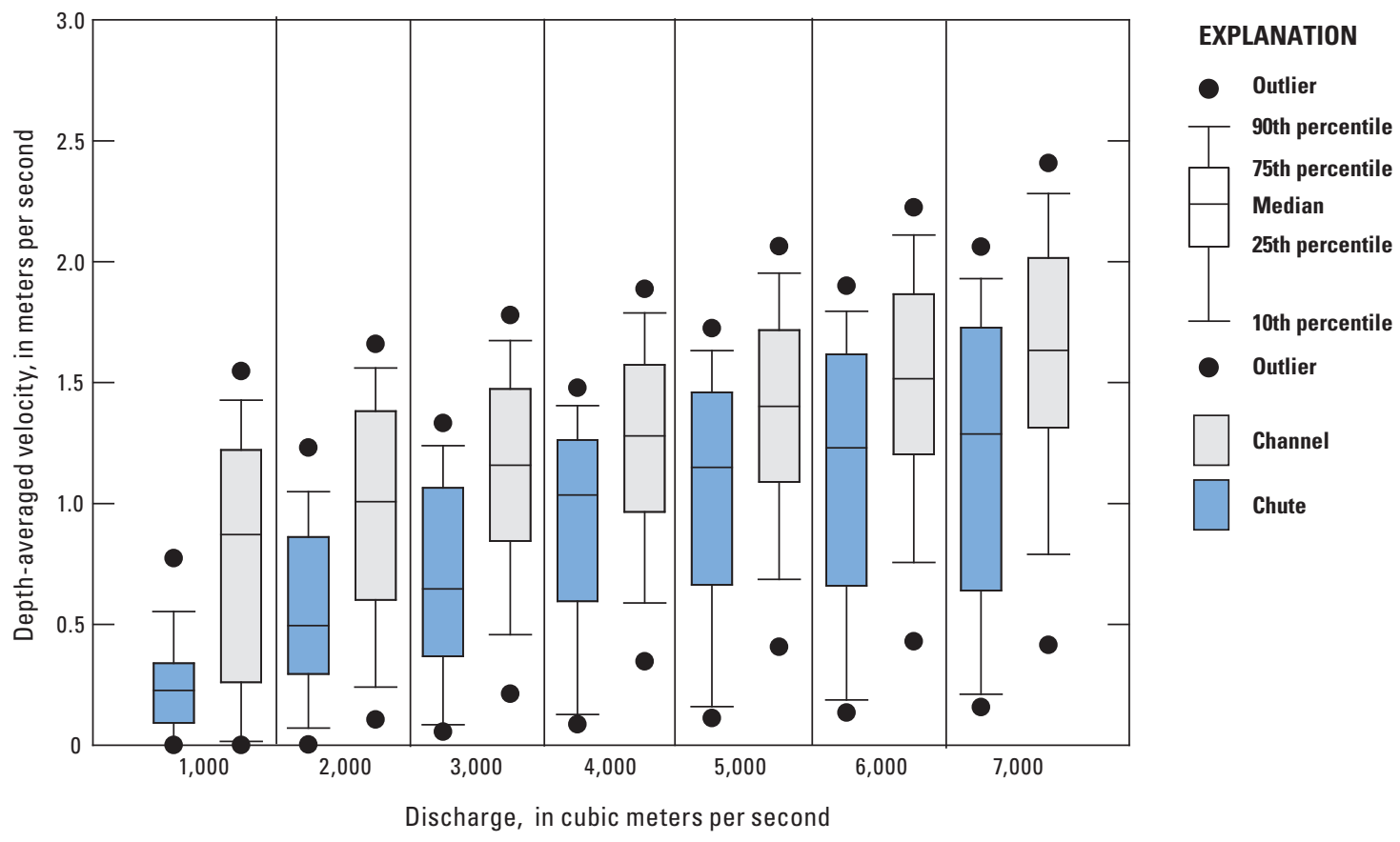

Figure 51. Box plot depicting the distribution of simulated velocities in the Lisbon-Jameson model, calculated for the two chutes and the main channel across a range of discharges.

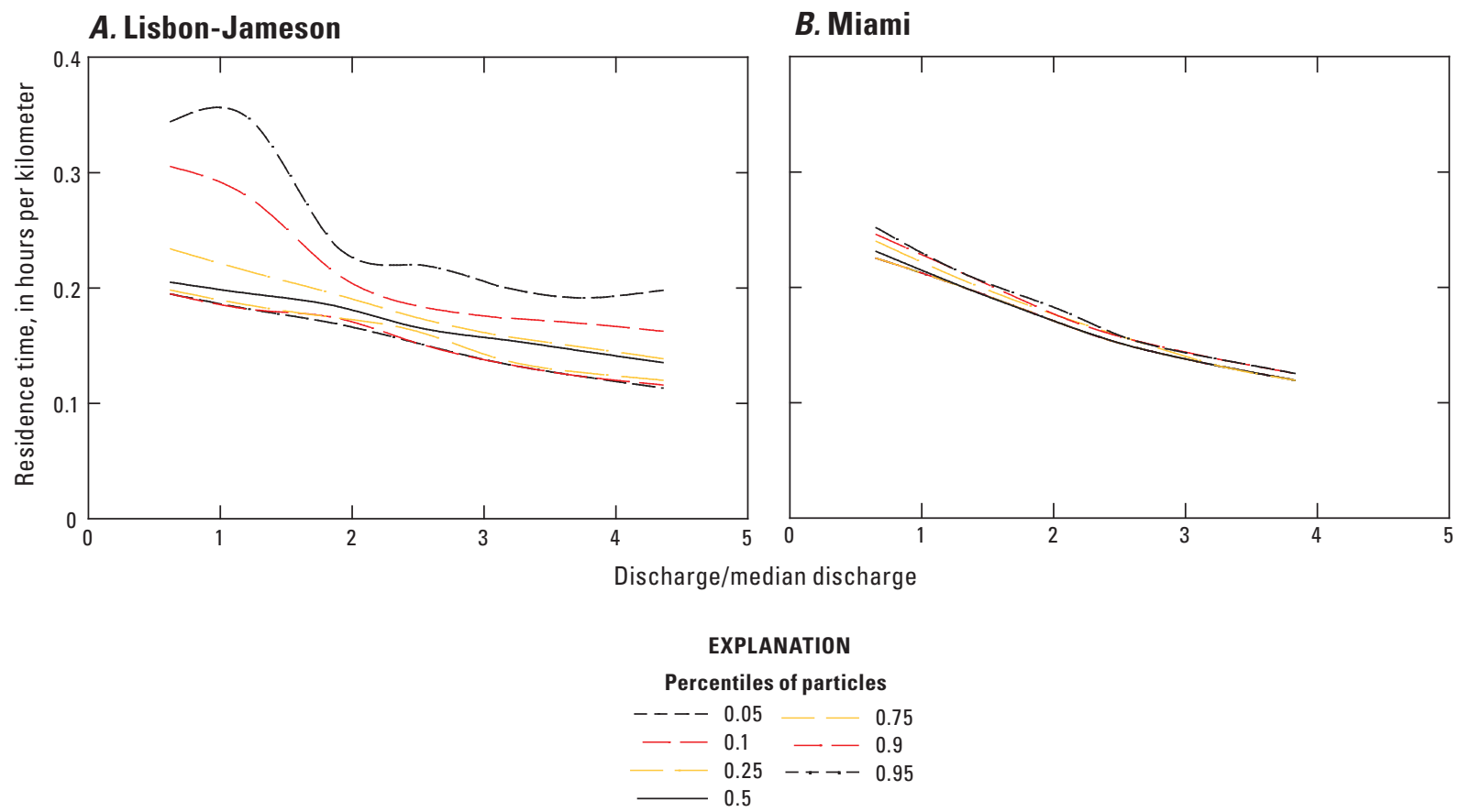

Figure 52. Distribution of particle residence times calculated for the Lisbon-Jameson and Miami modeling reaches. $A$, Lisbon-Jameson; and, $B$, Miami. 
Table 29. Water-quality properties of reconstituted water used in culture and experiments with early life stage paddlefish and pallid sturgeon.

[Water-quality property values are the mean plus or minus 1 standard deviation, and the value range is in parentheses. $\mathrm{mg} / \mathrm{L}$, milligram per liter; $\mathrm{CaCO}_{3}$, calcium carbonate; \pm , plus or minus; $\mathrm{SU}$, standard unit; $\mu \mathrm{S} / \mathrm{cm}$, microsiemen per centimeter at 25 degrees Celsius; $\mathrm{nm}$, not measured]

\begin{tabular}{|c|c|c|}
\hline Property (unit) & $\begin{array}{l}\text { Missouri River at } \\
\text { Sioux City, lowa }{ }^{1}\end{array}$ & $\begin{array}{l}\text { Blending } \\
\text { tanks }\end{array}$ \\
\hline Alkalinity $\left(\mathrm{mg} / \mathrm{L}\right.$ as $\left.\mathrm{CaCO}_{3}\right)$ & $\begin{array}{c}156 \pm 7 \\
(150-169)\end{array}$ & $\begin{array}{c}160 \pm 4 \\
(154-168)\end{array}$ \\
\hline Hardness $\left(\mathrm{mg} / \mathrm{L}\right.$ as $\left.\mathrm{CaCO}_{3}\right)$ & $\begin{array}{c}210 \pm 17 \\
(200-240)\end{array}$ & $\begin{array}{c}202 \pm 4 \\
(194-212)\end{array}$ \\
\hline Calcium (mg/L) & $\begin{array}{c}52 \pm 2 \\
(50-56)\end{array}$ & $\begin{array}{c}52 \pm 2 \\
(48-56)\end{array}$ \\
\hline Magnesium (mg/L) & $\begin{array}{c}19 \pm 3 \\
(18-24)\end{array}$ & $\begin{array}{c}18 \pm 1 \\
(16-19)\end{array}$ \\
\hline pH (SU) & $\begin{array}{c}8.1 \pm 0 \\
(8.0-8.1)\end{array}$ & $\begin{array}{c}7.9 \pm 0.3 \\
(7.3-8.3)\end{array}$ \\
\hline Conductivity $(\mu \mathrm{S} / \mathrm{cm})$ & $\begin{array}{c}669 \pm 19 \\
(654-701)\end{array}$ & $\begin{array}{c}652 \pm 8 \\
(639-668)\end{array}$ \\
\hline Dissolved oxygen $(\mathrm{mg} / \mathrm{L})$ & $\begin{array}{c}6.6 \pm 0.4 \\
(5.9-6.9)\end{array}$ & $\mathrm{nm}$ \\
\hline Number of samples & 5 & 22 \\
\hline
\end{tabular}

${ }^{1}$ Date sampled: 06/25/2003; Christiansen (2004).

In the second flume system (hereafter referred to as "Flume 2"), the horizontal spray bar was placed about $2.5 \mathrm{~cm}$ below the surface at the quarter point of a straight section, and a diversion tunnel (1.22 $\mathrm{m}$ long, consisting of a nitex screen roof attached to two PVC sheets) was placed below the water entry point. The tunnel was designed to convey the fish below and past the spreader bar to prevent them from coming in contact with of the microcurrents of water exiting the spreader bar holes, thereby lessening the physical trauma caused by the force (shear) of water entering the flume. Two small auxiliary PVC lines that discharged water at low velocities were placed at the surface entrance and bottom exit of the deflection tunnel where zero velocity areas happened to push embryos past these areas.

A removable viewing arena (61-cm long, U-shaped channel consisting of three white polyethylene sheets) was placed in the straight section opposite the incoming flow for visual observations. A small white polyethylene platform $(10 \mathrm{~cm}$ wide $\times 34.3 \mathrm{~cm}$ long) was suspended across the channel at mid-depth inside the viewing arena for monitoring fish location in the water column (upper or lower one-half). When the viewing arena was removed, a small acrylic plastic platform ( $6.4 \mathrm{~cm}$ wide $\times 38 \mathrm{~cm}$ long) was suspended across the channel at mid-depth for monitoring fish location in the water column (upper or lower one-half) during video counts.
Three waterproof closed-circuit television cameras, with a 3.6-mm fixed focus lens and 8 infrared light-emitting diodes for operating in the dark, were deployed in both flumes. One camera was placed upstream from the removable viewing arena and the other two cameras were placed upstream and downstream from the deflection tunnel or diffusion ramp. To minimize turbulence and impingement of fish on the cameras and wires, the cameras were mounted in 5-cm PVC pipe with the lens flush with the surface and the wires inside. The viewing arena camera was programmed to record to a dedicated laptop computer; daily video clips were made by manually stopping and restarting the recorded video stream at about 24-h intervals. The other two cameras were programmed to record continuously to an 8-channel digital video recorder with a monitor for viewing the recordings. Video clips were saved on portable hard drives and backed-up on an external hard drive.

\section{Drift Behavior Procedures}

One pilot study and four survival and drift behavior experiments were completed in the flume systems in 2014. The pilot study with PLS-6, and experiments 1 and 2 with PAH -3 consisted of a series of trials starting with newly hatched free embryos ( 0 or $1 \mathrm{dph})$. Each trial began by stocking 10 fish (from incubation tubes) into the flume and successive trials began with fish from the same lot. Observations on survival and drift behavior were made at selected time intervals (described below in this section for each experiment). Survival was measured before making the behavior observations (except for the first observation of a trial) to ensure that only live fish were being observed. To assess survival, the fish were collected into a 0.8 -L plastic rectangular container filled with water from the flume for observations. Dead and immobile fish were removed and preserved in 10-percent NBF. The live fish were restocked in the flume and allowed to acclimate for $5 \mathrm{~min}$ before the next behavior observations were made. A trial was terminated when there was 80 percent or more functional mortality (combination of dead and immobile fish). The behaviors observed were the number of fish passes (fish counts) and location in the water column (number of fish passing over or under the plastic platform; upper or lower onehalf) during one 5 -min period. In experiments 3 and 4 with PLS-8, the orientation to the current and location in the water column (upper or lower one-half) was also visually monitored over an additional 5-min period. Fish counts and location in the water column were made by an observer viewing the live streaming video captured by one of the submersed cameras while orientation and additional location observations were made visually by one observer over the removable viewing arena. The mean number of fish passes during the 5-min period was used to estimate the drift speed of fish during that interval. The video clips will be reviewed to verify fish counts, orientation counts, and fish locations; and for additional observations of these behaviors at other time periods. 


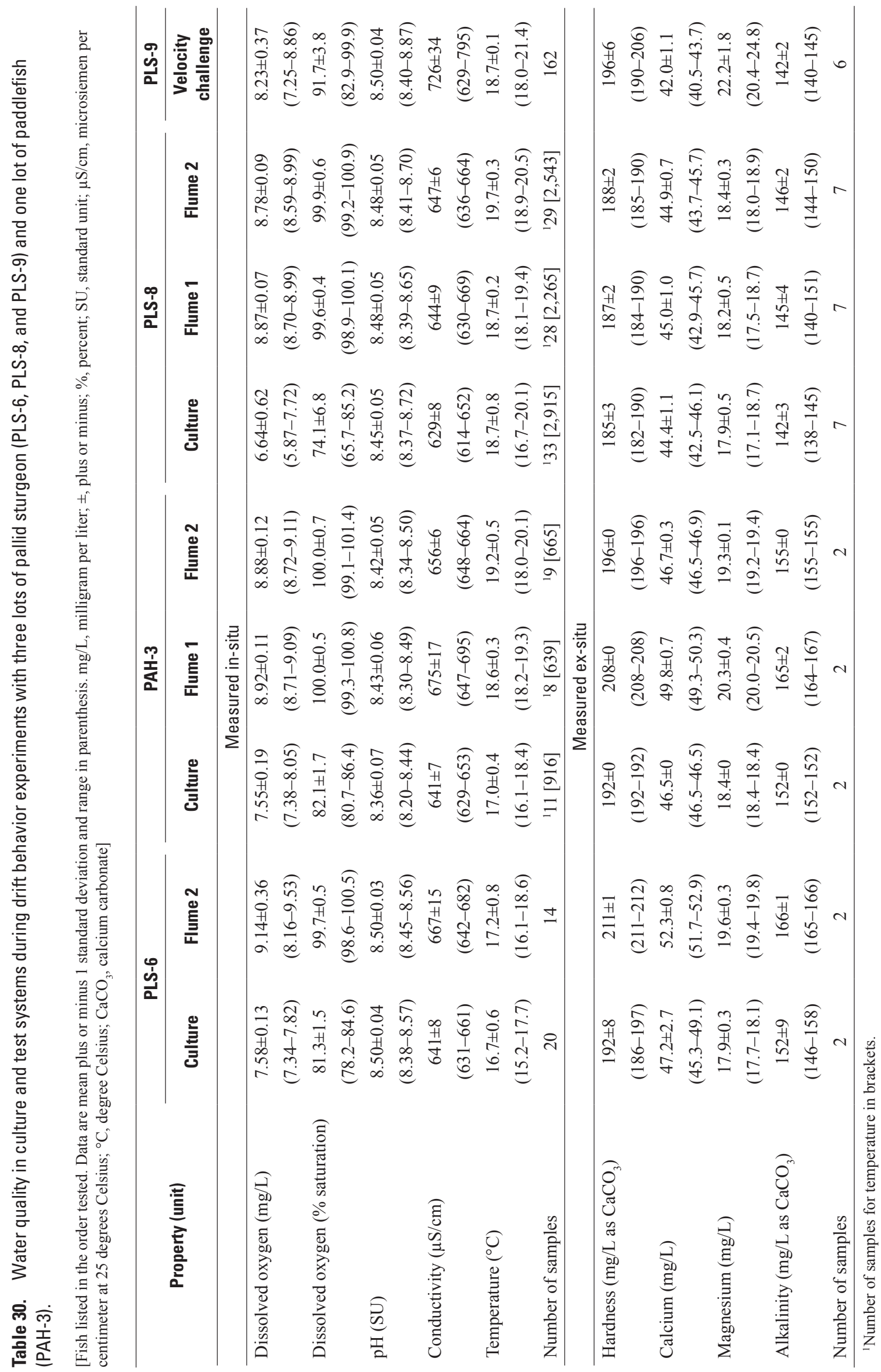


The nominal test velocity was $0.15 \mathrm{~m} / \mathrm{s}$, and the experiments were completed in the dark (to prevent the fish from orientating to light) except for one fluorescent fixture with two 40-watt cool white bulbs placed in red tubes and four lamps each with a 18-watt red fluorescent bulb mounted above the cameras. Water in flume systems was renewed once for experiments 1 and 2 (50 percent water replacement) and daily for experiments 3 and 4 ( 25 percent water replacement) with fresh, chilled $\left(17^{\circ} \mathrm{C}\right)$ reconstituted water.

Pilot Study.-The pilot study was completed with PLS-6 fish from early to mid-May in Flume 2. This study was intended to determine applicability of the flume design for behavioral observations and survival; and to identify any changes needed to the flume, equipment, and study protocols. Video counts and survival observations were made at 6-h intervals.

Experiments 1 and 2.-Experiments 1 and 2 were completed with PAH-3 fish from early to mid-June in Flumes 1 and 2; and were designed to test the potential differences on behavioral observations, survival, and water velocities between Flumes 1 and 2. Observations on survival and video fish counts were made $1 \mathrm{~h}$ after stocking and about every $3 \mathrm{~h}$ from 8:00 a.m. to 10:00 p.m. until the trial was terminated. We did experiment 1 in Flume 1 and experiment 2 in Flume 2.

Experiments 3 and 4.-Experiments 3 and 4 were completed with PLS -8 fish from late June to late July in Flumes 1 and 2. Observations on survival along with visual and video fish counts were made $1 \mathrm{~h}$ after stocking and every $3 \mathrm{~h}$ thereafter until the trial was terminated. Visual observations of fish orientation to the current and position in the channel were completed before the video counts. We performed experiment 3 in Flume 1 and experiment 4 in Flume 2.

\section{Velocity Challenge}

We also did a velocity challenge study to assess survival of early life stage pallid sturgeon at different water velocities. The study was completed in a recirculation system consisting of six 90.5-L circular polyethylene test tanks that drained to a polyethylene reservoir tank filled with approximately $172 \mathrm{~L}$ of test water. Each tank had a central PVC standpipe (6-cm diameter $\times 27.6 \mathrm{~cm}$ tall $)$ and sleeve $(10-\mathrm{cm}$ diameter $\times 35.6 \mathrm{~cm}$ tall $)$ to maintain a volume of $57 \mathrm{~L}$. To create the test velocities, water from the reservoir tank was pumped into the each test tank through one horizontal spray bar with an attached diffusion plate to equalize water flows and minimize shear forces at the surface. Flow into each tank was controlled by gate valves. The nominal velocities were $0.00,0.05,0.10,0.15,0.20$, and $0.25 \mathrm{~m} / \mathrm{s}$. Water in the reservoir tank was constantly recirculated through an aquarium chiller unit to maintain the test temperature $\left(19 \pm 1{ }^{\circ} \mathrm{C}\right)$.

The velocity challenge began with free embryos of PLS -9 at $1 \mathrm{dph}$. A total of 20 embryos was randomly stocked into each of the 6 velocity challenge tanks. To assess survival, all fish were collected into 0.8 -L plastic rectangular containers filled with water from the treatment tank. Dead and immobile fish were removed and preserved in 10-percent NBF. The live fish were restocked into the treatment tank. Observations on survival and immobility were made $1 \mathrm{~h}$ after stocking and then about every $3 \mathrm{~h}$ thereafter until the study was terminated when 100 percent functional mortality happened in all treatments. The study was completed in the dark except during survival observation times when the observer wore a headlamp for making the observations.

\section{Water Velocity and Quality}

Water velocity was measured daily in the flumes, velocity challenge tanks, and hatchery tank with an electromagnetic meter (Marsh-McBirney Flo-Mate 2000, Frederick, Maryland). In the flumes, velocities were measured at eight locations consisting of cross-sectional transects with nine measurement points: three near the bottom; three at mid-depth; and three at just below the surface at the inside, middle, and outside section of the channel. In velocity challenge tanks, velocities were measured at a single location at three depths (near bottom, mid-depth, and near surface). Water velocity measurements in the hatchery tank were taken at six points along a transect across the tank at three depths (near bottom, mid-depth, and near surface).

Water temperatures in the reservoir tanks of the flumes and headbox (except for PLS-6) were continuously recorded with a data logger (HOBO Water Temperature Pro v2 Data Logger, Onset Computer Corporation, Bourne, Massachusetts). Water temperatures in the flumes and culture units were also monitored twice daily with a laboratory-grade thermometer. Conductivity, $\mathrm{DO}, \mathrm{pH}$, and temperature were measured daily in the flumes, velocity challenge tanks, and culture units using calibrated portable meters; and water samples were collected weekly from the same vessels for general water quality analyses following standard methods (American Public Health Association, American Water Works Association, and Water Environment Federation, 1995).

\section{Growth and Development}

During all experiments, a sample of 5-10 fish was collected daily from the incubation vials or culture tank and examined under a stereoscope for presence or absence of the yolk plug. The fish were then euthanized with tricaine methanesulfonate and preserved in 10-percent NBF for later measurement of growth. The TL was measured to $0.1 \mathrm{~mm}$ with a stereo microscope fitted with a calibrated ocular micrometer. The fish were weighed (preserved body weight) individually $( \pm 0.1$ milligram) on an analytical balance. Before weighing, the fish were placed briefly on laboratory tissue to absorb excess preservative. Fulton-type condition factors were calculated for each fish by the formula of Anderson and Gutreuter $(1983)$ as: condition factor $=\left(\right.$ body weight $/$ total length $\left.^{3}\right) \times$ 100; body weight is in milligrams and TL is in millimeters.

Water temperatures from each logger were compiled into daily averages and summed to calculate the daily cumulative temperature units (CTUs) that the fish had been exposed to 
as described in Kynard and others (2007). The start time for calculating daily CTUs was 9:00 a.m. For tanks without a logger, the temperatures measured with meters and thermometers were averaged and used as the daily average temperature. Cumulative degree-days were calculated to the start time of each experiment when the first fish were stocked into the flume systems. The CTUs were used to link development with thermal exposure in the flumes and culture units.

\section{Data Analysis}

Routine statistical analyses were performed using Microsoft Excel (2010) and Statistical Analysis System (SAS) for Windows software, version 9.3 (SAS Institute Inc., Cary, North Carolina, 2008). Fish location in the water column was compared by paired t-tests. Mean daily number of fish passes were compared by repeated-measures ANOVA using the MIXED procedure in SAS with dph as the repeated factor and elapsed time as the subject. The least square means were compared using Tukey's adjustment (Statistical Analysis System Institute Inc., 2011). The Mann-Kendall test using the computer program of Helsel and others (2006) was used to identify trends in number of fish passes and drift velocity with fish age. The Kaplan-Meier analysis (Statistical Analysis System Institute Inc., 2011) was used to construct survival curves; survival curves in the flumes were compared by the log-rank test (using SAS) and those in the velocity challenge by the Holm-Sidak method (SigmaPlot, version 12.5, Systat Software, Inc., San Jose, California, 2013). Statistical significance probability $(p)$ was set at less than $(<) 0.05$ for all tests.

\section{Progress}

\section{Culture and Test Conditions}

Mean (range) water temperatures in the head box monitored by the logger were $17.0^{\circ} \mathrm{C}\left(16.1-18.4^{\circ} \mathrm{C}\right)$ for PAH-3 and $18.7^{\circ} \mathrm{C}\left(16.7-20.1^{\circ} \mathrm{C}\right)$ for PLS-8. Average water temperature in the PLS- 6 culture units was $16.7^{\circ} \mathrm{C}$ and ranged from 15.2 to $17.7^{\circ} \mathrm{C}$ (table 30). Mean DO concentrations ranged from 74.1 to 82.1 percent air saturation and were maintained at or above 66 percent air saturation for all fish lots. The $\mathrm{pH}$ ranged from 8.20 to 8.72 standard units (SUs), and total ammonia concentrations were less than $0.1 \mathrm{mg} / \mathrm{L}$ as nitrogen. Average daily water velocities in the culture tank for PLS-8 ranged from 0.06 to $0.07 \mathrm{~m} / \mathrm{s}$ with a mean of $0.07 \mathrm{~m} / \mathrm{s}$.

\section{Growth and Development}

Expulsion of the yolk plug in pallid sturgeon and paddlefish is commonly used as an indicator of the time when the fish has begun exogenous feeding and has transitioned from the free-embryo stage to the exogenously feeding, benthic larval stage. Based on the first day fish expelled their yolk plugs, free embryos of paddlefish started to transition into larvae at $8 \mathrm{dph}$ and 136 CTUs and pallid sturgeon at $12 \mathrm{dph}$ and $222 \mathrm{CTUs}$ (table 31). The transition period for pallid sturgeon extended over 5 days and was complete at $18 \mathrm{dph}$ and 339 CTUs. The five pallid sturgeon sampled at $11 \mathrm{dph}$ were not observed for the presence of a yolk plug until after they were placed in the preservative, and it was determined that yolk plugs may have expelled because of handling. Previous observations on pallid sturgeon revealed that some of the fish will expel their yolk plugs when placed in the anesthetic.

\section{Flume Trials}

Pilot Study.-Mean daily average water velocity was $0.14 \mathrm{~m} / \mathrm{s}$, and ranged from 0.13 to $0.15 \mathrm{~m} / \mathrm{s}$. Variation in daily average velocity among the eight transects ranged from 0.02 to $0.04 \mathrm{~m} / \mathrm{s}$ with a mean of $0.03 \mathrm{~m} / \mathrm{s}$. Mean water temperature in the flume (Flume 2) was $17.2^{\circ} \mathrm{C}$ and ranged from 16.1 to $18.6^{\circ} \mathrm{C}$ (table 30 ). The $\mathrm{DO}$ and $\mathrm{pH}$ ranged from 98.6 to 100.5 percent air saturation and 8.45 to 8.56 SUs, respectively.

The duration of embryo survival in the flume system varied with age; 80 percent of the 0 -dph embryos died within $1 \mathrm{~h}$ and 70 percent of the 1-dph embryos died within $72 \mathrm{~h}$. In the trial started with 4-dph embryos, survival was 100 percent at $66 \mathrm{~h}$ ( 2.8 days), 70 percent at $114 \mathrm{~h}$ (4.8 days), 50 percent at $156 \mathrm{~h}$ ( 6.5 days), and 40 percent at $210 \mathrm{~h}$ ( 8.8 days).

For the trial started with 4-dph fish, the mean daily number of fish passes decreased with age of the fish from 4.5 fish at 5 dph to $1.9-2.3$ fish at $11-12$ dph but increased to 3.6 fish at $13 \mathrm{dph}$. A higher percentage of the embryos were observed drifting in the upper part of the water column (65-85 percent) relative to those observed in the lower part except for 12- and 13-dph fish (54 and 34 percent, respectively, in the upper part).

The drift velocity of embryos was close to but always somewhat slower than the water velocity. The mean daily drift speeds were between 0.02 and $0.08 \mathrm{~m} / \mathrm{s}$ slower than the water current. Drift speeds of embryos generally decreased with age; fish at $5-7 \mathrm{dph}$ drifted at $0.12-0.13 \mathrm{~m} / \mathrm{s}(0.02-0.03 \mathrm{~m} / \mathrm{s}$ slower than the water), whereas fish at $8-12$ dph drifted at $0.05-0.08 \mathrm{~m} / \mathrm{s}(0.06-0.08 \mathrm{~m} / \mathrm{s}$ slower than the water).

Experiments 1 and 2 (paddlefish).- The mean daily average velocities were $0.14 \mathrm{~m} / \mathrm{s}(0.13-0.15 \mathrm{~m} / \mathrm{s})$ in experiment 1 and $0.15 \mathrm{~m} / \mathrm{s}(0.14-0.16 \mathrm{~m} / \mathrm{s})$ in experiment 2 . Variation in daily average velocity across all transects averaged $0.03 \mathrm{~m} / \mathrm{s}$ in both flumes, but the range was wider for experiment $2(0.01-$ $0.08 \mathrm{~m} / \mathrm{s})$ compared to experiment $1(0.02-0.04 \mathrm{~m} / \mathrm{s})$. Water temperatures were maintained at $19 \pm 1{ }^{\circ} \mathrm{C}$, DO concentrations at $99-101$ percent air saturation, and $\mathrm{pH}$ at 8.3-8.5 SUs (table 30).

Survival duration of free embryos in both flumes was the longest for trial 1 stocked with 1-dph embryos (fig. 53). Free embryos in trial 1 exhibited 100 percent survival for $72 \mathrm{~h}$ and 80 percent survival at $84 \mathrm{~h}$. Comparison of survival curves by the log-rank test indicated that survival rates of embryos in both flume systems were similar $(p=0.1406)$. In subsequent trials started with embryos at 5-8 dph, survival at $24 \mathrm{~h}$ was 20 percent or more in six trials and 40 percent in two trials. The surviving fish at $24 \mathrm{~h}$ in these eight trials seemed to be in 
Table 31. Age, daily cumulative temperature units, life stage, and growth metrics of one lot of paddlefish (PAH-3) and three lots of pallid sturgeon (PLS-6, PLS-8, and PLS-9) in culture system.

[dph, days post-hatch; CTU, cumulative temperature unit; ${ }^{\circ} \mathrm{C}$, degree Celsius; $\%$, percent; mm, millimeter; mg, milligram; N, number; \pm , plus or minus; --, no data]

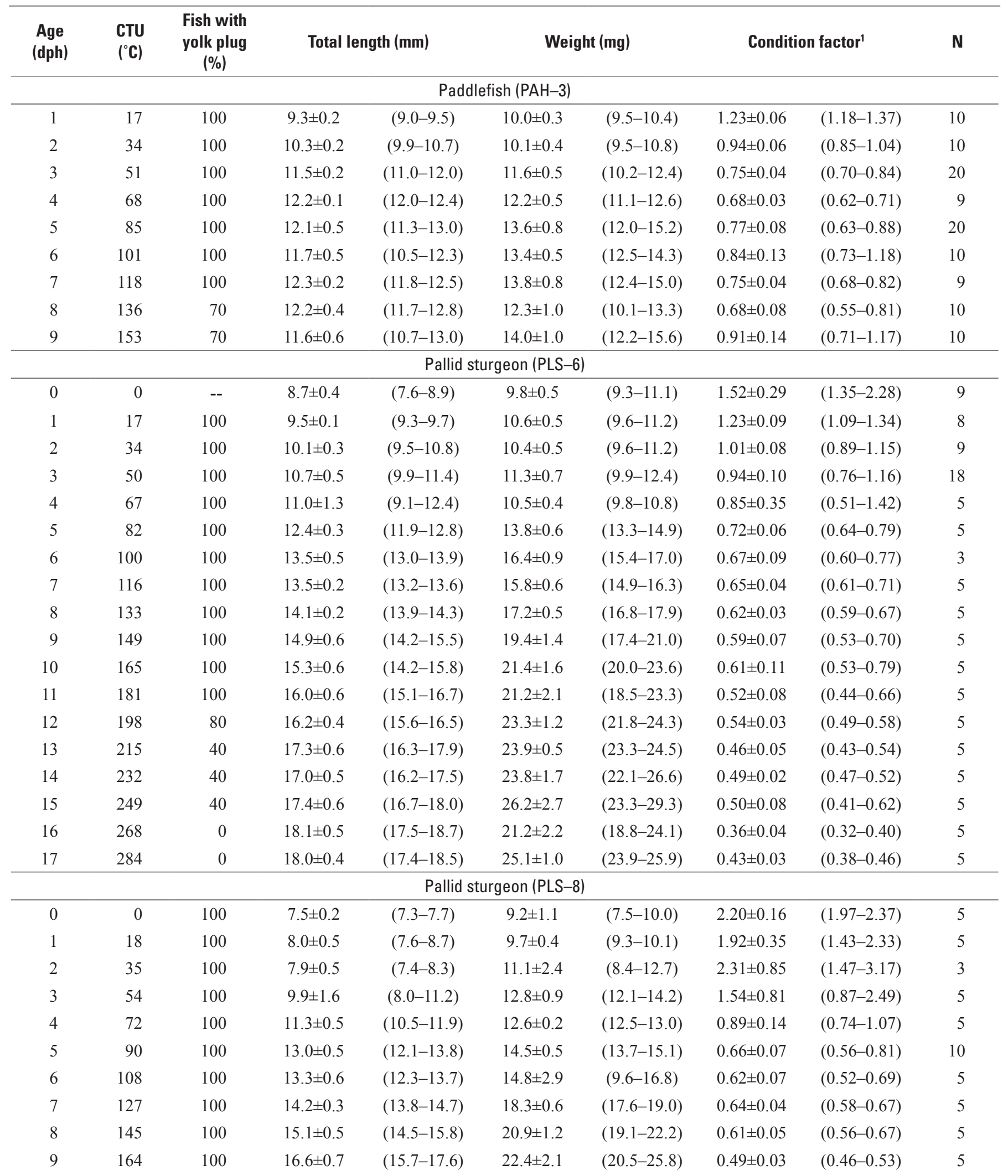


Table 31. Age, daily cumulative temperature units, life stage, and growth metrics of one lot of paddlefish (PAH-3) and three lots of pallid sturgeon (PLS-6, PLS-8, and PLS-9) in culture system.-Continued

[dph, days post-hatch; $\mathrm{CTU}$, cumulative temperature unit; ${ }^{\circ} \mathrm{C}$, degree Celsius; $\%$, percent; mm, millimeter; mg, milligram; $\mathrm{N}$, number; \pm , plus or minus; --, no data]

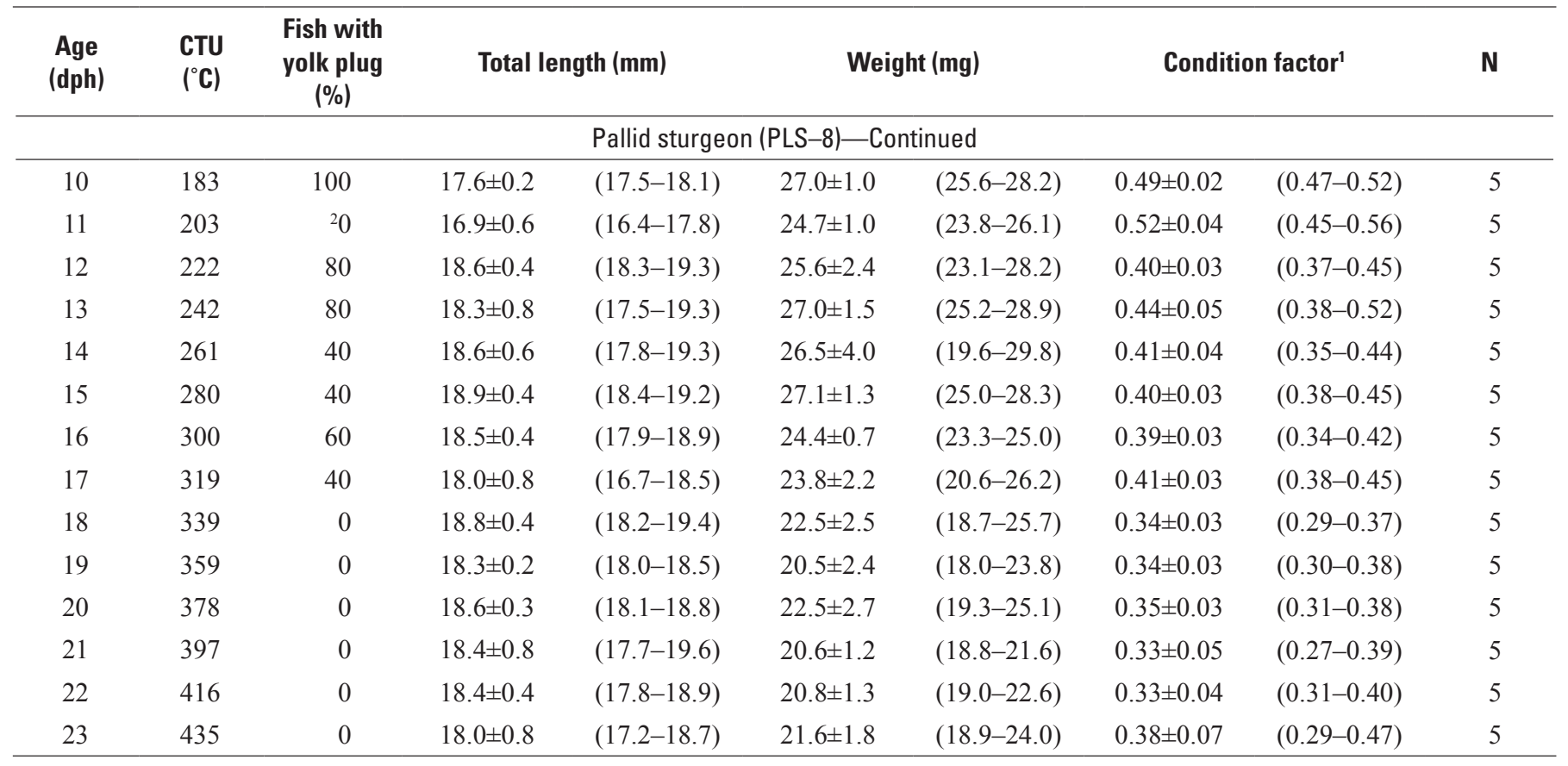

${ }^{1}$ Fulton-type condition factor, weight $(\mathrm{mg}) /$ total length $^{3}(\mathrm{~mm}) \times 100$.

${ }^{2}$ Yolk plugs were likely expelled because of handling.

poor condition and were lethargic; consequently, these trials were terminated at about $24 \mathrm{~h}$.

The mean daily number of fish passes for embryos at 1-3 dph was similar between flume systems, whereas the mean daily number of fish passes for fish at $4-8$ dph was higher in Flume 1 than Flume 2 (fig. 54). In general, the mean number of fish observed at the top part of the channel was similar to those at the bottom. In the four cases where there was a difference between the number of fish observed at the top and bottom part of the channel, a higher number of fish were in the top one-half in two cases and in the bottom one-half in the other two cases.

Drift speeds of embryos in Flume 1 were similar to the water velocity (fig. 55); the 95-percent confidence limits for the mean fish velocities overlapped the water velocity, and the differences between fish and water velocities ranged from $-0.04 \mathrm{~m} / \mathrm{s}$ for 6 -dph fish to $0.02 \mathrm{~m} / \mathrm{s}$ for 1- and 2-dph fish. In Flume 2, the estimated mean embryo drift velocities for fish at $4-8$ dph were $0.03-0.07 \mathrm{~m} / \mathrm{s}$ slower than the water velocity, and the 95-percent confidence limits for mean fish velocities at $4,5,6$, and 8 dph did not overlap the mean water velocity.

Experiments 3 and 4 (pallid sturgeon).- -Average daily velocity in Flume 1 (mean and range were $0.13 \mathrm{~m} / \mathrm{s}$ and 0.12 $0.15 \mathrm{~m} / \mathrm{s}$, respectively) were statistically higher $(p<0.0001)$ than those in Flume 2 (mean and range were $0.09 \mathrm{~m} / \mathrm{s}$ and
$0.07-0.12 \mathrm{~m} / \mathrm{s}$, respectively) and decreased over time. The average daily velocities were inversely correlated with dph (tau $[\tau]$ correlation coefficients $=-0.884$ and $-0.903, p<0.001$ in Flumes 1 and 2, respectively). The relative decrease in water velocity with time was greater in Flume 2 where the average daily velocity decreased by 45 percent from 0 to $26 \mathrm{dph}$. In Flume 1, the daily velocity decreased by 15 percent from 0 to $23 \mathrm{dph}$. The reduction in water velocity with time in both flumes may have been partly because of the precipitation of salts in the water delivery systems and, in Flume 2, to the precipitation of salts on the nitex screen on the tunnel, which would increase the total drag on the water column. Water temperatures ranged from 18.1 to $19.4^{\circ} \mathrm{C}$ (mean of $18.7^{\circ} \mathrm{C}$ ) in Flume 1 and from 18.9 to $20.5^{\circ} \mathrm{C}$ (mean of $19.7^{\circ} \mathrm{C}$ ) in Flume 2 (table 30). In both flumes, the DO concentrations were maintained at 98.9-100.9 percent air saturation and the $\mathrm{pH}$ at $8.39-8.70$ SUs.

Survival duration of fish between 0 and $16 \mathrm{dph}$ varied between the two flume systems (fig. 56). In Flume 1 (experiment 3), 100 percent of the fish survived for 8.5 days, 70 percent for 15 days, and 50 percent for 16.5 days. In Flume 2 (experiment 4), 80 percent of the fish survived for 2 days, 70 percent for 6 days, and 50 percent for 7 days. In both flumes, 30 percent of the fish survived for 22 days. Despite the observed difference in survival rates between the flumes, 


\section{Flume 1}

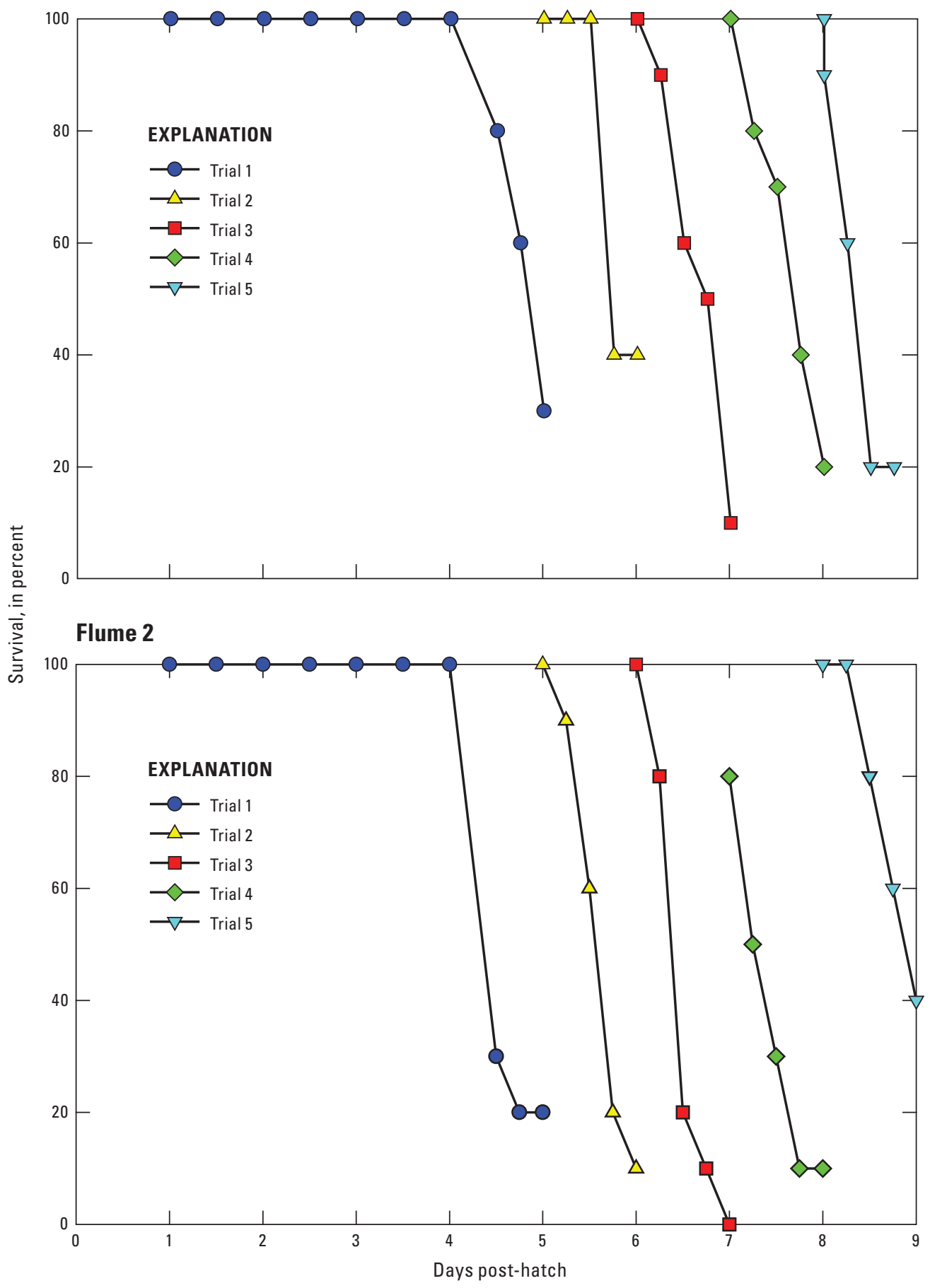

Figure 53. Percent survival of early life stage paddlefish in test flumes. 
Flume 1

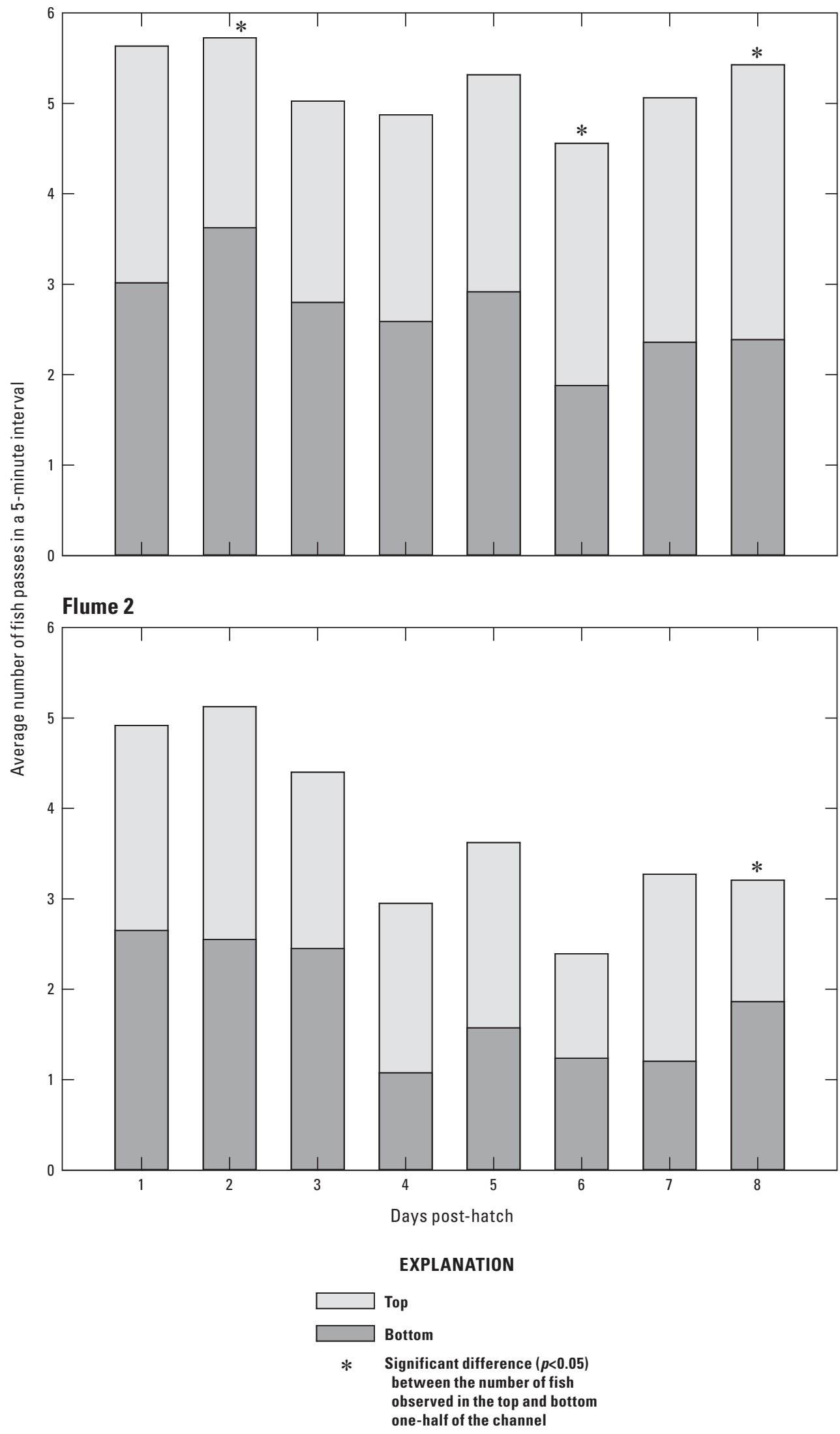

Figure 54. Average number of fish passes during a 5-minute period and number of fish in the top and bottom one-half of the channel. 


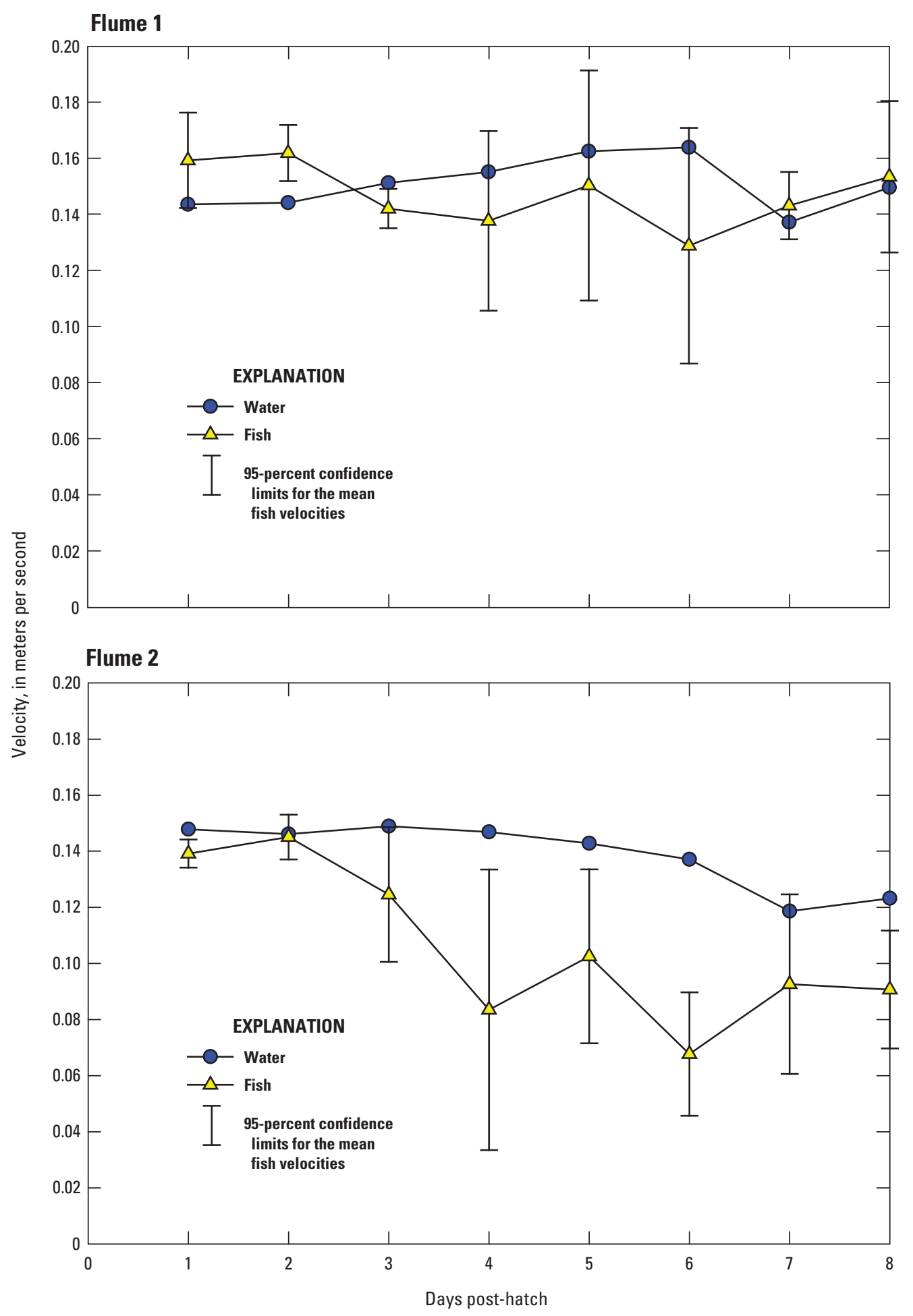

Figure 55. Drift speed of paddlefish and water velocity in test flumes. 


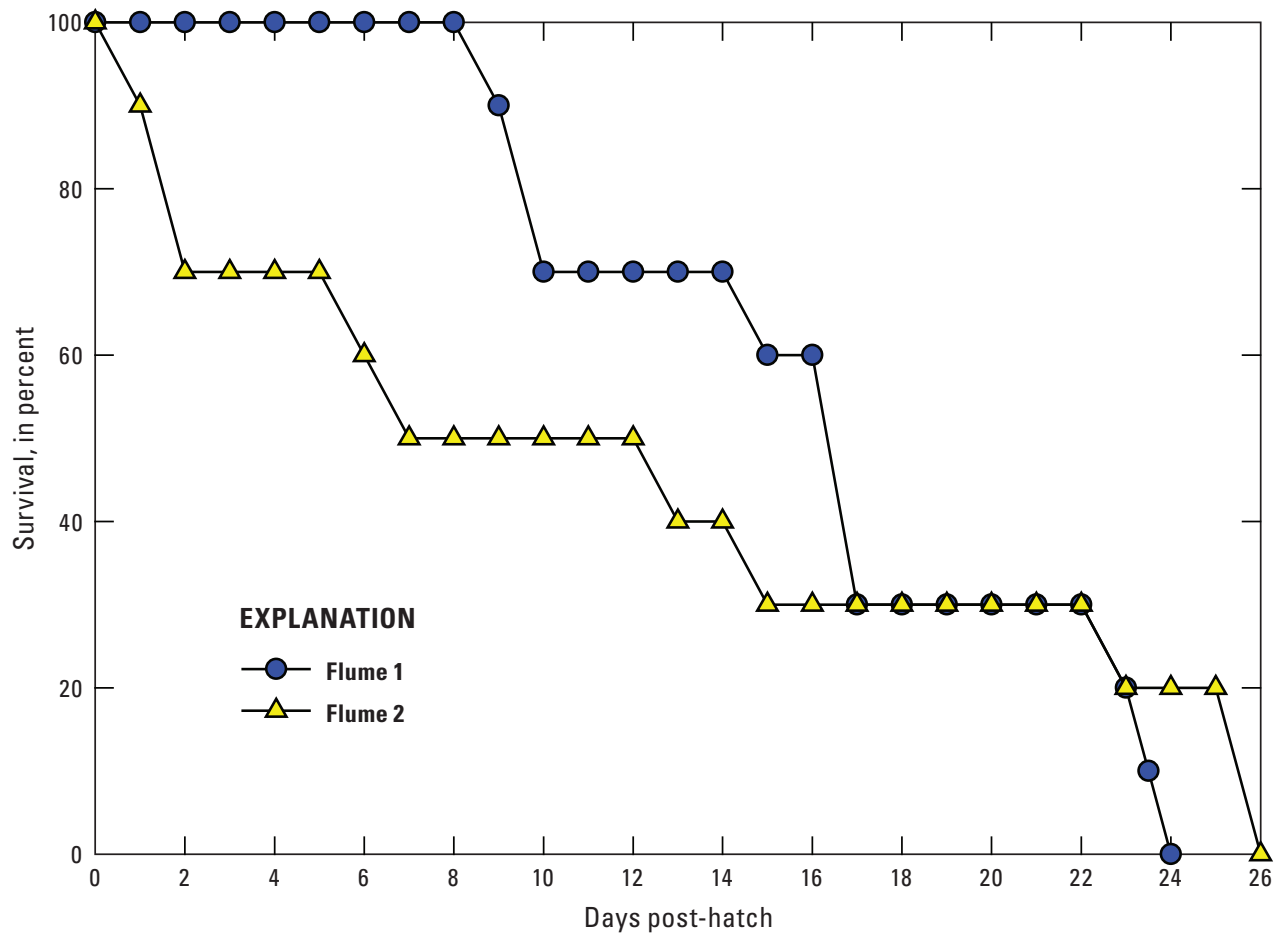

Figure 56. Percent survival of early life stage pallid sturgeon in test flumes. results of the log-rank test $(p=0.8326)$ and Wilcoxon test $(p=0.1939)$ indicated that there was no difference in survival of fish between flumes (Statistical Analysis System Institute Inc., 2011). In both flumes, there was a trend for a reduction in the mean number of fish passes with the age of the fish (fig. 57). The Mann-Kendall test showed that the trends were statistically significant $(p<0.001)$ with $\tau$ correlation coefficients of -0.558 and -0.672 for fish passes in Flume 1 and 2, respectively. For a given age, the mean number of fish passes was higher in Flume 1 compared to Flume 2 except for fish at $11,12,13$, and $14 \mathrm{dph}$.

In Flume 1, a statistically higher number of the fish were observed in the upper part of the water column relative to those observed in the lower part for 67 percent of the ages. The exceptions were for fish at $0-2,13,18,19,22$, and 23 dph (fig. 57). In Flume 2, a significantly higher number of fish were in the upper one-half of the water column for fish at 1-7 dph, whereas the opposite trend was observed for fish at 22,23 , and $25 \mathrm{dph}$.

The drift speeds of fish varied between the flume systems (fig. 58). In Flume 1, estimated drift velocities of fish at $0-10 \mathrm{dph}$ were faster $(0.01$ to $0.05 \mathrm{~m} / \mathrm{s})$, and those of fish at $11-23 \mathrm{dph}$ were slower $(-0.02$ to $-0.08 \mathrm{~m} / \mathrm{s})$ than that of the water. For most fish ages, the 95-percent confidence limits for mean fish velocities did not overlap the mean water velocity, which indicated that these velocities were significantly different. In Flume 2, drift rates of fish at 0-14 dph were similar to or slower $(-0.04$ to $0.01 \mathrm{~m} / \mathrm{s})$, and drift rates of older fish at $15-26$ dph were all slower $(-0.02$ to $-0.06 \mathrm{~m} / \mathrm{s})$ than the mean channel velocity. The trend for reduced drift velocity with age of fish was statistically significant for both flumes $(\tau=-0.391$, $p=0.008$ for Flume $1 ; \tau=-0.903, p<0.001$ for Flume 2).

In Flume 1, we started to observe a few fish holding position along the bottom against the current for at least 30 seconds at $12 \mathrm{dph}$, and the duration and frequency of this behavior increased progressively with age. We observed at least one fish at 13-18 dph holding position at least $2 \mathrm{~min}$ during the 5-min observation period. We observed similar holding behaviors in fish in Flume 2 starting at 14 dph, except the longest duration of the holding period for fish at 15-20 dph was about $1.5 \mathrm{~min}$.

Velocity Challenge.-In all treatments, water temperatures ranged from 18.0 to $21.4{ }^{\circ} \mathrm{C}$, DO concentrations from 82.9 to 99.9 percent air saturation, and $\mathrm{pH}$ from 8.40 to 8.87 SUs (table 30 ). Because of problems with the design of the test system, measured water velocities in four of the treatments were lower than the nominal values, and the ranges of the daily averages overlapped those of the adjacent treatment (table 32$)$. The two highest velocity treatments $(0.15$ and $0.21 \mathrm{~m} / \mathrm{s}$ ) were acutely lethal to the fish; survival in the 0.15 and $0.21 \mathrm{~m} / \mathrm{s}$ treatments were, respectively, 55 and 30 percent at $24 \mathrm{~h}, 40$ and 5 percent at $48 \mathrm{~h}$, and 20 and 5 percent at $96 \mathrm{~h}$. Survival at $96 \mathrm{~h}$ in the control treatment was 81 percent and ranged from 55 to 75 percent in the other treatments. The Kaplan-Meier survival curves for early life stage pallid sturgeon are displayed in figure 59. The log-rank test determined that there was a significant difference among survival curves, and the pairwise comparisons by the Holm-Sidak 
Flume 1

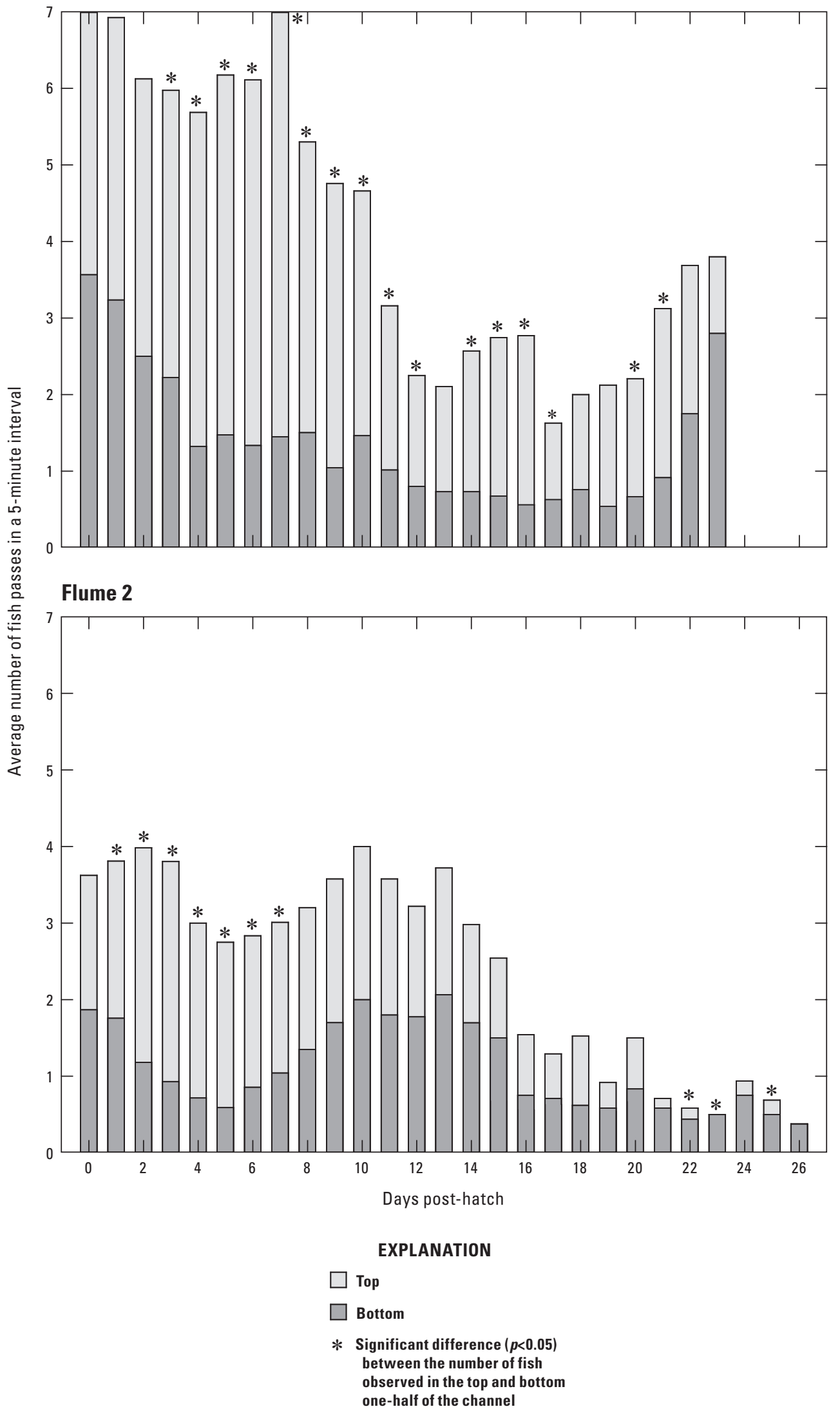

Figure 57. Average number of fish passes during a 5-minute period and number of fish in the top and bottom one-half of the channel. 
Flume 1

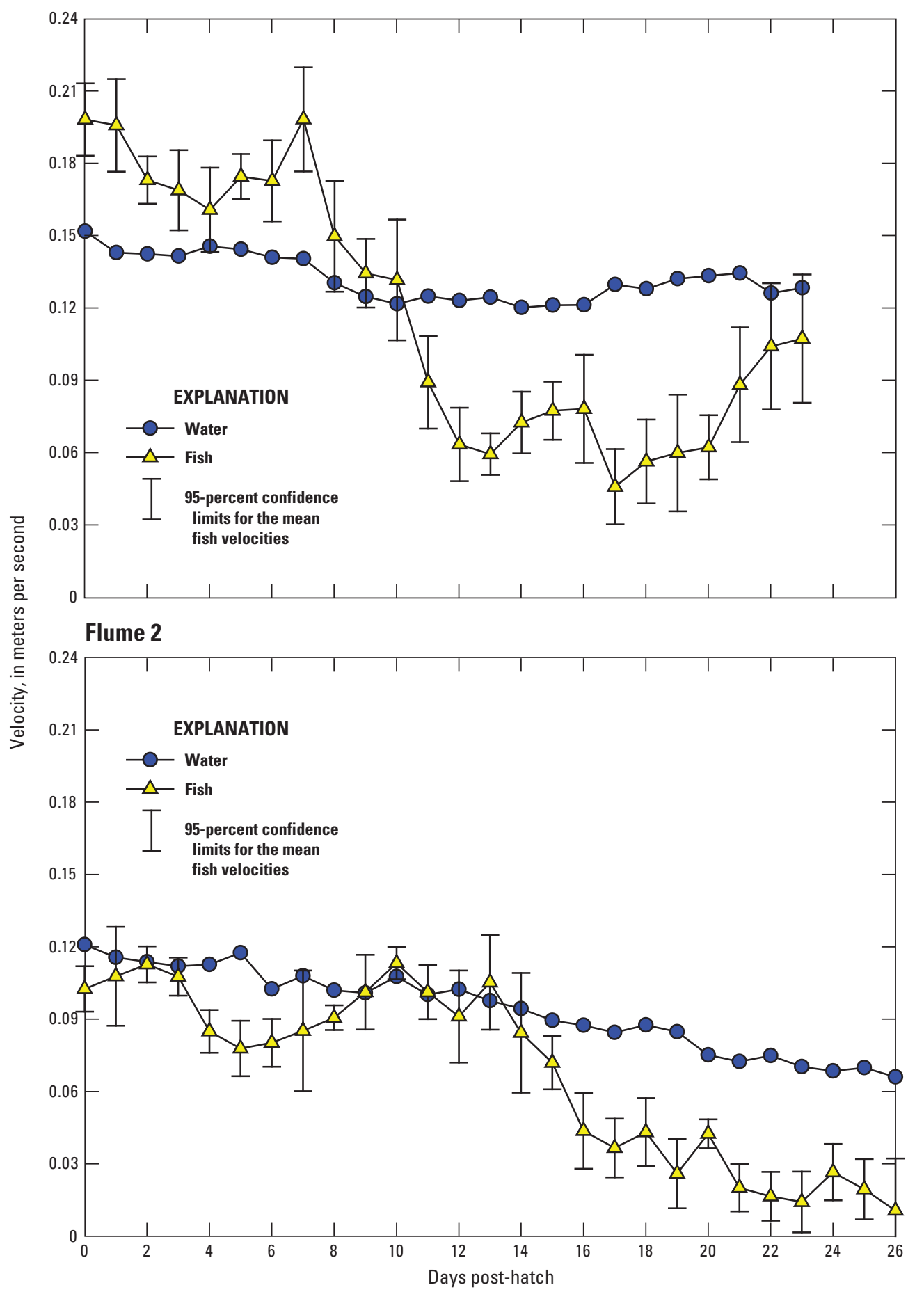

Figure 58. Drift speed of pallid sturgeon and water velocity in test flumes. 
Table 32. Water velocity measured in test tanks during velocity challenge test with early life stage pallid sturgeon.

$[\mathrm{m} / \mathrm{s}$, meter per second]

\begin{tabular}{ccc}
\hline Treatment $(\mathbf{m} / \mathbf{s})$ & Mean $^{\mathbf{1}}$ & Range \\
\hline $0.00($ Control $)$ & $0.00^{\mathrm{E}}$ & $0.00-0.00$ \\
0.05 & $0.05^{\mathrm{D}}$ & $0.06-0.06$ \\
0.10 & $0.07^{\mathrm{C}}$ & $0.05-0.09$ \\
0.15 & $0.06^{\mathrm{C}}$ & $0.04-0.11$ \\
0.20 & $0.15^{\mathrm{B}}$ & $0.11-0.20$ \\
0.25 & $0.21^{\mathrm{A}}$ & $0.16-0.24$ \\
\hline
\end{tabular}

${ }^{1}$ Means sharing the same upper case letter are not significantly different.

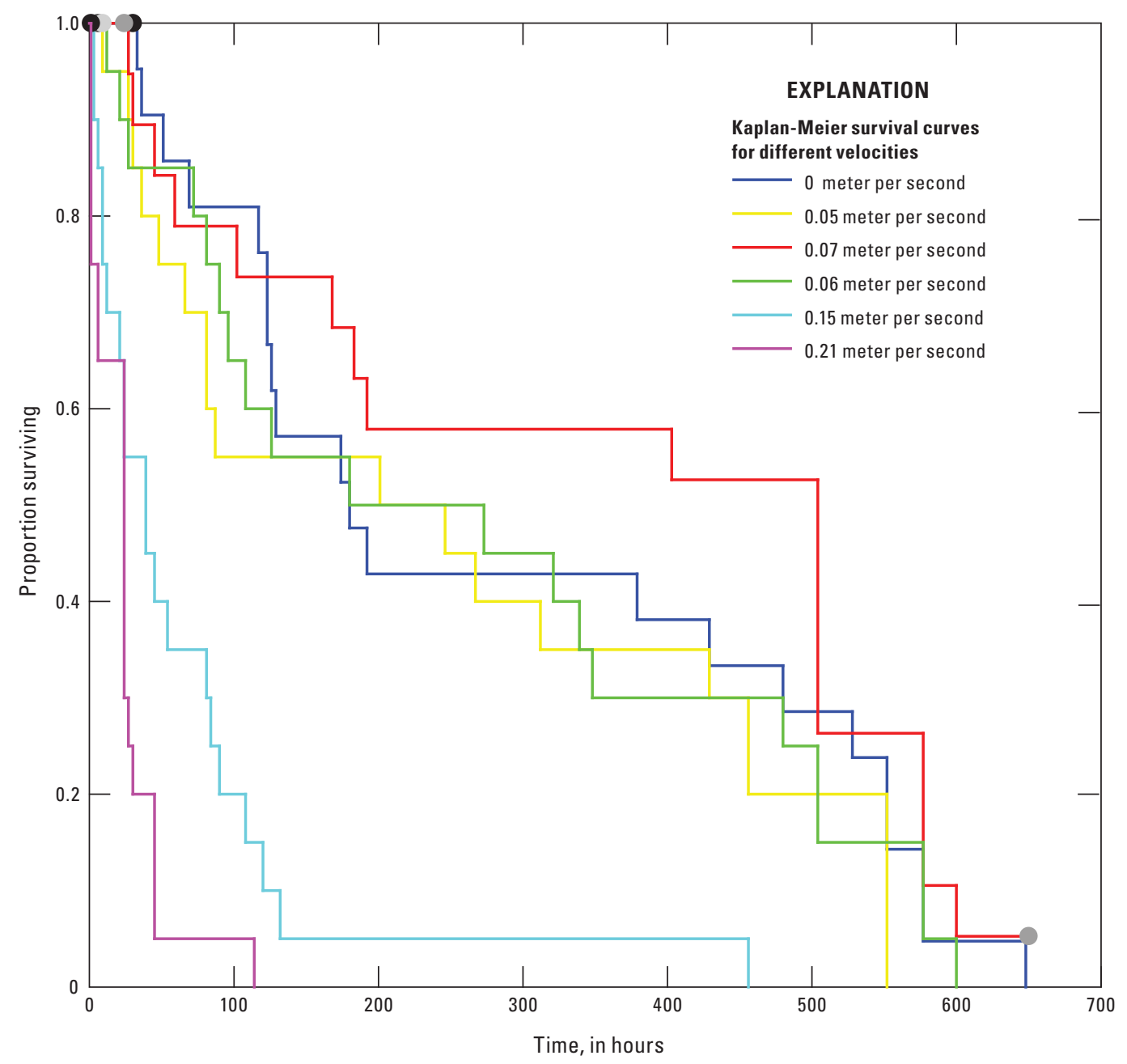

Figure 59. Kaplan-Meier survival curves for early life stage pallid sturgeon in the velocity challenge experiment. 
method indicated that the curves for the control, 0.05, 0.06, and $0.07 \mathrm{~m} / \mathrm{s}$ treatments were statistically similar and significantly different from the curves for 0.15 and $0.21 \mathrm{~m} / \mathrm{s}$ treatments. The curves for 0.15 and $0.21 \mathrm{~m} / \mathrm{s}$ treatments were not significantly different.

\section{Discussion}

One primary obstacle in these studies was to design a water delivery system that provided homogeneous water column velocities without damaging the fish. Flume 1 had less of an effect on water velocities and greater beginning survival of fish compared to Flume 2 based on the results of experiments 3 and 4 . The use of a tunnel to divert the fish below and downstream from the water entry point in Flume 2 reduced the water velocity (increased drag on the water column); moreover, it is not known if traveling through the tunnel affected the innate behavior or survival of the fish. The fish exited the tunnel near the bottom of the channel, and some fish may have been impinged on the nitex screen. The differences we observed in number of fish passes and drift velocity between the flumes may have been partly because of presence of the tunnel. We plan on using the design for Flume 1 in future dispersal studies.

Survival of early life stage pallid sturgeon embryos in both flumes was substantially greater than that of paddlefish. We were not able to discern whether the low survival of paddlefish was an artifact of the flume systems, a response to hydraulic conditions in the water column, or to the condition of the eggs. We plan on repeating the test with paddlefish (using Flume 1).

The use of reconstituted water that simulated the major cations and anions in the Missouri River was determined to be suitable for rearing early life stage pallid sturgeon and paddlefish and studying behavior. The water type is reproducible and will be used in future studies.

Based on the day fish began expelling their yolk plugs, the pallid sturgeon embryos in the culture system began transitioning to the larval stage at $12 \mathrm{dph}$ and had accumulated 222 CTUs. This finding matches the age at which the fish in experiment 3 (Flume 1) were starting to transition from drifting embryos to holding position as larvae (based on a reduction in fish passes and drift speeds and direct observations of the fish).

The transition to the larval interval for paddlefish in the culture system began at $8 \mathrm{dph}$ and 136 CTUs. We did not observe any indication that the fish in either flume (experiments 1 and 2) were beginning to exhibit a change in their drift behavior when studies were terminated at $8 \mathrm{dph}$; however, the trials started with fish at 5-8 dph were terminated at about $24 \mathrm{~h}$ because of low survival.

We plan on repeating the velocity challenge with pallid and shovelnose sturgeon and paddlefish using a different test system to provide the desired test velocities. We do not know the reason for the difference in survival between embryos exposed to a mean velocity of $0.13 \mathrm{~m} / \mathrm{s}$ in Flume
1 (experiment 3 ) and those exposed to a mean velocity of $0.15 \mathrm{~m} / \mathrm{s}$ in the velocity challenge. In the velocity challenge, only 40 percent of fish survived after 2 days and 10 percent after 5 days. In contrast, all fish survived for 8 days in Flume 1. The fish used in the velocity challenge were the progeny of the last spawning trial at GPNFH, which may have affected egg quality.

These experiments provided valuable insight into some of the difficulties involved with dispersal studies with early life stage shovelnose sturgeon, pallid sturgeon, and paddlefish. The information gained will be used to design the studies planned for 2015 .

\section{Missouri River Pallid Sturgeon Effects Analysis}

The need for a broadly defined EA was recognized by the Missouri River Independent Science Advisory Panel (ISAP) (Doyle and others, 2011). The Missouri River ISAP wrote: "The development of an adaptive management plan should be preceded by and based upon an effects analysis that incorporates new knowledge that has accrued since the 2003 Biological Opinion," (Doyle and others, 2011, p. 9) referring to the USFWS amended biological opinion for operation of the Missouri River main stem reservoir system and maintenance of the Missouri River Bank Stabilization and Navigation Project and operation of the Kansas River reservoir system (U.S. Fish and Wildlife Service, 2003). The concept of an EA is explained by Murphy and Weiland (2011) as a systematic evaluation of the effects of a federal agency action that has the potential to harm a listed species. The three essential components of an EA are as follows:

- collection of reliable scientific information,

- critical assessment and synthesis of available data and analyses, and

- analysis of the effects of actions on listed species and their habitats.

The last step needs to be as quantitative as possible to forecast expected ecological costs and benefits of an action and to evaluate tradeoffs with socioeconomic costs and benefits. The output of an EA provides a useful framework for ongoing assimilation of data from hypothesis-driven monitoring and research. If EA models are sufficiently quantitative, the EA can be used to evaluate alternative management actions in structured decision making (Murphy and Weiland, 2014). In the ideal situation, an EA includes quantitative population dynamics or population viability models that can be used to forecast population effects of management actions (Murphy and Weiland, 2011, 2014).

The Missouri River EA was started in fall 2013 and is made up of three interactive teams: 
- Hydrology, Hydraulics, and Geomorphology Team lead by Dr. Craig Fischenich, USACE;

- Pallid Sturgeon Team lead by Dr. Robert Jacobson, USGS; and

- Interior Least Terns and Piping Plovers Team lead by Dr. Kate Buenau, Pacific Northwest National Laboratories.

The three teams have worked together closely, especially in integrating management actions to habitat and species responses; and using linkages through hydrology, hydraulics, and geomorphic models. The efforts reported here are for the pallid sturgeon EA. The pallid sturgeon EA team is composed of sturgeon and river experts from the USGS, USFWS, USACE, Oregon State University, and Mississippi State University.

\section{Effects Analysis Scope and Objectives}

The pallid sturgeon EA is structured to provide information to address the fundamental species objective developed by the USFWS: Avoid jeopardizing the continued existence of the pallid sturgeon from U.S. Army Corps of Engineers actions on the Missouri River. (Jacobson and others, 2015a). The USFWS notes that this objective is consistent with species recovery goals (U.S. Fish and Wildlife Service, 2014) but is specific to Missouri River management actions. The fundamental species objectives are accompanied subobjectives that are measurable and relevant:

- Subobjective 1.-Increase pallid sturgeon recruitment to age 1 .

- Subobjective 2.-Maintain or increase numbers of pallid sturgeon as an interim measure until sufficient and sustained natural recruitment happens.

The emphasis on recruitment reflects the fact that no genetically determined successful recruitment of pallid sturgeon to age 1 has been recorded during the last 20 years in the Upper Missouri River (that is, no wild-spawned, naturally produced fish have been collected), and there is evidence of limited recruitment in the Lower Missouri River (U.S. Fish and Wildlife Service, 2014).

The geographic scope of the EA is the Upper Missouri River main stem from Fort Peck Dam to the headwaters of Lake Sakakawea, the Yellowstone River upstream from the confluence with the Upper Missouri River for an unspecified distance, the Lower Missouri River main stem from Gavins Point Dam to the confluence with the Mississippi River at St. Louis, tributaries used by pallid sturgeon, and an unspecified distance downstream in the Mississippi River. The geographic scope is constrained in part by decision making authority of the USACE and in part by present (2015) understanding of the geographic distribution of pallid sturgeon. The reservoirs and interreservoir reaches (from Lake Sakakawea to Lewis and
Clark Lake) are excluded from the EA based on the assumption that these habitats are unlikely to support reproductive populations of pallid sturgeon, although this assumption can certainly be relaxed if future information contradicts it. The distance in the Mississippi River is unspecified because presently available information (2015) is ambiguous about the extent to which Missouri and Mississippi River populations mix through migrations and dispersal.

The EA emphasizes three types of models. The first is a collaborative population dynamics model. Presently (2015), this model is a work in progress with forecasting ability; however, the validity of forecasted dynamics is uncertain. In the future it may provide a general population viability framework to assess management actions as envisioned in publications on EAs (Murphy and Weiland, 2011, 2014). The EA also uses advection and dispersion models (Dr. Craig Fischenich, U.S. Army Corps of Engineers, written commun., 2014) because of their utility in assessment of drift and dispersal of free embryos. The advection and dispersion modeling framework allows for robust consideration of transport and fate of free embryos under the assumption that they are transported mostly as passive particles. The models provide essential insights into management options on the Yellowstone and Upper Missouri Rivers. Finally, the EA also emphasizes development of twodimensional hydrodynamic models for habitat assessments on the Lower Missouri River. The hydrodynamic models allow for integrative assessment of the effects of hydrologic regime and channel reconfigurations on types and distributions of physical habitat units. The utility of the models depends on developing defensible definitions of functional habitat units from theoretical and empirical information on pallid sturgeon habitat selection and preference.

The quantitative model framework developed through the EA is intended to inform part of the framework for future adaptive management of species in the Missouri River. The redesigned adaptive management process for the Missouri River is likely to include an ongoing assessment process similar to the EA, whereby new information from monitoring, assessment, and research efforts will be used to improve management actions with time.

\section{Progress}

During 2014, the EA team completed drafts of three EA reports that address the following fundamental EA tasks:

- Develop conceptual ecological models (CEMs) to document and illustrate driver-stressor-response ecological relations for Missouri River pallid sturgeon (Jacobson and others, 2015a). The CEMs were collaboratively developed through a workshop process that began shortly before the EA began in summer 2013. The EA report refined, documented, and organized the CEMs.

- Compile and assess available information and modeling resources that can be used to understand historical 
and future changes of pallid sturgeon populations. This report focused on cataloging information available for evaluating past, present, and future driver-stressorresponse relations in pallid sturgeon population dynamics (Jacobson and others, 2015a).

- Develop a hierarchy of hypotheses to depict relations in the CEMs. The process of hypothesis formulation and filtering was accomplished through a series of expert opinion surveys, starting with hundreds of "global" hypotheses emanating from the CEMs and ending with 21 working management hypotheses (Jacobson and others, 2016)

The EA also completed a draft of an integrative report that synthesizes the previous three to present a lines-ofevidence analysis of the 21 working hypotheses. The analysis includes best available combinations of qualitative and quantitative models, theoretical and empirical data, and expert opinion, along with discussion of how the EA fits within the evolving adaptive management structure of the Missouri River (Robert Jacobson, U.S. Geological Survey, written commun, 2015).

In addition to the reports, the EA continued collaborative development of a pallid sturgeon population model. The model is intended to serve as a foundation for future adaptive management of the Missouri River and pallid sturgeon by providing the computational basis for keeping track of population dynamics. The model was compiled using several workshops and webinars to elicit input from pallid sturgeon experts on model structure and parameter values.

The EA members also provided input to the Missouri River Recovery Management Plan Product Delivery Team on alternative development, provided presentations to multiple agency groups, and met with the Missouri River Recovery Implementation Committee and ISAP at quarterly meetings.

\section{Discussion}

The Missouri River pallid sturgeon EA was designed to address three components of an assessment of management effects on pallid sturgeon population dynamics: collection of reliable scientific information, critical assessment and synthesis of available data and analyses, and analysis of the effects of actions on listed species and their habitats. All three components have presented challenges because of the varying quality and rapidly evolving nature of pallid sturgeon science, the wide range of expert opinion on the causes of recruitment failure, and the inherent high uncertainties about fundamental pallid sturgeon biology and demographic rates.

\section{Effects Analysis Syntheses}

The hypothesis filtering process produced 21 hypotheses almost evenly divided between the Upper Missouri and Yellowstone Rivers and the Lower Missouri River. For some of the 21 hypotheses, information is so sparse that lines of evidence are limited to theoretical deduction, inference from sparse empirical datasets, or expert opinion; nevertheless, useful models have been developed of the effects of management actions on survival of drifting free embryos in the Upper Missouri River and for assessing effects of flow and channelreconfigurations on habitat availability in the Lower Missouri River. We have also developed a population model that can be used to assess sensitivity of life stages, to assess some hypotheses related to stocking decisions, and to explore a limited number of management scenarios. Sensitivity analyses completed with the population model confirmed that early life stage survival values were the most uncertain and have the most leverage on population dynamics. Comparisons of the population model results with current (2015) average stocking rates and zero stocking confirmed the present-day (2015) dependence of population persistence on stocking; the zerostocking model runs typically predicted negative growth rates and quasi extinction. Model runs were also used to estimate early life stage survival rates needed to sustain a population under current (2015) average stocking rates. These numbers provide benchmarks against which to evaluate stocking and to guide refinement of survival rates.

One-dimensional advection and dispersion models have been developed through the EA process to assess drift dynamics of free embryos (Dr. Craig Fischenich, U.S. Army Corps of Engineers, written commun., 2014). The results of the models are instrumental in documenting the conditions under which flow management, temperature management, and drawdowns of Lake Sakakawea have the potential to affect survival of drifting free embryos; and the distances upstream on the Yellowstone that adults would need to migrate to have their drifting free-embryo progeny survive. Drift models on the Lower Missouri River are important for documenting the length of river traversed by drifting free embryos and for indicating locations along the river where foraging and food-producing habitats for free embryos might be constructed.

Functional habitat assessments using two-dimensional hydrodynamic models provide an understanding of how availability of functional habitats varies jointly with hydrologic regime and channel reconfigurations. Comparison of channelized and best-available channel configurations by hydrologicregime scenarios demonstrates that the effect of hydrologic regime on functional habitat availability diminishes substantially downstream from Kansas City, Mo., where unregulated discharges contribute variability to discharges. Among the functional habitats modeled, food producing and foraging habitats were substantially greater in the best-available habitat model reaches. These analyses show that hydrologic regime is effective in altering distributions of habitats in upstream reaches, channel reconfigurations are effective in altering distributions of habitats in all reaches, and the combination of the two can be especially effective in altering distributions of some habitats. The continuing challenge with functional habitat analyses is to improve the biological realism of habitat 
definitions so they have demonstrable relevance to pallid sturgeon growth and survival.

Each of the 21 hypotheses includes a discussion of hypothesis "routing;" that is, how the degree of uncertainty and risk associated with each hypothesis may guide implementation toward full field implementation of an action; limited implementations as field-scale experiments; or, in the case of greatest uncertainty and risk, emphasis on research and opportunistic experiments or gradient studies. Analysis of relations among management actions indicates some strong contingencies in which decisions are highly dependent on precursor information.

Finally, recognition of the substantial uncertainties associated with pallid sturgeon population dynamics and the need to continually assimilate and assess new information indicates that an EA-like process should be considered an integral part of ongoing Missouri River adaptive management. This will allow for the most effective use of the foundation of information and modeling tools that have been developed by the EA.

\section{Comprehensive Sturgeon Research Project and the Effects Analysis}

Not surprisingly, the EA concludes that present (2015) understanding of pallid sturgeon reproductive ecology is fraught with uncertainty. Although the thousands of hypotheses implicit in the CEMs have been filtered down to 21, that number is still a substantive challenge to decision making. The EA provides a new, systematic evaluation of what is known, what is not known, and what needs to be known to inform Missouri River management for the benefit of pallid sturgeon. As such, it provides a framework and sense of priorities for direction of the CSRP. Although previous science prioritization exercises have formed the basis for development and prioritization of CSRP tasks, the EA process has gone several steps further in defining a foundation for future research.

The CEM development (Jacobson and others, 2015a) and hypothesis prioritization processes (Jacobson and others, 2016) provide a comprehensive, documented, and extensively reviewed set of priority hypotheses for management actions to promote pallid sturgeon populations. The integrative report (Dr. Robert Jacobson, U.S. Geological Survey, written commun., 2015) presents the best available conceptual and quantitative models to address the 21 priority hypotheses. These models illustrate which processes and rates have the greatest sensitivity and uncertainty in explaining pallid sturgeon population dynamics and thereby provide a framework to prioritize research.

Because CSRP scientists have been involved in the EA, the process has not been an entirely independent evaluation of CSRP; however, the EA has added rigor, scope, and expertise to the evaluation of Missouri River pallid sturgeon science - in development of the EA and in its review - which have served to test the direction of CSRP science. The results of the EA have reinforced the perception that science should focus on early life stage processes - from spawning to survival to age 1 - with specific emphasis on integrated biophysical understanding of spawning and dispersal dynamics. Tasks within the CSRP to address these issues are already underway and have been discussed in this report.

The EA has also identified areas of research that have not received much interest in recent years, but which may be critical to pallid sturgeon recovery. Among them are the following:

- The role of contaminants in reproductive ecology. Although direct evidence for substantive contaminant effects on young-of-year or juvenile pallid sturgeon is lacking (Jacobson and others, 2015b), the hypothesis that agricultural and urban runoff is implicated in suppression of fecundity or fertility of adults persisted through the hypothesis filtering process (Jacobson and others, 2016), largely because of the high potential for exposure on the Lower Missouri River. No systematic research is presently (2015) underway on the cumulative effects of endocrine disruptors on pallid sturgeon populations.

- The role of genetics and propagation strategies in fitness. Hypotheses related to genetic fitness and optimization of stocking sizes were included among the 21 in the EA integrative report, but no models were presented to evaluate quantitative relations between strategies, fitness, and population health (Dr. Robert Jacobson, U.S. Geological Survey, written commun., 2015). There is presently (2015) no research underway to evaluate the cumulative result of propagation practices on population processes.

- Entrainment of drifting free embryos. Hypotheses related to the threat of entrainment of drifting free embryos by water intakes were discussed and presented in the CEM and hypotheses reports, but related hypotheses were not prioritized. Emerging understanding of drift behaviors that indicates concentration of free embryos near the bottom in the thalweg suggests that water intakes with specific geometries and capacities have the potential to entrain large numbers of free embryos. Research specifically to address entrainment processes is lacking.

- Predation of embryos and free embryos. Although laboratory information suggests that predation of age- 0 pallid sturgeon is likely not a mechanism for recruitment failure, predation of embryos at spawning sites and newly hatched free embryos downstream from spawning sites has not been assessed under field conditions. 
Conservation Genetics of Pallid Sturgeon and the Effects of Population Augmentation on Range-Wide Population Structure

The pallid sturgeon was listed as endangered in accordance with the Endangered Species Act in 1990. The first Pallid Sturgeon Recovery Plan developed in 1993 identified a critical need for a propagation and population augmentation program to prevent local extirpation and aid population restoration (Dryer and Sandovol, 1993). The PSCAP was established in the early 1990s with the participation of State and Federal agencies. The first successful propagation of pallid sturgeon happened in 1992 at the Missouri Department of Conservation BPSFH (U.S. Fish and Wildlife Service, 2008). Successful propagation did not happen again until 1997, when pallid sturgeon progeny were produced at both the BPSFH and the USFWS GPNFH. Since then, the PSCAP has produced and released tens of thousands of HOPS by artificially spawning wild-caught adult fish (U.S. Fish and Wildlife Service, 2007).

Early population augmentation practices resulted in the stocking of the Lower Missouri River with hatchery progeny from broodstock collected in the Middle Mississippi River and Upper Missouri River Basin. These early propagation and stocking practices have resulted in considerable transfer of genetic stocks from the Middle Mississippi and Upper Missouri Rivers into the Lower Missouri River. Under current (2015) practices, only field-collected, wild pallid sturgeon are artificially propagated to produce offspring for population augmentation. The HOPS are not used as broodstock to reduce the risks of inbreeding and outbreeding depression. All HOPS are marked before stocking; however, retention of hatchery tags is highly variable and not sufficiently reliable to identify hatchery progeny. Parental deoxyribonucleic acid (DNA) microsatellite genotypes have been developed as genetic tags to identify unmarked captive-bred pallid sturgeon; however, the absence of a complete broodstock inventory, coupled with missing parental genotypes, has compromised the ability to detect unmarked HOPS. In addition, many of the stocked hatchery fish with missing parental genotypes were propagated from broodstock of Upper Missouri River origin and were stocked into the Lower Missouri River. These captive-bred offspring are now becoming reproductively mature and may be inadvertently taken to hatcheries as potential broodstock; thus, continuing to use broodstock of unknown genetic provenance could result in unintentionally mating Upper Missouri River HOPS, the offspring of which would augment Lower Missouri River pallid sturgeon stocks, simultaneously violating two principles of the USFWS propagation plan (U.S. Fish and Wildlife Service, 2008) and USFWS policy (65 FR 56916-56922); namely, that broodstock should be wild fish and of local origin.
This study is an extension of ongoing research done in collaboration with Dr. Edward Heist at SIU to recover genotypes of pallid sturgeon broodstock. The objective of this study was to develop a relational database to support recovery of missing genotypes and enable the characterization of pallid sturgeon population structure within the Central Lowlands and Interior Highlands Management Units (MUs).

\section{Pallid Sturgeon Propagation Data Recovery and Broodstock Reconstruction}

At the beginning of the PSCAP, genetic analyses to differentiate pallid sturgeon from the closely related shovelnose sturgeon had not been developed (Campton and others, 2000; Schrey and Heist, 2005). Also absent was information on the range-wide genetic population structure of pallid sturgeon and the means to identify genetic stocks or locally adapted remnant populations. Pallid sturgeon were differentiated from shovelnose sturgeon and selected for broodstock solely based on morphometric measurements and meristic counts (Bailey and Cross, 1954; Sheehan and others, 1999; Kuhajda and Mayden, 2001; Tranah and others, 2001). Hybridization had been documented through the identification of morphological intermediates, but there were no means to identify hybrid backcrosses or quantify potential genetic introgression (Carlson and others, 1985; Keenlyne and others, 1994a; Tranah and others, 2004). In addition, identification of pallid sturgeon and selection of broodstock were complicated by observed regional variation among adult pallid sturgeon from different recovery priority management areas (RPMA) (Keenlyne and others, 1994b; Murphy and others, 2007). Unfortunately, given the perceived rarity of the species and the absence of effective genetic analyses, the critical necessity of sampling and archiving tissues from all broodstock used in the PSCAP for future genetic identification was not widely appreciated. Many adults used in the early propagation efforts were either not sampled or the samples were not properly archived.

Although geographic RPMAs were identified and delineated in the first recovery plan, RPMA boundaries were generally not used to guide broodstock collection or stocking of hatchery progeny. As a result, pallid sturgeon progeny from propagation efforts in one RPMA were commonly released into another RPMA and at one or more management areas distant from the capture location of the parents. The HOPS produced in 1992 and 1997 from broodstock collected in the Mississippi River (RPMA 5) were stocked upstream into the Lower Missouri River (RPMA 4). Almost annually from 1999 to 2007, HOPS produced from broodstock collected in the Upper Missouri and Yellowstone Rivers in Montana and North Dakota (RPMAs 1 and 2, respectively) were stocked far downstream into the Lower Missouri River (U.S. Fish and Wildlife Service, 2008). A review of advances in genetic identification and discrimination of Scaphirhynchus sturgeons by the Pallid Sturgeon Recovery Team and the Pallid Sturgeon Genetic Advisory Group in 2006 suggested that pallid sturgeon 
populations showed substantial genetic structure across the range of the species (Campton and others, 2000; Tranah and others, 2001; Schrey and Heist, 2007). Genetic evidence of population structure led to a moratorium on the translocation of Upper Missouri River HOPS downstream from Gavins Point Dam (beginning with the 2007 PSCAP year class) and an emphasis on the use of local broodstock for population augmentation in the Lower Missouri River (U.S. Fish and Wildlife Service, 2007). With these actions, the recovery program acknowledged that continuation of propagation and stocking practices that result in substantial transfer of genetic stocks from the Mississippi and Upper Missouri Rivers into the Lower Missouri River may result in outbreeding depression and the loss of locally adapted traits (Schrey and Heist, 2007). The Pallid Sturgeon Range-Wide Stocking and Augmentation Plan (U.S. Fish and Wildlife Service, 2008) and the revised Recovery Plan for the Pallid Sturgeon (U.S. Fish and Wildlife Service, 2014) subsequently replaced the six RPMAs with four Recovery MUs based on physiographic regions, existing threats to the species, and recovery potential. The Great Plains, Interior Highlands, Central Lowlands, and Coastal Plains MU designations in the revised plans also were structured to align loosely with the emerging understanding of pallid sturgeon genetic stock structure.

Protocols developed under the recovery program and PSCAP include a comprehensive tagging program and a national database to track captured pallid sturgeon and stocked progeny. The PSCAP protocols require that HOPS greater than $70 \mathrm{~mm}$ be marked such that wild pallid sturgeon can be discerned from captive-bred counterparts to quantify natural recruitment (DeHaan and others, 2008) and monitor the effectiveness of the PSCAP (U.S. Fish and Wildlife Service, 2008). From 1992 to 1997, HOPS were typically marked with coded wire tags and Floy tags, though some small groups of stocked fish also received additional marks during this period. Since 1998, HOPS have been generally marked with uniquely identifiable, PIT tags, coupled with other physical marks (such as colored elastomers and removal of specific lateral scutes). Retention rates among the tags used are highly variable and have been shown to be insufficient for accomplishing the aforementioned objectives of the recovery programs (DeHaan and others, 2008; Hamel and others, 2012).

Until recently (2013), HOPS with failed tags or otherwise undetected marks were commonly regarded as "probable wild," implying natural reproduction and recruitment. Assuming that unmarked pallid sturgeon are wild may result in overestimation of spawning success and recruitment (DeHaan and others, 2008). The presence of unmarked and undetected HOPS obscures the genetic population structure of the species and the relation between genetics and geography. Additionally, captive-bred fish from early propagation and stocking efforts are reaching sexual maturity (DeLonay and others, 2010) and are being taken to the hatchery for use as potential broodstock. Inadvertently using unmarked or undetected HOPS as broodstock increases the risk of inbreeding depression. Inadvertently using undetected HOPS from the Upper Missouri and
Yellowstone Rivers as broodstock in the Lower Missouri increases the risk of outbreeding depression, obscures natural population structure, and does not effectively advance one of the primary goals of the PSCAP: to conserve the genetic variation of the species (U.S. Fish and Wildlife Service, 2014).

Currently (2015), DNA microsatellite genotypes are used to identify unmarked HOPS and assign them to stocked hatchery cohorts based on genetic parentage analyses of known broodstock hatchery crosses (DeHaan and others, 2008); however, detecting unmarked HOPS requires a complete inventory of all fish used as broodstock for captive breeding in the PSCAP, and the genotypes of all broodstock must be known and archived. At the beginning of this project, a complete broodstock inventory did not exist, and the genotypes of many adults used for broodstock were missing. The absence of a complete broodstock inventory has compromised the ability to detect unmarked HOPS among field-collected sturgeons. Although stocking summary reports describing the captive breeding efforts of the PSCAP have been produced and have proven beneficial to identifying broodstock used for captive breeding, they have limitations. A report by Krentz and others (2005) contained range-wide captive breeding information but only through 2004. A report by Huenemann (2014) is current; however, it only contained identification of broodstock in the Lower Missouri River below Gavins Point Dam to the confluence with the Mississippi River and not the entire range of the species. The absence of a complete broodstock inventory made it difficult to determine with certainty the number and identity of broodstock that had been used for captive breeding efforts and, therefore, impossible to determine exactly how many genotypes were missing for these fish. Using records of genotypes from early captive breeding efforts (1992-2004), we determined the number of genotypes known to be missing. Based on estimates of data known to be missing, we estimated that more than 30 percent of HOPS could not be detected or discriminated from wild pallid sturgeon using DNA microsatellite parentage analyses at the beginning of this study.

The objective of this study was to develop a geospatially enabled relational database to support the recovery of missing captive breeding matrix data and reconstruction of missing genotypes of PSCAP broodstock. Achieving this objective will meet five critical recovery program and PSCAP needs, including the following: (1) improving the ability to identify unmarked HOPS using genetic parentage analyses, (2) increasing the reliability of HOPS survival and population estimates, (3) ensuring the ability to detect and resolve natural recruitment from population augmentation, (4) preventing the use of HOPS as PSCAP broodstock to reduce the risk of inbreeding and outbreeding depression, and (5) adequately characterizing the natural population structure of the pallid sturgeon within the Central Lowlands and Interior Highlands MUs to support the conservation of genetic diversity and locally adapted traits. 


\section{Data Compilation}

The National Pallid Sturgeon Database (NPSDB) maintained by the USFWS was obtained to document range-wide captive breeding crosses. The NPSDB contains two relevant tables: the "Recaptured Pallids" table records information about the capture of all pallid sturgeon, and the "Stocked Juveniles" table records details about HOPS stocked into the wild. Multiple versions of the NPSDB were obtained during the course of this study to compile all available data relevant to the temporal scope of interest (through 2012). Each newly acquired version of the NPSDB merited a data merge because of substantial changes made between each version. A data merge, in contrast to a simple data append of new, recent data, was warranted as the databases, both the USFWS database as well as our own, were continuously altered or edited to correct errors or omissions.

Potential sources of pallid sturgeon genetic material were identified at several facilities participating in pallid sturgeon recovery activities, including genetics laboratories, cryopreservation repositories, and the whole-body repository. Data were obtained and compiled detailing all samples (including PIT tag of the fish, tissue location, and status [analyzed or not]) retained at three genetic laboratories actively contributing to pallid sturgeon recovery efforts: USFWS Northeast Fishery Center, USFWS Warm Springs Fish Technology Center, and SIU. Data were compiled detailing the cryo-preserved milt samples collected from male pallid sturgeon and retained at two USFWS cryo-preservation facilities: USFWS Garrison Dam National Fish Hatchery in North Dakota and USFWS Warm Springs Fish Technology Center in Georgia. Data were also compiled detailing the identity of pallid sturgeon retained in the Whole Body Repository at the University of Alabama in Tuscaloosa.

Each of the above described datasets was imported into a table and compiled in SQL Server, a fully relational database management schema. During early data compilations, it became apparent that a number of fields in the NPSDB "Stocked Juveniles" table that were required to compile a complete list of all broodstock used for captive breeding in the PSCAP were blank, incomplete, or contained erroneous data. Of primary concern was the status of the PIT tag information, which is the range-wide standard identifier for pallid sturgeon. Many female and male broodstock records were missing PIT tag information, contained invalid PIT tags (that is, were greater or less than the standard 10 alphanumeric characters), or were assigned PIT tags with no corresponding capture record. Further inspection of the NPSDB "Recaptured Pallids" table revealed that individual fish have been documented with multiple, unique PIT tags. It is known that occasionally PIT tags are subject to expulsion or failure and are subsequently replaced by a new PIT tag with a new identification number. Presumably, these cases arose under unique circumstances; for example, a marked fish may shed their PIT tag, or the PIT tag may have failed, but it may also have secondary tags (for example, a uniquely coded telemetry transmitter or Floy tag) that allow the fish to be retagged and the two PIT tags linked to the same individual. Other examples include individuals that shed tags while in possession of a biologist or hatchery manager, individuals that are implanted with a second PIT tag when the first tag was undetected and thus were implanted with two functioning PIT tags simultaneously, or individuals that shed tags only to be later identified through genetic analysis and the subsequent PIT tags linked. Because PIT tag numbers serve as unique identifiers of fish records in the NPSDB, multiple PIT tags associated with an individual pallid sturgeon increasingly complicate even routine data management tasks, such as locating pertinent records for individual fish. As no framework existed to efficiently accommodate these circumstances within a relational database, we developed a mutually exclusive identifier (MEID) assigned to each fish. The MEID was used as the primary key for subsequent database relations and data query and summary.

\section{Data Enhancement}

A number of broodstock PIT tags contained in the NPSDB, genetics inventory, and other datasets were strikingly similar to known broodstock PIT tags, leading to the possibility that some PIT tags may have been recorded incorrectly (through character omission, transcription, or transposition errors). A string distance algorithm was developed to query PIT tags that were at least 80 percent similar among datasets based on the characters contained within each alphanumeric code and their relative position. This resulting list was manually assessed, comparing other tertiary data (for example, spawn date, stock site, capture location), to determine the true identity of each PIT tag. Some instances were relatively simple; for example, females 132211892A and $132211792 \mathrm{~A}$ were 90 percent similar based on the string distance algorithm, both were listed as broodstock in the NPSDB, and much of the tertiary spawning data matched; however, no capture record existed for 132211892A and only one progeny was listed, whereas capture records and numerous progeny existed for 132211792A. Lastly, 132211792A was verified in the Huenemann (2014) stocking report. Conversely, it is not safe to assume that very similar PIT tags are identical fish; for example, genetic analysis showed that male 7F7F06583D was a broodstock, but it was not listed as broodstock in the NPSDB. Using the string distance algorithm we found PIT tags 7F7F065A3D, 7F7065A3D (nine characters), and 7F7F065834 were also recorded in the NPSDB. Examination of records relating to all four PIT tags showed that 7F7F065834 was the only PIT tag recorded as broodstock $(1997,1999$, and 2004). Genetic samples existed for three of the four individuals, excluding the nine-character misreported PIT tag. Collaboration with geneticists determined that progeny from $1997(n=383)$ and $1999(n=339)$ shared microsatellite loci with 7F7F06583D but were misreported as 7F7F065834. Additionally, it was determined that 7F7F065A3D was a female, which was not used as broodstock in the PSCAP. Regardless of how seemingly trivial the error, 
each was thoroughly investigated and confirmed through multiple sources.

New data structure was also required to account for the hatchery practice of combining gametes from multiple (three or more) broodstock. Typically, eggs from a single female (F) are mixed with sperm from 3-5 males (M) to improve fertilization rates and streamline spawning $\left(F_{1} \times M_{1}, M_{2}, M_{3} \ldots M_{n}\right)$. In a few instances, these complex breeding crosses contained gametes from more than 10 broodstock. Additionally, HOPS from some family lots (unique $\mathrm{F} \times \mathrm{M}$ crosses) are combined before tagging to improve embryo survival in hatching jars or increase efficiency of space utilization during larval and juvenile stages. Multiple-male fertilization and mixed family lots, although acceptable hatchery practices under most instances, make later differentiation of individuals and unique family crosses impossible at subsequent recapture events. Because a data structure in the NPSDB was not present to accommodate such complex circumstances, the resulting parentage data in the stocking records is commonly left blank, partially documented (usually, F only), or simply recorded as "mix." These complex breeding crosses and mixed family lots were investigated to fill in previously undocumented broodstock data. An additional table within the relational database architecture was developed to accommodate these challenging data.

The provided NPSDB data also contained missing or incomplete temporal and spatial information relating to the capture and stocking of pallid sturgeon, which hindered spatial summary and analysis. At the broadest scale, our objective was to assign each capture or stocking event to a MU and specific year. At a finer scale, we attempted to attribute each record to a coordinate point and date for spatial analysis. This endeavor proved laborious because a number of records, both capture and stocking, were missing or contained erroneous data. In some cases, where coordinates were lacking, we were able to plot location using Dynamic Segmentation within ArcGIS. By creating spatially aware polylines of the Mississippi River Basin, we could then place points on a map based on river and RM, but numerous records remained uncharted because of incomplete original data.

Although our primary objective focused on the Central Lowlands and Interior Highlands MUs, we achieved substantial success in improving the quality of data pertaining to the Great Plains and Coastal Plains MUs. A large number of corrections were made to the data, though some analyses remain hindered because of missing information. Substantial inconsistencies among the NPSDB data and other various sources used for this project remain; however, rectifying these were beyond the scope of this project. Additional effort is warranted to ensure data are complete and accurate and that all available data are used efficiently and to their fullest potential.

\section{Progress}

A total of 1,438,600 HOPS were stocked throughout the Mississippi River Basin from 1992 through 2011 (fig. 60). Most of these individuals, 1,274,341 (88.6 percent), were stocked within the Great Plains MU. More than one-half (705,216 or 55.3 percent) of these were stocked as fry during early life history experiments (table 33). Stockings in all other MUs consisted of fingerling or older pallid sturgeon: 118,051 within the Central Lowlands MU; 31,041 within the Interior Highlands MU; and 15,149 within the Coastal Plains MU. Upon examining the NPSDB "Stocked Juveniles" table, it became apparent that about 20 percent of stocking records contained blank or only partial parentage data, thus, compromising the ability to efficiently compile a complete captive breeding matrix to facilitate the search for missing genotypes. At the outset of this project 54,927 (3.8 percent) of the $1,438,600$ stocked pallid sturgeon were missing broodstock identification in the NPSDB. Within the Great Plains MU, 17,001 (1.3 percent) of the total HOPS were missing broodstock identification from 9 years from 1997 to 2010. Within the Central Lowlands MU, 15,716 (13.3 percent) individuals were missing broodstock identification from 8 years from 1992 to 2010. Within the Interior Highlands MU, 6,991 (22.5 percent) individuals were missing broodstock identification from 3 years: 1992, 1997, and 2003. Within the Coastal Plains MU, 15,149 (100 percent) individuals were missing broodstock identification from 3 years: 1992, 1997, and 2004 (fig. 61A). In addition, we were able to document 22 mixes, containing 128 distinct broodstock affecting 14,293 progeny where previously no broodstock information was recorded in the NPSDB. Lastly, we were able to determine broodstock for an additional 408 progeny where previously no broodstock information existed. To date (2015), this project has corrected parentage for a total of 47,744 (86.9 percent) of the 54,927 HOPS with missing or incomplete parentage information from 1992 to 2011 . The efforts to rectify missing broodstock data resulted in identification of 25 new broodstock previously undocumented across all years within the NPSDB. The newly identified broodstock (9 females and 16 males) resolved the parental origin of 33,753 stocked progeny (table 34). A total of 15 broodstock PIT tags ( 5 female and 10 male) were corrected using the string distance algorithm affecting 10,148 stocked progeny (table 35 ). Specifically, there were 7,937 in the Great Plains MU; 2,163 in the Central Lowlands MU; and 48 in the Interior Highlands MU. To date (2015), this project has documented 71 female and 144 male uniquely identifiable broodstock used for captive breeding efforts, creating the most comprehensive breeding matrix available. After parentage data corrections, a total of 7,183 HOPS remain with missing or incomplete parentage information, specifically 6,917 in the Great Plains MU and 266 in the Central Lowlands MU (fig. 61B).

During this project, 64 individual pallid sturgeon were identified with more than one PIT tag or other alphanumeric identifier. We identified one male broodstock that was recorded as a parent by two different PIT tags in the NPSDB (132235554A and 7F7D487531) in 3 spawning years; 2004, 2007, and 2008. Correcting the parentage in the stocking records affected 93,969 stocked progeny. Addition of the new data structure resulted in linking 64 additional capture records. 


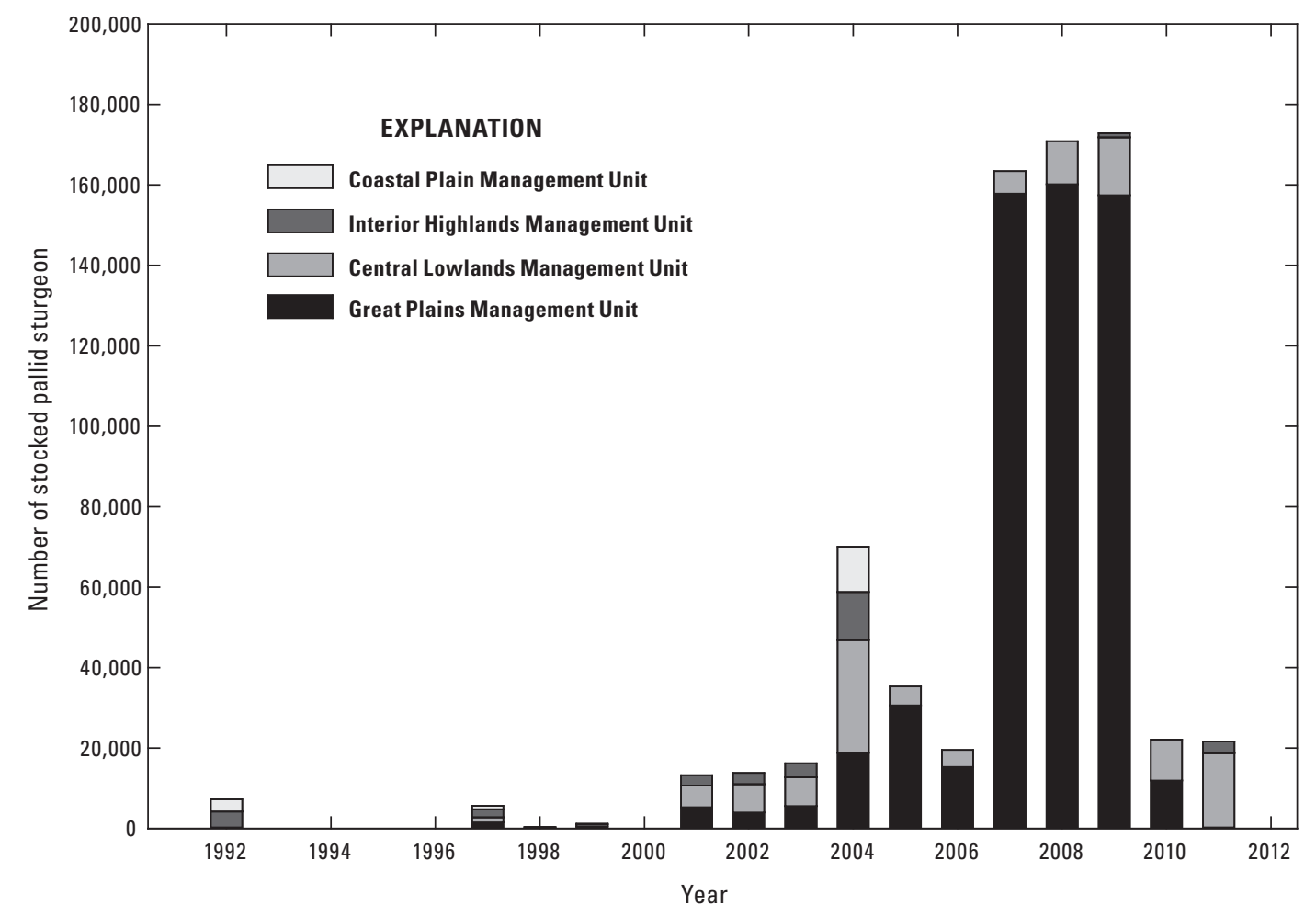

Figure 60. The number of stocked pallid sturgeon, not including those stocked as free embryos (less than or equal to 21 days post-hatch) for each management unit from 1992 to 2011.

Table 33. Description of age classes of hatchery-origin pallid sturgeon stocked by the Pallid Sturgeon Conservation Augmentation Program.

\begin{tabular}{lc}
\hline \multicolumn{1}{c}{ Age class } & \multicolumn{1}{c}{ Description } \\
\hline Fry & Less than 20 days post spawn. \\
Fingerling & $\begin{array}{c}\text { Greater than } 20 \text { days post spawn and stocked } \\
\text { the same year as spawn. }\end{array}$ \\
Yearling & $\begin{array}{l}\text { Less than 2 years post spawn and stocked the } \\
\text { year after spawn. }\end{array}$ \\
2-6 years old & Age based on the number of days post spawn. \\
\hline
\end{tabular}

There are now 706 capture records for the 202 broodstock, including records for 15 broodstock with previously unknown capture information. Only 15 broodstock remain without capture records.

Comprehensive collaborative efforts to recover potential genetic material were successful. Cryo-preserved milt for three male broodstock (1F4A4B5973, 7F7D461025, and 7F7D487531) was located at cryo-preservation repositories by compiling available data and cross-referencing these with known broodstock. Genotypes were successfully extracted by the USFWS Northeast Fishery Center. Female pallid sturgeon 7F7F056171 was in the Whole Body Repository at the University of Alabama. Collaborative efforts with Dr. Heist at SIU have resulted in the recovery and reconstruction of genotypes for 18 additional broodstock within all MUs from genetic samples taken from their known offspring or obtained from collaborative exchanges. Together, these 22 broodstock contributed 122,133 offspring; 93,892 of these were stocked in the Great Plains MU (37,433 of these were stocked as free embryos); 7,546 were stocked in the Central Lowlands MU; 6,411 were stocked in the Interior Highlands MU; and 14,284 were stocked in the Coastal Plains MU (fig. 61B). At this time, only 7 known broodstock are missing from the genetic baseline for range-wide captive breeding efforts from 3 year classes (fig. 61B) stocked into the Central Lowlands MU; the 1992 year class is missing 1 genotype, 1997 year class is missing 5 genotypes (2,816 resulting offspring), and 2001 year class is missing 1 genotype (12 offspring). Genotypes for five broodstock from the 1992 year class have been posthoc reconstructed except for one parent with too few known offspring to facilitate a complete genotype reconstruction. It is unknown if or how many offspring this broodstock may have contributed because gametes for the broodstock seem to have been pooled. 


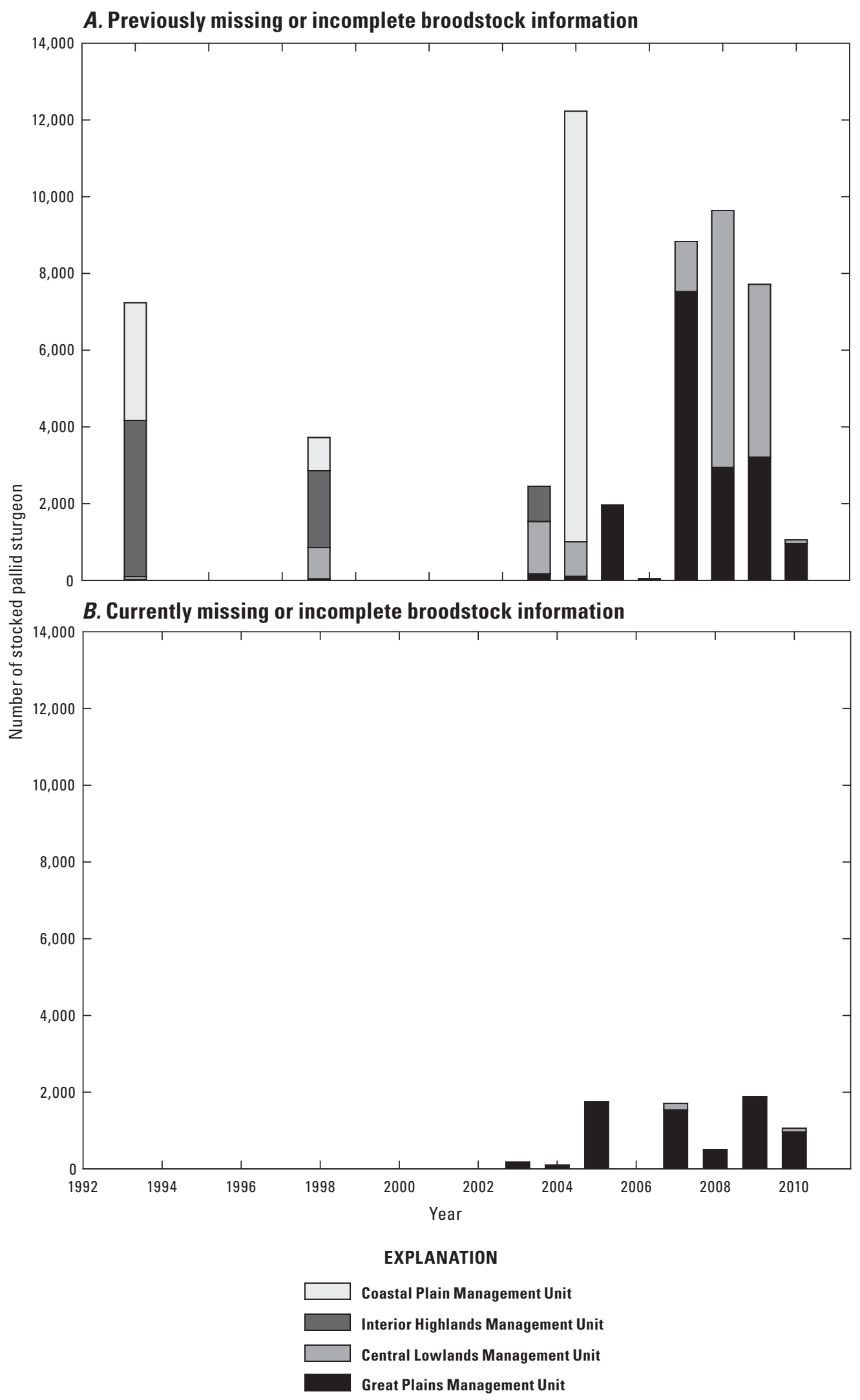

Figure 61. The number of stocked pallid sturgeon whose broodstock information was or is missing or incomplete in the U.S. Fish and Wildlife Service National Pallid Sturgeon Database for each management unit from 1992 to 2011. $A$, previously missing or incomplete; and, $B$, currently missing or incomplete. 
Table 34. The number of broodstock added to the data within each year class and the number of progeny affected by corrections.

\begin{tabular}{cccr}
\hline Year class & $\begin{array}{c}\text { Count of } \\
\text { females }\end{array}$ & $\begin{array}{c}\text { Count of } \\
\text { males }\end{array}$ & $\begin{array}{c}\text { Count of } \\
\text { progeny }\end{array}$ \\
\hline 1992 & 2 & 3 & 7,236 \\
1997 & 2 & 3 & 4,064 \\
1999 & 0 & 1 & 339 \\
2004 & 3 & 4 & 11,221 \\
2006 & 1 & 0 & 46 \\
2007 & 0 & 1 & 4,184 \\
2008 & 1 & 4 & 6,663 \\
\hline Total & $\mathbf{9}$ & $\mathbf{1 6}$ & $\mathbf{3 3 , 7 5 3}$ \\
\hline
\end{tabular}

\section{Discussion}

During this project, we discovered HOPS with partially or fully undocumented parentage, numerous broodstock identification errors (including character omission, transcription, and transposition errors of broodstock PIT tags), fish with multiple PIT tags, and undocumented broodstock that have contributed to the PSCAP. These errors serve to undermine the ability to accurately detect HOPS in monitoring and broodstock collection efforts. Without complete and accurate records of captive breeding crosses, it is impossible to ensure that genetics analyses can be effectively used to detect all HOPS. To eliminate undocumented parentage and broodstock identification errors in the future, a normalized and fully relational database management (RDBM) architecture should be developed. Normalization refers to the organization of data into smaller tables to minimize redundancy; it simplifies data management by isolating data so that modifications can be made in one table and propagated throughout the database using well-defined relationships. In a well-designed RDBM architecture, data stored in one table is related to data stored in one or more additional tables. Linkages, called relationships, are established between tables based on MEIDs. The establishment of a fully RDBM architecture would enable the development of proper data relationships; improve standardization; decrease data redundancy; and increase efficiency, completeness, and accuracy of underlying data. Normalization of the database would minimize or eliminate many types of errors by reducing the redundancy of the data.

For example, the current (2015) architecture of the NPSDB "Stocked Juveniles" table requires that parentage (PIT tag for each brood fish), as well as additional spawning information (for example, spawning date, spawning hatchery, rearing hatchery) be stored repetitively in numerous (from tens to thousands) stocking records for each individual HOPS or batch stocking. This redundancy makes the table vulnerable to omission, transcription, transposition, and other errors. In this example, it is possible to erroneously enter data in one or
Table 35. Broodstock passive integrated transponder tags corrected using the string distance algorithm and verified by the Garrison Dam National Fish Hatchery.

[PIT, passive integrated transponder; F, female; M, male]

\begin{tabular}{ccc}
\hline $\begin{array}{c}\text { PIT tag in National Pallid } \\
\text { Sturgeon Database }\end{array}$ & Corrected PIT tag & Sex \\
\hline 132211892A & 132211792A & $\mathrm{F}$ \\
7F7B023102 & 7F7B026102 & $\mathrm{F}$ \\
47151A2D3A & 47151A3D3A & $\mathrm{F}$ \\
454D30680D & 434D30680D & $\mathrm{F}$ \\
1F5597653E & 1F5569653E & $\mathrm{F}$ \\
461565767B & 431565767B & $\mathrm{M}$ \\
431567567B & $431565767 \mathrm{~B}$ & $\mathrm{M}$ \\
7F7D1441774 & 7F7D441774 & $\mathrm{M}$ \\
2F4A363031 & 1F4A363031 & $\mathrm{M}$ \\
435F714145 & $435 \mathrm{~F} 71414 \mathrm{~F}$ & $\mathrm{M}$ \\
7F7F065834 & 7F7F06583D & $\mathrm{M}$ \\
7F7D272A6B & 7F7D372A6B & $\mathrm{M}$ \\
1F6001721E & 1F5001721E & $\mathrm{M}$ \\
44436E3975 & $44436 \mathrm{E} 2975$ & $\mathrm{M}$ \\
34354641585 & 3435464185 & $\mathrm{M}$ \\
\hline
\end{tabular}

more stocking records, resulting in contradictory and erroneous query results. The alternative normalized design would be to maintain separate tables for spawning events and juvenile stockings so that spawning data is entered once, and relationships between the two tables ensure that the correct information is cascaded throughout the system; furthermore, a series of input validation rules and stored procedures (for example, to ensure that PIT tags are the standard 10 characters before commitment of the record) should be developed to further reduce erroneous data.

Currently (2015), captive breeding crosses are recorded in the NPSDB "Stocked Juveniles" table, where parentage is recorded for each individual HOPS or batch stocking (where HOPS are not individually marked and, therefore, recorded in groups) in two fields: "Female" and "Male." These data are recorded after the juvenile HOPS are stocked, which is months or even years after the captive breeding crosses are made. Capturing parentage and breeding crosses in the "Stocked Juveniles" table is not only cumbersome but prone to omission, transcription, transposition, and other errors because each parental PIT tag must be entered repeatedly for each stocked HOPS or group of HOPS, potentially resulting in hundreds or thousands of records per family lot; furthermore, the current table structure does not accommodate accurate documentation of the hatchery practice of multiple-male, mixed gamete breeding crosses (for example, $F_{1}, F_{2} \times M_{1}, M_{2}, M_{3} \ldots M_{n}$ ). Currently, (2015) these complex breeding crosses are either 
left blank or recorded as "mix," resulting in only partially documented (usually female only) or completely undocumented parentage. These data are difficult and, in some cases, potentially impossible to recover years later. It bears repeating that complete documentation of all hatchery crosses is compulsory to use genetic analyses to identify HOPS, therefore, enabling one to measure success of the PSCAP and accurately quantify recruitment of wild pallid sturgeon.

At a minimum, a new table should be developed within a fully RDBM architecture to accurately capture the breeding matrix (including simple crosses, such as $\mathrm{F}_{1} \times \mathrm{M}_{1}$; and complex crosses, such as $\mathrm{F}_{1}, \mathrm{~F}_{2} \times \mathrm{M}_{1}, \mathrm{M}_{2}, \mathrm{M}_{3} \ldots \mathrm{M}_{\mathrm{n}}$ ) created in multiple hatcheries at the time of spawning and not months or years later at the time of stocking the resulting progeny. This method of data retention and preservation would ensure that all captive breeding crosses made at multiple hatcheries throughout the range of the species are fully documented and that no crosses are inadvertently omitted; furthermore, mechanisms (such as cloud-based computing and other "thin-client" options) exist and should be investigated to directly record the critical breeding matrix data from hatcheries in near-real time and transmit the data to the "Breeding Crosses" table in a RDBM architecture located remotely. Well-defined, real-time input validation rules and scripts should be developed for any data recorded in the "Breeding Crosses" table. Fully leveraging RDBM architecture would allow a "Breeding Crosses" table to be linked to the "Stocked Juveniles" table to develop queries and reports detailing and summarizing accurate and complete propagation efforts, including captive breeding information and parentage for all HOPS. Advanced methods and mechanisms, such as those described above in this section, are necessary to eliminate incomplete and erroneous captive breeding crosses and parentage data in the future.

Additional thin-client options to further streamline data collection, retention, and preservation should be investigated for implementation at hatcheries to improve potential broodstock inventory management and prioritization. Although traditional paper-based forms are inexpensive and simple to develop and use, and require no specialized equipment, these methods commonly lack front-end architecture necessary to ensure accurate, consistent, and complete data collection and, as such, may result in unconstrained and inconsistent data values (Jones and others, 2007). Mechanisms should be investigated to automate data collection from the time potential broodstock arrive at the hatchery through spawning and stocking of captive-bred offspring using real-time scanning options to directly transfer PIT tag information into a thinclient database. These technologies can enable rapid, accurate, and complete data collection; and reduce lag-time associated with traditional data collection methods. Data collected using these methods can be quickly and accurately updated as information changes (such as, reproductive condition assessments) and shared with collaborators (for example, geneticists for development of breeding matrices) through a secure Internetbased interface.
At present (2015), individual pallid sturgeon are identified exclusively by PIT tag numbers in the NPSDB. It is known that PIT tags are subject to expulsion or failure and subsequent replacement by a new PIT tag with a new identification number that renders the first PIT tag identifier invalid in the database. During this project, we documented 64 fish with 2 or more PIT tags, including 1 individual with 4 PIT tags recorded in the NPSDB. These cases were and will continue to be discovered through the presence of uniquely coded telemetry tags or genotypic data. Multiple PIT tags associated with individual pallid sturgeon increasingly complicate even routine database management tasks, such as relating pertinent records for individual fish (for example, genetic samples and results) and calculating summary statistics (such as, numbers of wild pallid sturgeon caught). Integrating data from multiple sources is, therefore, especially challenging and prone to error and failure for fish with multiple PIT tags. A RDBM architecture should be implemented to accommodate this increasingly common instance by developing a crosswalk table and stored procedures to easily decipher the multiple PIT tags associated with individual pallid sturgeon throughout time.

This study has greatly improved the genetic baseline of pallid sturgeon by identifying and removing undocumented HOPS. Before this study, undocumented HOPS represented large numbers of genetically similar individuals, which showed up in monitoring and broodstock collection efforts. These "probable wild" fish skewed the pallid sturgeon baseline, effectively diluted the power to detect individuals with rare alleles, and altered the population structure analyses. The genetic baseline for pallid sturgeon improves and changes incrementally as samples are added or removed. Results of genetic analyses may change with changes or improvements in the baseline; therefore, it would likely prove beneficial in the long term to implement consensus standardization and versioning of the genetic baseline. In this case, versioning is the process of assigning a unique version number to a particular state of the genetic baseline to account for incremental changes. The versioning should serve as metadata for all genetic analysis by recording pertinent details including version number, version dates, and genetic samples that were included in the particular instance of the baseline. The details of each incremental version should be recorded, archived, and secured in a fully RDBM architecture with a tiered hierarchal permissions system. Versioning should provide clarity about when genetic analyses were done and whether or not analyses should be updated using a substantially improved genetic baseline.

\section{Summary and Conclusions}

The Comprehensive Sturgeon Research Project is an ongoing multidisciplinary research project completed by the U.S. Geological Survey in cooperation with the U.S. Army Corps of Engineers, Missouri River Recovery ProgramIntegrated Science Program. Studies under the Comprehensive 
Sturgeon Research Project in 2014 examined pallid sturgeon migration, spawning, hatch and free-embryo drift in four contrasting river sections in the Lower Missouri, Upper Missouri, and Yellowstone Rivers. Recent research has emphasized validation and verification of successful spawning through the collection of eggs and free embryos at spawning locations and the dynamics of free-embryo dispersal through laboratory studies of free-embryo behavior and hydraulic modeling of free-embryo dispersion and advection in the contemporary Missouri and Yellowstone Rivers. Laboratory studies expanded in 2014 to include spawning behavior, egg deposition, and embryo development to inform field studies and the development of models describing functional spawning habitats. Project scientists also have contributed to multiagency efforts to understand pallid sturgeon genetic structure and the effects of population augmentation on the conservation of pallid sturgeon genetic diversity. In addition, project scientists have contributed substantially to the Missouri River Effects Analysis process to determine the status of knowledge for endangered species and the development of hypotheses to guide the selection of Missouri River management alternatives.

Studies in the Lower Missouri River continue to contribute to the knowledge of pallid sturgeon reproductive biology, spawning site selection, and habitat characteristics. Studies have documented 32 spawning events by 27 individual females in the Lower Missouri River and tributaries. Observations of spawning in 2014 were consistent with trends observed in previous years. Spawning in the Lower Missouri River happens consistently on or along outside revetted banks in swift deep water with converging flow. Although it is clear that pallid sturgeon are capable of spawning in most reaches of the main stem Missouri River under a wide variety of conditions, it remains unclear if this is the natural condition. It is uncertain if spawning distributions have been altered by modified hydrology and channel engineering, and the relative success of sturgeon spawning at different locations along the Missouri River remains unknown. This study continues to document spawning by pallid sturgeon in the Platte River. Spawning in the Platte River by telemetered sturgeon has happened over several years with markedly different temperature and flow conditions. Although the precise location of spawning in the Platte River remains unknown, repeated observations suggest that there is some level of fidelity to the Platte River for individual sturgeon and that spawning in the Platte River is likely not an opportunistic event triggered by unusual flow conditions. No pallid sturgeon free embryos or larvae were collected below suspected spawning sites; however, pallid sturgeon free embryos were collected for the first time in continuous sampling in the Missouri River above the Platte River. No pallid sturgeon were collected in the Platte River near the mouth. The numbers of pallid sturgeon collected in the Lower Missouri River is low relative to the amount of sampling effort expended. This suggests that spawning or survival of eggs, free embryos, and larvae are limited in the Lower Missouri River.
Based on telemetry and free-embryo collection data from the Lower Missouri River, pallid sturgeon and paddlefish seem to be more synchronous in their spawning behavior, whereas shovelnose sturgeon spawn during a much greater time period and in a broader range of habitat and wider geographic extent. Although shovelnose sturgeon are very similar to pallid sturgeon, differences in the timing of spawning, hatch, and dispersal between species may be important when considering the implementation of management strategies to optimize reproduction of pallid sturgeon in the Lower Missouri River.

Observations of pallid sturgeon migration and spawning in the Yellowstone and Upper Missouri Rivers shared many similarities with observations made in previous years; however, work in 2014 also provided substantial new information. Specifically, after over-wintering primarily in the Missouri River, pallid sturgeon began early and persistent migrations into the Yellowstone River; nearly 50 percent of the telemetered population migrated upstream into the Yellowstone River by early April, and about 90 percent of the population was present in the river by late May and early June. In addition to early migration into the Yellowstone River, five pallid sturgeon (one female and four males) negotiated a natural side channel and migrated above Intake Diversion Dam. Spawning was again documented over sorted gravel patches amid sand dunes in the Yellowstone River, near Fairview, North Dakota, not far above the confluence with the Missouri River. Importantly, pallid sturgeon were also documented to spawn above Intake Diversion Dam in or near the Powder River for the first time. Building on these observations, additional work is necessary to determine the extent to which areas upstream from Intake Diversion Dam are used for spawning in subsequent years and the environmental conditions that promote spawning in upstream reaches of the Yellowstone River.

In contrast to the Yellowstone River, few adult pallid sturgeon used the Upper Missouri River in 2014. Higher discharges in the Yellowstone River may have caused spawning pallid sturgeon to choose to reside in the Yellowstone River instead of the Upper Missouri River. Unfortunately, in the absence of manipulation, little information outside of the discharge event of 2011 exists to evaluate flows required to cue pallid sturgeon to migrate into the Upper Missouri River. Additionally, further information on hydrologic regimes that would retain fish in this reach through the act of spawning is also absent.

Comparisons of spawning habitats used by pallid sturgeon among different reaches of the river have highlighted important areas for focused study. Hydrographic surveys indicate that pallid sturgeon in the Lower Missouri River are spawning in areas that are relatively faster and deeper than the Yellowstone River. While spawning habitats in the Lower Missouri River are associated with outside-bend revetment and are relatively insensitive to changes in discharge, spawning on the unchannelized Yellowstone River seems to be happening over sorted gravels in association with sand dunes. It is unclear how stable patches of habitat used by spawning pallid sturgeon are at spawning sites on the Yellowstone River and to what 
extent developing embryos may be affected by rearrangement of habitat patches with discharge events. A substantial gap remains between the estimates of spawning activity and the precise location of egg deposition. More precise estimates of the location of egg deposition and embryo development will allow studies of spawning behavior and habitat selection to progress toward a clearer understanding of what characteristics are necessary for these habitats to be optimally functional and result in sufficient survival and hatch of free embryos.

Complementary laboratory studies are providing insight into characteristics and requirements of eggs, developing embryos, and dispersing free embryos. In turn, hydraulic models are incorporating this information to examine the potential effect of channel engineering to improve conditions for successful reproduction and survival. Geomorphic and channel engineering features have the potential to create channel complexity and promote retention of drifting free embryos within the Lower Missouri River based on hydraulic simulations at select locations. Increased habitat complexity may increase sturgeon survival and growth during critical early stages by allowing young-of-year sturgeon to settle into more favorable environments with greater food availability. Further studies will examine the potential for channel form and engineering to affect where sturgeon spawn.

A review of genetic information shows that pallid sturgeon populations are structured on the landscape. At the present low population levels, artificial propagation and population augmentation clearly have the capacity to alter the genetic structure of natural populations. Past experiences with population augmentation have demonstrated the importance of accurate and adequate databases to record and track the contribution of hatchery broodstock and their subsequent progeny to determine if conservation augmentation is resulting in the desired outcome: the conservation of genetic diversity, preservation of genetic stock structure, and the increase in effective population size. Collaborative studies under the Comprehensive Sturgeon Research Project have mitigated many of the concerns associated with past propagation practices (for example, inbreeding and outbreeding depression) and have provided a clarified understanding of the range-wide genetic structure of pallid sturgeon.

\section{References Cited}

American Public Health Association, American Water Works Association, and Water Environment Federation, 1995, Standard methods for the examination of water and wastewater (19th ed.): Washington, American Public Health Association, 1,100 p.

Anderson, R.O., and Gutreuter, S.J., 1983, Length, weight, and associated structural indices, in Nielsen, L.A., and Johnson, D. eds., Fisheries Techniques (1st ed.): Bethesda, Md., American Fisheries Society, p. 283-300.
Aquaveo, LLC, 2013, Surface-water Modeling System user manual (ver. 11.1): Provo, Utah, Aquaveo, LLC.

Bailey, R.M., and Cross, F.B., 1954, River sturgeons of the American genus Scaphirhynchus - Characters, distribution and synonymy, 1954: Papers of the Michigan Academy of Science, Arts, and Letters, v. 39, p. 169-207.

Bajer, P.G., and Wildhaber, M.L., 2007, Population viability analysis of lower Missouri River shovelnose sturgeon with initial application to the pallid sturgeon: Journal of Applied Ichthyology, v. 23, no. 4, p. 457-464. [Also available at http://dx.doi.org/10.1111/j.1439-0426.2007.00879.x.]

Bazzetta, L.K., 2010, Linking river morphology to larval drift of an endangered sturgeon: Northfield, Minn., Carleton College, Senior Thesis, $46 \mathrm{p}$.

Bergman, H.L., Boelter, A.M., Parady, Katelyn, Fleming, Craig, Keevin, Tom, Latka, D.C., Korschgen, Carl, Galat, D.L., Hill, Tracy, Jordan, George, Krentz, Steve, NelsonStatsny, Wayne, Olson, Mike, Mestl, G.E., Rouse, Karen, and Berkley, Jim, 2008, Research needs and management strategies for pallid sturgeon recovery-Proceedings of a workshop, July 31-August 2, 2007, St. Louis, Missouri: William D. Ruckelshaus Institute of Environment and Natural Resources, University of Wyoming, 37 p.

Billard, Roland, and Lecointre, Guillaume, 2001, Biology and conservation of sturgeon and paddlefish: Reviews in Fish Biology and Fisheries, v. 10, no. 4, p. 355-392. [Also available at http://dx.doi.org/10.1023/A:1012231526151.]

Bonnot, T.W., Wildhaber, M.L., Millspaugh, J.J., DeLonay, A.J., Jacobson, R.B., and Bryan, J.L., 2011, Discrete choice modeling of shovelnose sturgeon habitat selection in the Lower Missouri River: Journal of Applied Ichthyology, v. 27, no. 2, p. 291-300. [Also available at http://dx.doi. org/10.1111/j.1439-0426.2010.01637.x.]

Braaten, P.J., Elliott, C.M., Rhoten, J.C., Fuller, D.B., and McElroy, B.J., 2014, Migrations and swimming capabilities of endangered pallid sturgeon (Scaphirhynchus albus) to guide passage designs in the fragmented Yellowstone River: Restoration Ecology, v. 23, no. 2, p. 186-195. [Also available at http://dx.doi.org/10.1111/rec.12161.]

Braaten, P.J., and Fuller, D.B., 2005, Fort Peck flow modification biological data collection plan-Summary of 2004 activities: U. S. Army Corps of Engineers, Contract Number DACW45-03-P-0202, p. 62.

Braaten, P.J., Fuller, D.B., Holte, L.D., Lott, R.D., Viste, William, Brandt, T.F., and Legare, R.G., 2008, Drift dynamics of larval pallid sturgeon and shovelnose sturgeon in a natural side channel of the upper Missouri River, Montana: North American Journal of Fisheries Management, v. 28 , no. 3, p. 808-826. [Also available at http://dx.doi. org/10.1577/M06-285.1.] 
Braaten, P.J., Fuller, D.B., Lott, R.D., and Ruggles, M.P., 2010, Spatial distribution of drifting pallid sturgeon larvae in the Missouri River inferred from two net designs and multiple sampling locations: North American Journal of Fisheries Management, v. 30, no. 4, p. 1062-1074. [Also available at http://dx.doi.org/10.1577/M09-149.1.]

Braaten, P.J., Fuller, D.B., Lott, R.D., Ruggles, M.P., Brandt, T.F., Legare, R.G., and Holm, R.J., 2012, An experimental test and models of drift and dispersal processes of pallid sturgeon (Scaphirhynchus albus) free embryos in the Missouri River: Environmental biology of fishes, v. 93, no. 3, p. 377-392. [Also available at http://dx.doi.org/10.1007/ s10641-011-9925-9.]

Braaten, P.J., Fuller, D.B., and McClenning, N.D., 2007, Diet composition of larval and young-of-year shovelnose sturgeon in the Upper Missouri River: Journal of Applied Ichthyology, v. 23, no. 4, p. 516-520. [Also available at http://dx.doi.org/10.1111/j.1439-0426.2006.00822.x.]

Bramblett, R.G., and White, R.G., 2001, Habitat use and movements of pallid and shovelnose sturgeon in the Yellowstone and Missouri Rivers in Montana and North Dakota: Transactions of the American Fisheries Society, v. 130 , no. 6 , p. 1006-1025. [Also available at http://dx.doi. org/10.1577/1548-8659(2001)130<1006:Huamop $>2.0$ .Co;2.]

Bryan, J.L., Wildhaber, M.L., Papoulias, D.M., DeLonay, A.J., Tillitt, D.E., and Annis, M.L., 2007, Estimation of gonad volume, fecundity, and reproductive stage of shovelnose sturgeon using sonography and endoscopy with application to the endangered pallid sturgeon: Journal of Applied Ichthyology, v. 23, no. 4, p. 411-419. [Also available at http://dx.doi.org/10.1111/j.1439-0426.2007.00889.x.]

Buscombe, Daniel, 2013, Transferable wavelet method for grain-size distribution from images of sediment surfaces and thin sections, and other natural granular patterns: Sedimentology, v. 60, no. 7, p. 1709-1732. [Also available at http://dx.doi.org/10.1111/sed.12049.]

Campton, D.E., Bass, A.L., Chapman, F.A., and Bowen, B.W., 2000, Genetic distinction of pallid, shovelnose, and Alabama sturgeon-Emerging species and the US Endangered Species Act: Conservation Genetics, v. 1, no. 1, p. 17-32. [Also available at http://dx.doi. org/10.1023/A:1010121417487.]

Candrl, J.S., Papoulias, D.M., and Tillitt, D.E., 2010, A minimally invasive method for extraction of sturgeon oocytes: North American Journal of Aquaculture, v. 72, no. 2, p. 184-187. [Also available at http://dx.doi.org/10.1577/ A09-006.1.]
Carlson, D.M., Pflieger, W.L., Trial, L., and Haverland, P.S., 1985, Distribution, biology, and hybridization of Scaphirhynchus albus and Scaphirhynchus platorhynchus in the Missouri and Mississippi rivers: Environmental Biology of Fishes, v. 14, no. 1, p. 51-59.

Carr, M.L., and Rehmann, C.R., 2007, Measuring the dispersion coefficient with acoustic Doppler current profilers: Journal of Hydraulic Engineering, v. 133, no. 8, p. 977-982.

Christiansen, D.E., 2004, Riverbed elevations and water quality of the Missouri River at Sioux City, Iowa, 2002-03: U.S. Geological Survey Scientific Investigations Report 2004-5079, 21 p. [Also available at http://pubs.usgs.gov/ sir/2004/5079/.]

Conte, F.S., Doroshov, S., Lutes, P.B., and Strange, E.M., 1988, Hatchery manual for the white sturgeon (Acipenser transmontanus Richardson) - With applications to the North American Acipenseridae: Oakland, Calif., Division of Agriculture and Natural Resources, University of California, $104 \mathrm{p}$.

DeHaan, P.W., Jordan, G.R., and Ardren, W.R., 2008, Use of genetic tags to identify captive-bred pallid sturgeon (Scaphirhynchus albus) in the wild-Improving abundance estimates for an endangered species: Conservation Genetics, v. 9, no. 3, p. 691-697. [Also available at http://dx.doi. org/10.1007/s10592-007-9374-3.]

DeLonay, A.J., Jacobson, R.B., Annis, M.L., Braaten, P.J., Chojnacki, K.A., Elliott, C.M., Fuller, D.B., Haas, J.D., Haddix, T.M., McElroy, B.J., Mestl, G.E., Papoulias, D.M., Rhoten, J.C., and Wildhaber, M.L., 2014, Ecological requirements for pallid sturgeon reproduction and recruitment in the Missouri River-Annual report 2011: U.S. Geological Survey Open File Report 2014-1106, 96 p. [Also available at http://dx.doi.org/10.3133/ofr20141106.]

DeLonay, A.J., Jacobson, R.B., Chojnacki, K.A., Braaten, P.J., Buhl, D.A., Eder, B.L., Elliott, C.M., Erwin, S.O., Fuller, D.B., Haddix, T.M., Ladd, H.L.A., Mestl, G.E., Papoulias, D.M., Rhoten, J.C., Wesolek, C.J., and Wildhaber, M.L., 2016a, Ecological requirements for pallid sturgeon reproduction and recruitment in the Missouri RiverAnnual report 2013: U.S. Geological Survey Open-File Report 2015-1197, 99 p. [Also available at http://dx.doi. org/10.3133/ofr20151197.]

DeLonay, A.J., Jacobson, R.B., Chojnacki, K.A., Braaten, P.J., Bulliner, E.A., Elliott, C.M., Erwin, S.O., Fuller, D.B., Haas, J.D., Ladd, H.L.A., Mestl, G.E., Papoulias, D.M., and Wildhaber, M.L., 2016b, Ecological requirements for pallid sturgeon reproduction and recruitment in the Missouri River-A synthesis of science, 2005-2012: U.S. Geological Survey Scientific Investigations Report 2015-5145, 224 p. [Also available at http://dx.doi.org/10.3133/sir20155145.] 
DeLonay, A.J., Jacobson, R.B., Papoulias, D.M., Simpkins, D.G., Wildhaber, M.L., Reuter, J.M., Bonnot, T.W., Chojnacki, K.A., and Korschgen, C.E., 2009, Ecological requirements for pallid sturgeon reproduction and recruitment in the Lower Missouri River-A research synthesis 2005-08: U.S. Geological Survey Scientific Investigations Report 2009-5201, 59 p. [Also available at http://pubs.usgs. gov/sir/2009/5201/.]

DeLonay, A.J., Jacobson, R.B., Papoulias, D.M., Wildhaber, M.L., Chojnacki, K.A., Pherigo, E.K., Bergthold, C.L., and Mestl, G.E., 2010, Ecological requirements for pallid sturgeon reproduction and recruitment in the Lower Missouri River-Annual report 2009: U.S. Geological Survey OpenFile Report 2010-1215, 64 p. [Also available at http://pubs. usgs.gov/of/2010/1215/.]

DeLonay, A.J., Jacobson, R.B., Papoulias, D.M., Wildhaber, M.L., Chojnacki, K.A., Pherigo, E.K., Haas, J.D., and Mestl, G.E., 2012, Ecological requirements for pallid sturgeon reproduction and recruitment in the Lower Missouri River-Annual report 2010: U.S. Geological Survey OpenFile Report 2012-1009, 51 p. [Also available at http://pubs. usgs.gov/of/2012/1009/.]

DeLonay, A.J., Papoulias, D.M., Wildhaber, M.L., Annis, M.L., Bryan, J.L., Griffith, S.A., Holan, S.H., and Tillitt, D.E., 2007, Use of behavioral and physiological indicators to evaluate Scaphirhynchus sturgeon spawning success: Journal of Applied Ichthyology, v. 23, no. 4, p. 428-435. [Also available at http://dx.doi.org/10.1111/j.14390426.2007.00894.x.]

Dettlaff, T.A., Ginsburg, A.S., and Schmalhausen, O.I., 1993, Sturgeon fishes-Developmental biology and aquaculture: Berlin, Springer-Verlag, 300 p. [Also available at http://dx.doi.org/10.1007/978-3-642-77057-9.]

Doyle, Martin, Murphy, Dennis, Bartell, Steven, Farmer, Adrian, Guy, C.S., Palmer, Margaret, and Turner, Robert, 2011, Missouri River Recovery Program Independent Science Advisory Panel-Final report on spring pulses and adaptive management: U.S. Institute for Environmental Conflict Resolution, Oak Ridge Associated Universities, 11-STRI-1482, 58 p.

Dryer, Mark, and Sandovol, Alan, 1993, Recovery plan for the pallid sturgeon (Scaphirhynchus albus): U.S. Fish and Wildlife Service, Endangered Species Bulletins and Technical Reports, Paper 35, 55 p.

Du, H., Wei, Q.W., Zhang, H., Liu, Z., Wang, C., and Li, Y., 2011, Bottom substrate attributes relative to bedform morphology of spawning site of Chinese sturgeon Acipenser sinensis below the Gezhouba Dam: Journal of Applied Ichthyology, v. 27, no. 2, p. 257-262. [Also available at http://dx.doi.org/10.1111/j.1439-0426.2010.01660.x.]
Edwards, T.K., and Glysson, G.D., 1999, Field methods for measurement of fluvial sediment: U.S. Geological Survey Techniques of Water-Resources Investigations, book 3, chap. C2, 89 p. [Also available at http://pubs.er.usgs.gov/ publication/twri03C2.]

Eenennaam, J.P. van, Linares-Casenave, J., and Doroshov, S.I., 2012, Tank spawning of first generation domestic green sturgeon: Journal of Applied Ichthyology, v. 28, no. 4, p. 505-511. [Also available at http://dx.doi.org/10.1111/ j.1439-0426.2012.02012.x.]

Eichelberger, J.S., Braaten, P.J., Fuller, D.B., Krampe, M.S., and Heist, E.J., 2014, Novel single-nucleotide polymorphism marker confirm successful spawning of endangered pallid sturgeon in the upper Missouri River basin: Transactions of the American Fisheries Society, v. 143, no. 6, p. 1373-1385. [Also available at http://dx.doi.org/10.1080/0 0028487.2014.935479.]

Elliott, C.M., Jacobson, R.B., and DeLonay, A.J., 2004, Physical aquatic habitat assessment, Fort Randall segment of the Missouri River, Nebraska and South Dakota: U.S. Geological Survey Open-File Report 2004-1060, 34 p.

Elliott, C.M., Reuter, J.M., and Jacobson, R.B., 2009, Channel morphodynamics in four reaches of the Lower Missouri River, 2006-07: Scientific Investigations Report 2009-5074, 258 p. [Also available at http://pubs.usgs.gov/ $\operatorname{sir} / 2009 / 5074 /$.

Erwin, S.O., and Jacobson, R.B., 2015, Influence of channel morphology and flow regime on larval drift of pallid sturgeon in the Lower Missouri River: River Research and Applications, v. 31, no. 5, p. 538-551. [Also available at http://dx.doi.org/10.1002/rra.2752.]

Frimpong, E.A., and Angermeier, P.L., 2010, Fish traits database: Virginia Technical University, accessed on December 29, 2010, at http:/www.fishtraits.info/.

Fuller, D.B., and Braaten, P.J., 2012, Fort Peck flow modification biological collection plan compendium-A summary of 2001-2009 activities: Fort Peck, Mont., Montana Fish, Wildlife, and Parks, $122 \mathrm{p}$.

Fuller, D.B., Jaeger, Matthew, and Webb, Molly, 2008, Spawning and associated movement patterns of pallid sturgeon in the lower Yellowstone River: U.S. Fish and Wildlife Service, Montana Fish, Wildlife, and Parks, 22 p.

Hamel, M.J., Hammen, J.J., and Pegg, M.A., 2012, Tag retention of t-bar anchor tags and passive integrated transponder tags in shovelnose sturgeon: North American Journal of Fisheries Management, v. 32, no. 3, p. 533-538. [Also available at http://dx.doi.org/10.1080/02755947.2012.6759 61.] 
Helsel, D.R., Mueller, D.K., and Slack, J.R., 2006, Computer program for the Kendall family of trend tests: U.S. Geological Survey Scientific Investigations Report 2005-5275, 4 p.

Holan, S.H., Davis, G.M., Wildhaber, M.L., DeLonay, A.J., and Papoulias, D.M., 2009, Hierarchical Bayesian Markov switching models with application to predicting spawning success of shovelnose sturgeon: Journal of the Royal Statistical Society-Series C (Applied Statistics), v. 58, no. 1, p. 47-64. [Also available at http://dx.doi.org/10.1111/ j.1467-9876.2008.00642.x.]

Huenemann, T., 2014, Central lowlands and interior highlands pallid sturgeon spawning and stocking summary 19922013: Nebraska Game and Parks Commission, 105 p.

Huizinga, R.J., 2013, Results of repeat bathymetric and velocimetric surveys at the Amelia Earhart Bridge on U.S. Highway 59 over the Missouri River at Atchison, Kansas, 2009-2013: U.S. Geological Survey Scientific Investigations Report 2013-5177, 50 p. [Also available at http://pubs.usgs.gov/sir/2013/5177/.]

Humphries, Paul, Serafini, L.G., and King, A.J., 2002, River regulation and fish larvae: variation through space and time: Freshwater Biology, v. 47, no. 7, p. 1307-1331. [Also available at http://dx.doi.org/10.1046/j.13652427.2002.00871.x.]

Jacobson, R.B., Annis, M.L., Parsley, M.J., James, D.A., Colvin, M.E., and Welker, T.L., 2015b, Science information to support Missouri River Scaphirhynchus albus (pallid sturgeon) effects analysis: U.S. Geological Survey Open-File Report 2015-1226, 78 p. [Also available at http://dx.doi. org/10.3133/ofr20151226.]

Jacobson, R.B., and Galat, D.L., 2008, Design of a naturalized flow regime-An example from the Lower Missouri River, USA: Ecohydrology, v. 1, no. 2, p. 81-104. [Also available at http://dx.doi.org/10.1002/eco.9.]

Jacobson, R.B., Johnson, H.E., III, and Dietsch, B.J., 2009, Hydrodynamic simulations of physical aquatic habitat availability for pallid sturgeon in the Lower Missouri River, at Yankton, South Dakota, Kenslers Bend, Nebraska, Little Sioux, Iowa, and Miami, Missouri, 2006-07: U.S. Geological Survey Scientific Investigations Report 2009-5058, 67 p. [Also available at http://pubs.usgs.gov/ $\operatorname{sir} / 2009 / 5058 /$.

Jacobson, R.B., Parsley, M.J., Annis, M.L., Colvin, M.E., Welker, T.L., and James, D.A., 2015a, Development of conceptual ecological models linking management of the Missouri River to pallid sturgeon population dynamics: U.S. Geological Survey Open-File Report 2015-1038, 47 p. [Also available at http://dx.doi.org/10.3133/ofr20151038.]
Jacobson, R.B., Parsley, M.J., Annis, M.L., Colvin, M.E., Welker, T.L., and James, D.A., 2016, Development of working hypotheses linking management of the Missouri River to population dynamics of Scaphirhynchus albus (pallid sturgeon): U.S. Geological Survey Open-File Report 20151236, 33 p. [Also available at http://dx.doi.org/10.3133/ ofr20151236.]

Jager, H.I., Lepla, K.B., Winkle, Webb van, James, B.W., and McAdam, S.O., 2010, The elusive minimum viable population size for white sturgeon: Transactions of the American Fisheries Society, v. 139, no. 5, p. 1551-1565. [Also available at http://dx.doi.org/10.1577/T09-069.1.]

Jennings, C.A., and Zigler, S.J., 2009, Biology and life history of paddlefish in North America-An update, in Paukert, C.P., and Scholten, G., eds., Paddlefish management, propagation, and conservation in the 21st Century-Building from 20 years of research and management: Bethesda, Md., American Fisheries Society, p. 1-22.

Jones, Christopher, Blanchette, Carol, Brooke, Matthew, Harris, John, Jones, Matthew, and Schildhauer, Mark, 2007, A metadata-driven framework for generating field data entry interfaces in ecology: Ecological Informatics, v. 2, no. 3, p. 270-278. [Also available at http://dx.doi.org/10.1016/j. ecoinf.2007.06.005.]

Keenlyne, K.D., Graham, L.K., and Reed, B.C., 1994a, Hybridization between the pallid and shovelnose sturgeons: Proceedings of the South Dakota Academy of Science, v. 73, p. 59-66.

Keenlyne, K.D., Henry, C.J., Tews, A., and Clancey, P., 1994b, Morphometric comparisons of upper Missouri River sturgeons: Transactions of the American Fisheries Society, v. 123 , no. 5, p. 779-785. [Also available at http://dx.doi. org/10.1577/1548-8659(1994)123<0779:MCOUMR >2.3 .CO;2.]

Khodorevskaya, R.P., Ruban, G.I., and Pavlov, D.S., 2009, Behavior, migrations, distribution, and stocks of sturgeon in the Volga-Caspian Basin: Norderstedt, Germany, Books on Demand, $233 \mathrm{p}$.

Kim, Dongsu, 2012, Assessment of longitudinal dispersion coefficients using Acoustic Doppler Current Profilers in large river: Journal of Hydro-environment Research, v. 6, no. 1, p. 29-39. [Also available at http://dx.doi. org/10.1016/j.jher.2011.06.001.]

Klimley, A.P., Allen, P.J., Israel, J.A., and Kelly, J.T., 2006, The green sturgeon and its environment-Introduction: Environmental Biology of Fishes, v. 79, no. 3, p. 187-190. [Also available at http://dx.doi.org/10.1007/s10641-0069155-8.] 
Kock, T.J., Congleton, J.L., and Anders, P.J., 2006, Effects of sediment cover on survival and development of white sturgeon embryos: North American Journal of Fisheries Management, v. 26, no. 1, p. 134-141. [Also available at http://dx.doi.org/10.1577/M05-073.1.]

Korman, J., Wiele, S.M., and Torizzo, M., 2004, Modelling effects of discharge on habitat quality and dispersal of juvenile humpback chub (Gila cypha) in the Colorado River, Grand Canyon: River Research and Applications, v. 20 , no. 4 , p. 379-400. [Also available at http://dx.doi. org/10.1002/rra.749.]

Krentz, Steven, Holm, Rob, Bollig, Herb, Dean, Jan, Rhodes, Mike, Hendrix, Dave, Heidrich, Gary, and Krise, Bill, 2005, Pallid sturgeon spawning and stocking summary report-1992-2004: U.S. Fish and Wildlife Service, 22 p.

Krykhtin, M.L., and Svirskii, V.G., 1997, Endemic sturgeons of the Amur River-Kaluga, Huso dauricus, and Amur sturgeon, Acipenser schrenckii: Environmental Biology of Fishes, v. 48, no. 1-4, p. 231-240. [Also available at http://dx.doi.org/10.1023/A:1007358027263.]

Kuhajda, B.R., and Mayden, R.L., 2001, Morphological comparisons of hatchery-reared specimens of Scaphirhynchus albus, S. platorynchus, and S. albus $\times$ S. platorynchus hybrids: Tuscaloosa, Ala., University of Alabama, Grant Agreement No. 1448-60181-98-G616, 119 p.

Kynard, Boyd, Henyey, Erika, and Horgan, Martin, 2002, Ontogenetic behavior, migration, and social behavior of pallid sturgeon, Scaphirhynchus albus, and shovelnose sturgeon, S. platorynchus, with notes on the adaptive significance of body color: Environmental Biology of Fishes, v. 62, no.4, p. 389-403. [Also available at http://dx.doi. org/10.1023/A:1014950202783.]

Kynard, Boyd, Parker, E., Pugh, D., and Parker, T., 2007, Use of laboratory studies to develop a dispersal model for Missouri River pallid sturgeon early life intervals: Journal of Applied Ichthyology, v. 23, no. 4, p. 365-374. [Also available at http://dx.doi.org/10.1111/j.14390426.2007.00908.x.]

McAdam, S.O., 2011, Effects of substrate condition on habitat use and survival by white sturgeon (Acipenser transmontanus) larvae and potential implications for recruitment: Canadian Journal of Fisheries and Aquatic Sciences, v. 68 , no. 5 , p. $812-822$. [Also available at http://dx.doi. org/10.1139/f2011-021.]

McAdam, S.O., 2012, Diagnosing causes of white sturgeon (Acipenser transmontanus) recruitment failure and the importance of substrate condition to yolksac larvae survival: University of British Columbia, 175 p.
McElroy, Brandon, and Mohrig, David, 2009, Nature of deformation of sandy bed forms: Journal of Geophysical Research-Earth Surface, v. 114, no. F4, accessed on December 15, 2014, at http://dx.doi. org/10.1029/2008JF001220.

Murphy, C.E., Hoover, J.J., George, S.G., and Killgore, K.J., 2007, Morphometric variation among river sturgeons (Scaphirhynchus spp.) of the Middle and Lower Mississippi River: Journal of Applied Ichthyology, v. 23, no. 4, p. 313-323. [Also available at http://dx.doi.org/10.1111/ j.1439-0426.2007.00883.x.]

Murphy, D.D., and Weiland, P.S., 2011, The route to best science in implementation of the endangered species act's consultation mandate-The benefits of structured effects analysis: Environmental Management, v. 47, no. 2, p. 161-172. [Also available at http://dx.doi.org/10.1007/ s00267-010-9597-9.]

Murphy, D., and Weiland, P., 2014, Science and structured decision making - Fulfilling the promise of adaptive management for imperiled species: Journal of Environmental Studies and Sciences, v. 4, no. 3, p. 200-207. [Also available at http://dx.doi.org/10.1007/s13412-014-0165-0.]

Papoulias, D.M., DeLonay, A.J., Annis, M.L., Wildhaber, M.L., and Tillitt, D.E., 2011, Characterization of environmental cues for initiation of reproductive cycling and spawning in shovelnose sturgeon Scaphirhynchus platorynchus in the lower Missouri River, USA: Journal of Applied Ichthyology, v. 27, no. 2, p. 335-342. [Also available at http://dx.doi.org/10.1111/j.1439-0426.2010.01657.x.]

Paragamian, V.L., Kruse, Gretchen, and Wakkinen, Virginia, 2001, Spawning habitat of Kootenai River white sturgeon, post-Libby Dam: North American Journal of Fisheries Management, v. 21, no. 1, p. 22-33. [Also available at http://dx.doi.org/10.1577/1548-8675(2001)021<0022:SHO $\mathrm{KRW}>2.0 . \mathrm{CO} ; 2$.

Park, Chulhong, and Chapman, F.A., 2005, An extender solution for the short-term storage of sturgeon semen: North American Journal of Aquaculture, v. 67, no. 1, p. 52-57. [Also available at http://dx.doi.org/10.1577/FA03-068.1.]

Parsley, M.J., and Beckman, L.G., 1994, White sturgeon spawning and rearing habitat in the lower Columbia River: North American Journal of Fisheries Management, v. 14, no. 4, p. 812-827. [Also available at http://dx.doi. org/10.1577/1548-8675(1994)014<0812:WSSARH $>2.3$ .CO;2.]

PBS\&J, 2009, Intake Diversion dam modification, lower Yellowstone Project: Missoula, Mont., PBS\&J, 147 p. 
Perrin, C.J., Rempel, L.L., and Rosenau, M.L., 2003, White sturgeon spawning habitat in an unregulated river-Fraser River, Canada: Transactions of the American Fisheries Society, v. 132, no. 1, p. 154-165. [Also available at http://dx.doi.org/10.1577/1548-8659(2003)132<0154:WSS $\mathrm{HIA}>2.0 . \mathrm{CO} ; 2$.

Piper, R.G., McElwain, I.B., Orme, L.E., McCraren, J.P., Fowler, L.G., and Leonard, J.R., 1982, Fish hatchery management: Washington, D.C., U.S. Fish and Wildlife Service, $517 \mathrm{p}$.

Quist, M.C., Boelter, A.M., Lovato, J.M., Korfanta, N.M., Bergman, H.L., Latka, D.C., Korschgen, Carl, Galat, D.L., Krentz, Steven, Oetker, Michael, Olson, Michael, Scott, C.M., and Berkley, Jim, 2004, Research and assessment needs for pallid sturgeon recovery in the Missouri River: Proceedings of a conference, William D. Ruckelshaus Institute of Environment and Natural Resources, University of Wyoming, Bloomington, Minn., May 18-20, 2004, 96 p.

Reuter, J.M., Jacobson, R.B., Elliott, C.M., and DeLonay, A.J., 2009, Assessment of Lower Missouri River physical aquatic habitat and its use by adult sturgeon (genus Scaphirhynchus), 2005-07: U.S. Geological Survey Scientific Investigations Report 2009-5121, 81 p. [Also available at http://pubs.usgs.gov/sir/2009/5121/.]

Reuter, J.M., Jacobson, R.B., Elliott, C.M., Johnson, H.E., III, and DeLonay, A.J., 2008, Hydraulic and substrate maps of reaches used by sturgeon (genus Scaphirhynchus) in the Lower Missouri River, 2005-07: U.S. Geological Survey Data Series 386, 442 p. [Also available at http://pubs.usgs. gov/ds/386/.]

Rubin, D.M., Chezar, Henry, Harney, J.N., Topping, D.J., Melis, T.S., and Sherwood, C.R., 2007, Underwater microscope for measuring spatial and temporal changes in bed-sediment grain size: Sedimentary Geology, v. 202, p. 402-408.

Scheidegger, K.J., and Bain, M.B., 1995, Larval fish in natural and regulated rivers-Assemblage composition and microhabitat use: Copeia, v. 1, no. 1, p. 125-135.

Schrey, A.W., and Heist, E.J., 2005, Genetic discrimination of pallid (Scaphirhynchus albus) and shovelnose sturgeons (S. platorynchus) using DNA microsatellite markers [abs.]: Scaphirhynchus Conference-Alabama, Pallid, and Shovelnose Sturgeon, St. Louis, Mo., January 11-13, 2005. [Also available at http://maydenlab.slu.edu/conferences/ abstracts/3.html.]

Schrey, A.W., and Heist, E.J., 2007, Stock structure of pallid sturgeon analyzed with microsatellite loci: Journal of Applied Ichthyology, v. 23, no.4, p. 297-303. [Also available at http://dx.doi.org/10.1111/j.1439-0426.2007.00881.x.]
Sheehan, R.J., Heidinger, R.C., Wills, P.S., Schmidt, M.A., Conover, G.A., and Hurley, K.L., 1999, Guide to the pallid sturgeon shovelnose sturgeon character index $(\mathrm{Cl})$ and morphometric character index ( $\mathrm{mCl})$ : Fisheries Research Laboratory, Southern Illinois University, 19 p.

Statistical Analysis System Institute, 2011, SAS/STAT ${ }^{\circledR} 9.3$ user's guide: Cary, N.C., SAS Institute, 8621 p. accessed December 28, 2015, at https://support.sas.com/documentation/cdl/en/statug/63962/PDF/default/statug.pdf.

Štěch, Ludek, Linhart, Otomar, Shelton, W.L., and Mims, S.D., 1999, Minimally invasive surgical removal of ovulated eggs from paddlefish: Aquaculture International, v. 7, no. 2, p. 129-133. [Also available at http://dx.doi. org/10.1023/A:1009253806766.]

Sulak, K.J., and Clugston, J.P., 1998, Early life history stages of Gulf sturgeon in the Suwannee River, Florida: Transactions of the American Fisheries Society, v. 127, no. 5, p. 758-771. [Also available at http://dx.doi. org 1 10.1577/1548-8659(1998) $127<0758:$ ELHSOG $>2.0$ .CO;2.]

Sustainable Ecosystems Institute, 2008, Review of comprehensive sturgeon research program: Portland, Oreg., Sustainable Ecosystems Institute, 49 p.

Tranah, G.J., Campton, D.E., and May, Bernie, 2004, Genetic evidence for hybridization of pallid and shovelnose sturgeon: Journal of Heredity, v. 95, no. 6, p. 474-480. [Also available at http://dx.doi.org/10.1093/jhered/esh077.]

Tranah, G.J., Kincaid, H.L., Krueger, C.C., Campton, D.E., and May, Bernie, 2001, Reproductive isolation in sympatric populations of pallid and shovelnose sturgeon: North American Journal of Fisheries Management, v. 21, no. 2, p. 367373. [Also available at http://dx.doi.org/10.1577/15488675(2001)021<0367:RIISPO >2.0.CO;2.]

U.S. Bureau of Reclamation, and U.S. Army Corps of Engineers, 2010, Intake diversion dam modification lower Yellowstone Project, Montana—Final environmental assessment: U.S. Bureau of Reclamation, and U.S. Army Corps of Engineers, $230 \mathrm{p}$.

U.S. Bureau of Reclamation, and U.S. Army Corps of Engineers, 2014, Intake diversion dam modification, lower Yellowstone Project, Montana - Draft supplement to the 2010 final environmental assessment: U.S. Bureau of Reclamation, and U.S. Army Corps of Engineers, 144 p.

U.S. Fish and Wildlife Service, 2000, Biological opinion on the operation of the Missouri River main stem reservoir system, operation and maintenance of the Missouri River bank stabilization and navigation project, and operation of the Kansas River reservoir system: U.S. Fish and Wildlife Service, accessed on December 15, 2014, at http://www. nwd-mr.usace.army.mil/mmanual/opinion.html. 
U.S. Fish and Wildlife Service, 2003, Amendment to the 2000 biological opinion on the operation of the Missouri River main stem reservoir system, operation and maintenance of the Missouri River bank stabilization and navigation project, and operation of the Kansas River reservoir system: U.S. Army Corps of Engineers, 308 p. [Also available at http://www.nwd-mr.usace.army.mil/mmanual/FinalBO2003. pdf.]

U.S. Fish and Wildlife Service, 2005, Upper Basin pallid sturgeon propagation plan: U.S. Fish and Wildlife Service, 89 p.

U.S. Fish and Wildlife Service, 2007, Pallid sturgeon (Scaphirhynchus albus) 5-year review summary and evaluation: Billings, Mont., U.S. Fish and Wildlife Service, 120 p.

U.S. Fish and Wildlife Service, 2008, Pallid sturgeon (Scaphirhynchus albus) range-wide stocking and augmentation plan: Denver, Colo., U.S. Fish and Wildlife Service, 55 p.

U.S. Fish and Wildlife Service, 2014, Revised recovery plan for the pallid sturgeon (Scaphirhynchus albus): U.S. Fish and Wildlife Service, $115 \mathrm{p}$.

U.S. Geological Survey, 2014, Montana flood-frequency and basin-characteristic data: U.S. Geological Survey WyomingMontana Water Science Center peakflow characteristics for Montana Web page, accessed December 28, 2014, at http://wy-mt.water.usgs.gov/freq?page_type=site\&site no $=06329500$.
Wildhaber, M.L., DeLonay, A.J., Papoulias, D.M., Galat, D.L., Jacobson, R.B., Simpkins, D.G., Braaten, P.J., Korschgen, C.E., and Mac, M.J., 2007a, A conceptual life-history model for pallid and shovelnose sturgeon: U.S. Geological Survey Circular 1315, 18 p. [Also available at http://pubs.usgs.gov/ circ/2007/1315/.]

Wildhaber, M.L., DeLonay, A.J., Papoulias, D.M., Galat, D.L., Jacobson, R.B., Simpkins, D.G., Braaten, P.J., Korschgen, C.E., and Mac, M.J., 2011a, Identifying structural elements needed for development of a predictive life-history model for pallid and shovelnose sturgeons: Journal of Applied Ichthyology, v. 27, no. 2, p. 462-469. [Also available at http://dx.doi.org/10.1111/j.1439-0426.2011.01731.x.]

Wildhaber, M.L., Holan, S.H., Davis, G.M., Gladish, D.W., DeLonay, A.J., Papoulias, D.M., and Sommerhauser, D.K., 2011b, Evaluating spawning migration patterns and predicting spawning success of shovelnose sturgeon in the Lower Missouri River: Journal of Applied Ichthyology, v. 27, no. 2, p. 301-308. [Also available at http://dx.doi.org/10.1111/ j.1439-0426.2010.01663.x.]

Wildhaber, M.L., Papoulias, D.M., DeLonay, A.J., Tillitt, D.E., Bryan, J.L., and Annis, M.L., 2007b, Physical and hormonal examination of Missouri River shovelnose sturgeon reproductive stage - A reference guide: Journal of Applied Ichthyology, v. 23, no. 4, p. 382-401. [Also available at http://dx.doi.org/10.1111/j.1439-0426.2007.00878.x.] 

Publishing support provided by:

Rolla and Pembroke Publishing Service Centers

For more information concerning this publication, contact: Director, USGS Columbia Environmental Research Center 4200 New Haven Road

Columbia, MO 65201

(573) 875-5399

Or visit the Columbia Environmental Research Center Web site at: http://www.cerc.usgs.gov 
